\title{
Reduction of Toxic Air Contaminants (TACs) and particulate matter emissions from heavy-duty natural gas engines
}

Hemanth K. Kappanna

West Virginia University

Follow this and additional works at: https://researchrepository.wvu.edu/etd

\section{Recommended Citation}

Kappanna, Hemanth K., "Reduction of Toxic Air Contaminants (TACs) and particulate matter emissions from heavy-duty natural gas engines" (2006). Graduate Theses, Dissertations, and Problem Reports.

1707.

https://researchrepository.wvu.edu/etd/1707

This Thesis is protected by copyright and/or related rights. It has been brought to you by the The Research Repository @ WVU with permission from the rights-holder(s). You are free to use this Thesis in any way that is permitted by the copyright and related rights legislation that applies to your use. For other uses you must obtain permission from the rights-holder(s) directly, unless additional rights are indicated by a Creative Commons license in the record and/ or on the work itself. This Thesis has been accepted for inclusion in WVU Graduate Theses, Dissertations, and Problem Reports collection by an authorized administrator of The Research Repository @ WVU. For more information, please contact researchrepository@mail.wvu.edu. 


\title{
Reduction of Toxic Air Contaminants (TACs) and Particulate Matter Emissions from Heavy-Duty Natural Gas Engines
}

\author{
Hemanth K. Kappanna \\ Thesis Submitted to the \\ College of Engineering and Mineral Resources \\ at West Virginia University \\ in partial fulfillment of the requirements \\ for the degree of \\ Master of Science \\ in \\ Mechanical Engineering \\ Mridul Gautam, Ph.D., Chair \\ Gregory. J. Thompson, Ph.D. \\ W. Scott Wayne, Ph.D. \\ Daniel. K. Carder, M.S.
}

Department of Mechanical and Aerospace Engineering

Morgantown, West Virginia

2006

Keywords: Exhaust Aftertreatment, Speciation, Toxic Air Contaminants, Natural Gas Engines 


\section{ABSTRACT \\ Reduction of Toxic Air Contaminants (TACs) and Particulate Matter Emissions from Heavy-Duty Natural Gas Engines}

\section{Hemanth K. Kappanna}

Increasing urban pollution levels have driven the Federal and the local air control boards to impose stricter emissions regulations on heavy-duty engines earmarked for transit buses. This has made natural gas a promising fuel for reducing the emissions of oxides of nitrogen and predominantly particulate matter from heavy-duty transit buses. Recent research studies performed at WVU and elsewhere have showed that natural gas engines emit an order of magnitude lower PM emissions, on a mass basis, when compared to diesel engines without any exhaust aftertreatment devices. However, on a number basis the emissions from natural gas fueled buses were an order of magnitude higher than their diesel counterparts.

This project was initiated by Southern California Air Quality Management District to design and develop an exhaust aftertreatment device for retrofitting urban transit buses powered by heavy-duty natural gas engines. The exhaust aftertreatment device was developed for a Cummins Westport C8.3G+ natural gas engine. Exhaust samples were collected by operating the vehicle on the Central Business District cycle on a chassis dynamometer. Regulated emissions were continuously measured while nonregulated emissions samples were collected on different media from a full flow dilution tunnel. In addition, PM concentrations and size distributions were also measured.

The project consisted of three phases. In Phase I, complete speciation of the emissions and particle size measurements were performed from the engine, with and without the OEM oxidation catalyst. Based on this data, WVU and Lubrizol developed an exhaust aftertreatment device which consisted of a particulate filter and an oxidation catalyst. The emissions measurement from the transit bus with the newly installed exhaust aftertreatment device was performed in Phase II. After six months of on-road demonstration, the exhaust aftertreatment device was retested in Phase III to check for any deterioration in the performance. The speciation results showed that the new exhaust aftertreatment device reduced the emissions of metallic elements like iron, zinc and nonmetallic minerals like calcium, phosphorus and sulfur derived from lube oil additives to non-detectable levels, which otherwise would form nuclei mode particles, thereby increasing the number of nanoparticles. The carbonyl compounds were reduced effectively by the oxidation catalyst to the levels below what were found in the dilution air. The PAHs and other heavier hydrocarbons identified as Toxic Air Contaminants (TACs) by CARB were reduced to non-detectable levels. This ultimately reduced the number of nanoparticles to the levels equal to that found in the dilution air. The Phase III results showed that the aged aftertreatment device performed efficiently without any deterioration. 


\section{ACKNOWLEDGEMENTS}

As this brings me to the end of an extended master's career I would like to take this opportunity to thank all those who have supported me in fulfilling my aspirations. First and foremost, I would like to thank my advisor, Dr. Mridul Gautam, for accepting me as his student, for the confidence he had in me and for the unconditional support I received from him. Dr. Gautam I am grateful to you for fulfilling the irresistible offer.

I am grateful to Daniel Carder for what he has taught me and the experience of learning from him, be it engines, emissions, work ethics, building PCs and much more. Hey Dan thanks for hooking me up with American football, a great pastime, and inviting me over to watch the playoffs.

I would like to thank Dr. Gregory Thompson and Dr. Scott Wayne for being on my committee. I admire Dr Thompson for his organization and time management skills. I am thankful to Dr Wayne for providing the flow rate and temperature data when it was needed very much. Thanks are due to Tom Long Jr., Ted Christian, Curt Leasor and Chris Rowe. Chris is the man who made things a reality, if it was not for him it would have taken a week or more to complete the testing. Special thanks to Bobby John for taking the responsibility of particle size measurements.

I would like to thank Tom Spencer, Ben Shade, Wesley Riddle, Richard Atkinson and Ron Jarett for all the technical help I received from them while working at EERC, Sabraton and Westover. I would like to thank my contemporaries Sam George, Gurudutt, Aseem, Vinay, Sairam, Michelangelo, Rafaello, Karthik, Shashi, Ravi, and Aaron for giving a great company all along my master's career.

I am ever grateful to my dearest mom and dad for the sacrifices they have made to make me what I am today and the values of life they have taught me. I would like to thank my sister Latha Suresh and my brother in-law Dr. H.N. Suresh, I still cannot believe that you made me leave my beloved Bangalore for US and I am ever thankful for transferring me from deep well to an ocean. Bhavana and the little Bhanavee please forgive me for not being there to play with you girls. I am thankful to Dr. Haritha and Dr. Chandraprabha for treating me as their family member and gifting me an untiring Toyota Camry. I would like to remember my late brother Ravi Kumar and dedicate my career to him. 


\section{TABLE OF CONTENTS}

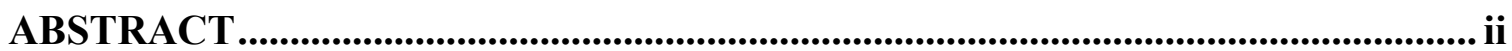

ACKNOWLEDGEMENTS ........................................................................................ii

TABLE OF CONTENTS ...................................................................................................... iv

LIST OF TABLES ......................................................................................................... vii

TABLE OF FIGURES....................................................................................................... ix

NOMENCLATURE

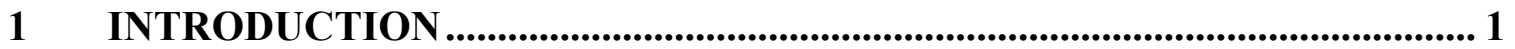

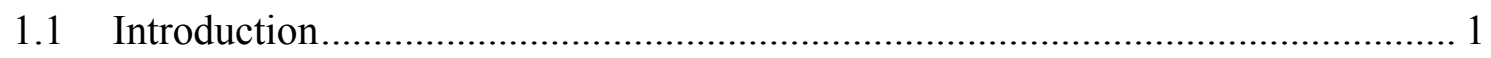

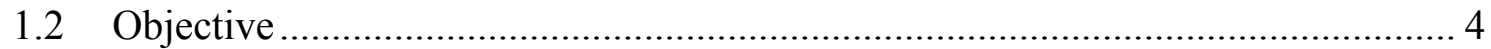

2 LITERATURE REVIEW ................................................................................... 6

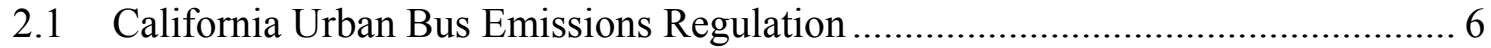

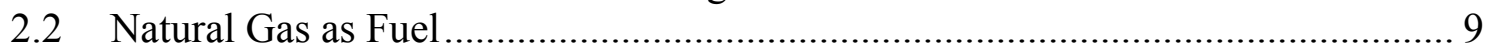

2.3 Significance of Different Emission Components ................................................ 10

2.4 Previous Studies Comparing Emissions Between Diesel and CNG Engines ....... 16

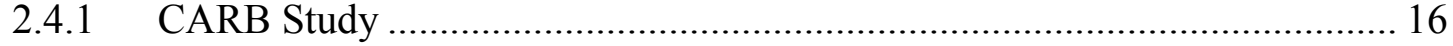

2.4.2 TNO Automotive Study, Netherlands..................................................... 18

2.4.3 International School Bus Study ……………….................................... 19

2.4.4 The Finnish National Bus Project.......................................................... 20

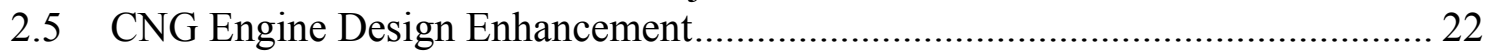

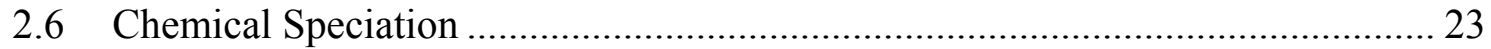

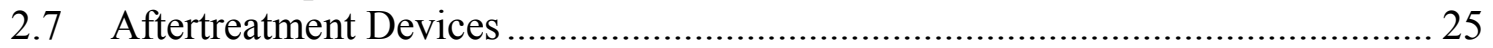

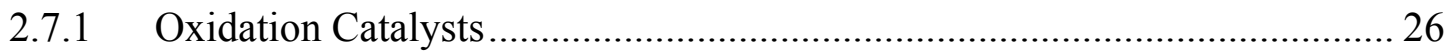

2.7.2 Diesel Particulate Filters .......................................................................... 27

3 EXPERIMENTAL SETUP .............................................................................. 31

$3.1 \quad$ Equipment and Procedures ......................................................................... 31

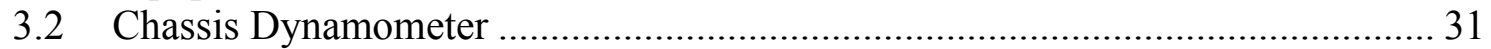

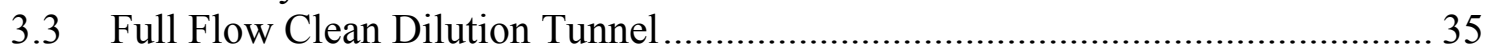

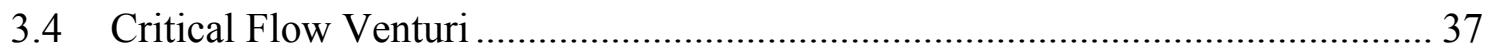

3.5 Secondary Dilution Tunnel and Particulate Sampling ......................................... 38

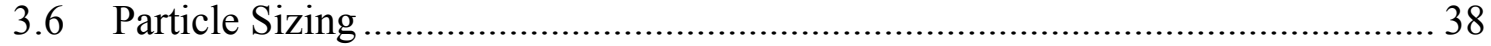

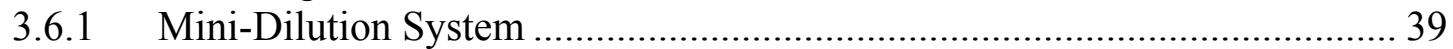

3.6.2 Scanning Mobility Particle Sizer ............................................................... 41

3.7 Gaseous Emission Sampling System. ............................................................... 44

3.7.1 Regulated Emission Sampling System ....................................................... 44

3.7.1.1 Oxides of Nitrogen (NOx) Analyzer........................................................ 45

3.7.1.2 Carbon Monoxide (CO) and Carbon Dioxide $\left(\mathrm{CO}_{2}\right)$ Analyzer ................ 45

3.7.1.3 Total Hydrocarbon (THC) Analyzer.......................................................... 46 
3.7.2 Non-regulated Emission Sampling System ……………………………..... 46

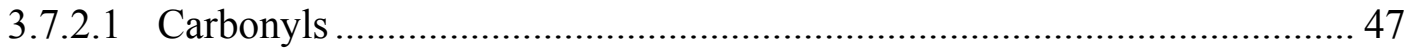

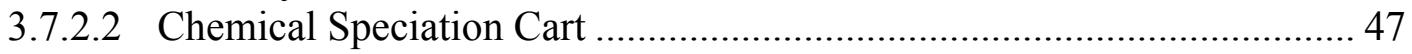

3.7.2.2.1 Volatile Organic Compound Bag Sampling System .......................... 47

3.7.2.2.2 Polycyclic Aromatic Hydrocarbon (PAH/n-PAH) Sampling System.. 47

3.7.2.3 VOC Canister Sampling System............................................................ 49

3.7.2.4 Cyclonic Particle Classifier......................................................................... 50

3.7.2.5 EC/OC and Elemental Sampling System............................................... 51

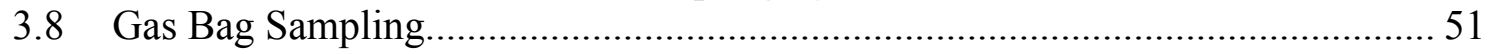

3.9 Temperature Control Module ......................................................................... 51

3.10 Instrumentation Control and Data Acquisition ............................................... 51

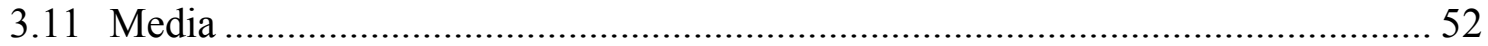

3.11.1 Media Conditioning and Weighing ............................................................ 52

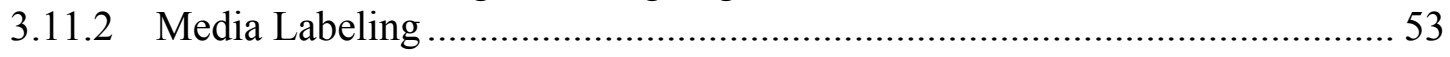

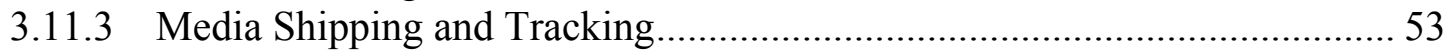

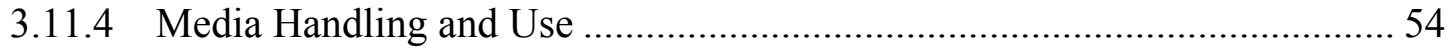

4 EMISSION TESTING PROCEDURE ..............................................................55

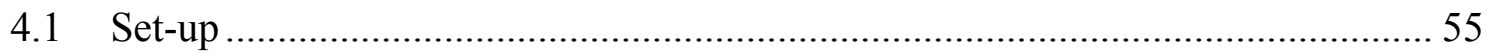

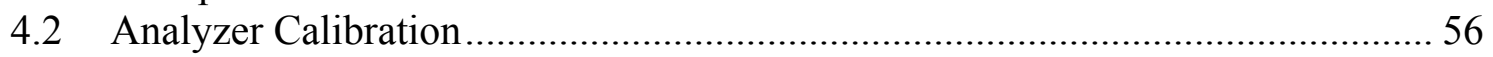

4.3 Mass Flow Controller Calibration .................................................................. 57

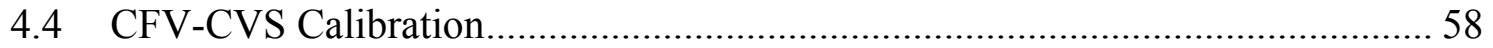

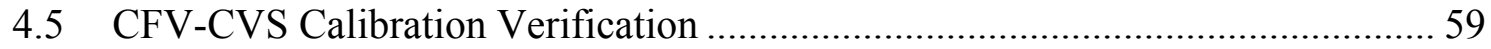

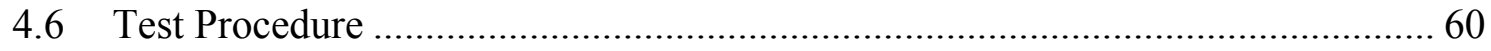

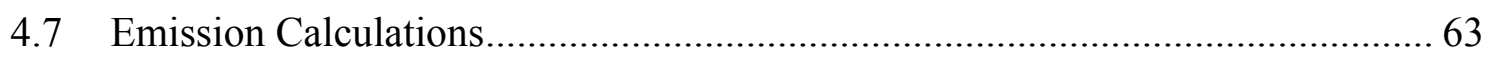

4.7.1 Equations to Calculate Distance Specific Mass of Regulated Emissions..... 64

4.7.2 Equations to Calculate Distance Specific Mass of Exhaust Species ............. 67

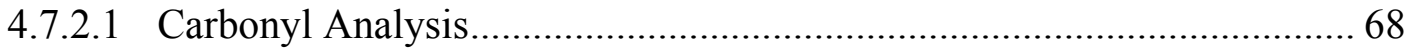

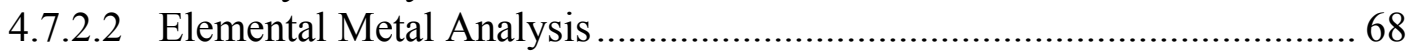

4.7.2.3 Elemental Carbon and Organic Carbon Analysis ...................................... 69

4.7.2.4 Volatile Organic Hydrocarbons ............................................................. 70

4.7.2.5 1,3-butadiene and BTEX On-site Analysis................................................ 71

4.7.2.6 Semi-Volatile and Particle Bound Hydrocarbon Analysis ........................ 71

5 RESULTS AND DISCUSSION......................................................................... 75

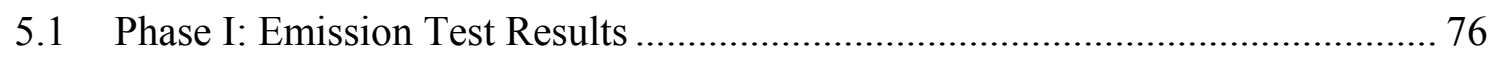

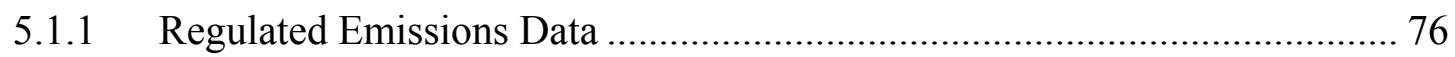

5.1.2 Non-Regulated Emissions................................................................... 78

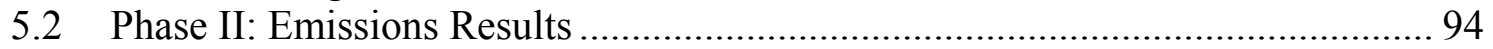

5.2.1 Design and Formulation of WVU-Lubrizol Aftertreatment Device............. 94

5.2.2 Reduction of Emissions by WVU-Lubrizol Aftertreatment Device.............. 95

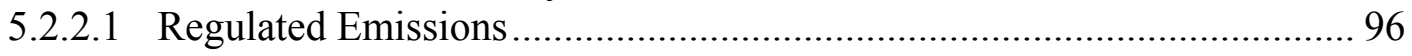

5.2.2.2 Non-Regulated Emissions...................................................................... 98

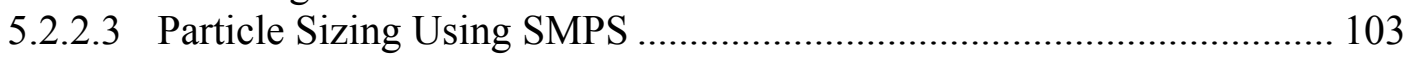

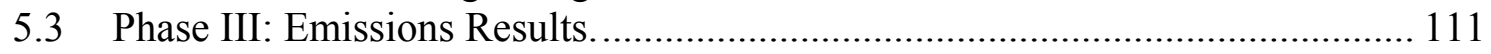

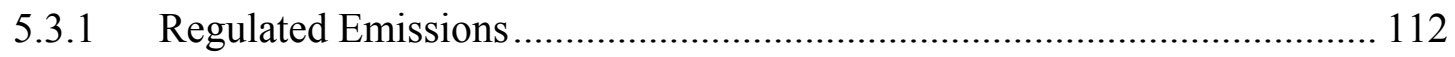

5.3.2 Non-Regulated Emissions...................................................................... 114 
5.3.3 Particle Sizing Using SMPS

6 CONCLUSIONS AND RECOMMENDATIONS ............................................ 127

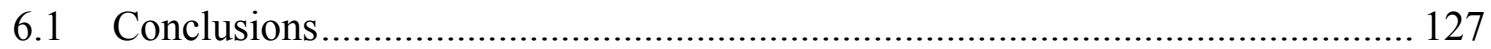

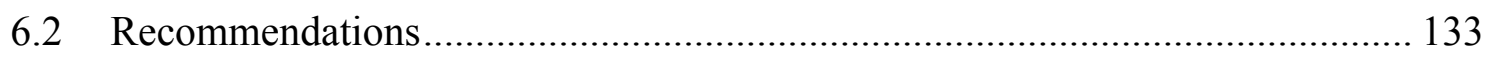

LITERATURE CITED ............................................................................................. 135

APPENDIX A: EXHAUST CHARACTERIZATION METHOD ............................. 144

APPENDIX B: TEST ENGINE AND VEHICLE SPECIFICATION...................... 163

APPENDIX C: CONSOLIDATED SPECIATION RESULTS ................................... 164 


\section{LIST OF TABLES}

Table 1.1 Regulated and Non-Regulated Emissions Sampled..................................... 5

Table 2.1 California and Federal Transit Bus NOx Emission Standards (g/bhp-hr) ......... 7

Table 2.2 California and Federal Transit Bus PM Emission Standards (g/bhp-hr) ........... 7

Table 2.3 Proposed Transit Bus Fleet Rule Requirements and Emission Standards ......... 8

Table 2.4 Natural Gas Specifications (mole \%).............................................................. 9

Table 2.5 California ARB Toxic Air Contaminants Associated with Diesel Exhaust,

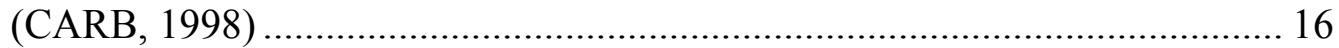

Table 3.1 Venturi Throat Diameter and Flow Rates (Ferguson, 1993) .......................... 37

Table 3.2 Chemical Species and Collecting Media .................................................. 52

Table 3.3 Media and Color Code.............................................................................. 53

Table 4.1 Summary of Sampling Media, and Methods used to Analyze Non-Regulated Exhaust Species.............................................................................................. 74

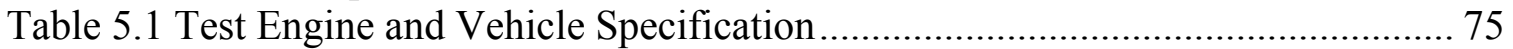

Table 5.2 Reduction of Regulated Emissions Achieved by WVU-Lubrizol Aftertreatment

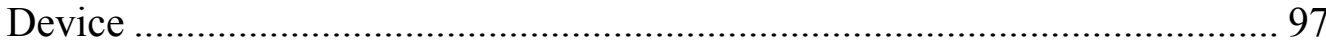

Table 5.3 Reduction in Emissions Observed in New and Aged Exhaust Aftertreatment

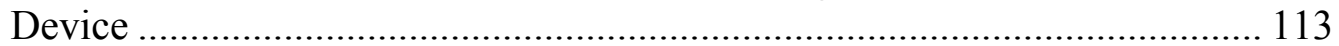

Table 5.4 Result from X-Ray Fluorescence Elemental Analysis .................................. 114

Table 5.5 Reduction of Toxic Emissions from Post-Use WVU-Lubrizol Trap Compared

to Baseline and Pre-Use Trap....................................................................... 118

Table 6.1 Reduction in Regulated Emissions compared to Baseline values .................. 128

Table 6.2 Reduction in Carbonyl Emissions compared to Baseline values.................... 129

Table A. 1 Target compounds for methane and non-methane hydrocarbon analysis.... 145

Table A. 2 Chromatographic conditions for the NMHC and LHC methods................. 146

Table A. 3 Target compounds for 1,3-butdiene BTEX method. .................................. 147

Table A. 4 Chromatographic conditions for 1,3-butdiene BTEX method..................... 147

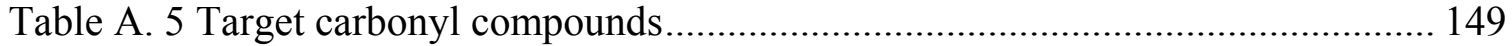

Table A. 6 Analytical Conditions for HPLC analysis of carbonyl derivatives.............. 149

Table A. 7 Authentic standards for biomarker quantitation. ..................................... 153

Table A. 8 Target analytes for the alkane and biomarker suites of compounds ............ 154

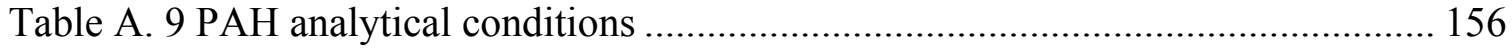

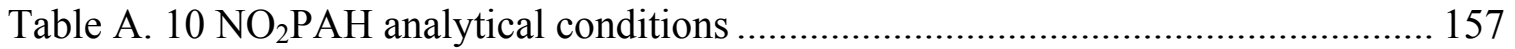

Table A. 11 Target Analytes and Monitored Ions for PAH Analysis............................ 158

Table A. 12 Quantitation Standards and Monitored Ions for Nitro-PAH analysis......... 160

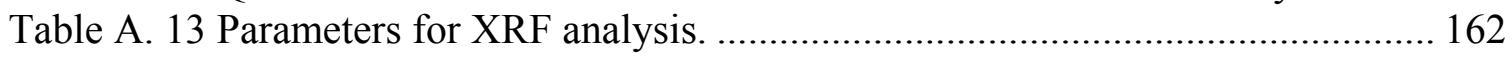

Table C. 1 Emissions of Alkanes Measured in Different Phases ................................. 164

Table C. 2 Emissions of Hopanes Measured in Different Phases.................................. 165

Table C. 3 Emissions of Steranes Measured in Different Phases ................................... 167

Table C. 4 Emissions of Polycyclic Aromatic Hydrocarbons Measured in Different

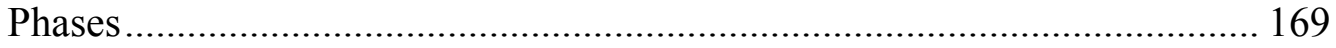

Table C. 5 Emissions of Methane and Non-Methane Hydrocarbons Measured in Different

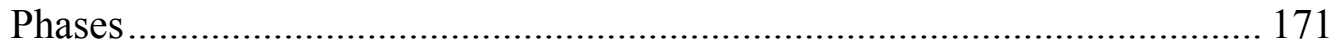

Table C. 6 Emissions of Toxic Gases Measured using Lab Grade Gas Chromatography,

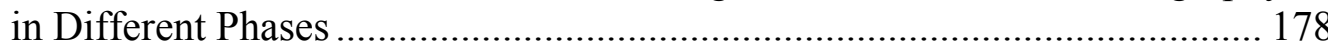


Table C. 7 Emissions of Toxic Gases Measured using Onsite Gas Chromatography, in

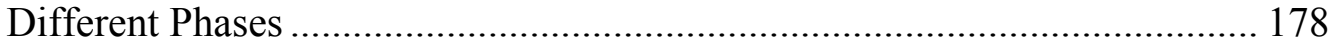

Table C. 8 Emissions of Carbonyls Measured in Different Phases .............................. 179

Table C. 9 Emissions of nitro-Polycyclic Aromatic Hydrocarbons Measured in Different

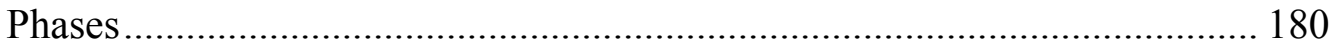

Table C. 10 Emissions of Regulated Compounds Measured in Different Phases .......... 182 


\section{TABLE OF FIGURES}

Figure 2.1 Summary of TAC emissions from diesel and CNG engines. (Intl. Bus Study)

Figure 2.2 Comparison of size classified particle number emissions among different

Diesel and CNG engine configurations on a transient duty cycle. (Finnish

National Bus Project) ....................................................................... 22

Figure 3.1 Components of a Chassis Dynamometer....................................................... 33

Figure 3.2 Connecting and supporting structure of chassis dynamometer ..................... 34

Figure 3.3 West Virginia University Mini-Dilution Tunnel ........................................ 39

Figure 3.4 Schematic of Pulsation Damper used during Transient Tests ......................... 41

Figure 3.5 DMA Column Schematic $\left(\right.$ TSI $\left._{\circledast}\right)$......................................................... 42

Figure 3.6 Polycyclic Aromatic Hydrocarbons Sampling Media Holder........................ 48

Figure 3.7 Speciation cart to collect PAH and bag samples of toxic gases ..................... 49

Figure 3.8 Volatile Organic Carbons Canister Sampling System.................................... 50

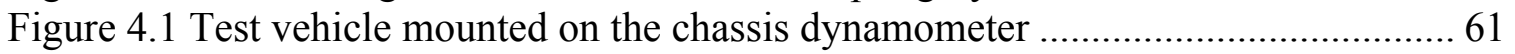

Figure 5.1 Regulated Emissions from Natural Gas Engine with and without OEM

Oxidation Catalyst.................................................................................. 77

Figure 5.2 Methane and NMHC from Natural Gas Engine with and without OEM

Oxidation Catalyst.................................................................................... 78

Figure 5.3 Emissions of Engine Wear Elements in Phase I........................................... 80

Figure 5.4 Emissions of Lube Oil Additives in Phase I............................................... 82

Figure 5.5 Emissions of Carbonyl Compounds in Phase I. ........................................ 83

Figure 5.6 Emissions of Polycyclic Aromatic Hydrocarbons in Phase I........................ 84

Figure 5.7 Emissions of Toxic Gases in Phase I........................................................ 85

Figure 5.8 Emissions of Elemental and Organic Carbons in Phase I. ............................. 86

Figure 5.9 Size Classified PM Emissions in Phase I. ................................................... 87

Figure 5.10 Phase I Steady-state Particle Size Distribution for the Baseline Engine....... 89

Figure 5.11 Phase I Particle Size Distribution with the OEM Oxidation Catalyst .......... 89

Figure 5.12 Concentration of 8nm Particles from a QCBD test with and without the OEM

Oxidation Catalyst.............................................................................. 90

Figure 5.13 Concentration of 19nm Particles from a QCBD test with and without the

OEM Oxidation Catalyst............................................................................. 91

Figure 5.14 Concentration of $31 \mathrm{~nm}$ Particles from a QCBD test with and without the

OEM Oxidation Catalyst...................................................................... 91

Figure 5.15 Concentration of 44nm Particles from a QCBD test with and without OEM

Oxidation Catalyst............................................................................ 92

Figure 5.16 Concentration of 84nm Particles from a QCBD test with and without OEM

Oxidation Catalyst....................................................................................... 93

Figure 5.17 Regulated Emissions from Phase II vs Phase I. ....................................... 96

Figure 5.18 Emissions of Methane and NMHCs from Phase II vs Phase I..................... 98

Figure 5.19 Emission of Engine Wear Elements from Phase II vs. Phase I. ................... 99

Figure 5.20 Emissions of Lube Oil Elements from Phase II vs. Phase I. ........................ 99

Figure 5.21 Emissions of Carbonyl Compounds from Phase II vs. Phase I. ................. 100

Figure 5.22 Emissions of Polycyclic Aromatic Hydrocarbons from Phase II vs. Phase I.

Figure 5.23 Emissions of Toxic Gases from Phase II vs. Phase I. 101 102 
Figure 5.24 Emissions of Elemental and Organic Carbons from Phase II vs. Phase I... 102

Figure 5.25 Size Classified PM Emissions from Phase II vs. Phase I.

Figure 5.26 Particle Size Distributions with Oxidation Catalyst and Particulate Trap for

25mph Steady-state Test

Figure 5.27 Background Particle Size Distributions.

Figure 5.28 Particle Size Distributions Particulate Trap@25Mph 106

Figure 5.29 Concentration of 46.49nm Particles from the Vehicle equipped with WVU-

Lubrizol Exhaust Aftertreatment Device, over QCBD cycle..... 107

Figure 5.30 Concentration of $91.11 \mathrm{~nm}$ Particles from the Vehicle Equipped with WVU-

Lubrizol ExhaustAftertreatment Device, over QCBD cycle. 108

Figure 5.31 Concentration of 136nm Particles from the Vehicle Equipped with WVU-

Lubrizol Exhaust Aftertreatment Device, over QCBD cycle... 108

Figure 5.32 Concentrations of 53.3nm Particles from the Vehicle Equipped with only the

Particulate Trap, over QCBD cycle.

Figure 5.33 Concentrations of 13.29nm Particles from the vehicle equipped with only the

Particulate Trap, over QCBD cycle.

Figure 5.34 Variation in the concentration of $19 \mathrm{~nm}$ Particles for three different vehicle

configurations, over QCBD cycle.

Figure 5.35 Regulated Emissions in Phase III Testing.

Figure 5.36 Emissions of Carbonyl Compounds in Phase III compared to Phase I and

Phase II.

Figure 5.37 Emissions of Polycyclic Aromatic Hydrocarbons in Phase III compared to

Phase I and Phase II. ....................................................................... 116

Figure 5.38 Emissions of Toxic Gases from Onsite Analysis in Phase III compared to

Phase II.

Figure 5.39 Emissions of Toxic Gases Analyzed from Canister Samples from Phase III compared to Phase I and Phase II.

Figure 5.40 Emission of Elemental and Organic Carbons in Phase III compared to Phase I and Phase II.

Figure 5.41 Comparison of Size Classified PM Emissions from different Phases........ 120

Figure 5.42 Particle Size Distribution with WVU-Lubrizol Exhaust Aftertreatment @

25mph compared to Baseline Values.

Figure 5.43 Particle Size Distribution with WVU-Lubrizol Exhaust Aftertreatment @ 35

mph compared to Background and Baseline Values.

Figure 5.44 Particle Size Distribution with WVU-Lubrizol Exhaust Aftertreatment @

$35 \mathrm{mph}$ compared to Background Values.

Figure 5.45 Particle Size Distribution with WVU-Lubrizol Exhaust Aftertreatment @

25mph compared to Background Values.

Figure 5.46 Concentration of 16.8nm Particle with WVU-Lubrizol Exhaust

Aftertreatment compared to Baseline Values.

Figure 5.47 Concentration of 35.9nm Particle with WVU-Lubrizol Exhaust

Aftertreatment compared to Baseline Values.

Figure 5.48 Concentration of 59.4nm Particle with WVU-Lubrizol Exhaust

Aftertreatment compared to Baseline Values.

Figure 6.1 Regulated Emissions from all three phases of test

Figure 6.2 Emissions of Carbonyl compounds 
Figure 6.3 Emissions of Polycyclic Aromatic Hydrocarbons................................... 130

Figure 6.4 Emissions of Toxic Gases ....................................................................... 131

Figure 6.5 Emission of Toxic Air Contaminants ............................................................ 132

Figure 6.6 Particle Size Distribution @ 35mph with DR = 30 ...................................... 133 


\title{
NOMENCLATURE
}

\author{
ADC: Analog to Digital Conversion \\ BSC: Braunschweig bus Cycle \\ CARB: California Air Resource Board \\ CBD: Central Business District \\ CD: Conventional Diesel \\ CFR: Code of Federal Regulations \\ CFV: Critical Flow Venturi \\ CNG: Compressed Natural Gas \\ CPC: Condensation Particle Counter \\ CRDPF: Continuously Regenerating Diesel Particulate Filter \\ CRT: Continuously Regenerating Trap \\ CSHVC: City Suburban Heavy Vehicle Cycle \\ CVS: Constant Volume Sampling \\ DBTC: Dutch urban-Bus Transient Cycle \\ DFNG: Duel Fuel Natural Gas \\ DI: Direct Injection \\ DING: Direct Injection Natural Gas \\ DMA: Differential Mobility Analyzer \\ DNPH: di-nitro-phenyl-hydrazine \\ DPF: Diesel Particulate Filter \\ EC: Elemental Carbon \\ ECD: Emission Control Diesel \\ ECM: Electronic Control Module \\ ECS: Emission Control System \\ EERL: Engine and Emissions Research Lab \\ EEV: Enhanced Environmentally Friendly Vehicle \\ EGR: Exhaust Gas Recirculation \\ ELPI: Electrical Low Pressure Impactor \\ ERMD: Emission Research and Measurement Department \\ ESC: European Stationary Cycle \\ ETC: European Transient Test \\ FT: Fischer Tropsch \\ FTP: Federal Test Procedure \\ GVW: Gross Vehicle Weight \\ HEPA: High Efficiency Particulate Absorbing \\ HFID: Heated Flame Ionization Detector \\ HPLC: High Performance Liquid Chromatography \\ HRGC: High Resolution Gas Chromatography \\ HRMS: High Resolution Mass Spectrogram \\ LB: Lean Burn \\ LED: Low Emitting Diesel \\ LEV: Low Emission Vehicle \\ LFE: Laminar Flow Element \\ LM: Lean Mix
}


LNG: Liquid Natural Gas

MY: Make Year

NDIR: Non Dispersive Infrared

NIST: National Institute of Standard and Technology

NMHC: Non Methane Hydrocarbons

n-PAH: Nitro Poly Aromatic Hydrocarbons

OC: Organic Carbon

OC: Oxidation Catalyst

OCC: Orange County Cycle

OEM: Original Equipment Manufacturer

PAH: Poly Aromatic Hydrocarbons

PCDD: polychlorodibenzo-p-dioxin

PCDF: polychlorodibenzo-p-furan

PDP: Positive Displacement Pump

PID: Proportional Integral Differential

PM: Particulate Matter

SI: Spark Ignited

SING: Spark Ignited Natural Gas

SM: Stoichiometric

SMPS: Scanning Mobility Particle Scanner

SOF: Soluble Organic Fraction

SVOC: Soluble Volatile Organic Carbon

SwRI: Southwest Research Institute

TAC: Toxic Air Contaminant

TCM: Temperature Control Module

THC: Total Hydrocarbons

THC: Total Hydrocarbons

TPM: Total Particulate Matter

TWC: Three Way Catalyst

ULEV: Ultra Low Emission Vehicle

ULSD: Ultra Low Sulfur Diesel

USEPA: United States Environmental Protection Agency

USHDD: US Heavy Duty Diesel

VOC: Volatile Organic Carbon

XRF: X-Ray Fluorescence Spectroscopy

ZEB: Zero Emission Bus 


\section{INTRODUCTION}

\subsection{Introduction}

Heavy-duty diesel engines are recognized as the mobile power plants of choice due to their higher power density, reliability, low fuel consumption, durability and low cost. However, they have been categorized as the highest contributor to the air pollution. The majority of advances taking place in the engine industry at present are related to emissions regulations. Indeed, the heavy-duty diesel engine technology is driven by the stringent regulations on NOx and PM emissions. Recent classification of diesel particulate matter as a probable human carcinogen by US Environmental Protection Agency (EPA, 2000) and the classification of diesel exhaust as Toxic Air Contaminant (TAC) by California Air Resource Board (CARB, 1998) have led these regulatory bodies to impose ever-increasing regulations on heavy-duty diesel engine manufacturers in efforts to reduce exhaust emissions. Stringent emissions regulations have promoted the use of Compressed Natural Gas (CNG) fueled heavy-duty engines in urban transit buses, school buses, refuse haulers, and delivery trucks operating within urban limits. CNGfueled engines are characterized for their lower Particulate Matter (PM) on a mass basis when compared to diesel-fueled engines. However, results from research conducted at different organizations revealed that emissions from CNG-fueled vehicles without exhaust aftertreatment devices are not as clean as considered by various fleet owners and pollution regulating authorities.

A year long study by Lev-On, et al. (2001) that focused on chemically characterizing the exhaust emissions from trucks and buses running on different test fuels, with and without exhaust aftertreatment devices showed that the introduction of ultra low sulfur diesel (ULSD) along with diesel particulate filter (DPF) significantly reduced diesel exhaust emissions both gaseous and PM emissions from diesel engines. The CNG-fueled vehicles exhibited emissions of non-regulated compounds and nanoparticles that were greater by a factor of 15-20 than corresponding emissions from a diesel engine equipped with an exhaust aftertreatment device. Lapin, et al. (2002) conducted a study to examine the mutagenic effects of exhaust emissions from a CNGfueled refuse hauler without any emission control device. In this study, diluted and cooled PM samples were collected isokinetically on a 20 in by 20 in 
polytetrafluoroethylene glass fiber filters. The PM samples collected on the filter were solvent extracted, and subjected to Ames bioassay. Results from the dose response assay were positive indicating mutagenic activity. Thus, the need for retrofitting the existing CNG-fueled vehicles with a reliable and durable exhaust aftertreatment device, and improving the engine technology to address the increase in nanoparticles and genotoxic exhaust emission was substantiated.

Mathis et al. (2004) studied the influence of volatile organic compounds (VOCs) on nucleation of nanoparticles in the exhaust of a modern light-duty diesel vehicle. In this study, different organic compounds, with a diverse molecular structure, were added to the dilution air. The size distribution and the particle concentrations were measured using a Scanning Mobility Particle Sizer (SMPS) while varying the sample temperature and relative humidity. The results showed a large variation in the number concentration of nucleation mode particles in response to the varying sampling conditions and different organic compounds. Any increase in the number concentration of nanoparticles in the exhaust of $\mathrm{CNG}$ engines despite the absence of carbonaceous soot nucleating sites has been linked not only with the ash and heavier hydrocarbon content in the lubrication oil but also to the non-regulated sulfur content in the lube oil and volatile organic compounds in the natural gas exhaust (Gautam 1999, 2001). In the present study a novel exhaust aftertreatment device was developed by WVU and Lubrizol to reduce the soluble organic fractions in the natural gas exhaust, promoting further reduction of PM emissions both by mass and number concentration. The exhaust aftertreatment device comprised of a catalyzed particulate filter and an oxidation catalyst, which trapped the ash, produced from lube oil additives and oxidized the heavier hydrocarbons from incomplete combustion of lube oil; thereby, minimizing nanoparticle formation.

The present study spanned over three phases in which the aftertreatment device was developed and tested on a urban transit bus, equipped with a state-of-the-art Cummins $\mathrm{C} 8.3 \mathrm{G}+$ natural gas engine ULEV certified by the California Air Resource Board. The present work focuses on the Phase III of the study- the post in-field performance demonstration of the novel exhaust aftertreatment device. The system was evaluated by measuring the emissions reduction potential and comparing the results with previous tests (Phase I and II). During this study a complete chemical speciation of the 
exhaust was performed to validate the removal of targeted toxic compounds and heavy hydrocarbons which are considered as possible human carcinogens. Heavy hydrocarbons derived from burning lube oil act as precursors to nanoparticle formation. Recently WVU was involved in two studies that included chemical characterization, performing bioassay tests and measuring particle size distribution from the emissions of heavy-duty vehicles equipped with different aftertreatment devices operating on ultra-low sulfur fuel, CARB diesel, and natural gas. The invaluable lessons learned from these projects regarding test procedures, test equipment, and exhaust analysis were useful in carrying out this study. It was found that performing chemical characterization of ULEV exhaust, which involves measurement of constituent concentrations that are close to background levels necessitates the use of a dilution tunnels that do not have extensive tunnel history and have not been used in cross-testing vehicles run on different fuels. Hence, a clean dilution tunnel, dedicated for sampling exhaust emissions from CNG fueled engines was used throughout this project.

During Phase I, regulated and unregulated emission components from the baseline engine (without any aftertreatment devices) were determined. A detailed chemical characterization of the engine-out emissions was performed by operating the vehicle over a "Quad CBD" (Central Business District) cycle on WVU's transportable chassis dynamometer. This cycle comprised of three consecutive CBD cycles preceded by a warm-up $\mathrm{CBD}$, was developed in order to collect sufficient mass to facilitate microbalance weighing and improve detection of low concentration chemical species. After determining the baseline emissions the vehicle was tested with the OEM oxidation catalyst to determine the reduction in emissions attained by the use of the OEM oxidation catalyst. A detailed analysis of the Phase I emissions data was carried out by engineers at Engine Control Systems, WVU and Lubrizol to develop a novel aftertreatment device. This device included a catalyzed particulate trap followed by an oxidation catalyst, which facilitated further reduction of emissions by oxidizing carbonyls and other hydrocarbons that escaped from the particulate trap.

During Phase II (Burlingame et al., 2004) both regulated and non-regulated emissions were measured after installation of the novel aftertreatment device following the same test protocol as in Phase I. After Phase II testing the transit bus was returned to 
its regular revenue service in order to demonstrate the emission reducing potential of the device and also to study the effect of backpressure on engine power, driveability and fuel consumption. In Phase III the emissions reduction performance of the aftertreatment device was reevaluated after a six month demonstration period in order to determine the durability of the exhaust aftertreatment device. A visual inspection was also performed in order to identify any structural damage.

\subsection{Objective}

The global objective of this study was to reduce nanoparticle emissions and toxic pollutants from a CNG-fueled heavy-duty transit bus by retrofitting it with a custom designed exhaust aftertreatment system.

The specific objective of this study was to evaluate deterioration, or drift, in the performance of the WVU-Lubrizol exhaust aftertreatment device by means of a complete characterization of exhaust emissions. Results from the baseline vehicle, post retrofit and, and after six months of in-use operation were collected. The transit bus driven for six months while equipped with the WVU-Lubrizol exhaust aftertreatment device, was tested over an extended Central Business District (QCBD) cycle, and complete speciation of the exhaust emissions was conducted. Baseline regulated emissions were also measured during this phase to verify any deterioration in the engine performance, from an emissions standpoint. The emissions measured during the baseline engine tests- both with- and without the OEM oxidation catalyst and those recorded after the installation of the new WVU-Lubrizol exhaust aftertreatment device by Burlingame et al. (2004), were compared with those collected after the six month demonstration period to validate the performance of the aged aftertreatment device.

A list of regulated and various non-regulated emissions sampled during this test is shown in Table 1.1. 
Table 1.1 Regulated and Non-Regulated Emissions Sampled

\begin{tabular}{|l|l|}
\hline Regulated Emissions & Non-Regulated Emissions \\
\hline Oxides of Nitrogen (NOx) & Volatile Organic Compounds (VOCs) \\
\hline Carbon Monoxide (CO) & Polycyclic Aromatic Hydrocarbon (PAH) \\
\hline Total Hydrocarbon (THC) & Nitro-Polycyclic Aromatic Hydrocarbon (n-PAH) \\
\hline Total Particulate Matter (TPM) & $\begin{array}{l}1,3 \text { Butadiene \& Benzene, Toluene, Ethyl-benzene, } \\
\text { o-Xylene, m \& p Xylene. (BTEX) }\end{array}$ \\
\hline Non Methane Hydrocarbon (NMHC) & Aldehydes \\
\hline Methane $\left(\mathrm{CH}_{4}\right)$ & Hopanes and Steranes \\
\hline & Elemental Carbon and Organic Carbon \\
\hline & Elemental Analysis \\
\hline & $\mathrm{PM}_{10}$ Gravimetric \\
\hline & $\mathrm{PM}_{2.5}$ Gravimetric \\
\hline & $\mathrm{PM}_{1.0}$ Gravimetric \\
\hline
\end{tabular}




\section{LITERATURE REVIEW}

This chapter describes, in brief, the existing and new emissions regulation standards. A review of published literature on toxic emissions from the CNG-fueled engines and the higher concentration of nano particles in comparison to diesel engines equipped with exhaust aftertreatment devices and operating on low sulfur fuels has been presented. Engine design enhancement, exhaust aftertreatment devices, and the effect of fuel/ lube oil in reducing emissions are also reviewed.

\subsection{California Urban Bus Emissions Regulation}

Urban buses by CARB's definition are typically $40 \mathrm{ft}$ long, powered by a heavyduty diesel engine and are classified as heavy heavy-duty class vehicles, which have a gross vehicle weight (GVW) ratings greater than 33,000 pounds. In the state of California, mobile sources were accounted to produce 60 percent of ozone precursors responsible for urban smog and 40 percent of PM emissions, of which 30 percent was accounted to diesel-powered engines (CARB, 2000). Identifying PM emissions from diesel-fueled engines as TACs (August 1998), California Air Resource Board (CARB) adopted a resolution to encourage public transport agencies to buy cleaner vehicles running on alternative fuels in order to reduce urban emissions and in-turn reduce public exposure to TACs. With the proposition of using alternative fuels such as $\mathrm{CNG}$, liquid petroleum gas (LPG), synthetic diesel (Fischer Tropsch) fuel, and advanced emission reduction technologies which require ultra-low sulfur fuel, public transport corporations have significant potential to improve urban air quality as they are maintained and fueled at a centralized facilities.

The United States Environmental Protection Agency (USEPA) passed a regulation (1995) for urban bus retrofits and rebuild program according to the Clean Air Act Amendments of 1990. This regulation included options for reducing PM emissions from urban transit buses through the use of particulate traps and oxidation catalysts. Similar to USEPA regulations, CARB adopted new emissions standards in 2002 affecting urban transit agencies and the engine manufacturers who supply engines for transit buses. Increasing pollution levels in urban areas has deliberated the new regulations toward further reduction of PM and NOx emissions, in order to attain federal and state air quality standards. 
As urban buses predominantly operate in densely populated and congested urban areas, they not only expose a large population to toxic particulate emissions but also deteriorate the air quality and the visibility in these areas. Hence, urban buses are subjected to more stringent PM and NOx emissions regulations than heavy-duty highway vehicles. Recent history of both California and Federal emission standards for urban bus engines (CARB, 2000) is shown in Table 2.1 and 2.2.

Table 2.1 California and Federal Transit Bus NOx Emission Standards (g/bhp-hr)

\begin{tabular}{|c|c|c|}
\hline Year & California & Federal \\
\hline 1988 & 6.0 & 10.7 \\
\hline 1990 & 6.0 & 6.0 \\
\hline 1991 & 5.0 & 5.0 \\
\hline 1996 & 4.0 & 5.0 \\
\hline 1998 & 4.0 & 4.0 \\
\hline October 2002 & 2.0 & 2.0 \\
\hline
\end{tabular}

Table 2.2 California and Federal Transit Bus PM Emission Standards (g/bhp-hr)

\begin{tabular}{|c|c|c|}
\hline Year & California & Federal \\
\hline 1988 & 0.6 & 0.6 \\
\hline 1991 & 0.1 & 0.25 \\
\hline 1993 & 0.1 & 0.1 \\
\hline 1994 & 0.07 & 0.07 \\
\hline 1996 & 0.05 & 0.05 \\
\hline October 2002 & 0.05 & 0.05 \\
\hline
\end{tabular}

New regulations are attempting to reduce the emissions from urban buses by having short-term and long-term goals. The fleet rule is designed to achieve short-term goals by encouraging purchase of cleaner vehicles, providing financial support to retrofit old vehicles with aftertreatment devices and giving incentives to rebuild old buses with higher emissions to comply with the current standards. Long-term goals include compliance with stringent emissions standards for manufacturers of engines used in urban buses. The regulations for the existing and the future urban transit bus emissions are shown in Table 2.3. 
Table 2.3 Proposed Transit Bus Fleet Rule Requirements and Emission Standards

\begin{tabular}{|c|c|c|c|c|}
\hline \multirow{2}{*}{ Model Year } & \multicolumn{2}{|c|}{ "Diesel" Path } & \multicolumn{2}{|c|}{ "Alternative Fuel" Path } \\
\hline & NOx (g/bhp-hr) & PM (g/bhp-hr) & NOx (g/bhp-hr) & PM (g/bhp-hr) \\
\hline 2000 & 4 & 0.05 & $2.5_{\text {optional }}$ & 0.05 \\
\hline 2002 & $\begin{array}{c}2.5 \\
\mathrm{NOx}+\mathrm{NMHC} \\
\end{array}$ & 0.01 & $\begin{array}{c}1.8 \\
\mathrm{NOx}+\mathrm{NMHC} \\
\end{array}$ & 0.03 \\
\hline $\begin{array}{l}\text { 2002-2006 } \\
\text { Fleet Rule }\end{array}$ & \multicolumn{2}{|c|}{$\begin{array}{c}\text { 4.8 NOx fleet average, PM retrofit } \\
\text { requirement and demonstrate } 3 \\
\text { ZEBs for large fleet }(>200)\end{array}$} & \multicolumn{2}{|c|}{$\begin{array}{l}\text { 4.8 NOx fleet average and PM } \\
\text { retrofit requirement }\end{array}$} \\
\hline 2004 & 0.5 & 0.01 & N/A & $\mathrm{N} / \mathrm{A}$ \\
\hline 2007 & 0.2 & 0.01 & 0.2 & 0.01 \\
\hline $\begin{array}{l}2008 \text { Fleet } \\
\text { Rule }\end{array}$ & \multicolumn{2}{|c|}{$\begin{array}{l}15 \% \text { ZEBs among new vehicles } \\
\text { for large fleet }(>200)\end{array}$} & $\mathrm{N} / \mathrm{A}$ & N/A \\
\hline $\begin{array}{l}2010 \text { Fleet } \\
\text { Rule }\end{array}$ & N/A & N/A & \multicolumn{2}{|c|}{$\begin{array}{l}15 \% \text { ZEBs among new vehicles } \\
\text { for large fleet }(>200)\end{array}$} \\
\hline
\end{tabular}

According to the above regulations, the transit authorities have the flexibility to choose between diesel and alternative fuel paths. In both paths, there is a requirement to achieve minimum fleet averaged NOx and PM reductions. This can be done by replacing or rebuilding older vehicles with higher emissions to comply with current emissions regulations or by retrofitting existing vehicles with aftertreatment devices. According to the new fleet rule, larger fleet $(>200)$ owners on the diesel path have to demonstrate three Zero Emission Buses (ZEBs) by 2002-2006 and 15\% of their new purchases should be ZEBs from 2008. However, large fleet owners pursuing alternative fuel paths do not have to demonstrate ZEBs and the requirement to purchase $15 \%$ of ZEBs does not start until 2010.

The particulate emissions from CNG engines without any exhaust aftertreatment devices are 10 to 100 times lower by mass than the uncontrolled diesel engines, due to the gaseous nature of the fuel. Unlike diesel, the CNG fuel which is pre-dominantly methane, will combust in a soot free nature independent of the combustion technology. Consequently, in order to meet the strict mass-based PM emissions regulations, many transit authorities have considered the alternative fuel path and have promoted the use of CNG engines for urban buses. 


\subsection{Natural Gas as Fuel}

Ever increasing demand for crude oil required for conventional fuels and the depleting oil reserves has made natural gas a popular choice as an alternative fuels. Natural gas, which is available in abundance in its raw form, contains mainly methane $\left(\mathrm{CH}_{4}\right)$, other light non-methane hydrocarbons, hydrogen sulfide, carbon dioxide, water vapor, helium and other trace gases. Crude natural gas is refined by removing water, hydrogen sulfide and heavier hydrocarbons in order to make it fuel-worthy. Typical composition of a fuel-grade natural gas is shown in the table below

Table 2.4 Natural Gas Specifications (mole \%)

\begin{tabular}{|c|c|c|c|}
\hline Constituent & EPA Cert Fuel & CARB Cert Fuel CARB In-Use Fuel \\
\hline Methane & $89.0(\min )$ & $90.0 \pm 1$ & $88.0(\min )$ \\
\hline Ethane & $4.5(\max )$ & $4.0 \pm 0.5$ & $6.0(\max )$ \\
\hline $\mathrm{C}_{3}$ and higher & $2.3(\max )$ & $2.0 \pm 0.3$ & $3.0(\max )$ \\
\hline $\mathrm{C}_{6}$ and higher & $0.2(\max )$ & $0.2(\max )$ & $0.2(\max )$ \\
\hline Hydrogen & - & $0.1(\max )$ & $0.1(\max )$ \\
\hline Carbon monoxide & - & $0.1(\max )$ & $0.1(\max )$ \\
\hline Oxygen & $0.6(\max )$ & $0.6(\max )$ & $1.0(\max )$ \\
\hline Inert gases $\left(\mathrm{CO}_{2}+\mathrm{N}_{2}\right)$ & $4.0(\max )$ & $3.5 \pm 0.5$ & $1.5-4.5$ \\
\hline
\end{tabular}

Natural gas mainly consists of methane, which has a higher octane rating, making it suitable for use in spark ignition engines. Since natural gas is considered as an alternative to diesel fuel, diesel engines have been adapted accordingly. Various engine modifications for using natural gas as fuel are classified into following categories:

- Spark ignition natural gas (SING), Otto cycle

- Direct injection natural gas (DING), Diesel cycle

- Dual fuel natural gas (DFNG), Diesel cycle

Spark ignition natural gas engines can be operated as stoichiometric or lean-burn engines. Stoichiometric combustion is used in light-duty vehicles with a three-way catalyst to reduce exhaust emissions. Heavy-duty SING engines employ lean-burn combustion to control the thermal loads and the overall combustion process. The increase in NOx emissions due to lean-burn conditions could be controlled by using cooled Exhaust Gas 
Recirculation (EGR) or by selective catalytic reduction of NOx. According to the federal definition, a compression ignition engine is classified based on its operating cycle rather than the ignition mechanism. Since the power in heavy-duty spark-ignited natural gas engines is controlled by throttling the fuel supply as in lean burn diesel engines, they are subjected to diesel emissions regulation.

DING and DFNG engines use a small quantity of diesel fuel (pilot injection) as a source of ignition instead of a spark plug. The diesel fuel injection system, in DING engines supplies just enough diesel to aid in ignition, thereby limiting them from operating as dual fuel engines. The engine manufacturers prefer lean-burn natural gas engines as it is easier to control the thermal load on the engine. These lean-burn engines, if not tuned properly, could produce higher NOx emissions compared to diesel engines. However, the mass emissions of PM from the natural gas engines are very low, because methane gives relatively soot free combustion independent of combustion mechanisms.

\subsection{Significance of Different Emission Components}

Emissions from internal combustion engines operating on fossil fuels are considered a major source of urban air pollution, which adversely affects human health and living conditions. PM emissions from diesel exhaust has been declared as a TAC by the USEPA, which has led to the promotion of natural gas as an alternative fuel for automobiles, including heavy-duty engines. Various studies comparing emissions characteristics of diesel and natural gas engines by comprehensive exhaust speciation have found species in the natural gas exhaust which are classified under TACs. South West Research Institute (SWRI) conducted a study to compare exhaust emissions, including TACs, from school buses operating on diesel engines with and without exhaust aftertreatment devices and on natural gas engines without catalysts (Ullman et al., 2003). This study showed the concentrations of TACs found in the natural gas exhaust were equal to, or even higher than concentrations found in exhaust of diesel engines with aftertreatment. As both diesel and natural gas engine emissions are a concoction of chemical species that are considered toxic at high levels, there is a need for further research to find which exhaust species are more carcinogenic and what serves as nucleating sites for these species to form nanoparticles. 
Under ideal conditions, complete combustion of any hydrocarbon fuel gives carbon dioxide and water vapor as products. Therefore, emissions other than $\mathrm{CO}_{2}$ and water are called pollutants, which include gases and PM. These pollutants, which are toxic to human health and detrimental to the environment, are produced in several nonideal processes during actual combustion. This includes incomplete combustion of fuel, reaction between mixture components in the cylinder at high temperature and pressure, combustion of lube oil, and post-exhaust reactions. Regulated emissions include oxides of nitrogen (NOx), carbon monoxide, hydrocarbons, and PM all of which are measured on a mass basis. The non-regulated pollutants include, but are not limited to, the following: 1) volatile organic compounds (VOC), 2) carbonyls, 3) polycyclic aromatic and nitrogenated polycyclic aromatic hydrocarbons $(\mathrm{PAH} / \mathrm{n}-\mathrm{PAH}), 4)$ elemental metals, 5) elemental and organic carbon (EC/OC), 6) hopanes and steranes, 7) dioxins and furans, 8) sulfur dioxide and nitrous oxides.

NOx is a combination of nitric oxide (NO) and nitrogen dioxide $\left(\mathrm{NO}_{2}\right)$. EPA regulates oxides of nitrogen together because $\mathrm{NO}$ is oxidized to $\mathrm{NO}_{2}$ in ambient air and both these oxides have a detrimental effects on human health as well as the environment. NOx is produced according to the following reaction, known as Zeldovich mechanism, at high temperature and pressure inside the combustion chamber (Heywood, 1988).

$$
\begin{aligned}
& \mathrm{O}+\mathrm{N}_{2}=\mathrm{NO}+\mathrm{N} \\
& \mathrm{N}+\mathrm{O}_{2}=\mathrm{NO}+\mathrm{O} \\
& \mathrm{N}+\mathrm{OH}=\mathrm{NO}+\mathrm{H}
\end{aligned}
$$

Equation 2-1

Equation 2-2

Equation 2-3

$\mathrm{NO}$ found in higher concentration in the exhaust oxidizes to $\mathrm{NO}_{2}$ at ambient conditions by the following reaction.

$$
2 \mathrm{NO}+\mathrm{O}_{2}=2 \mathrm{NO}_{2}
$$

Equation 2-4

$\mathrm{NO}_{2}$ is a toxic red-brown gas with an unpleasant odor, and is extremely reactive with strong oxidation properties. This property of $\mathrm{NO}_{2}$ is often used in regenerating diesel particulate filters. Nitrogen oxides are highly active ozone precursors and play a leading role in urban smog phenomena (www.casadata.org).

$\mathrm{CO}$ is a colorless, odorless gas and highly toxic at higher concentrations. It is found in the atmosphere due to incomplete combustion of carbon based fuels. Carbon monoxide emissions from diesel and other lean-burn engines are very low when 
compared to gasoline engines without catalytic converters, which operate on fuel rich pre-mixed combustions. $\mathrm{CO}$ is easily adsorbed in the blood, where it binds with hemoglobin to form carboxyhemoglobin, reducing the oxygen supply to vital parts of the body, leading to strokes, heart attack, and lung inflammation (CARB, 2005).

Hydrocarbon emissions are a complex mixture of partially burned and unburned fuel and lubricating oil, including a variety of species formed during combustion at high temperature and pressure. The unburned hydrocarbons derived from several sources in the combustion system are suspected to adsorb on to elemental carbon, condense on nuclei mode sulfate particles, or undergo homogeneous nucleation increasing the emission of nanoparticles. Mathis et al. (2004) studied the effect of organic compounds on the formation of nano particles in diluted exhaust by adding a variety of VOCs into the primary dilution air while varying the temperature and humidity of the dilution air over a wide range. He found that alcohols generally increased nucleation mode particles, and short aliphatic hydrocarbons had no effect on nucleation of nanoparticles. Many carcinogenic compounds are grouped under volatile, semi-volatile and particle-bound hydrocarbons, while some of them are found to be highly reactive in the formation of ground-level ozone, leading to urban smog. US EPA regulates THC by dividing them into two groups - methane and non-methane hydrocarbon (NMHC) with more emphasis on NMHC components since methane is a stable compound.

Total Particulate Matter (TPM), by definition is the material collected on a specified filter medium after raw exhaust has been cooled and diluted with HEPA filtered air to a temperature of $325^{\circ} \mathrm{K}\left(52^{\circ} \mathrm{C}\right)$. TPM has traditionally been regulated on the basis of gravimetric mass (CFR 40, 2001). Particulates collected by this method primarily consist of elemental carbon, heavier hydrocarbons (derived from the fuel and lubricating oil), soluble organic fraction, and hydrated sulfuric acid (derived from the fuel and lube oil sulfur). Even after a considerable amount of basic research, neither the formation of PM in the cylinder, nor its physical and chemical properties are fully understood. Research was conducted by Khalek et al. (1999) to study the effects of dilution ratio and residence time on the formation of nanoparticles showed that volatile particle precursors collected in the exhaust sampling system during low temperature operating modes are released during high temperature excursions. The released hydrocarbons undergo 
homogeneous nucleation, forming nanoparticles as the exhaust dilutes and cools. It was concluded that nanoparticle formation depends on dilution ratio, residence time, humidity, temperature, and relative concentrations of carbon and volatile matter. Mayer (2002) has suggested that carbonaceous particles generated during combustion are usually found as relatively dense spheres in the size range of 20-30 nanometers, known as primary particles which however tend to form agglomerates and aggregates at an early stage depending on particle concentration and residence time.

The particle formation begins with nuclei mode particles, whose nature is still being studied by many researchers. These nuclei mode particles are primarily volatiles which mainly consist of hydrocarbons and hydrated sulfuric acid condensates formed by homogeneous nucleation. This takes place when the saturation ratio, $(\mathrm{S})$, which is the ratio of partial pressure of the volatile hydrocarbon species to its local vapor pressure, exceeds unity. This ratio depends on the exhaust temperature, dilution air temperature, concentration of condensable species, and the dilution ratio. It is also observed that sulfate nuclei coated with organic substances decreases their evaporation rate, making them last longer in the atmosphere, hence, posing greater health risk (Mathis et al., 2004). Gautam (2001) suggested the nucleating sites for nanoparticles, in the natural gas vehicle exhausts, may arise not only due to the metals, ash, and heavier hydrocarbons in the lubricating oil but also due to the high sulfur content in the lubricating oil that could be as high as 4500ppm. Anderson et al. (2004) studied the effect of fuel and lubricant on the nucleation mode particle emissions. It was found that phosphorus, an antiwear agent, and sulfur influenced the formation of nucleation mode particles. He suggested hot idle, which emitted the highest number of nucleation mode particles, as a preferred test condition to study the effect of lube oil. Yilmaz et al. (2004), while studying the impact of lube oil derived components on particulate emissions using sample data from tests done by Sharp et al. (2000), found that lube oil contribution to the total particulate emissions was about $0.023 \mathrm{~g} / \mathrm{bhp}-\mathrm{hr}$ to $0.038 \mathrm{~g} / \mathrm{bhp}-\mathrm{hr}$. This accounted for 20 to $30 \%$ of the total engine-out particulate emissions, which was clearly above the US EPA 2007 total particulate levels. An on-line measurement of the composition of diesel nanoparticles conducted by Sakurai et al. (2002) using a Thermal Desorption Particle Beam Mass Spectrometer (TDPBMS) showed that the volatile component of the total 
diesel particulates were comprised of at least 95\% unburned lube oil. Tandem Differential Mobility Analyzer (TDMA) volatility measurements showed that organic components of diesel nanoparticles with carbon numbers in the range of $\mathrm{C}_{24}-\mathrm{C}_{32}$ were derived mostly from unburned oil.

Based on analysis performed by a combination of physical and chemical methods, PM is traditionally classified into three main fractions which are further categorized as given below (www.dieselnet.com)

1. Solid fraction (SOL)

- Elemental carbon

- Ash

2. Soluble Organic Fraction (SOF)

- Organic material derived from engine lubricating oil

- Organic material derived from fuel

3. Sulfate particulates

- Sulfuric acid

- Water

According to the above classification, total particulate matter (TPM) is defined as $\mathrm{TPM}=\mathrm{SOL}+\mathrm{SOF}+$ Sulfate particulates

When exhaust gases, are mixed with air, either in a dilution tunnel or the atmosphere, the chemical and physical properties of PM are altered to a great extent. Under such conditions, heavy hydrocarbons, derived from lubricating oil and unburned fuel, are condensed or adsorbed onto the surface of carbon particles, thus forming the organic portion of PM (SOF). Advanced engine technology, use of efficient particulate filters, and use of alternative fuels, like natural gas have reduced the emission of carbonaceous soot substantially, which typically serves as a sponge in adsorbing all soluble organic fractions. However, this has increased the number of volatile nuclei mode particles. These particles carry the suspected genotoxic constituents with a potential to penetrate deep into the lungs and dissolve in the bodily fluids, eventually transferring into the blood stream. Sulfates found in the volatile nuclei mode particles are derived from fuels and lubricating oils. According to Baumgard et al. (1996), sulfate 
particulates are formed by a hetromolecular nucleation reaction between the molecules of $\mathrm{H}_{2} \mathrm{SO}_{4}$ and $\mathrm{H}_{2} \mathrm{O}$, even in unsaturated conditions.

Several non-regulated pollutants, or suspected TACs can be found in the exhaust of diesel and alternative fueled engines, usually at concentration levels much lower than the regulated emissions. Some of them are part of the complex particulate matter emissions, while others are in gaseous phase. These pollutants exist as particle bound volatile hydrocarbons under reduced temperature, and are known as VOCs. VOCs are further classified as unburned hydrocarbons (derived from fuel and lubricating oils), oxygenated hydrocarbons (derived from partially burned heavier hydrocarbons), and PAH (formed due to incomplete combustion). PAHs are found in gaseous phase, as well as particle bound organics (www.casadata.org). The VOCs are further grouped according to their molecular structure, which includes paraffins (single-bonded open-chain saturated hydrocarbons), olefins (open-chain hydrocarbon containing a double bond), acetylenes (open-chain unsaturated hydrocarbon containing one carbon-carbon triple bond), cycloparaffins (single bond unsaturated ring hydrocarbons), and aromatics (a stable compound consisting of benzene rings) (Heywood, 1988). The oxygenated hydrocarbons include ketones, alcohols, and aldehydes with acrolein, acetaldehyde, and formaldehyde being the most common aldehydes. According to various exhaust speciation studies, it has been found that oxygenated hydrocarbons found in diesel exhaust are low when compared to engines running on alternative fuels. VOCs of major concern are the aromatics and aldehydes. Benzene, a building block of aromatic compounds, is a toxic and classified as a carcinogen. It has been estimated that $80 \%$ of the benzene in the atmosphere is emitted from automobiles (CARB, 2005).

Several toxicological and epidemiological studies have investigated the adverse health effects of particulate matter from mobile sources including development of cancer and other diseases (Dockery et al., 1993). Long term exposure to particulate matter has been associated with lung cancer in laboratory animals (IARC, 1998). These adverse health effects are linked to the inhalation of nanoparticles which are mainly soluble organic compounds. The US EPA has associated 20 toxic air contaminants with the hydrocarbon emissions from internal combustion engines. A TAC is defined as an air pollutant that may cause or contribute to an increase in mortality or serious illness, or 
which may pose a hazard to human health (CARB, 2005). There is no regulating limit set for these TACs by the EPA, as they are very toxic and pose a threat to public health even at lower concentrations. In other words, there is no safe concentration limit that would not present at least some risk.

Table 2.5 California ARB Toxic Air Contaminants Associated with Diesel Exhaust, (CARB, 1998)

\begin{tabular}{|l|l|l|}
\hline Acetaldehyde & Cobalt compounds & Nickel \\
\hline Acrolein & Cresol isomers & 4-Nitrobiphenyl \\
\hline Aniline & Cyanide compounds & Phenol \\
\hline Antimony compounds & di-n-Butylphthalate & Phosphorus \\
\hline Arsenic & Dioxins and dibenzofurans & POM (Polycyclic Organic \\
\hline Benzene & Ethylbenzene & $\begin{array}{l}\text { Matter), including PAHs and } \\
\text { derivatives }\end{array}$ \\
\hline Beryllium compounds & Formaldehyde & Propionaldehyde \\
\hline Biphenyl & Hexane & Selenium \\
\hline Bis[2-ethylhexyl]phthalate & Inorganic lead & Styrene \\
\hline 1,3-Butadiene & Manganese & Toluene \\
\hline Cadmium & Mercury & Xylene isomers and mixtures \\
\hline Chlorine (chloride) & Methanol & o-Xylene \\
\hline Chlorobenzene and derivatives & Methyl ethyl ketone & m-Xylene \\
\hline Chromium compounds & Naphthalene & p-Xylene \\
\hline
\end{tabular}

\subsection{Previous Studies Comparing Emissions Between Diesel and CNG Engines}

Various studies have been carried out comparing the emissions between diesel and $\mathrm{CNG}$ engines. In these tests, comparisons were made by complete speciation of the exhaust in order to study the differences in the emissions of various non-regulated TACs. Most of these studies were performed using $\mathrm{CNG}$ engines equipped with oxidation catalysts. In the following section, four different studies are summarized, emphasizing the reduction in NMHC and nanoparticle emissions in particulate trap equipped diesel engines compared to lean-burn $\mathrm{CNG}$ engines, both with and without oxidation catalysts.

\subsubsection{CARB Study}

In 2001, CARB conducted a comparative study to evaluate the toxicity of the emissions from transit buses running with heavy-duty clean diesel and new $\mathrm{CNG}$ engines. Test vehicles were powered by similar engines and fueled by Emissions Control Diesel (ECD-1), which is a low sulfur fuel $(<15 \mathrm{ppm})$ and motor grade CNG. The diesel transit 
bus was powered by a 1998 DDC S50 engine fitted with an oxidation catalyst. The same diesel engine was retested by replacing the oxidation catalyst with a Johnson Matthey CRT $^{\text {TM }}$ particulate filter, and the CNG bus was powered by a 2000 DDC S50G engine without any aftertreatment. This engine configuration represented the vast majority of CNG transit buses operating in Los Angeles. The emissions data were collected by operating the test vehicles on four different driving cycles using a heavy-duty chassis dynamometer in order to study the effect of driving cycles on emissions. The driving schedules used were Steady-State Cruise at 55mph, Central Business District cycle (CBD), Urban Dynamometer Driving Schedule (UDDS), and New York Bus Cycle (NYBC). The NYBC test schedule is a short-distance cycle marked with fast accelerations and low speeds with frequent stops and is considered as the most challenging in terms of emissions among the four test cycles. Emissions samples were collected over multiple test cycles to ensure collection of sufficient sample for subsequent exhaust speciation analysis. Size-resolved mass and particle number emissions were also measured during this study. Hydrocarbon speciation included the analysis of VOCs and toxic NMHCs, carbonyls, PAHs, organic and inorganic elemental analysis, and Ames bioassay analysis. The results showed that diesel engines emitted more NOx, compared to $\mathrm{CNG}$ engines and the emissions of NOx remained unchanged for CRT equipped diesel engines compared to those outfitted with a diesel oxidation catalyst. There was a significant reduction of TPM emissions in the CRT equipped bus, which averaged at $85 \%$ across all the test cycles when compared to baseline diesel engine with an oxidation catalyst. It also showed an average PM advantage over the CNG engine. Results indicated that $\mathrm{HC}$ emissions of CRT equipped engines were near or below detection limits. The total HC emissions from the baseline diesel engine were lower than the NMHC emissions from the CNG engine, indicating that $\mathrm{CNG}$ engines were not much cleaner than clean diesel engines.

From the onsite analysis of VOCs, it was found that the CNG engine had highest emissions of 1,3-butadiene, benzene, and toluene of all the three vehicle configurations tested, while the diesel engine equipped with CRT had the least emissions. Emissions of carbonyls, which was predominantly formaldehyde and acetaldehyde, were in the following order $\mathrm{CNG}>$ Diesel $+\mathrm{OC}>$ Diesel $+\mathrm{CRT}$. PAH emissions were in the 
following order Diesel $+\mathrm{OC}>\mathrm{CNG}>$ Diesel + CRT. The bioassay results showed that CNG vehicle had the highest specific mutagenic activity for all test cycles.

Particle size distribution measurements, using an SMPS, were performed by Holmen et al. (2002) by sampling exhaust from a mini diluter, as well as a full flow CVS tunnel using a SMPS. The results showed that a CRT effectively reduced the concentrations of both accumulation and nucleation mode particles by a factor of 10-100, compared to the baseline diesel engine, when sampled from a mini diluter during a $55 \mathrm{mph}$ SS test. The particle size distribution data for the CNG engine showed significantly more nuclei mode particles $(<20 \mathrm{~nm})$ for SS tests, suspected to be derived from the lube oil and volatile particle precursors in the absence of an oxidation catalyst. The sulfur content in the CNG lubrication oil (5400 ppm) was found to be 1.4 times higher than the diesel bus. The study concluded that the lubricating oil consumption by the $\mathrm{CNG}$ engine could be a likely contributor to the measured levels of PM and toxic emissions, and proposed to study the emissions from a CNG engine equipped with oxidation catalyst. At the same time, it was uncertain whether a CNG oxidation catalyst would reduce the nanoparticles derived from the lube oil because its primary role is to oxidize VOCs of lower molecular weight - especially formaldehyde.

\subsubsection{TNO Automotive Study, Netherlands}

TNO Automotive carried out a comparative study of PM size distribution and exhaust emissions from heavy-duty diesel and natural gas engines used in urban transit buses. This study was sponsored by Novem, the Netherlands Agency for Energy and the Environment, to help the public transport companies in their decision to acquire Enhanced Environmentally friendly Vehicles (EEVs). The test engines included two diesel engines, one with a continuously regenerating diesel particulate filter and one without. Both were certified for Euro 3 emission standards. The other three buses were powered by gas engines, two on natural gas and one on LPG gas engine. The LPG engine was a stoichiometric combustion engine equipped with a three-way catalyst. For the natural gas engines, one of them was a lean-burn with an oxidation catalyst, and the other one was a stoichiometric engine equipped with a three-way catalyst. The buses were tested on the European Transient Cycle (ETC) and Dutch Bus Transient Cycle (DBTC). Particle size distributions were measured using an SMPS from the European 
Stationary Cycle (ESC), a steady state. HC results showed that all the engines with exhaust aftertreatment devices had lower emissions, when compared to the diesel engine without aftertreatment, on both test cycles. The NOx emissions from the natural gas engine with stoichiometric combustion and three-way catalyst were below $2.0 \mathrm{~g} / \mathrm{kWh}$, and met the EEV limits, while the emissions from the lean-burn gas and the diesel engines were between $5 \mathrm{~g} / \mathrm{kWh}$ and $6.5 \mathrm{~g} / \mathrm{kWh}$. The PM emissions from the diesel engine equipped with diesel particulate filter and natural gas engines were low, near the detection limits. However, the PM levels from the diesel engine equipped with the DPF was lower than the natural gas engines, supporting the uncertainty involved in reducing the PM emissions from natural gas engines using oxidation catalyst alone.

Particle size distributions were measured at steady-state conditions using SMPS in the size range of $12 \mathrm{~nm}-600 \mathrm{~nm}$. Particle size measurement from the diesel engine without exhaust aftertreatment was carried out by running the engine on two different fuels having different sulfur content (290ppm and 13ppm). The result showed that there was an increase in the number of particles in the nucleation mode range $(25 \mathrm{~nm})$ with high sulfur fuel. The diesel engine with the particulate trap running on low sulfur fuel showed a reduction in the number of particles of size $>50 \mathrm{~nm}$ by two to three orders of magnitude. But a sharp increase was observed in the nucleation mode particles and it was attributed to the increase in sulfate emissions from the oxidation catalyst of the DPF. The number of particles in the accumulation mode range from the $\mathrm{CNG}$ engines with exhaust aftertreatment devices was comparable to the results of the diesel engine with the DPF. The difference between particle numbers of the gas engines was attributed to the different rates of oil consumption combined with the catalyst behavior in oxidizing oil derived particle precursors.

\subsubsection{International School Bus Study}

International Trucks and Engine Inc. performed a comprehensive emissions measurement from two diesel engines, one with a DPF, and one natural gas engine that were used to power school buses. It included measurements of VOCs, aldehydes, PAHs and other compounds labeled as TACs by the EPA. The results showed that the emissions of TACs and other non-regulated hydrocarbons were significantly reduced by the particulate filter installed on the diesel engine, when compared to the emissions from 
the $\mathrm{CNG}$ engine. The result of TAC emissions from all the three engines is shown in the figure below.

Results of aldehydes, ketones and other species between $\mathrm{C}_{1}$ and $\mathrm{C}_{12}$, excluding methane, showed that $\mathrm{CNG}$ engine emits more than diesel engines. PAH results showed that the diesel engines with a DPF had lower values than the CNG engine except for naphthalene, benzo(b)flouranthene, indeno(1,2,3-cd) pyrene, 1-nitropyrene, where the difference were not significant. The study was successful in showing CNG engines without aftertreatment devices produce more toxic emissions than diesel engines with aftertreatment devices.

\begin{tabular}{|c|c|c|c|c|c|c|c|c|}
\hline \multirow[b]{2}{*}{ Count } & \multirow{2}{*}{$\begin{array}{l}\text { Toxic Air } \\
\text { Contaminant Found } \\
\text { (TAC No.) }\end{array}$} & \multirow[b]{2}{*}{$\begin{array}{l}\text { Detection } \\
\text { Limit }\end{array}$} & \multicolumn{3}{|c|}{ Adjusted Average } & \multicolumn{3}{|c|}{$\begin{array}{l}\text { Relative Significance }{ }^{e} \text { and } \\
\text { Direction of Comparison }\end{array}$} \\
\hline & & & $C D$ & LED & CNG & $\begin{array}{l}\text { CD vs } \\
\text { LED }\end{array}$ & $\begin{array}{l}\text { CD vs } \\
\text { CNG }\end{array}$ & $\begin{array}{l}\text { LED vS } \\
\text { CNG }\end{array}$ \\
\hline 1 & Acetaldehyde (1), $\mathrm{mg} / \mathrm{mi}$ & 0.2 & 9.5 & 2.7 & 24 & $\gg>$ & e<< & e<< \\
\hline 2 & Acrolein (2), $\mathrm{mg} / \mathrm{mi}$ & 0.2 & 3.3 & 0.45 & 4.9 & >> & $<$ & $\ll<$ \\
\hline 3 & Benzene (6), $\mathrm{mg} / \mathrm{mi}$ & 1 & 4.7 & ND & 4.3 & $\gg$ & $=$ & $\ll$ \\
\hline 4 & Biphenyl (8), $\mu \mathrm{g} / \mathrm{mi}$ & 2 & 410 & 4.0 & 5.3 & $\gg$ & $\gg>$ & $=$ \\
\hline 5 & Bis[2-ethylhexyl]phthalate $(9), \mu \mathrm{g} / \mathrm{mi}$ & 2 & 1.7 & 0.98 & 1.6 & $=$ & $=$ & $=$ \\
\hline 6 & 1,3-Butadiene (10), $\mathrm{mg} / \mathrm{mi}$ & 2 & ND & $1.3^{\mathrm{b}}$ & 4.5 & $=$ & $<$ & $=$ \\
\hline 7 & Cresol isomers (16), $\mu \mathrm{g} / \mathrm{mi}$ & 2 & 190 & 49 & 73 & > & $>$ & $=$ \\
\hline 8 & Cyanide compounds (17), $\mathrm{mg} / \mathrm{mi}$ & 0.15 & 0.33 & $0.11^{\mathrm{b}}$ & $0.29^{\mathrm{b}}$ & $=$ & $=$ & $=$ \\
\hline 9 & di-n-Butylphthalate (18), $\mu \mathrm{g} / \mathrm{mi}$ & 2 & $0^{2}$ & 6.9 & 4.7 & $<$ & $=$ & $=$ \\
\hline 10 & Dioxins and furans (19), pg/mi & $18-89$ & 260 & 260 & 250 & $=$ & $=$ & $=$ \\
\hline 11 & Formaldehyde (21), $\mathrm{mg} / \mathrm{mi}$ & 0.1 & 27 & 5.2 & 500 & $\gg>$ & $\ll<$ & $\ll$ \\
\hline 12 & Hexane (22), mg/mi & 1 & ND & $0.39^{b}$ & ND & $=$ & $=$ & $=$ \\
\hline 13 & Methanol (26), $\mathrm{mg} / \mathrm{mi}$ & 1 & 10 & 23 & 30 & $=$ & $<$ & $=$ \\
\hline 14 & Methyl ethyl ketone (27), $\mathrm{mg} / \mathrm{mi}$ & 0.1 & 0.51 & $0.0016^{b}$ & 0.28 & $>$ & $>$ & $<$ \\
\hline 15 & Naphthalene (28), $\mu \mathrm{g} / \mathrm{mi}^{\mathrm{d}}$ & 0.02 & 0.73 & 0.069 & 0.074 & $\gg>$ & $\gg>$ & $=$ \\
\hline 16 & Phenol (31), $\mu \mathrm{g} / \mathrm{mi}$ & 2 & 650 & 150 & 170 & $\gg>$ & $>$ & $=$ \\
\hline 17 & Phosphorus (32), $\mu \mathrm{g} / \mathrm{mi}$ & 380 & $130^{b}$ & ND & $300^{\circ}$ & $=$ & $=$ & $=$ \\
\hline 18 & $\begin{array}{l}\text { POM (polycyclic organic matter), } \\
\text { including PAHS and derivatives } \\
\text { (33), } \mathrm{mg} / \mathrm{mi}^{\mathrm{d}}\end{array}$ & $\begin{array}{c}0.002- \\
0.02\end{array}$ & 2.8 & 0.076 & 0.16 & >> & $\gg$ & $=$ \\
\hline 19 & Propionaldehyde (34), mg/mi & 0.1 & 3.0 & 0.35 & 6.9 & $\gg>$ & $<$ & $\ll<$ \\
\hline 20 & Toluene (37), mg/mi & 1 & 4.3 & 2.0 & 3.2 & >> & $=$ & $=$ \\
\hline
\end{tabular}

Figure 2.1 Summary of TAC emissions from diesel and CNG engines. (Intl. Bus Study)

\subsubsection{The Finnish National Bus Project}

Nylund, et al. (2004) of VTT Processes conducted a comprehensive study to compare the emissions performance of the latest models of diesel and CNG engines equipped with exhaust aftertreatment devices which were used to power transit buses, in Finland. The test vehicles included four new natural gas transit buses (MY2002-2004) equipped with oxidation catalysts and one diesel vehicle, which was tested in three 
configurations: without aftertreatment, with an oxidation catalyst, and with a CRT particulate filter. Two of the lean-burn $\mathrm{CNG}$ engines were equipped with oxidation catalysts. The other two engines used lean mix and stoichiometric combustion with a three-way catalyst. The vehicles were tested on a chassis dynamometer on two different test cycles, the European Braunschweig city bus cycle and the US Orange County Cycle. Comprehensive emissions measurements were performed, which included non-regulated emissions and particle number and mass distributions.

Comparisons of non-regulated emissions were emphasized in this study as they highlight the functionality of the exhaust aftertreatment devices. The NMHC and TPM emission result showed that diesel engines equipped with CRT performed better than one of the lean-burn CNG buses equipped with an oxidation catalyst, and it was attributed to the decreased efficiency of the oxidation catalyst.

Particle number and size distribution results showed that the diesel engine with $\mathrm{CRT}$ and three of the four $\mathrm{CNG}$ engines had reduced the number particles by two orders of magnitude, compared to baseline diesel. However, the total number of particles in the size range above and below 60nm (aerodynamic size) from the diesel engine with CRT was lower than both lean-burn CNG engines equipped with oxidation catalyst, as shown in the figure below. This confirms that oxidation catalysts are not efficient in oxidizing the heavier hydrocarbons derived from lube oil.

Hydrocarbon speciation results showed that the diesel engine with CRT had lower emissions of isobutene, toluene, formaldehyde and acetaldehyde when compared to leanburn CNG engine with an oxidation catalyst. The PAH results showed that the diesel engine with CRT effectively reduced PAH compounds greater than four rings and the priority PAHs, suspected mobile source carcinogens were reduced even better than the Lean Burn (LB) CNGs with oxidation catalyst. The priority PAHs are derived from the lube oil, which is heavier than other PAHs and the results show it is better controlled by a catalytic trap than an oxidation catalyst. 


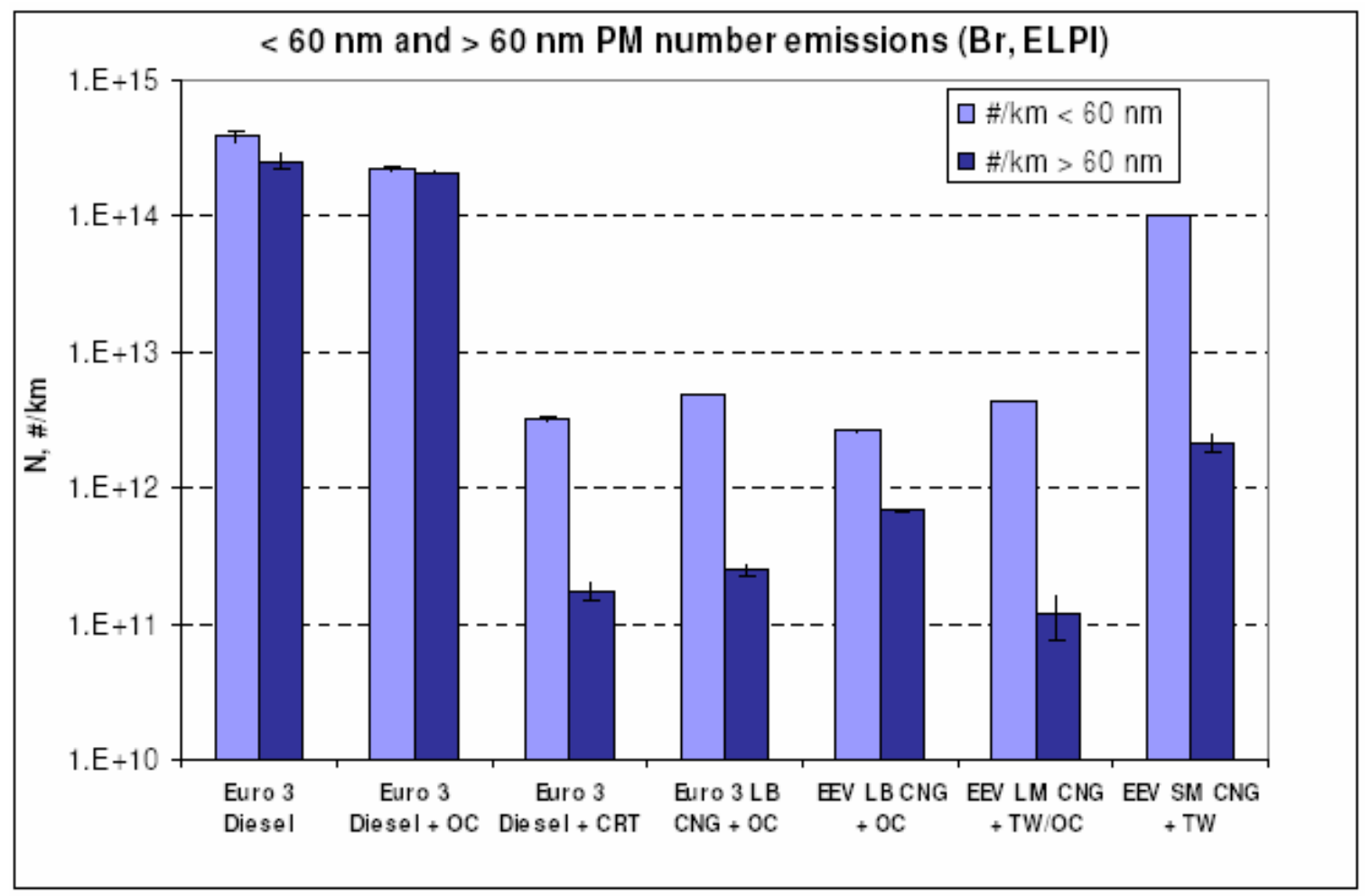

Figure 2.2 Comparison of size classified particle number emissions among different Diesel and CNG engine configurations on a transient duty cycle. (Finnish National Bus Project)

\subsection{CNG Engine Design Enhancement}

CNG heavy-duty engines have evolved from heavy-duty diesel engines. Diesel engines were adapted to use natural gas as a fuel by providing a source of ignition since natural gas does not auto ignite because of its high octane number. The natural gas fueled transit buses are favored over their diesel fueled counterparts, due to their inherent quality of low particulate emissions, as a result of soot free combustion. Natural gas engines are widely used in transit buses, refuse haulers, school buses, street sweepers and airport vehicles due to their short range of travel, centralized fuelling facility, and centralized maintenance garage.

A recent study was conducted by CARB over multiple driving cycles comparing the emissions between two transit buses, one running on a diesel engine outfitted with an oxidation catalyst and a CRT trap and the other bus was running on a CNG engine with no exhaust aftertreatment device, (representative of the vast majority of the current $\mathrm{CNG}$ bus fleet). It was found that the diesel transit bus with exhaust aftertreatment device had 
the lowest PM and toxic hydrocarbon emissions rates compared to the CNG bus in all the tests. The increase in PM and volatile hydrocarbon emissions were suspected to be from the combustion of lubrication oils. This indicates that there is a possibility to reduce the emissions of unburned hydrocarbons by improving the piston ring and liner package in order to decrease lube oil leak into combustion chamber, and reduce blow-by emissions. Improving the piston bowl design promotes uniform combustion by reducing temperature spikes, thereby decreasing the lube oil consumption. Improving fuel injection and the ignition system promotes diffusion combustion and reduces knocking, which is associated with increased lube oil consumption (Hailin Li, et al., 2004). Cummins Westport Inc is developing a new direct injection system for CNG engines, known as High Pressure Direct Injection (HPDI), where CNG is injected directly into the cylinder following a small quantity of diesel, which is ignited at high compression ratio. This in turn facilitates the combustion of $\mathrm{CNG}$ through diffusion combustion mechanism as observed in diesel engines (www.westport.com).

It has been demonstrated in various studies that the current $\mathrm{CNG}$ engine technology is capable of reducing the PM emissions more than $90 \%$ by mass when compared to a similar baseline diesel engine. However, it is also observed that a $\mathrm{CNG}$ engine produces more nanoparticles compared to diesel engines and significant amount of volatile particles derived from lube oil.

\subsection{Chemical Speciation}

Exhaust speciation of heavy-duty engines operating on diesel or alternative fuels is performed to identify the hydrocarbons which exist as gas and/or condensates (particulate bound) at ambient conditions in order to determine the ozone forming potential and the toxicity of the exhaust emissions. A well defined speciation methodology, developed to identify $\mathrm{C}_{1}-\mathrm{C}_{12}$ compounds with gas chromatography, was successfully used to compare vehicles running on alternative fuels (alcohol and natural gas) with gasoline fueled vehicles on the basis of potential ozone formation. However, diesel emissions requires complex sampling and advanced analysis methods in order to identify and quantitate heavier hydrocarbons in the range of $\mathrm{C}_{12}-\mathrm{C}_{22}$, as they are temperature sensitive and undergo quick phase change (Newkirk, et al., 1993). 
Newkirk, et al. (1995) conducted a speciation study to determine mass of individual hydrocarbon species, their ozone forming potential, and toxicity found in the exhaust emissions of heavy-duty engines operating on different fuels. The test vehicles included two gasoline engines with and without catalyst, a diesel engine, a LPG, and a CNG engine which was tested with and without an oxidation catalyst. The exhaust emissions were speciated for all VOCs in $\mathrm{C}_{1}-\mathrm{C}_{12}$ range, aldehydes and ketones. Analysis of toxic emissions included benzene, formaldehyde, acetaldehyde and 1,3-butadiene. The VOC samples were collected in a tedlar bag and speciated, using a GC, while aldehydes and ketones were sampled by bubbling the exhaust through impingers containing 2,4dinitrophenylehydrazine (DNPH) and perchloric acid. A difference of $41 \%$ was observed between the mass of speciated hydrocarbons and THC for diesel engine during hot FTP, because heavier and semi-volatile hydrocarbons in the range of $\mathrm{C}_{13}-\mathrm{C}_{24}$ were not accounted for in the GC speciation. The volatile organics, which have potential to form ozone, were multiplied with the Maximum Incremental Reactivity (MIR $=\mathrm{g} \mathrm{O}_{3} / \mathrm{g}$ VOC) assigned to each compound to find the potential mass of ozone formation. The results showed that ozone forming hydrocarbons and toxics were reduced by $95 \%$ with the use of a catalyst in the gasoline engine. Similar results were observed in the CNG engine indicating that hydrocarbons with lower molecular weight can be reduced effectively with oxidation catalyst. The diesel engine without a catalyst emitted lower ozone potential and toxic hydrocarbons compared to gasoline engine without catalyst and $\mathrm{CNG}$ engine in both configurations.

Tobias et al. (2001) studied the chemical composition of the nanoparticles using a Thermal Desorption Particle Beam Mass Spectrometer (TDPBMS), due to low mass concentrations and potential contamination risks associated with sampling by standard techniques. The composition measurement results showed that the small nanoparticles (26-30nm) were formed by higher molecular weight organics with an average alkanes carbon number of $\mathrm{C}_{19}-\mathrm{C}_{25}$, whereas large nanoparticles $(38-58 \mathrm{~nm})$ were made of volatile organics with a carbon number of $\mathrm{C}_{17}-\mathrm{C}_{19}$, derived from the fuel and lube oil. At high engine loads, it was found that sulfate particles played an active role in forming nuclei mode particles, which grow by condensation of heavier volatile organics at reduced temperature. It was found that the number of nuclei mode particles decreased with 
increasing load, indicating complete combustion of unburned/partially burned fuel and lubricating oil. Mathis et al. (2004) performed Transmission Electron Microscope (TEM) analysis of volatile nanoparticles consisting of hydrophilic and hydrophobic components, and found that they were made of at least two compounds with different volatility. The nanoparticles observed on the TEM image, were classified into three groups. After exposing these particles to an electron beam, partial evaporation was observed either in the center or at the rim of the particles signifying a volatile hydrophilic part. But some of them did not show any change in their structure, signifying the hydrophilic portion could be coated by organic compounds that protect them from evaporation. The energy dispersive analysis validated this hypothesis by showing the presence of the hydrophilic sulfur and potassium in the nanoparticles.

From the previous speciation studies, it is clear that VOCs with carbon numbers in the $\mathrm{C}_{1}-\mathrm{C}_{12}$ range exist in gas phase and take part in the ozone formation more readily than the heavier hydrocarbons, which lose their volatility at reduced temperatures. Most

of these heavier hydrocarbons are labeled as toxics by the EPA. So, speciation plays an important role in quantifying them and in tracing their sources. Advanced techniques and sampling methods, involving different collecting media, have been developed to perform this task, which is discussed in the following chapters.

\subsection{Aftertreatment Devices}

Until 2004, the stringent emissions regulations to reduce NOx and PM emissions from heavy-duty engines could be achieved by improving the engine design and developing new technologies to reduce them, without the use of exhaust aftertreatment devices. However, recent emissions legislation has been so stringent that it has eventually forced heavy-duty engine manufacturers consider exhaust aftertreatment devices as an efficient solution to gain compliance. In the case of the urban transportation sector, there have been additional regulations in order to reduce emissions from the older vehicles which that are still in active revenue service. This trend has lead to the development of different exhaust aftertreatment devices, to be used as OEM parts for new engines, and as retrofit parts for older engines. Among the different exhaust aftertreatment devices, the most commonly used are oxidation catalysts and particulate traps to reduce NMHC, CO and PM. SCR catalysts are used for reducing NOx emissions 
from constant speed stationary engines and also in marine engines, while NOx adsorberdisadsorber known as DeNOx catalysts intended to reduce NOx emissions, are still in the development stage.

\subsubsection{Oxidation Catalysts}

The basic principle of operation of an oxidation catalyst is to reduce the emissions of $\mathrm{CO}$ and unburned hydrocarbons by oxidizing them into $\mathrm{CO}_{2}$ and $\mathrm{H}_{2} \mathrm{O}$ at reduced temperature. Oxidizing hydrocarbons, in the absence of the catalyst, requires a residence time on the order of $50 \mathrm{~ms}$ and temperatures in excess of $600 \mathrm{deg} \mathrm{C}$, whereas oxidizing $\mathrm{CO}$ requires temperature in excess of $700 \mathrm{deg} \mathrm{C}$. This would have been impossible with the raw exhaust temperature of a lean-burn engines which are in the range of 200 to 500deg C (Heywood, 1988). Noble metals are preferred over base metal oxides as catalysts, because they show higher specific activity for HC oxidation, and are also less susceptible to sulfur poisoning and loss of low temperature activity. A mixture of platinum $(\mathrm{Pt})$ or Palladium (Pd) and an inert support, such as alumina, are commonly used in oxidation catalysts. Pt catalyst is preferred over Pd for diesel exhaust, but Pd was found to be more effective in lean-burn CNG engines. Gluck et al. (1994) conducted research to develop a catalyst to oxidize methane and $\mathrm{CO}$ under lean-burn and stoichiometric operation of a $\mathrm{CNG}$ engine. The study showed that $\mathrm{Pt} / \mathrm{Rh}$ (Rhodium) based three-way catalyst was able to oxidize $\mathrm{CO}$ efficiently. However, careful control of equivalence ratio between 0.98 and 0.99 was required for high methane conversion. The Pt-based catalyst lost its activity rapidly under lean-burn ageing whereas a $\mathrm{Pd} / \mathrm{Rh}$ based catalyst oxidized methane both in stoichiometric and lean-burn conditions without any loss of activity after ageing. Oxidation catalysts are widely used in retrofitting and as a standard equipment in CNG engines to further reduce toxic compounds, such as aldehydes, $\mathrm{PAH}$, and other mutagenic emissions. This is resultant from findings that indicated $\mathrm{CNG}$ engines without exhaust aftertreatment had measurable levels of VOCs and other TACs when compared with their diesel counterpart equipped with either DOC or particulate filters. A study conducted by CARB to evaluate the effect of oxidation catalyst on CNG transit bus emissions, in comparison to clean diesel engines, showed that there was significant decrease in the emissions of PM, THC, $\mathrm{CO}$ and other non-regulated compounds, while formaldehyde was reduced by $95 \%$. Toxics such as 1,3-butadiene and benzene were reduced below 
detection limit and a considerable reduction in the emissions of PAH was also observed when tested over two different duty cycles. Common modes of failure for an oxidation catalyst are thermal degradation and catalytic poisoning. Thermal degradation is usually caused due to high exhaust temperatures and uncontrolled exothermic reactions, whereby catalytic activation sites are sintered to the washcoat rendering them inactive. This is not considered to be a major problem for $\mathrm{CNG}$ and diesel engines, as the peak exhaust temperatures are in the range of 300 to $400 \mathrm{deg}$ C. Catalytic poisoning is usually caused due to phosphorus, zinc, calcium, and sulfur present in the lube oil additives. The unburned oil and their additives which get deposited within the catalytic washcoat during low temperature operation get oxidized at elevated temperatures leaving behind the additives. Such additives accumulate over the surface leaving a permanent glaze layer which has a masking effect on the catalyst. Phosphorus, in particular, deactivates the catalyst permanently (www.dieselnet.com). It has been found that oxidation catalysts promote oxidation of $\mathrm{SO}_{2}$ to particulate sulfates. Though natural gas as a fuel consists of only traces of sulfur, it is suspected that the lube oil, with sulfur in the range of 400 to $5000 \mathrm{ppm}$, increases the emission of sulfate nanoparticles (sulfur levels in lube oils is not regulated).

Increased use of oxidation catalysts has improved the catalyst formulations, which are now more resistant to sulfur poisoning and have reduced light-off temperatures. Bardasz, et al. (2003) investigated the effect of lube derived species on aftertreatment devices with advanced formulations. Driving distance of $115,000 \mathrm{~km}$ was simulated based on oil consumption by doping the fuel with the lube oils containing different additives at varying concentrations. The $\mathrm{CO}$ and $\mathrm{HC}$ oxidation activities were later compared between the fresh and aged catalysts. It was found there was no significant difference in the catalytic activity.

\subsubsection{Diesel Particulate Filters}

Failure to reduce PM emissions to the level of current regulations by improving the engine design has led to the development of particulate filters. PM filters commonly used for on-road diesel engine applications are ceramic monoliths with a wall flow structure, where the exhaust flows through walls that act as a filter media. A particulate trap fitted to a diesel engine becomes quickly clogged with diesel soot, collected during 
the low temperature operations, increasing the back pressure beyond the permissible limit. Hence the traps are frequently regenerated to oxidize PM at elevated temperatures. The exhaust temperatures of a heavy-duty diesel engine are usually low, because of leanburn operation. Therefore additional measures are required to promote regeneration. There are several onboard continuous particulate regeneration processes, these are broadly classified into active and passive regeneration schemes. In active regeneration, the exhaust temperature is increased by external sources such as an external diesel burner. The burner is activated when the backpressure crosses a preset value. In passive regeneration, exhaust heating is assisted by an oxidation catalyst placed before the particulate trap, wherein, post injected fuel promotes an exothermic reaction in the oxidation catalyst increasing the exhaust temperatures, or by catalyzing the trap with catalysts that reduce the soot oxidation temperature.

Mayer et al. (1998) stated that a "drastic curtailment of pulmonary intruding particulates is not feasible by further development of the engine combustion, nor by reformulation of fuels, nor by deployment of oxidation catalytic converters." However, at the end of 18 months of evaluating particulate traps in the field, he found that they were capable of reducing the total particulate count in the size range of $50 \mathrm{~nm}$ by more than two orders of magnitude. It was also found that particulate traps were beneficial in reducing the PAH emissions, that are considered as carcinogenic, by $90 \%$ or more. This is probably due to the adsorption of PAH on large active surfaces of the trap, where it is oxidized to less harmful compounds during the regeneration process.

Based on the results of the comprehensive experimental work in the VERT project, Mayer et al. (2000) recommended the use of CRT particulate trap, as retrofit devices, on 200 city buses operating on diesel engines, in Switzerland. This retrofit program resulted in reducing the emissions of ultrafine particles in the range of 20$200 \mathrm{~nm}$ by $90 \%$. No increase in back pressures were observed, as the traps were continuously regenerated under most operating conditions. Based on the success of this study, more and more diesel buses in Swiss cities are retrofitted with these particulate traps, instead of investing in new technologies, such as CNG and electric drive systems.

Lanni, et al. (2001) conducted a performance and durability evaluation of CRDPFs on urban transit buses in New York. The tests included evaluation of PM 
reduction achievable using CRDPFs, effect of sulfur level in the fuel, and durability and maintainability of such devices in rigorous city transit service. The evaluation program was carried out over a period of 9-12 months. The emissions testing was performed on a chassis dynamometer under transient cycles to evaluate the emissions reduction obtained with the CRDPF fitted on a DDC S50 engine, both at the beginning and at the end of the test period. The test fuels included an ULSD fuel $(<30 \mathrm{ppm} \mathrm{S})$ and the standard DF \#1 diesel fuel (300ppm S). The durability of the CRDPFs was tested by continuously monitoring real-time exhaust back pressure and temperature upstream of the filter, using electronic data loggers. The buses equipped with CRDPFs were compared with those without CRDPFs to evaluate the operational and maintenance parameters. Results indicated that a significant reduction of emissions could be achieved by using CRDPF with ULSD fuel. The reductions were in the following range: 90\% in PM, CO and THC, $99 \%$ in carbonyls, $80 \%$ in PAHs and more than $90 \%$ in $\mathrm{NO}_{2}$-PAHs. Particle count was reduced by more than $99 \%$ in all size ranges.

Lanni, et al. (2002), at the end of the evaluation program, found an increase in the PM mass during emissions testing. This was predominantly due to increase in sulfate particles that were being released during the CBD test. Based on the field evaluation data, it was found that there were no CRDPF related failures and no unplanned maintenance calls, indicating successful operation of the CRDPF over a period of fourteen months. However, the fuel consumption of CRDPF equipped buses increased by $12 \%$ when compared to the baseline buses. The post durability emissions reduction results showed more than $90 \%$ reduction in $\mathrm{PM}$ and $\mathrm{CO}$, more than $70 \%$ in $\mathrm{HC}, 99 \%$ reduction in carbonyls and $72 \%$ reduction in PAHs. Overall, the CRDPF exhibited the same reduction efficiencies and excellent durability over the evaluation period, making it a most preferred retrofit exhaust aftertreatment device for urban transit buses.

Nagendran (2003) performed a yearlong study to evaluate the emissions reduction performance of two different particulate filters on an off-road diesel engine used in a scraper. Fuels of different sulfur levels were used during this test. The particulate traps used were a Johnson Matthey CRT ${ }^{\mathrm{TM}}$ trap and an Engelhard DPX ${ }^{\mathrm{TM}}$ trap. The Johnson Matthey $\mathrm{CRT}^{\mathrm{TM}}$ was regenerated by a passive process, wherein the oxidation catalyst placed before the particulate trap oxidizes $\mathrm{NO}$ to $\mathrm{NO}_{2}$. This was further reduced to 
nitrogen in a reverse process by oxidizing the soot in the particulate trap. These traps are susceptible to sulfur poisoning and increase the emission of sulfate particles, which counter-benefits the reduction in PM. Engelhard DPX ${ }^{\mathrm{TM}}$ traps are catalyzed with noble metals that reduce the soot ignition temperature significantly to about 360 to $400 \mathrm{deg} \mathrm{C}$, thereby initiating the regeneration process when such conditions are attained for sufficient duration. Test results showed that there was a significant reduction in the emissions of $\mathrm{PM}, \mathrm{CO}$ and $\mathrm{HC}$ from both traps for all the fuels, when compared to the baseline engine. PM emissions were reduced to the level of $0.02 \mathrm{~g} / \mathrm{bhp}$-hr for both steadystate and transient tests, resulting in the scraper engine meeting 2006 emissions standards.

From previous studies, it can be determined that using exhaust aftertreatment devices to aid in the reduction of emissions is a viable alternative. Studies that employ methods approved by the regulating authorities, like EPA, for determining the in-use emissions of vehicles are effective in analyzing exhaust aftertreatment devices. This research follows the CFR 40, Part 86, Subpart $\mathrm{N}$ for measuring the emissions. The rest of this work will be concerned with the equipment, procedure, and analysis of the results obtained. 


\section{EXPERIMENTAL SETUP}

The following section discusses the working principles and setup of different equipment used in conducting the experiment. It also discusses various sampling devices involved in collecting the samples for speciation analysis.

\subsection{Equipment and Procedures}

This section discusses the experimental setup and procedure used in evaluating the performance of the novel aftertreatment device retrofitted onto a CNG-fueled transit bus. All the testing were conducted on a WVU transportable laboratory chassis dynamometer stationed at Riverside, CA. WVU's Heavy Duty Vehicle Emission Testing Transportable Laboratory (HDVETTL) has been operational since 1993 and has been traveling coast-to-coast with innumerable successful emission tests to its credit. The transportable emissions laboratory consists of chassis dynamometer, which is instrumental for driving the test vehicle on desired duty cycles, and an instrument trailer, which houses a full flow primary dilution tunnel, secondary tunnel for particulate sampling, regulated and non-regulated gas emission sampling train, data acquisition, and control systems. The transportable laboratory and the devices used in sampling various regulated emissions comply with the procedures published in the CFR 40, Part 86, Subpart N, where applicable. A detailed description of the laboratory equipment, aftertreatment device, test vehicle, and test cycle is discussed in the following sections.

\subsection{Chassis Dynamometer}

The chassis dynamometer test bed consists of rollers, flywheel assembly, eddy current power absorbers, differentials, hub adapter, torque and speed transducer built onto a tandem axle semi trailer. The hydraulic jack on the chassis dynamometer test bed is functional in setting the test bed on the ground and onto the trailer (Ferguson, 1993). The various components of the chassis dynamometer are discussed in detail below.

- Rollers: The chassis dynamometer consists of a set of two paired rollers in the front, which supports the single or forward drive axle and a set of rollers at the back that support the rear axle of tandem axle vehicles. The rear pair of rollers can be placed in three different positions to accommodate tandem spacing of 4 to $5 \mathrm{ft}(1.22-1.52 \mathrm{~m})$ and each roller is 12.6 in $(32 \mathrm{~cm})$ in diameter with their axis along the length of the test bed (Ferguson, 1993). Each pair of rollers is linked by a flexible coupling to have 
uniform rotational speed on either side of the vehicle, and the coupling was designed to accept $20 \%$ of the wheel torque in case of any imbalance due to uneven surface at the test location.

- Hub Adapters: The hub adapters are used to couple the engine drive axle with the flywheel assembly and eddy current power absorber via torque and speed transducers. The adapter is made of a 0.5 in $(13 \mathrm{~mm})$ thick aluminum plate of diameter $1.8 \mathrm{ft}(0.55$ m) (Ferguson, 1993).

- Load Simulation System: The load simulation system consists of a flywheel assembly, an eddy current power absorber, a speed and torque transducer, double differentials, and universal couplings on either side of the vehicle to be tested as shown in the figure below. The power from the vehicle's drive axle is transmitted to the flywheel assembly and power absorbers by a hub adapter, which is connected to a 24 in $(61 \mathrm{~mm})$ long spline shaft running into a pillow block. The spline shaft is connected to the speed and torque transducer by a universal coupling, which can withstand torque up to $16,415 \mathrm{lb}-\mathrm{ft}(222,256 \mathrm{~N}-\mathrm{m})$ on either side. The speed and torque transducer is capable of providing the data logging computer with time varying output torque at a rate of $10 \mathrm{~Hz}$ (Ferguson, 1993). The torque transducer drives a second shaft via companion flange. This shaft transfers power to a right-angle speed increasing drive, a double reduction differential with a ratio of 1:3.65, which drives the flywheel assembly and a second differential. The second differential with a ratio of 1:5.73 drives the eddy current power absorbers.

- Flywheel Assembly: The flywheel assembly is designed to simulate vehicle gross weights of 40,000 to $66,000 \mathrm{lb}$. With the maximum being $40,000 \mathrm{lb}(18,144 \mathrm{~kg})$ at a wheel diameter of $4 \mathrm{ft}(1.22 \mathrm{~m})$ and $66,000 \mathrm{lb}(30,000 \mathrm{~kg})$ at a wheel diameter of 3.25 $\mathrm{ft}(1 \mathrm{~m})$. The flywheel assembly consists of a drive shaft with four drive rotors running in two pillow blocks. Each drive shaft supports eight flywheels of different sizes with bearings resting on the shaft. By selectively engaging the flywheels to the drive rotors, vehicle mass can be simulated in $250 \mathrm{lb}(113 \mathrm{~kg})$ increments.

- Eddy Current Power Absorbers: A Mustang model CC300 air cooled eddy current dynamometer mounted on two bearings is used as power absorbers. The power absorbers are used to simulate load due to rolling friction of the tires and the 
aerodynamic drag resistance. The eddy current dynamometer has the capability of absorbing $300 \mathrm{hp}(224 \mathrm{~kW})$ continuously and $1000 \mathrm{hp}(745.7 \mathrm{~kW})$ intermittently during peak operation. Dynamometer load at any speed is controlled by the direct current supplied to the coils, and the power absorbed is measured by the torque arm force transducer (load cell).

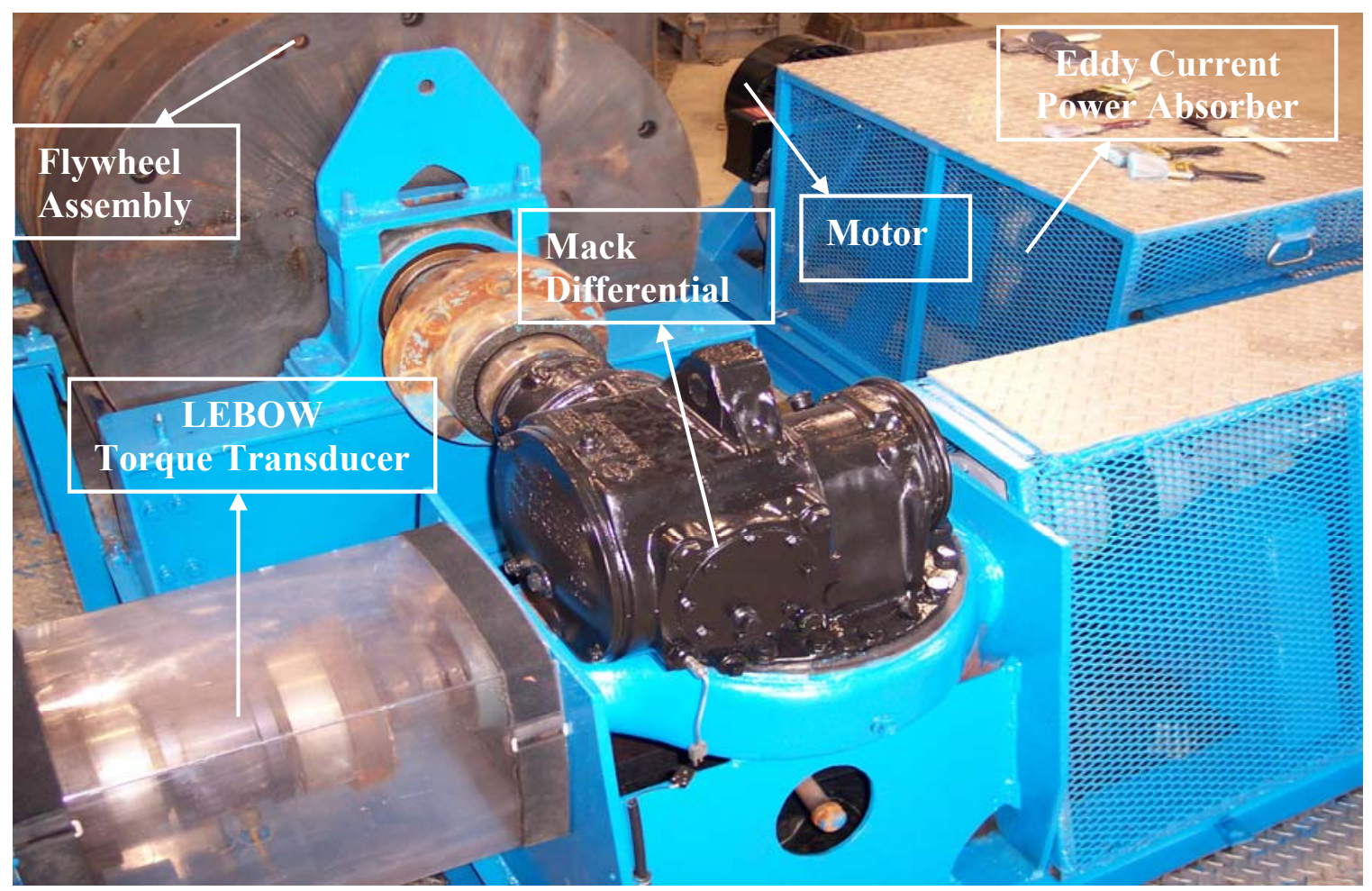

\section{Figure 3.1 Components of a Chassis Dynamometer}

- Motor: A motor was coupled to the eddy current power absorber in recent upgradation of the chassis dynamometer. The motor was added to overcome the frictional losses in various rotating elements and improve the simulation of coast down operations by supplying power to the eddy current dynamometer. The motor has a maximum power of $20 \mathrm{hp} @ 1775 \mathrm{rpm}$ and a maximum torque of $59 \mathrm{lb}$ - $\mathrm{ft}$. The motor is activated and controlled by the speed encoder coupled to the motor and the dynamometer control system. The motor is operated based on the total cruise time of a given test cycle. 


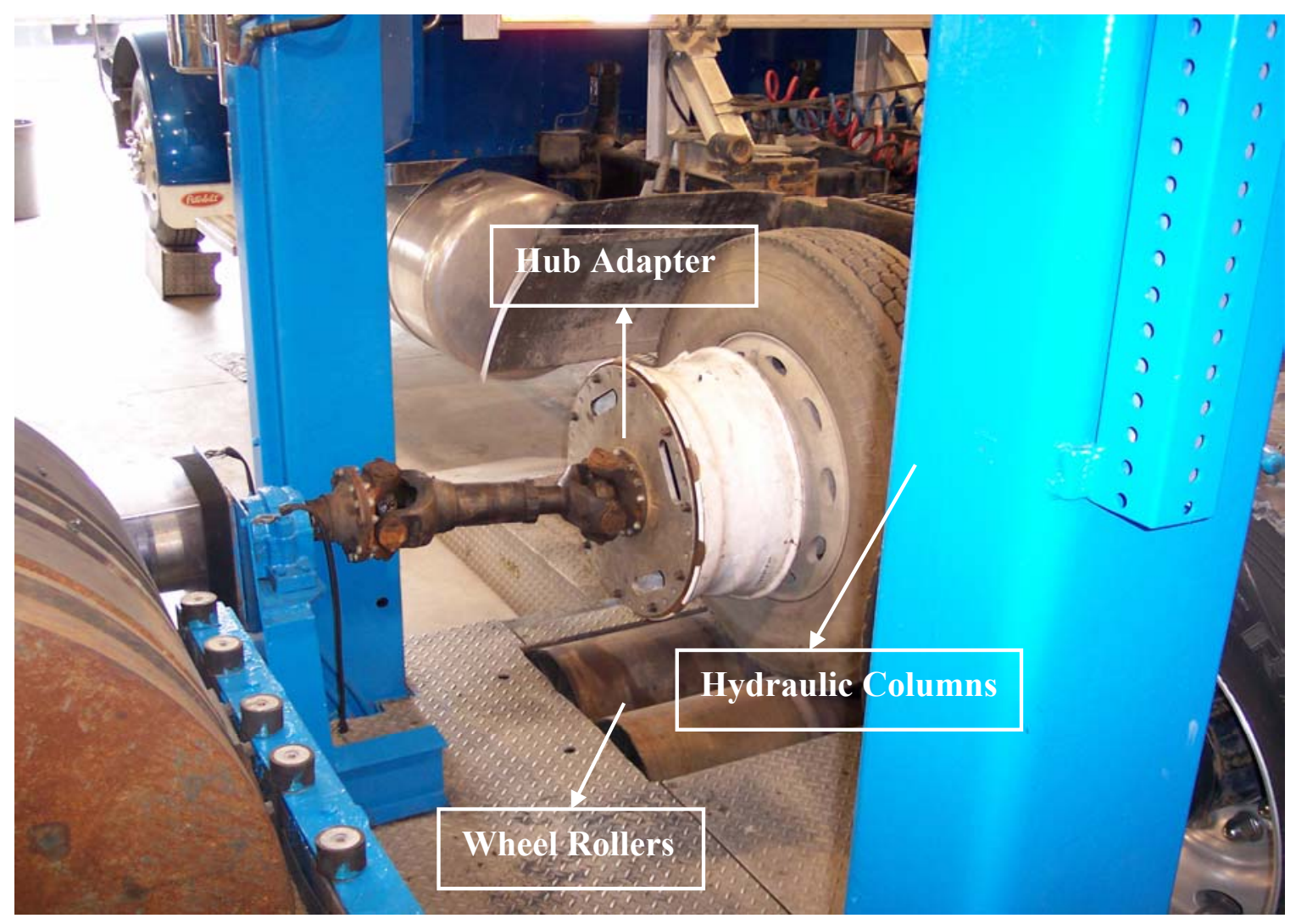

Figure 3.2 Connecting and supporting structure of chassis dynamometer

According to the regulations published in CFR 40, Part 86, Subpart N, the speed and load of a dynamometer must be controlled simultaneously. While the driver is responsible for the control of the speed, the transient torque must be controlled by an automated system. The load supplied by the flywheels simulates the inertia of the vehicle and is controlled by their rotational speed, while the load due to rolling friction and wind drag is simulated by the eddy current dynamometer. The eddy current dynamometer is controlled by a Dyn-Loc IV control system provided by Dyne-Systems. The Dyn-Loc IV control system operated by a PID control loop where "P" stands for proportional control in which the controller calculates error between the actual and the desired output This corrective measure results in a restoration signal linearly proportional to the error. "I" stands for integral control, in which the controller calculates the average error over a time and provides a restoring signal. This signal is the product of the error and the time the error persisted, and is used to restore the original set point. D stands for differential control, in which the controller calculates the rate at which the set point is changed, and produces a corrective signal to reach the set point quickly. Hence, a PID controller 
provides a fast and smooth response in controlling the transient set points. During the test, the power absorbers receive the torque set point from the dyne-loc controller. The set point is equal to the road load power and it is calculated using the following equation

$$
P_{r}=\left(C_{r} M g+\frac{1}{2} \rho_{a} C_{D} A V^{2}\right) V
$$

Equation 3-1

Where

$\mathrm{P}_{\mathrm{r}}=$ Road load power

$\mathrm{C}_{\mathrm{r}}=$ Coefficient of rolling resistance

$\mathrm{M}=$ Vehicle gravitational mass

$\rho_{\mathrm{a}}=$ Air density

$\mathrm{A}=$ Frontal area of vehicle

$\mathrm{C}_{\mathrm{D}}=$ Coefficient of drag

$\mathrm{V}=$ Vehicle speed

The set point is updated every 100 milliseconds. The speed and torque values are logged at a frequency of $10 \mathrm{~Hz}$ to ensure the test has been performed to the specification.

\subsection{Full Flow Clean Dilution Tunnel}

In 2003, the WVU - Transportable Laboratory was upgraded with a new full-flow dilution tunnel that was designed to coexist with the original unit. This "Clean Dilution Tunnel" was implemented to sample emissions exclusively from CNG-fueled heavy-duty engines. It has been observed from previous research studies that sampling of exhaust gases from $\mathrm{CNG}$ engines in the same tunnel exposed to diesel emissions would introduce sampling error, due to re-entrainment of particulates and out-gassing of compounds deposited on the tunnel wall from diesel emissions. The problem gets magnified particularly when sampling PM from a CNG engines in a tunnel that has extensive test history. High background PM levels will give negative values when testing ultra low emission vehicles, as their PM emission level will be closer to the background level (Burlingame, 2004).

The clean dilution tunnel is designed and operated according to the regulations specified in CFR 40, Part 86, and Subpart N. The tunnel works on the principle of critical flow venturi - constant volume sampling (CFV-CVS), in which the diluted exhaust is drawn through a critical flow venturi using a blower. The dilution tunnel was 
used to mimic the reaction of exhaust gas with ambient air in the atmosphere and to also cool exhaust gas sufficiently to reduce the dew point and avoid condensation. The condensation of exhaust gas in the tunnel will lead to artifacts in the values of the emission reported, as water droplets absorb certain gaseous compounds (example $\mathrm{NO}_{2}$ ) and interfere with certain exhaust measuring devices (example NDIR analyzers and particulate measurements). The inner diameter of the tunnel is 18 inches, which was selected according to the minimum specification set forth in CFR 40. The Clean Dilution Tunnel was built as a stand alone system, so that it could be used with other transportable labs operated by WVU (Burlingame, 2004). The tunnel was designed in several small sections as it could be easily transported. The tunnel consisted of 5 sections.

- Inlet Section: This section connects the mixing section with the HEPA filtered dilution air filtration system. This was designed as a necking section, which reduces from 24 inches diameter on the mixing section side to 20 inches on the dilution air entrance side.

- Mixing Section: This section was made of a 24 inch diameter flanged section connected to an 18 inch flanged section via ribs welded between the two sections (Burlingame, 2004). This section was connected to the tunnel extension with an orifice plate in between the flanges. The orifice plate aids in inducing turbulent mixing between the dilution air and the exhaust gas which was introduced upstream of the orifice plate.

- Tunnel Extending Sections: Consists of two 18-inch diameter 7-ft long sections connected to each other by flanges. This section aids in thorough mixing of the exhaust and the dilution air before reaching the sampling section, satisfying the 10-diameter rule.

- Sampling Section: Consists of two 3-ft sections with the sampling ports located in the middle of each $3-\mathrm{ft}$ section. The two sampling sections were connected to the tunnel extension section by flanges effectively positioning the first sampling zone at $15 \mathrm{ft} 6$ in from the mixing orifice, which meets and exceeds the 10-diameter rule set forth in CFR 40. The regulated emissions were sampled from first sampling zone, while the non-regulated emissions were sampled in the following sampling zone. Each regulated sampling zone consists of 8 sampling ports with 
flanges of 4.25 inch outer diameter, while non-regulated sampling zone consists of 8 sampling ports with alternating flanges of 4.25 inch and 7 inch outer diameters, in order to accommodate probes of different sizes.

- Outlet Section: This is a reducing section with an 18-inch flange connecting the sampling section to the critical flow venturis via a 12 inch flexible tube fitted to an unflanged end.

The above five sections were connected to each other with bolted flanges and gasket to have a leak proof seal. The gasket used was made of compressed non-asbestos, buna-

nitrile material, which will prevent the material from outgassing under high temperature conditions. The fully connected tunnel was checked for leaks by injecting gas of known concentrations (propane) and measuring the same.

\subsection{Critical Flow Venturi}

A constant mass flow rate was maintained in the tunnel by drawing the diluted exhaust through a Critical Flow Venturi (CFV) at choked condition. The CFV-CVS system can operate at nominal flow rates from 1000 to $3000 \mathrm{scfm}$, which can be changed in increments of $500 \mathrm{scfm}$ by threading the correct plug into the throat of the venturi. The change in the venturi throat diameter by the plug changes the flow rate. The nominal flow rates obtained at different throat diameters is shown in the table below

Table 3.1 Venturi Throat Diameter and Flow Rates (Ferguson, 1993)

\begin{tabular}{|c|c|}
\hline $\begin{array}{c}\text { Throat } \\
\text { Diameter } \\
\text { Inches }\end{array}$ & $\begin{array}{c}\text { Flow Rate } \\
\text { SCFM }\end{array}$ \\
\hline 0.429 & 1000 \\
\hline 0.701 & 1500 \\
\hline 0.997 & 2000 \\
\hline 1.324 & 2500 \\
\hline 1.694 & 3000 \\
\hline
\end{tabular}

At choked conditions, the flow rate through the CFV is a function of the diameter of the venturi throat and the upstream temperature and pressure. The mass flow rate is then determined using the following equation 


$$
\mathrm{Q}=\frac{\mathrm{K}_{\mathrm{v}} \mathrm{P}}{\sqrt{\mathrm{T}}}
$$

Equation 3-2

Where

$\mathrm{Q}=$ the flow rate in scfm at standard conditions $\left(20^{\circ} \mathrm{C}\right.$ and $\left.101.3 \mathrm{kPa}\right)$

$\mathrm{K}_{\mathrm{V}}=$ the discharge coefficient of the venturi

$\mathrm{P}=$ the absolute pressure at the inlet of the venturi in $\mathrm{kPa}$

$\mathrm{T}=$ the absolute temperature at the inlet of the venturi in ${ }^{\circ} \mathrm{K}$

The calibration of the venturi using an accurate flowmeter and a restrictor valve traceable to NIST standards is discussed in detail in the next chapter.

\subsection{Secondary Dilution Tunnel and Particulate Sampling}

A double dilution method, in accordance with the CFR 40, was employed for collecting the particulate matter onto the filter. This method essentially involves drawing the diluted exhaust from the full flow dilution tunnel into the secondary dilution tunnel at the sampling zone. The sample in the secondary dilution tunnel can be further diluted by additional air in order to keep the filter face temperature below $125{ }^{\circ} \mathrm{F}$. The diluted exhaust from the secondary tunnel is passed through two Teflon coated glass fiber filters to collect particulate matter, which consists of elemental carbon, soluble organic fraction, sulfates and bound water.

The secondary dilution tunnel consists of a 30 inch long stainless steel tube of 3 inch diameter, providing sufficient residence time in order to mix with the secondary air and reduce the temperature to $125^{\circ} \mathrm{F}$. The exhaust is drawn into the secondary tunnel through a 0.5 inch diameter transfer tube from the sampling zone. The flow into the dilution tunnel is controlled by two rotary vane pumps and two mass flow controllers-one each for the total secondary tunnel flow and secondary dilution air flow. The mass flow controller is recalibrated periodically using a laminar flow element. The range of total secondary tunnel flow is $0-6 \mathrm{scfm}$ and $0-3 \mathrm{scfm}$ for secondary dilution airflow. The exhaust exits the secondary tunnel through two $70 \mathrm{~mm}$ Pallflex fluorocarbon coated glass fiber filters housed in a stainless steel filter holder. The filters used for collecting PM exhibits $99.95 \%$ collection efficiency for particle size of $0.3 \mu \mathrm{m}$ and below.

\subsection{Particle Sizing}


WVU employed a mini-dilution tunnel for particle sizing, along with a Scanning Mobility Particle Sizer (SMPS) and a Condensation Particle Counter (CPC), to determine particle size distribution. The mini-dilution tunnel reasonably mimics the particle formation that takes place in the atmosphere by facilitating the raw exhaust sample with higher dilution ratios and enough residence time to nucleate and grow in size. Ejector type dilution systems have been used as an alternative to dilution tunnels to achieve higher dilution ratios. The major drawback of the ejector dilution systems is the lack of residence time for the particles to nucleate, which, therefore, falls short in giving a representative measure of real world particle size distribution.

\subsubsection{Mini-Dilution System}

The mini-dilution system developed by West Virginia University for measuring particle size distribution is shown in Figure 3.3. The mini-dilution system incorporates a tunnel with its length maintained at ten times its diameter, and an orifice plate to facilitate good mixing and uniform distribution of exhaust at the sampling zone. The tunnel is wrapped with heating tape and insulation to maintain a temperature of $115^{\circ} \mathrm{F}$ in order to prevent condensation of moisture.

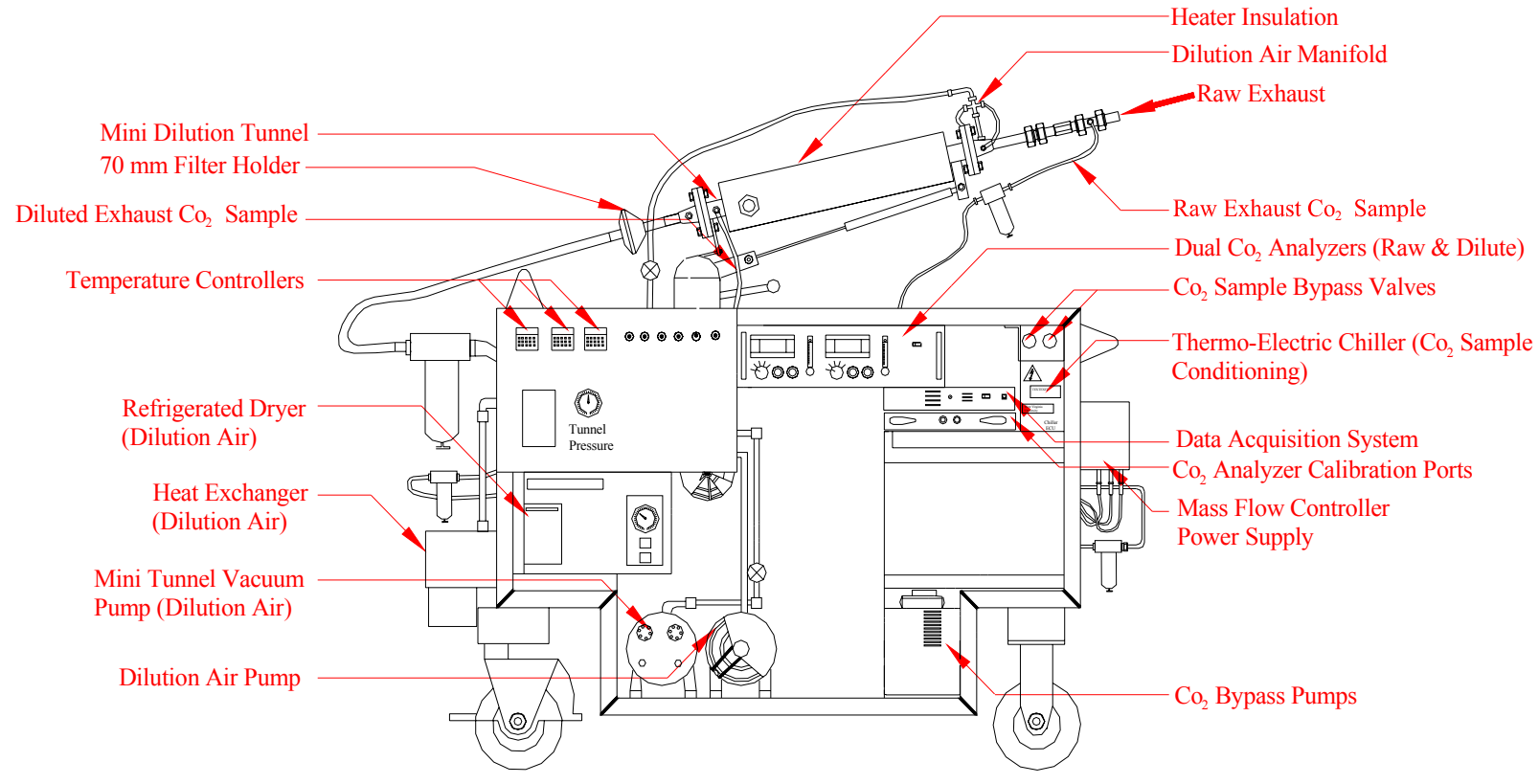

Figure 3.3 West Virginia University Mini-Dilution Tunnel 
The sample line from the probe to the mini dilution tunnel was kept as short as possible and was well insulated to prevent particle loss. The dilution air was passed through a refrigerated dryer and a HEPA filter to remove moisture and particles. A separate vacuum pump was used to draw in the exhaust sample. Both the dilution and total air supply were controlled by two Sierra mass flow controllers calibrated for flow rates of 0 to $200 \mathrm{slpm}$. Sampling probes were installed ten diameters downstream of the mixing orifice to ensure uniform concentration. A dual range $\mathrm{CO}_{2}$ analyzer was used to measure the raw and dilute $\mathrm{CO}_{2}$ concentrations. A 10 point analyzer calibration was done using $15 \%$ and $1 \% \mathrm{CO}_{2}$ bottles. The analyzer was checked everyday for zero and span using nitrogen as zero gas and $15 \%$ and $1 \% \mathrm{CO}_{2}$ as span gas. The raw and dilute exhaust gases were filtered by inline filters and chilled by thermoelectric chillers for removal of particulates and moisture, respectively. The filters were checked everyday and replaced if necessary. A purge air supply for the $\mathrm{CO}_{2}$ analyzers was provided by an external oil free compressor through a HEPA filter. This purge air is useful to flush the analyzer of any residual gas present, which may provide erroneous readings.

The mass flow controllers and the $\mathrm{CO}_{2}$ analyzers were wired to a data acquisition system (National Instruments DAQ 6020-E BNC). A program in Visual Basic was specially developed by WVU to control the sampling, dilution air mass flow controllers and to save continuous data from the analyzers. Other parameters such as tunnel pressure, and temperature, were recorded on a continuous basis. The program that controlled the mass flow controllers maintained the dilution ratio set by the user, which was achieved in two ways. One was based on the sample and the dilution air flow and the other was based on $\mathrm{CO}_{2}$ concentration. Flow based dilution ratio was used in this study and is calculated by the following equation.

$$
\mathrm{DR}=\frac{\text { total }}{(\text { total }- \text { dilute })}
$$

The total and dilute flow rates were measured and set by the mass flow controllers. Through experience, it has been determined by WVU that the flow based system is more accurate in controlling the dilution ratio and the $\mathrm{CO}_{2}$ readings are used to verify the set dilution ratio. One probe was installed next to the dilute $\mathrm{CO}_{2}$ probe for particle size distribution measurements. Carbon impregnated electrically conductive 
Tygon tubing was used to transfer the sample from the tunnel to the particle sizing instrument (SMPS). This tubing was used to prevent any particle losses due to electrostatic effects.

An exhaust pulsation damper was used to reduce pulsations encountered in sampling the exhaust from a transient test. It consisted of a 5 gallon tank with one end cut off and sealed with a rubber diaphragm as shown in Figure 3.4. The top of the tank had a T-connection which incorporated a straight probe as seen in the figure to minimize particle losses into the damper. The damper was flushed with particle free air and evacuated after every test to remove any remaining particles and volatile compounds reducing measurement errors.

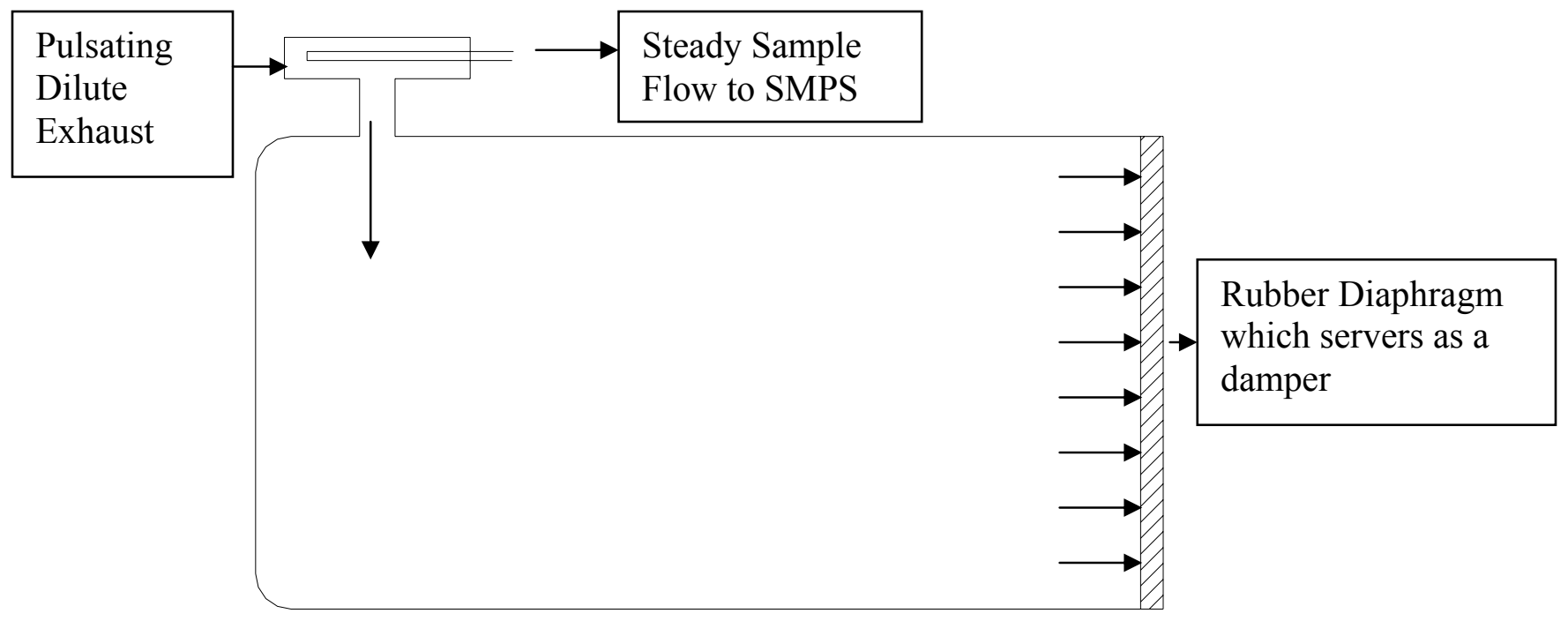

Figure 3.4 Schematic of Pulsation Damper used during Transient Tests

\subsubsection{Scanning Mobility Particle Sizer}

The SMPS system comprises of two basic components, the Electrostatic Classifier, or the Mobility Analyzer, and a Condensation Particle Counter. The classifier or mobility analyzer, separates particles based on electrical mobility. The segregated sample is then transported to the particle counter to obtain number concentrations. In mobility analyzers, particles are first charged, and later they are classified in an elevated electric field, according to the electrical mobility of the particles. The particle size distribution is obtained on the basis of the relationship between mobility and sizes. The 
electrical mobility diameter is a close approximation of the Stokes diameter, which is defined as the diameter of a spherical particle having the same density and settling velocity as the measured particle.

In general, the mobility diameter is different from the aerodynamic diameter measured in aerodynamic particle sizers. The aerodynamic diameter provides good representation of the particle behavior in such processes as impaction and settling, which are characteristic of larger particles with high inertial forces (high Stokes numbers). The mobility or Stokes diameter, on the other hand represents the diffusion process, which dominates in small particles. The correlation between the aerodynamic and mobility diameters depends, on particle density. Since densities of diesel particles are typically less than $1 \mathrm{~g} / \mathrm{cm}^{3}$, their aerodynamic diameters are less than the mobility diameters. The mobility diameter is more representative than the aerodynamic diameter to describe the movement of small diesel particles in the human lungs.

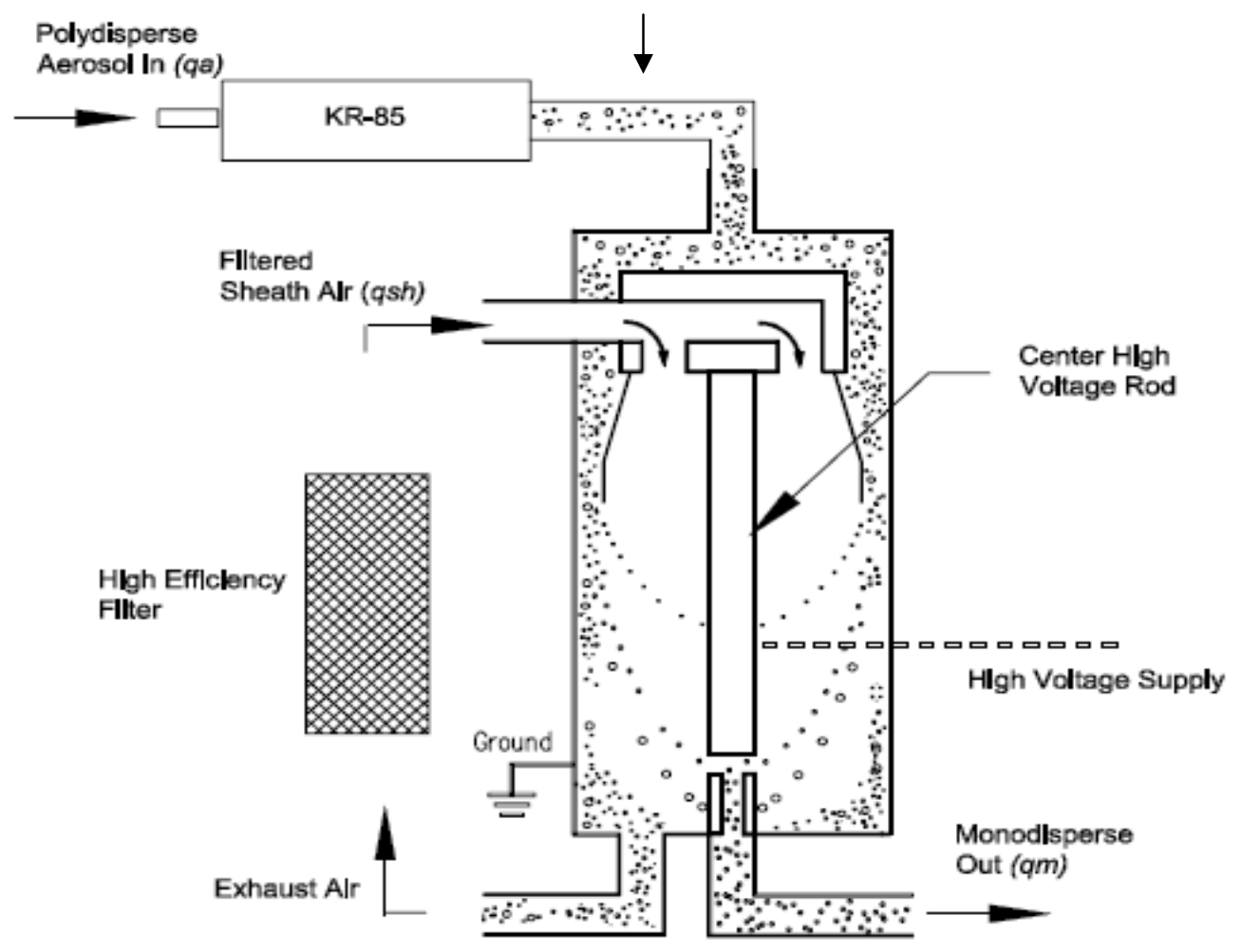

\section{Figure 3.5 DMA Column Schematic (TSI $\left.{ }_{\circledast}\right)$}

A schematic of the Differential Mobility Analyzer (DMA) is shown in Figure 3.5. The inlet of the classifier has an impactor that removes all particles above $1 \mu \mathrm{m}$ since large particles tend to have multiple charges that are difficult to strip. The impactor has a 
nozzle and an impactor plate, and different size orifices $(0.071$ and $0.0475 \mathrm{~cm})$ for different flow rates. The polydisperse aerosol passes through the bipolar charger, which contains a radioactive source (Krypton) and particles of single positive charge pass out of the charger. The polydisperse aerosol then enters the DMA between an outer cylinder and a sheath flow which acts as an air curtain. The central rod is charged with a high negative voltage that attracts positive particles. Particles with high mobility precipitate at the top end of the rod and particles with low mobility exit the DMA along with the bypass air. Only particles with a narrow mobility range exit the DMA through the slit as monodisperse aerosol, which then pass into the Condensation Particle Counter (CPC) for concentration measurements. To obtain a full scan of the particle sizes, the voltage in the central rod is increased exponentially (termed as the up-scan) and the voltage is dropped to zero (termed as the down-scan). The up-scan and down-scan times are typically 120 and 15 seconds, respectively. These times can be increased by the user to obtain a better resolution if the particle concentrations are steady.

The CPC, is the most common instrument used to determine number concentrations of diesel particles. Upon entering the CPC, the aerosol stream is saturated with alcohol (butanol) vapor. As the mixture cools in the condenser tube, the vapor becomes supersaturated and condenses on particles. As a result, the particles grow to a diameter of about $10 \mu \mathrm{m}$, allowing for optical detection. Particle size detection limit in the $\mathrm{CPC}$ is related to the increasing saturation ratio which is required with decreasing particle diameters. Modern CPCs have detection limits of around $10 \mathrm{~nm}$.

CPCs can be operated in two modes: (1) the counting mode and (2) the opacity mode. In the counting mode, pulses of scattered light from individual particles are counted. This mode provides the most accurate measurements, but can be used only at low particle concentrations. In the opacity mode, used for measuring concentrations typically $10^{4}$ particles $/ \mathrm{cm}^{3}$ or more, the number concentrations are determined from total scattering intensity. However, this mode requires that all particles grow to the same diameter, needs the optical system to be frequently calibrated, and produces results subject to larger errors. The CPC is very sensitive to internal temperature, which affects the degree of super-saturation, as well as to positioning and vibration. This makes its use 
in the field more challenging. The CPC is used for particle detection in many aerosol size distribution measuring instruments.

The CPC and an Electrostatic Classifier together makes the SMPS system. The $\mathrm{CPC}$ is interfaced with the classifier via analog BNC connector cable. A computer with custom software provided by TSI is used to record data and control the parameters of the classifier. TSI model 3936 SMPS system was used for this study which is shown in the figure below. DMA models 3081 (Long DMA) and 3085 (Nano DMA) were used interchangeably to obtain a full particle size distribution from $800 \mathrm{~nm}$ to $4 \mathrm{~nm}$. Model $3025 \mathrm{~A} \mathrm{CPC}$ was used for particle counting, since it could detect particles as low as $3 \mathrm{~nm}$ and has a response time of one second.

\subsection{Gaseous Emission Sampling System.}

The gaseous emission sampling system consisted of heated probes with "tip span" feature, heated sample lines, and gas analyzer bench built in accordance to CFR 40 regulations. The samples were drawn 10-diameters downstream of the mixing zone, in order to ensure thorough mixing of the exhaust with dilution air and a fully developed turbulent flow. The exhaust emissions were sampled by gas analyzers via heated lines, and the flow to the analyzers were controlled by flow meters and Magnahelic pressure regulators. Four separate heated probes and sample lines were used to sample THC, NOx, $\mathrm{CO} / \mathrm{CO}_{2}$, and aldehydes. The temperature of the probes and the sample lines were controlled and maintained by a temperature control module (TCM) (Burlingame, 2004). The sample lines were chosen depending on the gas to be analyzed by the analyzer, Teflon coated lines were used for sampling $\mathrm{CO}, \mathrm{CO}_{2}, \mathrm{NOx}$ and aldehydes while a temperature controlled stainless steel heated line was used for analyzing THC. The mass emission rates of the exhaust gases from the test were determined by measuring the concentration and the total flow.

\subsubsection{Regulated Emission Sampling System}

The analyzers used for sampling regulated gaseous emissions were housed in the analytical trailer, where all the dynamometer control and signal conditioning devices were placed. The gas analyzers used heated lines to sample from the dilution tunnel. The samples were conditioned for a set humidity and temperature, using chillers and temperature control module. The regulated emission bench consisted of $\mathrm{CO}_{2}$ analyzer, 
$\mathrm{CO}$ analyzer, NOx analyzer and THC analyzer. The operating principle and the sample conditions required for these analyzers are explained in the following sections.

\subsubsection{Oxides of Nitrogen (NOx) Analyzer.}

The regulated emission bench consisted of two Rosemount Model 955 NOx analyzers one for analyzing NO and the other for analyzing NOx. Both NO and NOx samples were sampled from the same heated probe and sampling line, which were maintained at a temperature of $240{ }^{\circ} \mathrm{F}\left(115.5^{\circ} \mathrm{C}\right)$ during the test. The sample line was maintained at a high temperature in order to prevent condensation of water, and thereby reducing loss of water soluble $\mathrm{NO}_{2}$.

The analyzer uses heated chemiluminescent method to determine NO and NOx. For $\mathrm{NO}$ determination, the sample is quantitatively converted into $\mathrm{NO}_{2}$ by gas-phase oxidation with molecular ozone. As a result of this reaction, approximately $10 \%$ of the $\mathrm{NO}_{2}$ molecules are raised to an electronically excited state, followed by immediate reversion to the non-excited state accompanied by emission of photons. The photons emitted impinge on a photo-multiplier detector generating a low-level DC current proportional to the amount of NO present in the sample. The NOx analyzer operates on the same principle as the NO analyzer, except the sample is passed through a converter, where $\mathrm{NO}_{2}$ is converted into $\mathrm{NO}$ before entering into the reaction chamber. Now the analyzer response will be proportional to the NO present in the original sample plus the NO produced by dissociation of $\mathrm{NO}_{2}$.

\subsubsection{Carbon Monoxide (CO) and Carbon Dioxide $\left(\mathrm{CO}_{2}\right)$ Analyzer}

$\mathrm{CO}$ and $\mathrm{CO}_{2}$ emissions were measured continuously to determine dilution factor in the tunnel and to calculate fuel consumption of the vehicle being tested. The $\mathrm{CO}$ and $\mathrm{CO}_{2}$ in the sample were analyzed using Horiba Model AIA-210 and Rosemount Model 880A Non-Dispersive Infrared analyzers. Both carbon monoxide and carbon dioxide were sampled from the same heated probe and heated sample line. The sample line was maintained at a temperature of $240{ }^{\circ} \mathrm{F}\left(115.5^{\circ} \mathrm{C}\right)$ in order to avoid water condensation in the sample line and thereby preventing the water soluble compounds in the exhaust from dissolving in the condensed water. The sample was passed through a refrigerator/dryer system before entering into the analyzer to remove any traces of water in the sample as it 
would affect the analyzer response. The sample was passed through a heated filter element in order to prevent particulate matter from entering into the analyzer.

An NDIR analyzer works on the principle of selective absorption of infrared energy. The analyzer consists of two cells, a flow through sample cell and sealed reference cell, through which two equal energy infrared beams are passed. The difference between the infrared energy absorbed by the two cells is continuously measured, using solid-state electronics, and it is proportional to the amount of $\mathrm{CO} / \mathrm{CO}_{2}$ present in the sample. There are two $\mathrm{CO}$ analyzers in the bench, one for low $\mathrm{CO}$ which had an operating range from $0-100 \mathrm{ppm}$ and $0-2500 \mathrm{ppm}$ and the other one for high $\mathrm{CO}$ which had an operating range of $0-1000 \mathrm{ppm}$ and $0-5000 \mathrm{ppm}$. The $\mathrm{CO}_{2}$ analyzer had an operating range of $0-2 \%$ and $0-6 \%$.

\subsubsection{Total Hydrocarbon (THC) Analyzer}

A hydrocarbon analyzer (Beckman Model 402) working on the principle of heated flame ionization detector was used to analyze Total Hydrocarbons (THC). The $\mathrm{HC}$ sampling system included a heated probe with heated sampling line maintained at a temperature of $375{ }^{\circ} \mathrm{F}\left(190.5{ }^{\circ} \mathrm{C}\right)$ in order to prevent heavier hydrocarbons from condensing, and reducing error in the $\mathrm{HC}$ measurement. The analyzer has an operating range from 5-250,000ppm carbon.

The hydrocarbon analyzer consists of a burner which works as a sensor through which a regulated flow of sample gas is passed. The flame in the burner is sustained by regulated flows of fuel gas (40\% hydrogen and 60\% helium) and air. The hydrocarbon passing through the flame undergoes a complex ionization process that produces electrons and positive ions. Polarized electrodes collect these ions, causing current to flow through an electronic measuring circuit. The ionization current generated is proportional to the rate at which carbon atoms enter the burner, and, hence, a measure of the concentration of the hydrocarbons in the original sample.

\subsubsection{Non-regulated Emission Sampling System}

The samples of non-regulated emissions were drawn at the second sampling section downstream of the regulated emission sampling section. The non-regulated emission sampling system consisted of various sampling trains to sample different emissions which are described in the following sections. 


\subsubsection{Carbonyls}

The carbonyl sampling system consisted of a heated probe and a heated sampling line, whose temperatures were maintained at $240{ }^{\circ} \mathrm{F}\left(115.5{ }^{\circ} \mathrm{C}\right)$ to prevent water condensation. A flow of $1 \mathrm{lpm}$ was maintained using a mass flow controller and a vacuum pump. The sample was collected into cartridges packed with silica gel coated with acidified 2, 4-dinitrophenylhydrazine (DNPH). The cartridges were then sent to a laboratory where the concentration of carbonyls was determined using High Performance Liquid Chromatography (HPLC).

\subsubsection{Chemical Speciation Cart}

The chemical speciation cart was used to sample VOCs and PAHs. This cart consists of a vacuum pump, mass flow controller, vacuum bag collecting system, and support for PUF/XAD cartridge holder. VOCs were collected in Tedlar bags for onsite analysis and PAHs were collected in the PUF/XAD cartridge.

\subsection{Volatile Organic Compound Bag Sampling System}

The exhaust samples for VOC analysis were collected in a Tedlar bag, using a vacuum bag sampling system. The sampling train consists of a vacuum chamber, which is a $15 \mathrm{~L}$ Pelican case with a vacuum release valve and a diaphragm pump to create vacuum. The chamber was fitted with quick disconnects for easy installation of the Tedlar bags, sampling and evacuation lines. The evacuation of air in the chamber was controlled by a flowmeter, thereby controlling the sample flow into the bag. The pressure differential caused by the pump in the chamber causes the exhaust sample to flow into the bag. The sample flow was regulated to prevent the bag from bursting, due to overfilling. The bag samples were analyzed for VOCs at the test site using a portable gas chromatograph (GC) to reduce errors in the measurement caused by adsorption of the chemical species to the bag material.

\subsection{Polycyclic Aromatic Hydrocarbon (PAH/n-PAH) Sampling System}

Polycyclic Aromatic Hydrocarbon and nitro-PAH were analyzed by sampling the exhaust into PUF/XAD cartridges. The PAH sampling system consists of a mass flow controller and a vacuum pump. Using the pump, the exhaust was sampled from the primary dilution tunnel into the PUF/XAD cartridge through a 70mm Emfab filter, with the flow being regulated by a mass flow controller. A picture of PUF/XAD/PUF 
cartridge with the filter holder housing and the speciation cart is shown in Figure 3.6 and 3.7 .

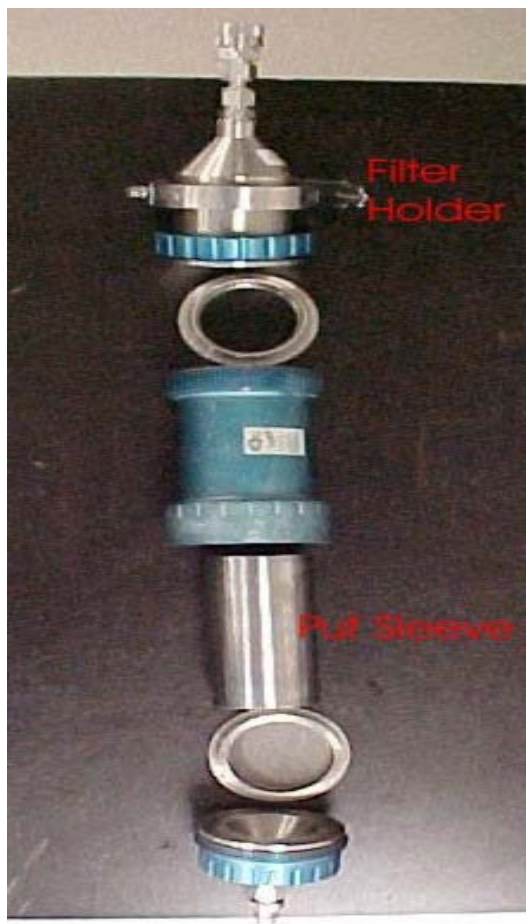

Figure 3.6 Polycyclic Aromatic Hydrocarbons Sampling Media Holder 


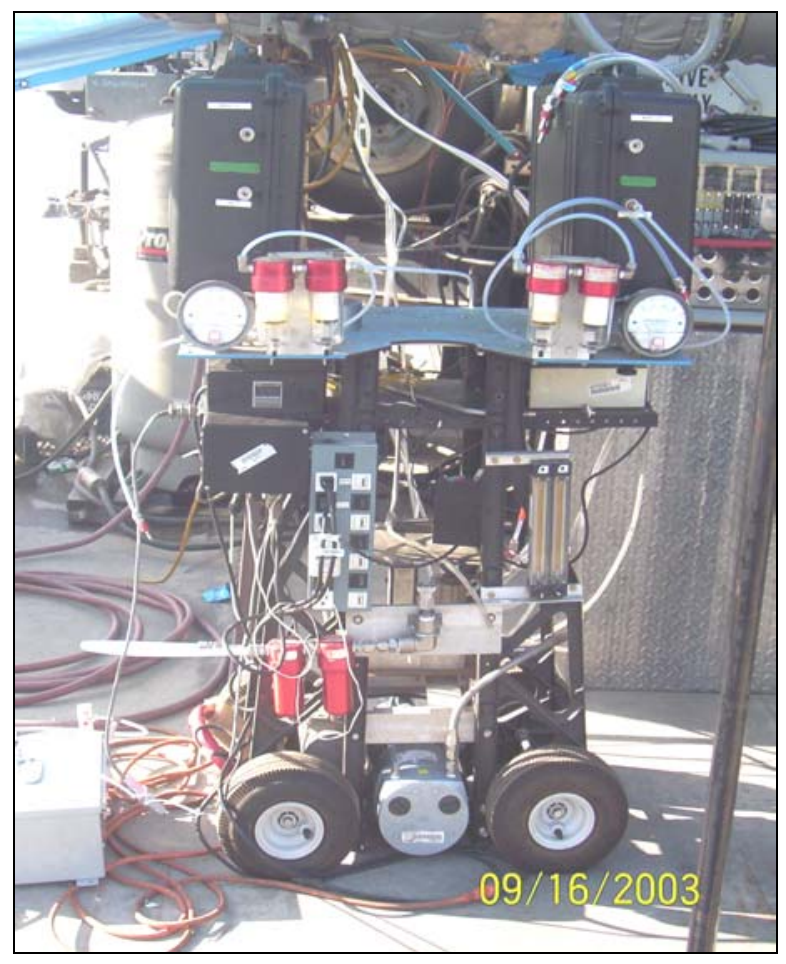

Figure 3.7 Speciation cart to collect PAH and bag samples of toxic gases

\subsubsection{VOC Canister Sampling System}

VOCs were collected into a steel canister for laboratory analysis using a flow control system provided by Environment Canada. The canister, which had a capacity of 6.0 $\mathrm{L}$ at atmospheric condition, was pressurized to $10 \mathrm{psig}$ in order to hold $10.1 \mathrm{~L}$ of sample. The flow control system consists of one inlet and three exit ports. The sample inlet port was connected to the primary dilution using a probe and the flow through the inlet port was controlled by the mass flow controller. The canister sample port was used to fill the canister. The sample by-pass port assisted in leak checking and changing the sample canisters between tests. The pump by-pass port was used to maintain a pressure of 15 psig, using a needle valve, which resulted in a sample that was 5 psig above the final canister pressure. The power supply to the pump and the flow display were integrated into the system as shown below 


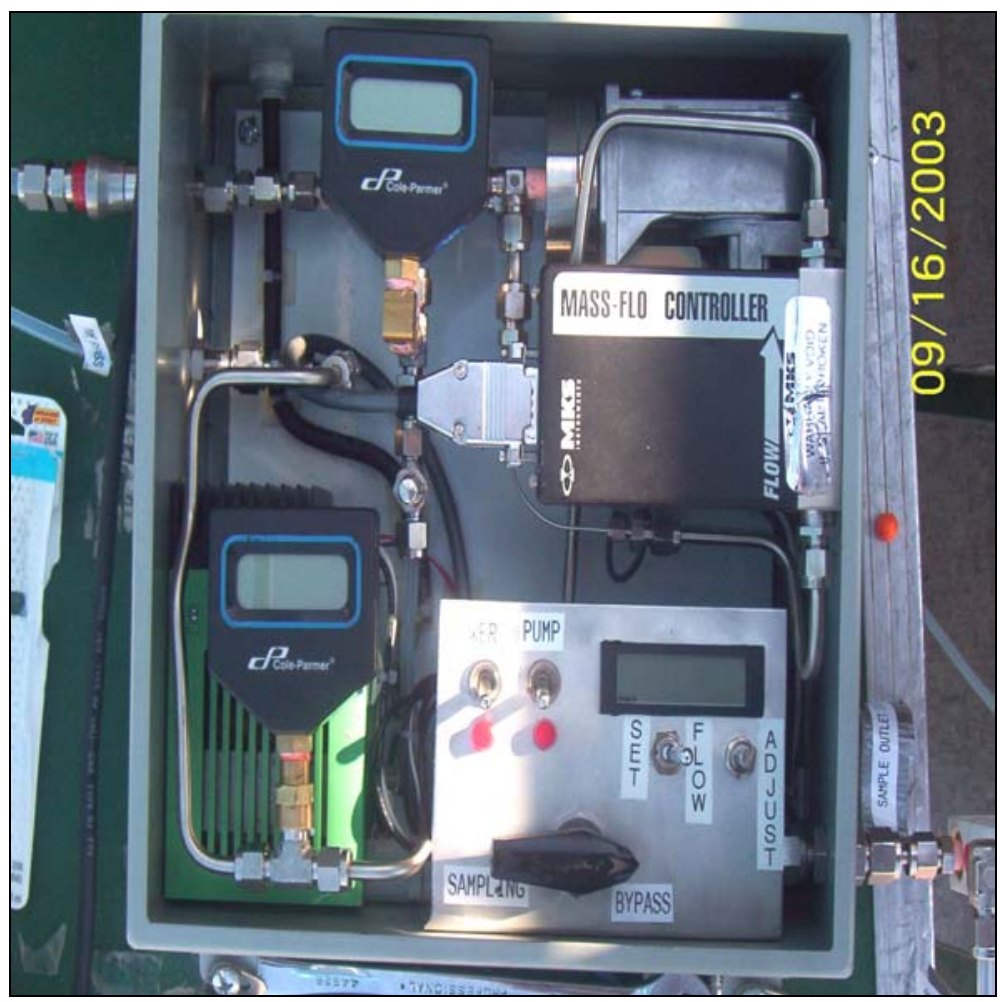

Figure 3.8 Volatile Organic Carbons Canister Sampling System.

\subsubsection{Cyclonic Particle Classifier}

Sampling of non-regulated emissions included gravimetric analysis of particulate matter in size fractions of $10 \mu \mathrm{m}, 2.5 \mu \mathrm{m}$ and $1 \mu \mathrm{m}$. This was accomplished by using cyclonic classifiers. A cyclone classifier makes use of vertical flow inside a cylindrical or conical chamber to separate particles depending on the flow rate. A double vortex flow is induced in the conical body of the cyclone by introducing the sample tangentially at the top. The flow then spirals down along the wall and is then reversed and spiraled through the inner core to exit the chamber. Particles with sufficient inertia impact on the cyclone wall as they cannot follow the streamlines of the flow exiting the chamber. The various size fractions of PM were sampled directly from the primary dilution, as the tunnel was built to a single stage PM sampling specification. The samples were collected on $47 \mathrm{~mm}$ Teflon coated glass fiber filters (T60A20). The flow through the cyclone was controlled using mass flow controllers. The flow exiting the mass flow controller was directed back into the tunnel before the venturi to reduce the variability in the measurement of the total flow. 


\subsubsection{EC/OC and Elemental Sampling System}

The elemental and organic carbon in the exhaust was analyzed by collecting the sample on a $47 \mathrm{~mm}$ prefired quartz filter using a $\mathrm{PM}_{2.5}$ cyclone separator. The exhaust was sampled directly from the primary dilution tunnel using a Gast oil-less rotary vane pump through a mass flow controller. The elemental sampling system also used a $\mathrm{PM}_{2.5}$ cyclonic separator and the exhaust was collected onto a $47 \mathrm{~mm}$ Teflon filter.

\subsection{Gas Bag Sampling}

Tedlar bags were used to collect samples of dilute exhaust gas and dilution air during each emission test. The bag samples were analyzed to find the integrated concentrations and the contribution of dilution air to the actual emissions. The dilute exhaust bag served as a $\mathrm{QA} / \mathrm{QC}$ check point when compared with the continuous sample.

\subsection{Temperature Control Module}

All the regulated emissions were sampled through heated probes and heated sample lines maintained at different temperatures, as per CFR 40 regulations. A temperature control module was used to maintain the desired temperatures of different sampling probes and sampling lines.

The temperature control module uses a closed loop control to maintain the temperatures of the heated components on the regulated emission sampling system. Omega CNI-32 temperature controllers and Crydom Quad solid state relays were used to control the temperature (Burlingame, 2004). The temperature controllers operate on a set point temperature value to determine when to activate the solid state relay. The solid state relay receives a signal from the TCM when the measured temperature is below the set point and closes the relay to supply power to the heated line. The temperatures of the heated probes were measured using $\mathrm{J}$ type thermocouples, and heated line temperatures were measured using $\mathrm{K}$ type thermocouples. The measured temperatures were recorded in a computer from the TCM.

\subsection{Instrumentation Control and Data Acquisition}

A software application developed in-house controlled the power absorbers and the data acquisition system. The program acquired the raw data (ADC codes), and a reduction program converted the raw data into proper engineering units using respective calibration curves. 


\subsection{Media}

Different types of media were used to collect samples for speciation and gravimetric analysis during the test procedure. The media were conditioned, weighed, and handled as per the regulations outlined in CFR 40. A list of species and the media used to collect them is given in Table 3.2.

Table 3.2 Chemical Species and Collecting Media

\begin{tabular}{|l|l|}
\hline Species & Collecting Media \\
\hline VOCs, Methane and NMHC & VOC Canister \\
\hline $\begin{array}{l}\text { PAH, n-PAH, Hopanes, } \\
\text { Steranes }\end{array}$ & $\begin{array}{l}70 \text { mm TX 40 Filter }+ \\
\text { PUF/XAD Cartridge }\end{array}$ \\
\hline Aldehydes & DNPH Cartridge \\
\hline 1,3 Butadiene/BTEX & Tedlar Bag \\
\hline PM2.5 Elemental analysis & Teflon Filter \\
\hline PM2.5 EC/OC & Pre-fired Quartz Filter \\
\hline PM2.5 Gravimetric & T60A20 $(47 \mathrm{~mm})$ Filter \\
\hline PM1.0 Gravimetric & T60A20 $(47 \mathrm{~mm})$ Filter \\
\hline PM10 Gravimetric & T60A20 $(47 \mathrm{~mm})$ Filter \\
\hline Total PM Gravimetric & T60A20 $(70 \mathrm{~mm})$ Filter \\
\hline
\end{tabular}

\subsubsection{Media Conditioning and Weighing}

The media used in collecting PM for gravimetric analysis were conditioned and pre-weighed in the WVU EERL facility, before transporting them to the test site. The filters were conditioned in an environmentally controlled chamber, maintained at $70{ }^{\circ} \mathrm{F}$ a relative humidity of $50 \%$, for at least 1 hour and not more than 80 hours before being weighed according to CFR 40 specifications. The $70 \mathrm{~mm}$ filters were placed in the glass petri dishes and $47 \mathrm{~mm}$ filters were placed in plastic analyslides, with their lids closed, but not sealed, in order to prevent dust from accumulating on the media, while allowing for humidity exchange. Two reference filters were conditioned with the test filters and placed in the environmental chamber in order to account for changes in the filter weight due to fluctuation in humidity. The reference filters were weighed before and after any set of media were weighed to ensure that the conditions in the environmental chamber were stable.

The filters were pre-weighed after a stabilization period of 24 hours using a Metler-Toledo Microbalance. The balance was interfaced with a computer in which the 
filter weights were logged for future reference and use. The filters were conditioned for several hours in the chamber before the petri dishes were sealed and packed in padded envelopes for shipping to the test site.

\subsubsection{Media Labeling}

A unique number, with a barcode, was assigned for each media in order to identify the media with their respective pre and post weights, while automating the process of tracking filter weights. The barcode labels were placed on the petri dishes and on the QA/QC sheet to identify the media with test sequence and run numbers. As there were various media types involved in this project, a color coding system was followed for identifying the media with the species to be sampled. The probes and the sampling system on the dilution tunnel were also color coded to aid in loading the sampling media at correct locations on the tunnel. A table of the sampling media and their respective color code is shown in Table 3.3 .

Table 3.3 Media and Color Code

\begin{tabular}{|l|l|}
\hline \multicolumn{1}{|c|}{ Sampling Media } & \multicolumn{1}{c|}{ Color Code } \\
\hline VOC Canister & Black \\
\hline TX 40 70 mm Filter & Salmon \\
\hline PUF/XAD Cartridge & Yellow-Neon \\
\hline DNPH Cartridge & Dark Blue \\
\hline Tedlar Bag & White \\
\hline Teflon Filter (47mm) Elemental & Light Green \\
\hline Pre-fired Quartz Filter (47mm) EC/OC & Orange \\
\hline T60A20 (47mm) Filter (PM1.0) & Red \\
\hline T60A20 (47mm) Filter (PM2.5) & Yellow \\
\hline T60A20 (47mm) Filter (PM10) & Light Blue \\
\hline T60A20 (70mm) Filter (TPM) & Dark Green \\
\hline
\end{tabular}

\subsubsection{Media Shipping and Tracking}

The petri dishes containing the filter media were sealed and placed in padded envelopes after they had been pre-weighed. The set of envelopes, containing media required for one test, were placed together to aid in quick loading of the media into the sampling system. The sealed media were transported overnight to the test site in coolers filled with frozen water pouches. After the media was received at the test site, it was placed in the conditioning room until used. A media tracking application was developed 
to identify the media with the test sequence and run number. The tracking tool also aided in following the QA/QC protocol. The used media were placed back into their respective petri dishes in the conditioning room and tracked.

\subsubsection{Media Handling and Use}

The media required for sampling various species were removed from their respective storage locations and loaded into the sampling devices. The media loading was done in a controlled environment. Before loading the media, the barcodes were logged into a used media database with respect to the test sequence and run number so that the exhaust samples could be associated with a particular test. 


\section{EMISSION TESTING PROCEDURE}

This chapter describes the preparatory steps, which includes calibration and verification, taken in setting up the test vehicle, the chassis dynamometer, primary and secondary dilution tunnels, emission sampling probes and lines, gas analyzers, and mass flow controllers. The equations used in calculating the brake specific emissions of regulated and various non-regulated species are also discussed in this chapter.

\subsection{Set-up}

The chassis dynamometer, which is built onto a flat bed trailer, was set-up on a level surface and checked for any inclination, in order to prevent variation in the vehicle's inertial loading that is simulated using rotating flywheels. The instrumentation trailer, which houses the analyzers, dilution tunnel, dynamometer control and signal conditioning devices, was placed close to the chassis dynamometer. This reduced the length of exhaust tubing between the tail pipe and the dilution tunnel, in turn reducing thermo-phoretic and other losses of particulate matter in the transfer tube. Since a new dilution tunnel was used for this test, the tunnel was mounted close to the instrumentation trailer using height adjustable stands. The blower/CFV was placed at the end of the dilution tunnel, and a flexible air duct was used in connecting the tunnel to the blower/CFV. The HEPA filtered dilution air was connected to the inlet of the dilution tunnel by a flexible air duct. After all the connections were made to the dilution tunnel, the instrument trailer was prepared for testing.

The instrument trailer set-up included preparing emission bench, environmental chamber, and dynamometer controls. The connections between the gas bench, probes, sample lines, and secondary dilution tunnel were left attached to the primary dilution tunnel, that was installed in the trailer during transportation, in order to minimize set-up time. Since a clean dilution tunnel was used for this test the probes, sampling lines and the secondary dilution tunnel was attached after the primary dilution tunnel was assembled. The probes were attached facing in the upstream direction of the flow. The sampling system was leak checked and blown out with high pressure air to clean the lines from any residual particulate matter. The primary dilution tunnel was covered with heat insulation wraps to prevent thermo-phoretic loss of particulate matter. Thermocouples 
were installed at the mixing zone, sampling zone, secondary dilution air inlet, and at the filter face.

The laboratory was capable of testing the vehicles without the need for electrical power at the test location. When available and convenient, power was taken from the source at the test location. However, if it was unavailable a $135 \mathrm{hp}(100 \mathrm{~kW})$ generator was used to power the blower, power absorber and instrumentation [Ferguson, 1993].

The air compressor and zero air generators were powered well in advance in order to store enough air, which is required in running NOx and $\mathrm{HC}$ analyzers. The analyzers were powered and allowed to stabilize once the air required to operate them was available. After the stabilization period, the temperatures were verified and the analyzers were prepared for calibration.

\subsection{Analyzer Calibration}

Calibration of the analyzers was performed in accordance with the regulations stated in CFR 40, Part 86, and Subpart N. All analyzers were calibrated to the range of emissions level that were observed when the vehicle was being tested. Span gases used in calibrating the analyzers had an accuracy of $1 \%$ traceable to NIST, whereas the zero reference was attained by using a zero air generated at the site. The flame in the HFID analyzer used for $\mathrm{HC}$ analysis was fueled by a mixture of $40 \%$ hydrogen and $60 \%$ helium. Once the analyzers were stabilized, the temperature of the sampling lines were verified and a 10 point calibration was performed. A gas divider was used to obtain 10 equally spaced concentration levels by mixing the span gas and the zero air. The analyzers were allowed to stabilize at each calibration point, and a computer averaged reading of that value was recorded. After the calibration, the data points corresponding to the gas concentration were fitted to a polynomial curve, which was used in converting the ADC codes to engineering units. The analyzers were checked for zero and span values before and after each test, and, if the drift value was found to be more than $3 \%$ for THC, $2 \%$ for $\mathrm{CO} / \mathrm{CO}_{2}$ and $\mathrm{NOx}$, they were recalibrated, and the test was repeated. The analyzers were recalibrated with different span gas concentration, if the emissions were out of the measuring range. The calibration was performed frequently, and these calibration files were overwritten by the new calibration points in order to prevent the use of wrong calibration files. 
A 'FID burner peaking test' was performed on the THC analyzer to determine the highest HFID response. In this process the analyzer response was measured for $100 \%$ span gas and zero air for different combination of FID burner fuel and air pressures. The setting at which the analyzer gave the highest response was selected. An 'HC hang-up' check was also performed on the FID analyzer. The sampling probes were back flushed and steps were taken to rectify if the difference in the response was more than $2 \%$.

A NOx efficiency test was performed on the NOx analyzer, in order to determine the converter efficiency in converting $\mathrm{NO}$ to $\mathrm{NO}_{2}$. If the conversion efficiency turned out to be less than $90 \%$, then maintenance was performed to rectify the situation.

Water interference along with $\mathrm{CO} / \mathrm{CO}_{2}$ cross-interference check was performed on NDIR analyzers used for analyzing $\mathrm{CO} / \mathrm{CO}_{2}$ as moisture and could affect the response of these analyzers. The test was performed by supplying $\mathrm{CO} 2$ and $\mathrm{CO}$ span gas of known concentration bubbled, through water to $\mathrm{CO}$, and $\mathrm{CO} 2$ analyzers respectively via dryer/chiller. If the response of analyzers exceeded the maximum allowable value then corrective actions were taken.

\subsection{Mass Flow Controller Calibration}

Mass flow controllers were used for controlling the volumetric flow rate through cyclonic particle classifier, TPM flow rate through the filter, and various other nonregulated emissions sampling systems. The calibration was performed against a Laminar Flow Element (Meriam Flow Measurement Devices). Meriam provides a calibration equation and coefficients for each LFE, which is obtained by calibrating against a flow meter that is traceable to NIST standards. A five point calibration was performed on the MFCs between fully open and fully closed position. The flow through the LFE was calculated using the following equation

$$
\dot{\mathrm{V}}_{\text {actual }}=[\mathrm{B} \times(\Delta \mathrm{P})+\mathrm{C} \times(\Delta \mathrm{P})] \times \frac{\mu_{\text {std }}}{\mu_{\text {flow }}}
$$

Where,

$\mathrm{B}$ and $\mathrm{C}=\mathrm{LFE}$ specific co-efficient

$\Delta \mathrm{P}=$ Pressure differential measured across LFE

$\frac{\mu_{\text {std }}}{\mu_{\text {flow }}}=$ Viscosity correction factor 
The viscosity variations were calculated using the correction factor given in the following equations

$$
\begin{gathered}
\text { Correctionfactor }=\left(\frac{529.67}{459.67+\mathrm{T}\left(\text { in }^{\circ} \mathrm{F}\right)}\right) \times\left(\frac{181.87}{\mu_{\mathrm{g}}}\right) \\
\mu_{\mathrm{g}}=\frac{14.58+\left(\frac{459.67+\mathrm{T}\left(\text { in }^{\circ} \mathrm{F}\right)}{1.8}\right)}{110.4+\left(\frac{459.67+\mathrm{T}\left(\text { in }^{\circ} \mathrm{F}\right)}{1.8}\right)}
\end{gathered}
$$

Equation 4-2

Equation 4-3

Differential pressure across the LFE and absolute pressure were measured using a Heise pressure reader, and the temperature was measured using a Fluke Temperature calibrator. The actual flow measured with the LFE was converted to standard flow rate by CFR 40 specified standard condition of $20{ }^{\circ} \mathrm{C}$ and $101.1 \mathrm{kPa}$.

\subsection{CFV-CVS Calibration}

The Critical Flow Venturi (CFV) used in the Constant Volume Sampler (CVS) system was calibrated, when the lab was setup at the test site, using a subsonic flowmeter, and an accurate flow restrictor, as specified in CFR 40. The calibration of the CFV was based on the following flow equation for a critical venturi where gas flow rate is a function of inlet temperature and pressure.

$$
\mathrm{Q}_{\mathrm{S}}=\frac{\mathrm{K}_{\mathrm{V}} \mathrm{P}}{\sqrt{\mathrm{T}}}
$$

Equation 4-4

Where,

$\mathrm{Q}_{\mathrm{S}}=$ Flow rate in $\mathrm{cfm}$

$\mathrm{P}=$ Absolute inlet pressure, $\mathrm{kPa}$

$\mathrm{T}=$ Absolute inlet temperature, ${ }^{\mathrm{o}} \mathrm{K}$

$\mathrm{K}_{\mathrm{v}}=$ Calibration co-efficient

The calibration set-up was leak checked before taking the readings, and initially, the blower was started with flow restrictor completely open. The pressure reading was recorded after the system was stabilized, and, the flow restriction was varied to obtain eight readings in the critical flow range of the venturi. The air flow rate $\mathrm{Q}_{\mathrm{s}}$ at each data 
point was calculated in standard cubic feet per minute, and the calibration co-efficient is calculated using the following equation

$$
\mathrm{K}_{\mathrm{V}}=\frac{\mathrm{Q}_{\mathrm{S}} \sqrt{\mathrm{T}_{\mathrm{V}}}}{\mathrm{P}_{\mathrm{V}}}
$$

Equation 4-5

Where,

$\mathrm{Q}_{\mathrm{S}}=$ Flow rate, $\mathrm{SCFM}$ at standard conditions $20^{\circ} \mathrm{C}$ and $101.1 \mathrm{kPa}$

$\mathrm{T}_{\mathrm{V}}=$ Venturi inlet temperature, ${ }^{\circ} \mathrm{K}$

$\mathrm{P}_{\mathrm{V}}=$ Venturi Inlet Pressure, $\mathrm{kPa}$

During choked flow conditions, $\mathrm{K}_{\mathrm{V}}$ has a relatively constant value. However, as the pressure decreases, the flow becomes unchoked and the value of $\mathrm{K}_{\mathrm{V}}$ decreases drastically. The calibration co-efficient was determined for a minimum of eight points in the choked region, the average calibration co-efficient and standard deviation was calculated. If the standard deviation was more than $0.3 \%$ of the average $\mathrm{K}_{\mathrm{V}}$ value then calibration was repeated, after checking for leaks and errors in the pressure and temperature measurements.

\subsection{CFV-CVS Calibration Verification}

The CVS system was verified by injecting a known quantity of propane into the primary dilution tunnel while the CFV-CVS system was operating. The concentration of the propane at the sampling zone in the primary tunnel was determined using a precalibrated HFID analyzer, and the mass of propane injected was calculated using the flow rate data, and the density of propane. The propane injection test helped in determining any potential leak in the tunnel, and any discrepancy in the flow rate measuring device (CFV-CVS system). While the CFR 40 proposes a gravimetric method, WVU used critical orifice method for the propane injection test.

In this method a propane injection kit with a critical flow orifice meter to was used to accurately measure the amount of propane injected into the tunnel (Horiba, 1990). The flow rate of propane through the orifice meter was determined by measuring the inlet temperature and pressure using the following equation

$$
\mathrm{q}=\frac{\mathrm{A}+(\mathrm{B} \times \mathrm{P})+\left(\mathrm{C} \times \mathrm{P}^{2}\right)}{\sqrt{460+\mathrm{T}}}
$$

Where, 
$\mathrm{q}=$ flow rate through orifice in scfm at standard condition $\left(20^{\circ} \mathrm{C}\right.$ and $\left.101.1 \mathrm{kPa}\right)$

$\mathrm{A}, \mathrm{B}$ and $\mathrm{C}=$ calibration co-efficients provided by the orifice manufacturer

$\mathrm{P}=$ absolute orifice inlet pressure, in psia (gauge pressure + atmospheric pressure)

$\mathrm{T}=$ orifice inlet temperature in ${ }^{\circ} \mathrm{F}$

The total flow rate through CVS is given by the following equation

$$
\mathrm{Q}=\frac{\mathrm{V}}{\mathrm{t}} \times 60
$$

Equation 4-7

Where,

$\mathrm{Q}=$ total volume in scf

$\mathrm{V}=$ flow rate in scfm measured by CVS

$\mathrm{T}=$ time interval in seconds, usually 300 seconds

The calculated sample concentration was determined by the following equation

$$
\mathrm{C}_{\text {calc }}=\left(\frac{\mathrm{q}}{\mathrm{Q}} \times 10^{6}\right) \times 3
$$

Equation 4-8

The system error was then given by

$$
\text { Error }=\left(\frac{C_{\text {obs }}}{C_{\text {calc }}}-1\right) \times 100
$$

Equation 4-9

Where,

$\mathrm{C}_{\mathrm{obs}}=$ measured concentration of the injected propane by HFID analyzer

If the error was greater than $\pm 2 \%$, then the cause for discrepancy was found and corrected. The error could be resultant of a leak in the system, a heavily loaded venturi or an improperly calibrated HFID analyzer. The critical flow orifice method was used in the WVU facility because of its size advantage when compared to gravimetric method (Ferguson, 1993).

\subsection{Test Procedure}

Before mounting the vehicle on the chassis dynamometer, the appropriate flywheel combination was determined and locked in place to simulate the inertial load of the vehicle. The inertia setting for trucks was equal to $70 \%$ of the gross vehicle weight. For buses, the equivalent inertia was the sum of empty vehicle weight plus half the passenger load and the driver, plus the equivalent weight of the non-rotating wheel assemblies (Ferguson, 1993). The outer rear wheel on the drive axle was removed and 
fitted with hub adapters, which were later connected to the face plate. The vehicle was backed onto the dynamometer, and the vehicle drive axle which drives the flywheel assembly and power absorbers were connected through a hub adapter. The vehicle was leveled with the drive axle, and the tires were checked for any distortion as it would add to the vehicle loading. The vehicle exhaust was now connected to the dilution tunnel via insulated transfer tube. The vehicle was chained down to the dynamometer bed, as a safety measure. The vehicle mounted on the dynamometer is shown in Figure 4.1.

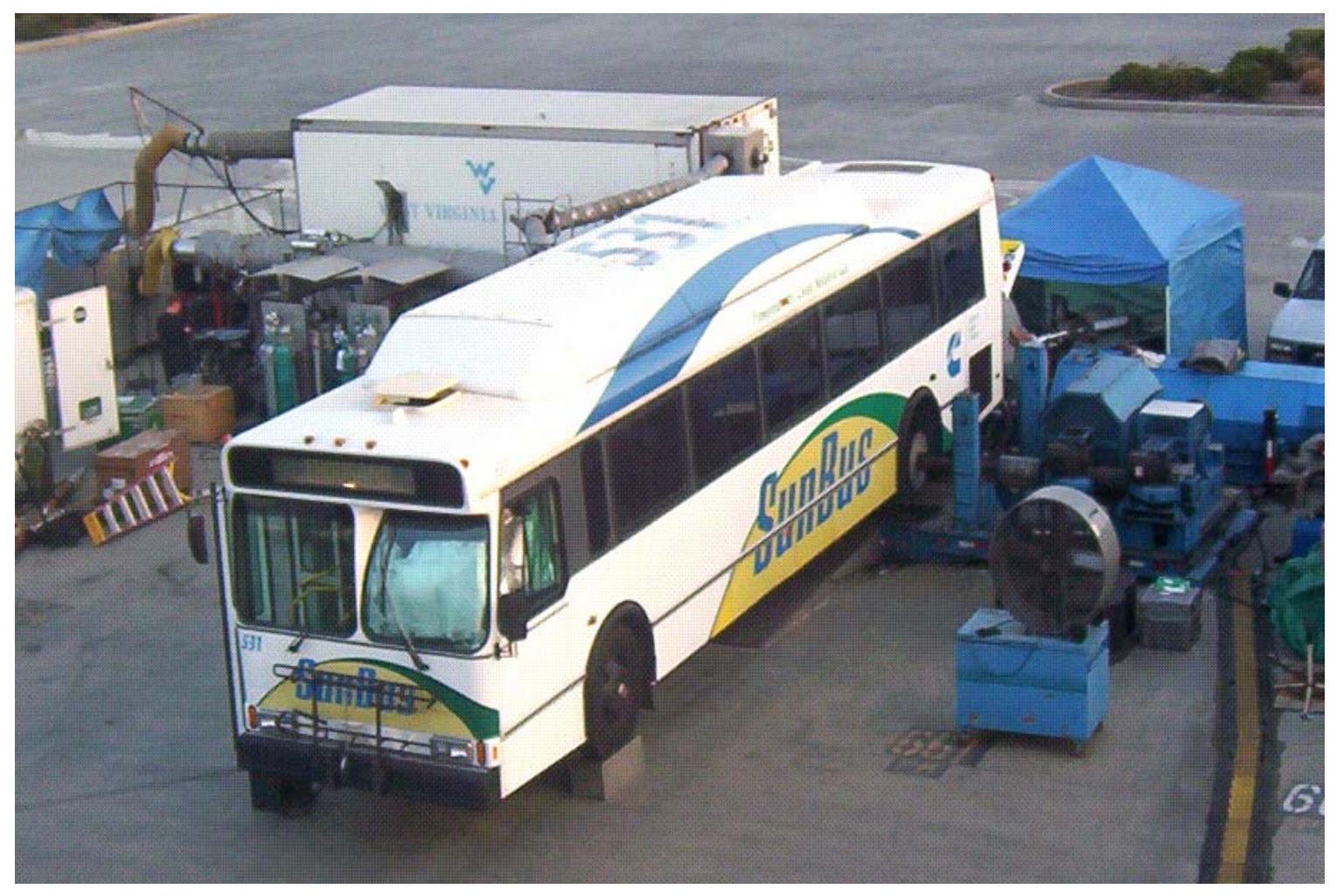

\section{Figure 4.1 Test vehicle mounted on the chassis dynamometer}

The vehicle was made to run at high speed, after being mounted on the dynamometer, to warm the lubricating oil in the differentials. This was done to reduce additional load on the vehicle due to highly viscous oil. During warming up of the differentials, the gas analyzers were zero-spanned with blower operating normally. The driver interface speed monitor and communication head sets were put in place to aid the driver in following the scheduled drive cycle. A practice test was conducted by operating the vehicle over the scheduled drive cycle, with media loaded in the tunnel, to check whether the gas analyzers operated within the range for which they were calibrated and to 
check the flow rates through the mass flow controllers. If analyzers over-ranged or measured below the range, then they were recalibrated with proper span gas, and the mass flow controllers were checked for any malfunction. After the warm-up test, the vehicle was turned off and allowed to soak for twenty minutes. During the soak time, the sampling media required for various targeted species were loaded in their respective holders and mounted onto the tunnel. The media loading was carried out in the controlled environment chamber to avoid accumulation of dust or other debris. A set of field blanks were maintained to study the effect of transportation on the mass of the media. The color coding assisted in loading the media onto their respective location on the tunnel. Tedlar bags that were used for sampling the dilution air and the dilute exhaust were evacuated before the test.

The driving schedule used for this test was a Central Business District cycle that was repeated back-to-back four times, QCBD. The first CBD cycle was a warm-up cycle, during which no samples were collected. The samples were collected during the next three consecutive CBD cycle on the same media, effectively using one set of media for one "Quad CBD" cycle. The sampling devices and the mass flow controllers were actuated after the warm-up CBD. Temperature, pressure, humidity, and the flow rate data were continuously recorded at a frequency of $10 \mathrm{~Hz}$, after the warm up CBD. The speed of the vehicle was controlled by the driver according to the driving schedule displayed on the monitor. The torque set points for the power absorber were controlled by the computer. If there was any failure in the dynamometer, data acquisition or any discrepancy in the driving schedule followed, the driver was alerted and the test was repeated.

After the completion of one Quad CBD cycle, the vehicle was shut down for twenty minutes - allowing the vehicle to return to its rested state to eliminate test-to-test variability. During the soak time, the loaded media were placed in appropriate containers and the different sampling systems were reloaded with new set of media. Also at this time one of the field engineers was responsible to make sure the flow rate data from the mass flow controller were within the limits. If there were any problem, then corrective actions were taken before repeating the next Quad CBD cycle. The continuous data 
stored in the computer were reduced by a post-processing program to report the emissions results in distance specific (grams/mile) units.

\subsection{Emission Calculations}

The continuous voltage signals from gas analyzers were converted to ADC codes by an analog to digital converter, before storing in the computer. These ADC codes were converted to concentration values (in ppm) using analyzer calibration equations by a post processing program. The concentrations (in $\mathrm{ppm}$ ), together with the total volume of exhaust sampled, dilution factor and background concentration level, were used for calculating the distance specific emissions rates.

The total volume of the dilute exhaust drawn through the tunnel over a period of time was given by the following equation. This equation was used in calculating both regulated and non-regulated emissions in distance specific units.

$$
\mathrm{V}_{\text {mix }}=\sum_{\mathrm{i}=1}^{\mathrm{n}}\left(\mathrm{V}_{(\text {mix }) \mathrm{i}} \times \Delta \mathrm{t}\right)
$$

Where,

$\mathrm{V}_{(\text {mix)i }}=$ Instantaneous dilute exhaust gas mixture flow rate $\left(\mathrm{ft}^{3} / \mathrm{sec}\right)$, was given by the following equation

$$
\mathrm{V}_{(\text {mix }) \mathrm{i}}=\frac{\mathrm{K}_{\mathrm{V}} \times \mathrm{P}_{\mathrm{Vi}}}{\sqrt{\mathrm{T}_{\mathrm{Vi}}}}
$$

Equation 4-11

$\Delta \mathrm{t}=$ Time interval between instantaneous measurement points (seconds)

$\mathrm{n}=$ number of instantaneous points taken during the test

$\mathrm{K}_{\mathrm{v}}=$ Calibration constant for Critical Flow Venturi corrected to standard conditions during calibration

$\mathrm{P}_{\mathrm{vi}}=$ Instantaneous absolute pressure at venturi inlet (in. $\mathrm{Hg}$ )

$\mathrm{T}_{\mathrm{vi}}=$ Instantaneous temperature at the venturi inlet $\left({ }^{\mathrm{O}} \mathrm{R}\right)$

Dilution Factor is a ratio of the theoretical amount of carbon dioxide in the raw exhaust for stoichiometric combustion to the summation of actual measured concentration of $\mathrm{CO}, \mathrm{CO}_{2}$ and the individual components of the organic matter. The composition of the fuel used was given by $\mathrm{C}_{\mathrm{x}} \mathrm{H}_{\mathrm{y}} \mathrm{O}_{\mathrm{z}}$ as a measurement of the fuel used. 


$$
\mathrm{DF}=\frac{100 \times\left(\frac{\mathrm{x}}{\mathrm{x}+\mathrm{y} / 2+3.76 \times(\mathrm{x}+\mathrm{y} / 4-\mathrm{z} / 2)}\right)}{\left(\mathrm{CO}_{2 \mathrm{e}}+\mathrm{CO}_{\mathrm{e}}+\sum \mathrm{OM}_{\mathrm{e}}\right) \times 10^{-4}}
$$

Equation 4-12

Where,

$\mathrm{CO}_{2 \mathrm{e}}=$ Carbon dioxide concentration of the dilute exhaust sample corrected for background, in ppm.

$\mathrm{CO}_{\mathrm{e}}=$ Carbon monoxide concentration of the dilute exhaust sample corrected for background, in ppm.

$\Sigma \mathrm{OM}_{\mathrm{e}}=$ Summation of the individual components of the organic matter such as $\mathrm{HC}_{\mathrm{e}}$, $\mathrm{CH}_{3} \mathrm{OH}_{\mathrm{e}}$ etc in ppm carbon equivalent.

The concentration of the $\mathrm{CO}_{2}$ present in the stoichiometrically combusted air/fuel mixture was determined by the following equation

$$
\mathrm{C}_{\mathrm{x}} \mathrm{H}_{\mathrm{y}} \mathrm{O}_{\mathrm{z}}+\mathrm{k}\left(\mathrm{O}_{2}+3.76 \mathrm{~N}_{2}\right) \rightarrow \mathrm{aCO}_{2}+\mathrm{bH}_{2} \mathrm{O}+3.76 \mathrm{cN}_{2} \quad \text { Equation 4-13 }
$$

The constants a, b, c was obtained by solving the following equations

$$
\begin{array}{ll}
\mathrm{C}: & \mathrm{x}=\mathrm{a} \\
\mathrm{H}: & \mathrm{y}=2 \mathrm{~b} \\
\mathrm{O}: & \mathrm{z}+2 \mathrm{k}=2 \mathrm{a}+\mathrm{b} \\
\mathrm{N}_{2}: & \mathrm{k}=\mathrm{c}
\end{array}
$$

This gives the following result

$$
\begin{aligned}
& a=x \\
& b=y / 2 \\
& c=x+y / 4-z / 2
\end{aligned}
$$

\subsubsection{Equations to Calculate Distance Specific Mass of Regulated Emissions}

The distance specific mass of the regulated emissions, is defined as the ratio of the mass of an exhaust constituent to the distance traveled by the vehicle. The mass of each of the exhaust constituent was determined using the following general equations.

$$
\dot{\mathrm{C}} \mathrm{O}_{\text {mass }}=\sum_{\mathrm{i}=1}^{\mathrm{n}}\left[\frac{\left(\mathrm{CO}_{\mathrm{e}}\right)_{\mathrm{i}}}{1 \times 10^{6}} \times \mathrm{V}_{(\text {mix }) \mathrm{i}} \times \rho_{\mathrm{CO}} \times \Delta \mathrm{t}\right]-\frac{\mathrm{CO}_{\mathrm{d}}}{1 \times 10^{6}} \times\left(1-\frac{1}{\mathrm{DF}}\right) \times \mathrm{V}_{\text {mix }} \times \rho_{\mathrm{CO}}
$$

Where,

\section{Equation 4-14}


$\left(\mathrm{CO}_{\mathrm{e}}\right)_{\mathrm{i}}=$ Instantaneous carbon monoxide concentration of the dilute exhaust sample taken from the $\mathrm{CO}$ analyzer, in ppm.

$\mathrm{V}_{(\mathrm{mix}) \mathrm{i}}=$ Instantaneous dilute exhaust gas mixture flow rate, in scfm.

$\rho_{\text {co }}=$ Density of carbon monoxide which is $32.97 \mathrm{~g} / \mathrm{ft}^{3}$ at STP.

$\Delta \mathrm{t}=$ Time difference between two instantaneous measurement points, in sec.

$\mathrm{CO}_{\mathrm{d}}=$ Concentration of carbon monoxide in the dilution air corrected for water vapor, in ppm.

$$
\mathrm{CO}_{\mathrm{d}}=(1-0.000323 * \mathrm{R}) * \mathrm{CO}_{\mathrm{dm}}
$$

Equation 4-15

$\mathrm{R}=$ Relative humidity

$\mathrm{CO}_{\mathrm{dm}}=$ Concentration of carbon monoxide of the dilution air as measured, in ppm.

$\mathrm{DF}=$ Dilution Factor.

$\mathrm{V}_{\text {mix }}=$ Total volume of dilute exhaust gas mixture for the entire test, in $\mathrm{ft}^{3}$.

Similarly the mass of Carbon dioxide is determined by the following equation

$$
\dot{\mathrm{C}} \mathrm{O}_{2 \text { mass }}=\sum_{\mathrm{i}=1}^{\mathrm{n}}\left[\frac{\left(\mathrm{CO}_{2 \mathrm{e}}\right)_{\mathrm{i}}}{1 \times 10^{6}} \times \mathrm{V}_{(\text {mix }) \mathrm{i}} \times \rho_{\mathrm{CO}_{2}} \times \Delta \mathrm{t}\right]-\frac{\mathrm{CO}_{2 \mathrm{~d}}}{1 \times 10^{6}} \times\left(1-\frac{1}{\mathrm{DF}}\right) \times \mathrm{V}_{\text {mix }} \times \rho_{\mathrm{CO}_{2}}
$$

Where,

\section{Equation 4-16}

$\left(\mathrm{CO}_{2 \mathrm{e}}\right)_{\mathrm{i}}=$ Instantaneous carbon dioxide concentration of the dilute exhaust sample taken from the $\mathrm{CO}_{2}$ analyzer, in ppm.

$\mathrm{V}_{(\mathrm{mix}) \mathrm{i}}=$ Instantaneous dilute exhaust gas mixture flow rate, in scfm.

$\rho_{\mathrm{co} 2}=$ Density of carbon dioxide which is $51.81 \mathrm{~g} / \mathrm{ft}^{3}$ at STP.

$\Delta \mathrm{t}=$ Time difference between two instantaneous measurement points, in sec.

$\mathrm{CO}_{2 \mathrm{~d}}=$ Concentration of carbon dioxide in the dilution air corrected for water vapor, in ppm.

$\mathrm{DF}=$ Dilution Factor.

$\mathrm{V}_{\text {mix }}=$ Total volume of dilute exhaust gas mixture for the entire test, in $\mathrm{ft}^{3}$.

The mass of the oxides of nitrogen was calculated by the following equation

$$
\dot{\mathrm{NO}_{\text {Xmass }}}=\mathrm{K}_{\mathrm{H}} \times\left[\sum_{\mathrm{i}=1}^{\mathrm{n}}\left\{\frac{\left(\mathrm{NO}_{\mathrm{Xe}}\right)_{\mathrm{i}}}{1 \times 10^{6}} \times \mathrm{V}_{(\text {mix }) \mathrm{i}} \times \rho_{\mathrm{NO}_{\mathrm{X}}} \times \Delta \mathrm{t}\right\}-\frac{\mathrm{NO}_{\mathrm{Xd}}}{1 \times 10^{6}} \times\left(1-\frac{1}{\mathrm{DF}}\right) \times \mathrm{V}_{\text {mix }} \times \rho_{\mathrm{NO}_{\mathrm{X}}}\right]
$$

Where,

\section{Equation 4-17}


$\left(\mathrm{NOx}_{\mathrm{e}}\right)_{\mathrm{i}}=$ Instantaneous oxides of nitrogen concentration of the dilute exhaust sample taken from the NOx analyzer, in ppm.

$\mathrm{V}_{(\mathrm{mix}) \mathrm{i}}=$ Instantaneous dilute exhaust gas mixture flow rate, in scfm.

$\rho_{\mathrm{NOx}}=$ Density of oxides of nitrogen which is $54.16 \mathrm{~g} / \mathrm{ft}^{3}$ at STP assuming that they are in the form of $\mathrm{NO}_{2}$.

$\Delta \mathrm{t}=$ Time difference between two instantaneous measurement points, in sec.

$\mathrm{K}_{\mathrm{H}}=$ Humidity correction factor, which is given by

$$
\begin{gathered}
\mathrm{K}_{\mathrm{H}}=\frac{1}{(1-0.0026 \times(\mathrm{H}-75))} \\
\mathrm{H}=\frac{\left(43.478 \times \mathrm{R}_{\mathrm{i}} \times \mathrm{P}_{\mathrm{d}}\right)}{\left(\mathrm{P}_{\mathrm{b}}-\frac{\left(\mathrm{P}_{\mathrm{d}} \times \mathrm{R}_{\mathrm{i}}\right)}{100}\right)}
\end{gathered}
$$

Equation 4-18

Equation 4-19

$\mathrm{H}=$ Absolute humidity of the engine intake air in grains of water per pound of dry air.

$\mathrm{R}_{\mathrm{i}}=$ Relative humidity of the engine intake air, in $\%$.

$P_{d}=$ Saturated vapor pressure, $\mathrm{mm} \mathrm{Hg}$, at the engine intake air dry bulb temperature

$\mathrm{P}_{\mathrm{b}}=$ Barometric pressure, $\mathrm{mm} \mathrm{Hg}$.

$\mathrm{NOx}_{\mathrm{d}}=$ Concentration of oxides of nitrogen in the dilution air corrected for water vapor, in ppm.

$\mathrm{R}=$ Relative humidity.

$\mathrm{DF}=$ Dilution Factor.

$\mathrm{V}_{\text {mix }}=$ Total volume of dilute exhaust gas mixture for the entire test, in $\mathrm{ft}^{3}$.

The mass of hydrocarbons is determined by using the following equation

$$
\mathrm{THC}_{\text {mass }}=\sum_{\mathrm{i}=1}^{\mathrm{n}}\left[\frac{\left(\mathrm{HC}_{\mathrm{e}}\right)_{\mathrm{i}}}{1 \times 10^{6}} \times \mathrm{V}_{(\text {mix }) \mathrm{i}} \times \rho_{\mathrm{HC}} \times \Delta \mathrm{t}\right]-\frac{\mathrm{HC}_{\mathrm{d}}}{1 \times 10^{6}} \times\left(1-\frac{1}{\mathrm{DF}}\right) \times \mathrm{V}_{\text {mix }} \times \rho_{\mathrm{HC}}
$$

Where,

\section{Equation 4-20}

$\left(\mathrm{HC}_{\mathrm{e}}\right)_{\mathrm{i}}=$ Instantaneous carbon dioxide concentration of the dilute exhaust sample taken from the $\mathrm{CO}_{2}$ analyzer, in ppm.

$\mathrm{V}_{(\text {mix)i }}=$ Instantaneous dilute exhaust gas mixture flow rate, in scfm.

$\rho_{\mathrm{HC}}=$ Density of hydrocarbons for CNG-fueled vehicle which is $18.85 \mathrm{~g} / \mathrm{ft}^{3}$ at STP.

$\Delta t=$ Time difference between two instantaneous measurement points, in sec.

$\mathrm{HC}_{\mathrm{d}}=$ Concentration of hydrocarbons in the dilution air, in ppm. 
$\mathrm{DF}=$ Dilution Factor

$\mathrm{V}_{\text {mix }}=$ Total volume of dilute exhaust gas mixture for the entire test, in $\mathrm{ft}^{3}$.

The mass of particulate matter collected on the filter from secondary dilution tunnel and in cyclonic separators is a proportional sampling of the PM emissions. The following equation was used to determine the total amount of PM present in whole diluted exhaust flowing through the primary dilution tunnel.

$$
\dot{\mathrm{P}}_{\text {mass }}=\left(\mathrm{V}_{\text {mix }}+\mathrm{V}_{\mathrm{sf}}\right) \times\left[\frac{\mathrm{P}_{\mathrm{f}}}{\mathrm{V}_{\mathrm{sf}}}-\left(\frac{\mathrm{P}_{\mathrm{bf}}}{\mathrm{V}_{\mathrm{bf}}} \times\left(1-\frac{1}{\mathrm{DF}}\right)\right)\right]
$$

Equation 4-21

Where,

$\mathrm{P}_{\text {mass }}=$ Uncorrected mass of PM emitted during one complete test, in grams.

$\mathrm{V}_{\text {mix }}=$ Total diluted exhaust flowing through the primary dilution tunnel corrected for standard conditions, in SCF.

$\mathrm{V}_{\mathrm{sf}}=$ Total Sample dilute exhaust flow through the secondary dilution tunnel corrected for standard conditions, in SCF.

$\mathrm{P}_{\mathrm{f}}=$ Actual mass of PM collected on the sample filter, in grams.

$\mathrm{P}_{\mathrm{bf}}=$ Actual mass of PM collected on the background filter, in grams.

$\mathrm{DF}=$ Dilution factor

\subsubsection{Equations to Calculate Distance Specific Mass of Exhaust Species}

The equation used in calculating the distance specific emissions of non-regulated components is similar to the equation used in calculating the regulated emissions. The emission levels of non-regulated species were analyzed by Environment Canada, which were later used in calculating the distance specific emissions.

The chemical speciation analysis was performed by calculating the total volumetric flow through the tunnel. The total flow through the tunnel was given by

$$
\mathrm{V}_{\text {Tunnel }}=\left(\mathrm{V}_{\text {mix }}+\mathrm{V}_{\text {mini }}+\mathrm{V}_{\mathrm{PUF} / \mathrm{XAD}}+\mathrm{V}_{\mathrm{DNPH}}+\mathrm{V}_{\mathrm{VOC}}\right)
$$

Equation 4-22

Where,

$\mathrm{V}_{\text {Tunnel }}=$ Total tunnel flow before removing the samples, in SCF

$\mathrm{V}_{\text {mix }}=$ Total flow through the tunnel with samples removed for analysis, in SCF

$\mathrm{V}_{\mathrm{PUF} / \mathrm{XAD}}=$ Total flow through the PUF/XAD cartridge, in SCF

$\mathrm{V}_{\text {mini }}=$ Total flow through the secondary dilution tunnel, in SCF

$\mathrm{V}_{\mathrm{DNPH}}=$ Total flow through the DNPH cartridge, $\mathrm{SCF}$ 
$\mathrm{V}_{\mathrm{VOC}}=$ Total flow collected into VOC canisters, in SCF

The flow ratio, which is a ratio of the total tunnel flow to the total sample drawn from the primary dilution tunnel, is given by.

$$
\mathrm{V}_{\text {ratio }}=\frac{\mathrm{V}_{\text {Tunnel }}}{\mathrm{V}_{\text {sample }}}
$$

Equation 4-23

The methods used in analyzing the emission levels of the non-regulated species and the equations used for calculating distance specific emissions are discussed in the following sections.

\subsubsection{Carbonyl Analysis}

Exhaust samples for speciating carbonyl compounds were collected by drawing the diluted exhaust through a silica gel Sep-Pak cartridge coated with 2,4-DNPH (dinitrophenylhydrazine), at constant sampling rate of $11 / \mathrm{min}$. The carbonyl compounds collected in the cartridge undergoes selective reaction with 2,4-DNPH forming hydrazones and are retained on the cartridge. These hydrazones was later extracted using a solvent and analyzed by a HPLC, for detailed analysis procedure please refer Appendix A, (Graham, 2005).

The distance specific emissions of carbonyls were calculated by the following equation

$$
\mathrm{X}_{\text {emitted }}=\mathrm{V}_{\text {ratio }} \times \mathrm{X}_{\text {mass }} \times \frac{1}{\mathrm{~L}} \times 10^{-6}
$$

$\mathrm{X}_{\text {emitted }}=$ Total amount of respective carbonyl emitted during a test phase $(\mathrm{g} / \mathrm{mile})$

$\mathrm{X}_{\text {Conc }}=$ Carbonyl concentration obtained during HPLC analysis $(\mu \mathrm{g} / \mathrm{l})$.

$\mathrm{V}_{\text {ratio }}=$ Ratio of total tunnel flow to the total sample flow.

$\mathrm{L}=$ Total distance traveled (miles).

\subsubsection{Elemental Metal Analysis}

Exhaust samples for the elemental metal analysis were collected on a $47 \mathrm{~mm}$ Teflon filters using PM2.5 cyclonic separator. Elemental metals are found in the exhaust due to the engine wear and additives used in the lubricating oil. The filters were analyzed using XRF spectrometry. An XRF spectrometer uses primary radiation from an X-ray tube to excite secondary (fluorescent) $\mathrm{X}$-ray emission from a sample. The radiation emerging from the sample includes the characteristic X-ray peak of major and trace 
elements present in the sample. The height of each characteristic X-ray peak relates to the concentration of the corresponding element in the sample, allowing quantitative analysis of the sample for most elements in the concentration range of $1 \mathrm{ppm}$ to $100 \%$ for detail please refer APPENDIX A.

The total mass (in $\mathrm{g} /$ mile) of the metal in the exhaust was calculated using the concentration value obtained from the XRF spectrometry by the following equation.

$$
\mathrm{X}_{\text {emitted }}=\mathrm{V}_{\text {ratio }} \times \operatorname{Metal}_{\text {Conc }} \times \mathrm{A}_{\mathrm{s}} \times \frac{1}{\mathrm{~L}} \times 10^{-6}
$$

Equation 4-25

Where,

$\mathrm{X}_{\text {emitted }}=$ Total amount of respective metal emitted during a test phase $(\mathrm{g} / \mathrm{mile})$

$V_{\text {ratio }}=$ Ratio of total tunnel flow to the total sample flow

Metal $_{\text {Conc }}=$ Concentration of the respective metal determined in X-ray spectrometer $\left(\mu \mathrm{g} / \mathrm{cm}^{2}\right)$

$\mathrm{A}_{\mathrm{s}}=$ Filter stain area $\left(\mathrm{cm}^{2}\right)$

$\mathrm{L}=$ Total distance traveled (miles).

\subsubsection{Elemental Carbon and Organic Carbon Analysis}

Elemental and organic carbon (EC/OC) samples were collected on a pre-fired quartz filter using a PM2.5 cyclonic separator, and were analyzed using Thermal Optical Transmittance (TOT) method. NIOSH Method 5040, an evolved gas TOT method was chosen for the analysis of organic carbon (OC), elemental carbon (EC). The basic principle of TOT is to heat the filter, progressively, in a pure helium atmosphere to liberate the carbon species that are continuously analyzed by a laser beam that passes through the filter. The organic carbon vaporized during the initial heating phase is immediately oxidized to $\mathrm{CO}_{2}$. The $\mathrm{CO}_{2}$ is then reduced to methane and analyzed by flame ionization detector (FID). This methane is measured to estimate organic carbon. The transmittance is restored back to the initial level by adding oxygen to the heating chamber, which aids in complete combustion and removal of light absorbing pyrolized carbon. Organic carbon is defined as that which evolves prior to re-attainment of the initial transmittance, and elemental carbon as that material that evolves after the original transmittance has been attained (Graham, 2005). Analysis results are reported in units of $\mu \mathrm{g} / \mathrm{cm}^{2}$ for details please refer APPENDIX. A 
The total emission of elemental and organic carbon was determined by the following equation

$$
\mathrm{EC} / \mathrm{OC}_{\text {mass }}=\mathrm{V}_{\text {ratio }} \times \text { Carbon }_{\text {Conc }} \times \mathrm{A}_{\mathrm{s}} \times \frac{1}{\mathrm{~L}} \times 10^{-6}
$$

Where,

$\mathrm{EC} / \mathrm{OC}_{\text {mass }}=$ Total $\mathrm{EC}$ or OC mass emissions $(\mathrm{g} / \mathrm{mile})$.

Carbon $_{\text {Conc }}=$ Concentration of EC or OC from TOT analysis $\left(\mu \mathrm{g} / \mathrm{cm}^{2}\right)$.

$\mathrm{A}_{\mathrm{s}}=$ Total stain area on the sample filter $\left(\mathrm{cm}^{2}\right)$.

$\mathrm{L}=$ Total distance traveled (miles).

\subsubsection{Volatile Organic Hydrocarbons}

Volatile Organic Hydrocarbons were sampled using a VOC sampling system into a $6 \mathrm{~L}$ stainless steel electro polished (SUMMA) VOC canister. Analysis of volatile organic hydrocarbon included quantization of methane and approximately 165 nonmethane hydrocarbons, along with 1,3-butadiene and BTEX (in addition to the onsite measurements) compounds. The SUMMA canisters were evacuated and cleaned before using them for sampling, by Environment Canada. The dilute exhaust samples were collected in the canister at a pre-determined flow rate until the canister was pressurized to approximately 10 psig. The canisters were shipped back to Environment Canada's measurement facility for analysis. The non-methane hydrocarbons were analyzed using high resolution gas chromatography with a flame ionization detector following cryogenic pre-concentration.

Methane and other lighter hydrocarbons $\left(\mathrm{C}_{2}\right.$ and $\mathrm{C}_{3}$ hydrocarbons $)$ were determined using an alternate method to NMHC, known as light hydrocarbons method (LHC). In this method the sample loop was flushed with the sample, and the contents of the loop are directly injected onto the capillary column. The sample was later analyzed by a gas chromatograph with a flame ionization detector (for details please refer to APPENDIX A).

The concentrations of the methane, non-methane, and other volatile organic compounds were used in the following equation to obtain the total emissions in grams/mile. 


$$
\mathrm{X}_{\text {emitted }}=\mathrm{X}_{\text {Conc }} \times \mathrm{V}_{\text {tunnel }} \times \frac{1}{\mathrm{~L}} \times 10^{-6}
$$

Equation 4-27

Where,

$\mathrm{X}_{\mathrm{emitted}}=$ Total methane or non-methane hydrocarbon emitted by the test vehicle $(\mathrm{g} / \mathrm{mile})$.

$\mathrm{X}_{\mathrm{Conc}}=\mathrm{VOC}$ concentration obtained during GC analysis (ng/l).

$\mathrm{V}_{\text {tunnel }}=$ Total flow through the tunnel before removing the samples, in liters.

$\mathrm{L}=$ Total distance traveled (miles).

\subsubsection{1,3-butadiene and BTEX On-site Analysis}

VOC samples to be analyzed onsite were collected in Tedlar bags using a vacuum sampling system. The exhaust samples collected in the gas bag were analyzed at the test site for 1,3-butadiene and BTEX-benzene, toluene, ethyl benzene, m\&p-xylene, and oxylene isomers using a high resolution $\mathrm{GC}$ with a flame ionization detector provided by Environment Canada (for details refer to APPENDIX A). The bags were protected from direct light using a dark covering (black suitcase) during sample collection. The bags were pre-cleaned by purging multiple times with Ultra High Purity Nitrogen before using them for sample collection. A cryogenic pre-concentrator was used to improve the detection limits (in the microgram per mile range) from the exhaust samples of a vehicle certified for ultra low emissions. The total emission of the aforementioned compounds was determined by the following equation.

$$
\mathrm{X}_{\text {emitted }}=\mathrm{X}_{\text {Conc }} \times \mathrm{V}_{\text {tunnel }} \times \frac{1}{\mathrm{~L}} \times 10^{-6}
$$

Where,

$\mathrm{X}_{\mathrm{emitted}}=$ Total methane or non-methane hydrocarbon emitted by the test vehicle $(\mathrm{g} / \mathrm{mile})$.

$\mathrm{X}_{\mathrm{Conc}}=\mathrm{VOC}$ concentration obtained during GC analysis (ng/l).

$\mathrm{V}_{\text {tunnel }}=$ Total flow through the tunnel before removing the samples, in liters.

$\mathrm{L}=$ Total distance traveled (miles).

\subsubsection{Semi-Volatile and Particle Bound Hydrocarbon Analysis}

Semivolatile and particle-bound organic speciation included analyzing PUF/XAD and filter media for hopanes, steranes, polycyclic aromatic hydrocarbons (PAH), and nitro-polycyclic aromatic hydrocarbons (n-PAH). The process for collecting these 
species, and the equations used to calculate the mass emissions, will be discussed in this section.

During the test procedure, a PUF/XAD canister and 70mm filters were placed in series to collect semivolatile and particle-bound organic compounds. After the test, the media cartridge was removed from the sleeve in a dimly lit area and the ends were covered with aluminum foil to prevent any measurement artifacts due to secondary reactions. Analysis of the species was performed through extraction and column fractionation. Extraction involved placing the media in an extraction apparatus, spiking the media with PAH, n-PAH, alkane, and biomarker surrogates, and allowing the media to sit for about an hour while solvent containing the surrogates evaporated. A 1-liter round-bottomed flask was charged with $750 \mathrm{~mL}$ of dichloromethane, connected to the extraction apparatus, and placed in a heating mantle. Extraction took 20 hours for completion, after which the solvent was allowed to cool, and was concentrated before column clean up and fractionation.

A column of deactivated silica gel was prepared and transferred to a chromatography column packed with glass wool and topped with one gram of sodium sulfate. The sample was then loaded onto the column and fractionated. Vials were prepared for hopane, sterane, and PAH analysis. The vials were then concentrated and used to determine the levels of semivolatile and particle-bound species (for details refer to APPENDIX A, (Graham, 2005)). The concentration values were used in the following equations to determine emission levels.

$$
X_{\text {emitted }}=V_{\text {ratio }} * X_{\text {mass }} * \frac{1}{L} * 10^{-6}
$$

Where,

$\mathrm{X}_{\text {emitted }}=$ Hopanes or Steranes emitted from the test vehicle $(\mathrm{g} / \mathrm{mile})$.

$\mathrm{X}_{\text {mass }}=$ Mass of Hopane or Sterane collected from column fractionation $(\mu \mathrm{g})$.

$\mathrm{L}=$ Total distance traveled (miles).

To determine polycyclic aromatic and nitro-polycyclic aromatic hydrocarbon emissions, a second fractionation vial was analyzed. This vial was split in half and one half was analyzed for PAH, while the other was analyzed for n-PAH. The PAH sample was analyzed using a low-resolution gas chromatograph and the n-PAH was analyzed 
using an HRGC/HRMS. The values obtained during the vial analysis were used in the following equation to determine the polycyclic aromatic hydrocarbon and nitropolycyclic aromatic hydrocarbon emission levels.

$$
X_{\text {emitted }}=V_{\text {ratio }} * X_{\text {mass }} * \frac{1}{L} * 10^{-6}
$$

Equation 4-30

Where,

$\mathrm{X}_{\text {emitted }}=\mathrm{PAH}$ or $\mathrm{n}-\mathrm{PAH}$ compound level emitted from test vehicle $(\mathrm{g} / \mathrm{mile})$.

$\mathrm{X}_{\text {mass }}=\mathrm{PAH}$ or $\mathrm{n}-\mathrm{PAH}$ compound mass collected from column fractionation $(\mu \mathrm{g})$.

A summary of different sampling system, sampling media and the method used to analyze the non-regulated emissions is shown in Table 4.1. 
Table 4.1 Summary of Sampling Media, and Methods used to Analyze NonRegulated Exhaust Species

\begin{tabular}{|c|c|c|c|}
\hline $\begin{array}{l}\text { Compound } \\
\text { Class }\end{array}$ & Sampling Media & $\begin{array}{l}\text { Flow Rate } \\
\text { (lpm) }\end{array}$ & Method \\
\hline $\begin{array}{l}\text { Volatile } \\
\text { Organic } \\
\text { Compounds } \\
\text { (VOC) }\end{array}$ & $\begin{array}{l}\text { Tedlar bags for onsite analysis and } \\
\text { steel canisters for lab analysis }\end{array}$ & $\begin{array}{l}\text { 6L @ } 10 \mathrm{psi} \\
\text { total volume }\end{array}$ & $\begin{array}{l}\text { GC/MS/FID equipped with pre } \\
\text { concentrator }\end{array}$ \\
\hline $\begin{array}{l}\text { Carbonyl } \\
\text { Compounds }\end{array}$ & $\begin{array}{c}\text { Two Sep-Pak cartridges } \\
\text { impregnated with acidified 2,4- } \\
\text { DNPH }\end{array}$ & 1 & $\begin{array}{l}\text { High Performance Liquid } \\
\text { chromatography (HPLC) for } \\
\text { separation and quantization }\end{array}$ \\
\hline $\begin{array}{l}\text { Metals and } \\
\text { elemental } \\
\text { analysis }\end{array}$ & $\begin{array}{l}\mathrm{PM}_{2.5} \text { cyclonic separator with } \\
\quad 47 \mathrm{~mm} \text { teflon filter }\end{array}$ & 16.7 & $\begin{array}{l}\text { X-Ray Fluorescence metal } \\
\text { detection }\end{array}$ \\
\hline $\begin{array}{l}\mathrm{EC} / \mathrm{OC} \text { and } \\
\text { Inorganic Ions }\end{array}$ & $\begin{array}{l}\mathrm{PM}_{2.5} \text { cyclonic separator with } \\
47 \mathrm{~mm} \text { pre-fired quartz filter }\end{array}$ & 15 & $\begin{array}{l}\text { Thermal Optical Reflectance } \\
\text { (TOR) for EC/OC. Ion } \\
\text { chromatography and automated } \\
\text { Colorimetry for inorganic ions }\end{array}$ \\
\hline $\begin{array}{l}\text { PAHs and } \\
\text { nitro-PAHs, } \\
\text { Hopanes and } \\
\text { Steranes }\end{array}$ & $\begin{array}{c}70 \mathrm{~mm} \text { teflon-impregnated, glass } \\
\text { fiber filter (TX40) backed by } \\
\text { PUF/XAD/PUF adsorbing cartridge }\end{array}$ & 60 & $\begin{array}{c}\text { Accelerated solvent/microwave } \\
\text { extraction followed by GC/MS. } \\
\text { Nitro-PAHs separated by HPLC } \\
\text { before GC/MS. }\end{array}$ \\
\hline Total PM mass & $\begin{array}{c}\text { 70mm teflon coated glass-fiber } \\
\text { filter (T60A20) }\end{array}$ & 81 & Gravimetric Analysis \\
\hline $\mathrm{PM}_{10}$ mass & $\begin{array}{l}\text { Size selective cyclone and } 47 \mathrm{~mm} \\
\text { T60A20 filter }\end{array}$ & 28.3 & Gravimetric Analysis \\
\hline $\mathrm{PM}_{2.5}$ mass & $\begin{array}{l}\text { Size selective cyclone and } 47 \mathrm{~mm} \\
\text { T60A20 filter }\end{array}$ & 16.7 & Gravimetric Analysis \\
\hline $\mathrm{PM}_{1.0}$ mass & $\begin{array}{l}\text { Size selective cyclone and } 47 \mathrm{~mm} \\
\text { T60A20 filter }\end{array}$ & 16.7 & Gravimetric Analysis \\
\hline
\end{tabular}




\section{RESULTS AND DISCUSSION}

The present study was carried out in three different phases, with a primary objective of developing an efficient, reliable, and a durable exhaust aftertreatment device to reduce gaseous and particulate emissions from natural gas fueled heavy-duty engines used in urban transit buses. A natural gas fueled urban transit bus powered by a Cummins $\mathrm{C} 8.3 \mathrm{G}+$ engine and equipped with an OEM oxidation catalyst was selected to develop an exhaust aftertreatment device as a collective effort between WVU and Lubrizol-ECS (Engine Control Systems). The exhaust samples were collected by running the vehicle over a Central Business District (CBD) duty cycle using a transportable chassis dynamometer. The regulated emissions, along with the size classified PM mass, were measured by WVU, and the non-regulated emissions were collected by WVU, and analyzed by Environment Canada. The results in this study are presented in distance specific units. The specifications of the engine used for this study is shown in Table 5.1.

Table 5.1 Test Engine and Vehicle Specification

\begin{tabular}{|l|l|}
\hline Bus Manufacturer & Orion \\
\hline Bus Model Year & 1998 \\
\hline Engine Manufacturer & Cummins Westport Innovations \\
\hline Engine Series & C-Series, Gas Plus \\
\hline Engine Model Year & 2000 \\
\hline Engine Displacement & 8.3 liter \\
\hline No of Cylinders & 6 \\
\hline Compression Ratio & $10: 1$ \\
\hline Ignition & Spark Ignited \\
\hline Fuel Injection & Premixed Air/Fuel \\
\hline Net Weight & $1330 \mathrm{lbs}$ \\
\hline Fuel Type & Auto Grade Natural Gas \\
\hline Engine Power rating & $280 \mathrm{hp} \mathrm{@} 2400 \mathrm{rpm}$ \\
\hline Peak Torque & $850 \mathrm{lb}-\mathrm{ft} @ 1400 \mathrm{rpm}$ \\
\hline
\end{tabular}

Distance-specific emissions results presented in this chapter include the following:

1. Baseline emissions from the Cummins $\mathrm{C} 8.3 \mathrm{G}+$ engine without the $\mathrm{OEM}$ oxidation catalyst.

2. Emissions from the engine with the OEM oxidation catalyst. 
3. Emissions from the engine after retrofitting it with the novel aftertreatment system developed by WVU and Lubrizol-ECS.

4. Emissions from the engine retrofitted with the WVU-Lubrizol system after a six month on-road demonstration.

The design and the formulation of the aftertreatment system are discussed later in this chapter. The regulated emissions included total oxides of nitrogen, total hydrocarbons, carbon monoxide, and total particulate matter. Hydrocarbon results are presented as methane and non-methane hydrocarbons. The non-regulated emissions include carbonyls, VOCs, 1,3-butadiene, PAHs, n-PAHs, hopanes, steranes, and toxic gases (BTEX) including 1,3-butadiene. Dilute exhaust samples were drawn from a "clean dilution tunnel", which was used exclusively for studies on natural gas engines. It should be noted that bar graphs show emissions results, which represent an average of multiple runs, excluding the outliers. Measurement outliers were determined by upper and lower quartile method. The non-regulated emissions presented here are not corrected for background levels.

\subsection{Phase I: Emission Test Results}

The specific objective of the Phase I was to evaluate the emissions characteristics of the CNG engine without the OEM oxidation catalyst, known as the baseline configuration. In addition, it was to determine the reduction of emissions when the OEM oxidation catalyst was reinstalled on the engine. Both regulated and non-regulated emissions were analyzed during this phase.

\subsubsection{Regulated Emissions Data}

The regulated emission levels from the baseline engine and from the engine with the oxidation catalyst are shown in Figure 5.1. All the regulated emissions were corrected for background levels. It is evident from the plot that OEM oxidation catalyst effectively reduced emission levels for all regulated pollutants. The carbon monoxide emissions were reduced by $97 \%$, total particulate matter was reduced by approximately $62 \%$ and the total hydrocarbon emissions were reduced by $28 \%$ by OEM catalyst. A $13 \%$ reduction in the NOx emissions with OEM catalyst was observed, but this was rather unexpected and could be due to the inherent variability of the measurement and sampling systems. The error bars in the figure illustrates \pm 2 standard deviations of 
variability in the measured values. The total hydrocarbon emissions were analyzed using a GC because a flame ionization detector has a high response factor towards methane, which is found in large amount in the CNG engine exhaust. A plot of methane and nonmethane hydrocarbons determined using GC analysis is shown in Figure 5.2.

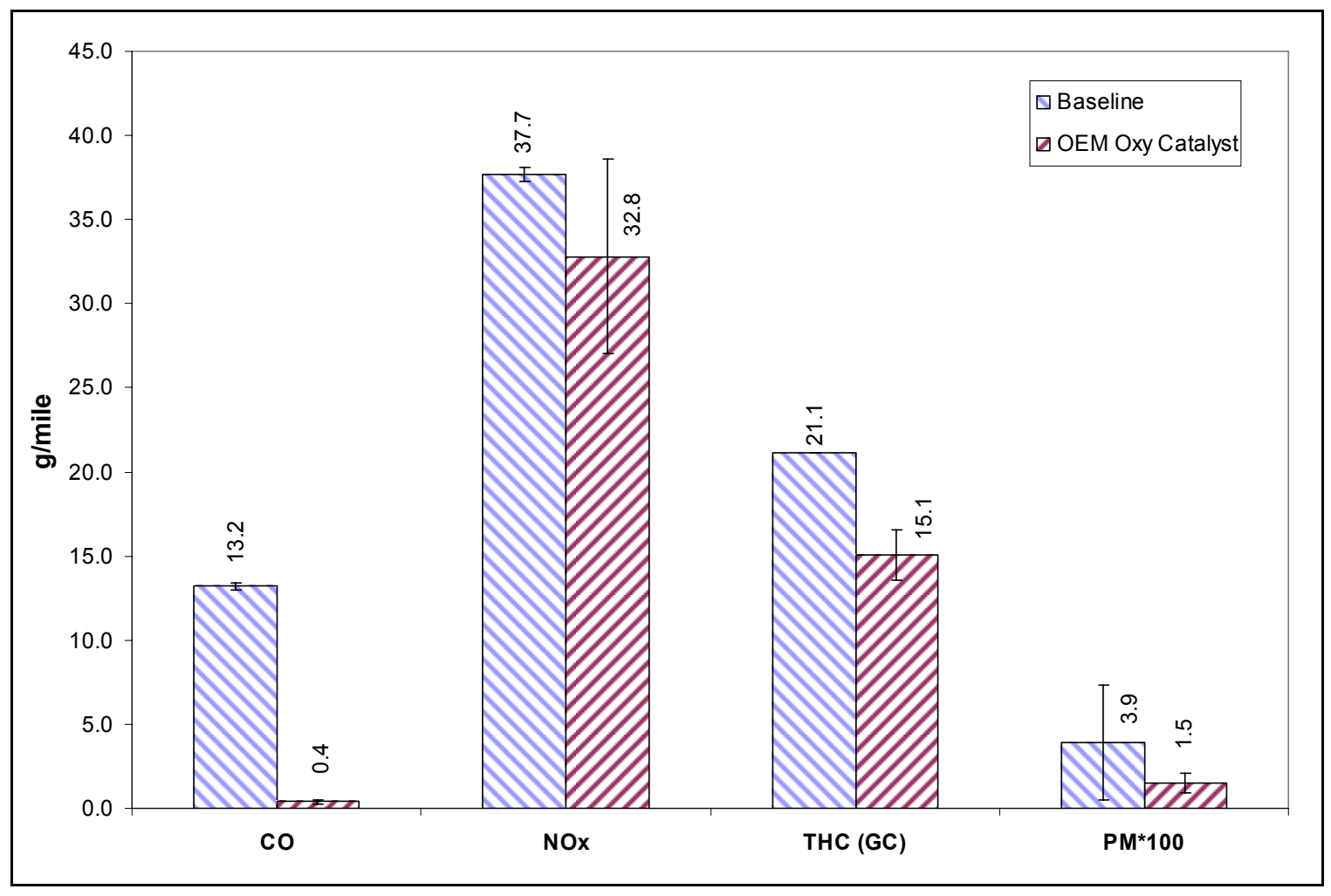

Figure 5.1 Regulated Emissions from Natural Gas Engine with and without OEM Oxidation Catalyst.

Note: The PM emissions are multiplied by a factor of 100 for better visualization of the results. 


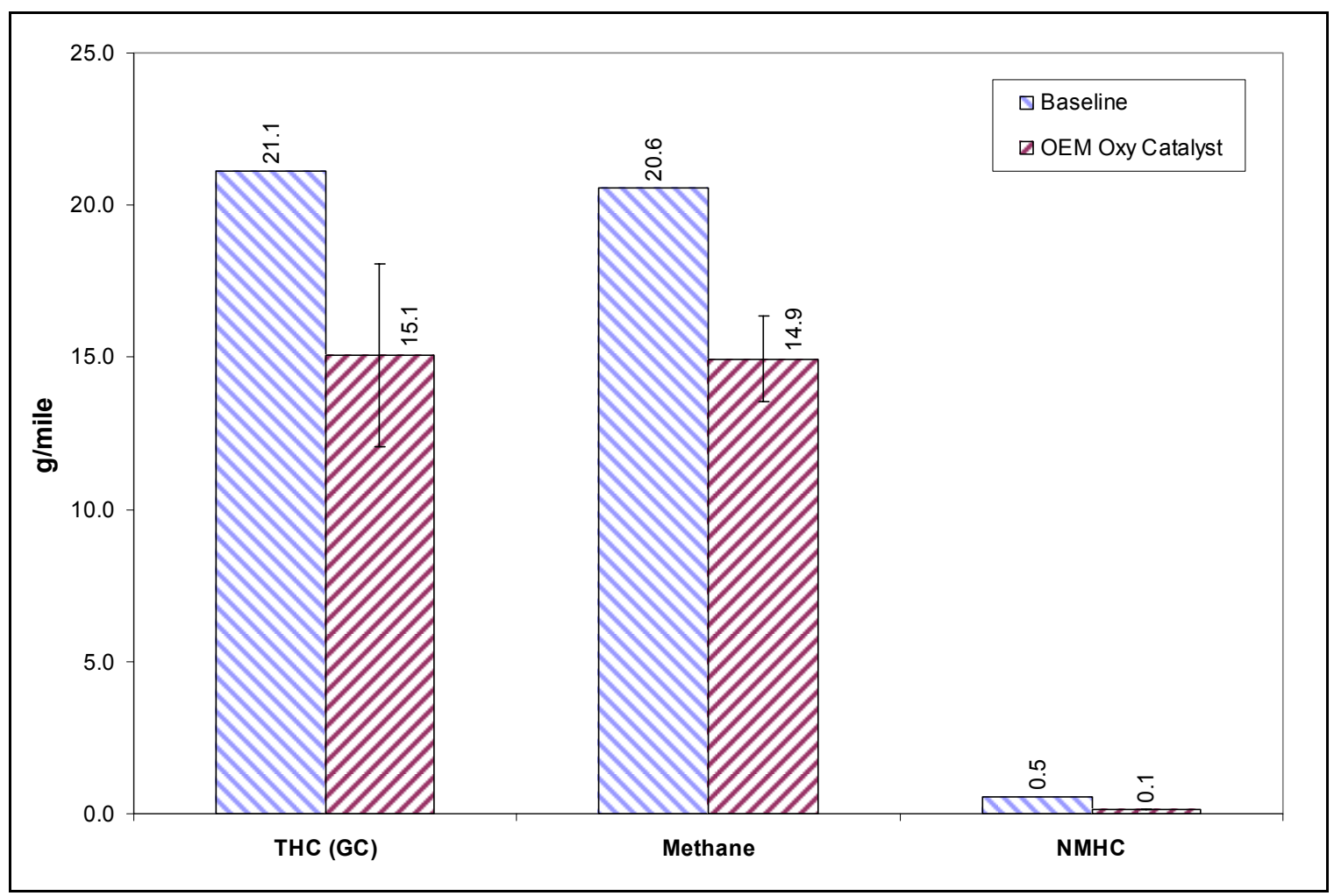

Figure 5.2 Methane and NMHC from Natural Gas Engine with and without OEM Oxidation Catalyst.

The GC analysis of hydrocarbons showed that $97 \%$ of the total $\mathrm{HC}$ emissions were methane. Even though methane is non-regulated and considered to be stable and non-reactive it is classified as a greenhouse gas: hence, a contributor to the globalwarming phenomena. Regulated emission do show some reduction with the use of the OEM oxidation catalyst, but when compared to the vehicles equipped with sophisticated exhaust aftertreatment devices it appears there was a potential to achieve further reduction of emissions.

\subsubsection{Non-Regulated Emissions}

The non-regulated emissions were collected using a wide variety of sampling devices on different kinds of media as discussed in Chapter 4. These non-regulated emission samples were analyzed by Environment Canada. Species such as 1,3 butadiene and BTEX (which includes benzene, toluene, ethyl benzene, $\mathrm{m} \& \mathrm{p}$ xylene and o-xylene compounds) were analyzed at the test site due to the fact that these species are highly unstable and degrade with time. The other species which included volatile organic 
compounds, polycyclic aromatic hydrocarbons, EC/OC, carbonyls, nitro-polycyclic hydrocarbons, hopanes, steranes, engine wear elements and other inorganic ions associated with the lubrication oil were analyzed at Emission Research and Measurement Division (ERMD), Environment Canada. The sampling media were shipped overnight to the ERMD, Canada in coolers filled with ice to avoid any degradation of the collected samples. The results presented for non-regulated emissions except for size classified PM are not background corrected for reasons associated with the dilution tunnel, which will be discussed in the subsequent sections.

Samples for engine wear elements and other inorganic ions were collected on a $47 \mathrm{~mm}$ Teflon filter using a cyclonic separator of size PM2.5 $\mu \mathrm{m}$. The metallic and other related inorganic ions were analyzed using XRF spectrometry as discussed in Chapter 4. Emission of metallic elements in the engines is mainly caused due to the wear of valve train, camshaft, cylinder liner, piston ring, connecting rod bearing and also due to the removal of the engine wear elements deposited onto the piston, valve face, and from valve recessions. Lead, iron and copper were the engine wear elements analyzed during this study. The emission of these wear elements is shown in Figure 5.3. 


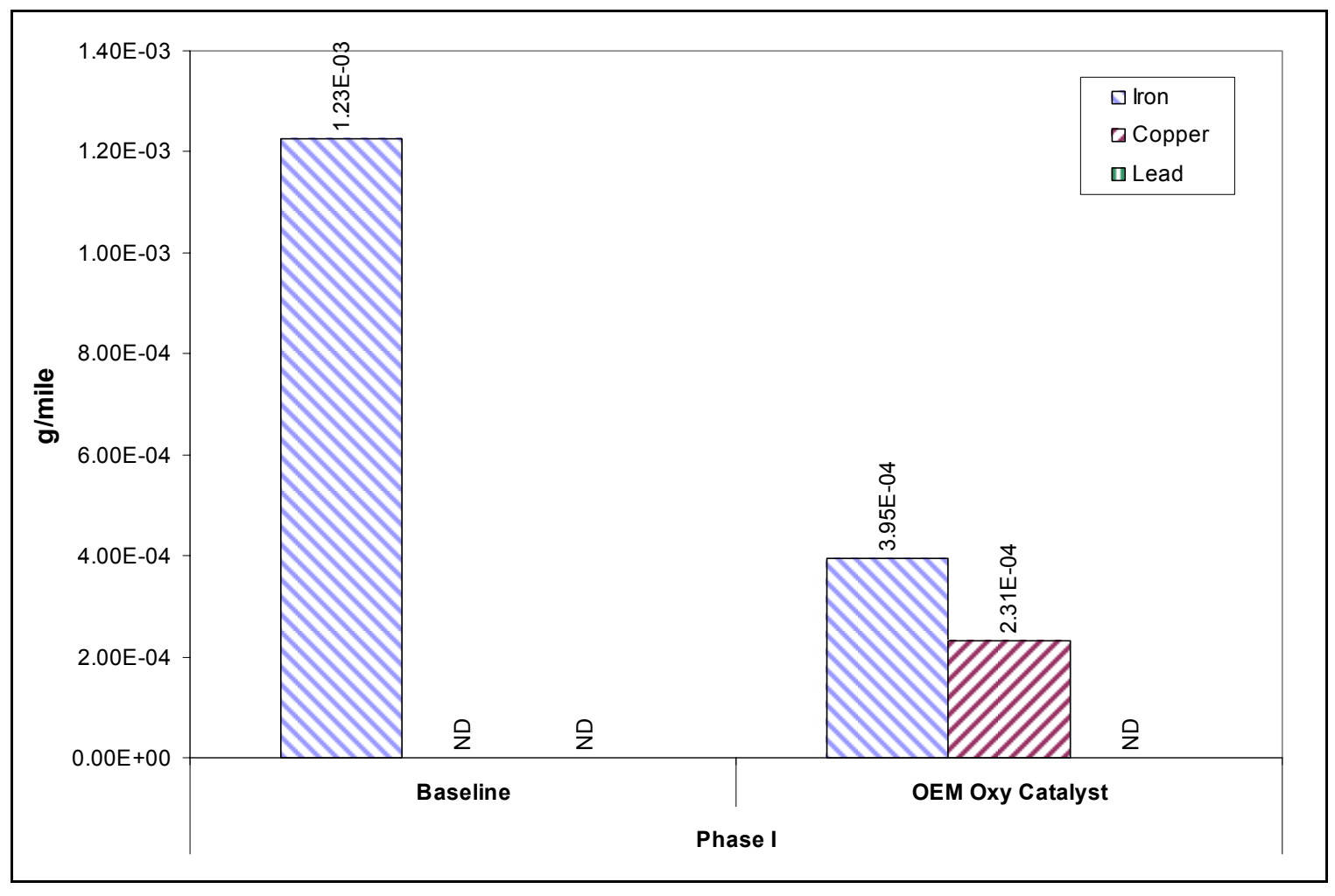

Figure 5.3 Emissions of Engine Wear Elements in Phase I

Results indicate that the OEM catalyst was effective in removing elemental iron and reduced the emission by $68 \%$. This was likely due to deposition in the ceramic channels. The emission of copper was observed only with the OEM catalyst and it was suspected to have originated in the catalyst housing. The emission of lead was not observed in either of the two engine configurations. Increase in the engine wear elements is generally associated with the use of incorrect grade lubrication oil and any malfunction of the moving parts inside the engine cylinder. The negative effect of engine wear includes increase in oil consumption, poor gas mileage, and decreased performance of the engine. Any unnoticed severe engine wear would lead to premature failure of the engine.

The elements associated with lube oil include zinc, phosphorus, sulfur and calcium. These elements are commonly found in additives which are added to the base stock, and act as antiwear and EP (erosion prevention) agents, corrosion and rust inhibitors, detergents, dispersants, friction modifiers, seal well agents, antioxidants and metal deactivators. Lube oil contribution to emission levels is linked to the oil leak into the cylinder past the piston rings, oil evaporation from the cylinder liner and from the 
valve stem seals. Other sources include oil leak past the turbocharger into the exhaust manifold and crankcase blow-by circulated back into the engine exhaust. In a study conducted by Yilmaz (2003) to determine the source and characteristics of oil consumption in a spark ignition engine it was found that oil consumption increased with increasing engine speed and the load, and blow-by emissions increased with engine load and decreased with speed. The experimental results showed that the oil accumulated in the top ring grove during low loads resulting from low blow-by flow rates was transported into the combustion chamber with reverse gas flow through the top ring grove due to top ring flutter at full load conditions. The emissions level of lube oil elements from the baseline engine and the engine with the OEM oxidation catalyst is shown in Figure 5.4. The results indicate an increase in the emissions of phosphorus, sulfur, and zinc with the use of oxidation catalyst when compared to baseline emissions. In order to clarify the increase in emissions of these elements the oxidation catalyst was dismantled and analyzed after the Phase 1 testing. The reports from the transit agency indicated that the oxidation catalyst on the vehicle was approximately ten years old and upon analysis of the dismantled catalyst it was found that some structural failure had occurred and the catalyst substrate was crumbling inside the catalyst housing. These may have lead to an increased engine back pressure which would increase lubrication oil blow-by during the combustion process and consequently increase lube oil elements in the exhaust. The causes of failure include sintering due to high temperature, sulfur and phosphorus poisoning or due to gradual deterioration. 


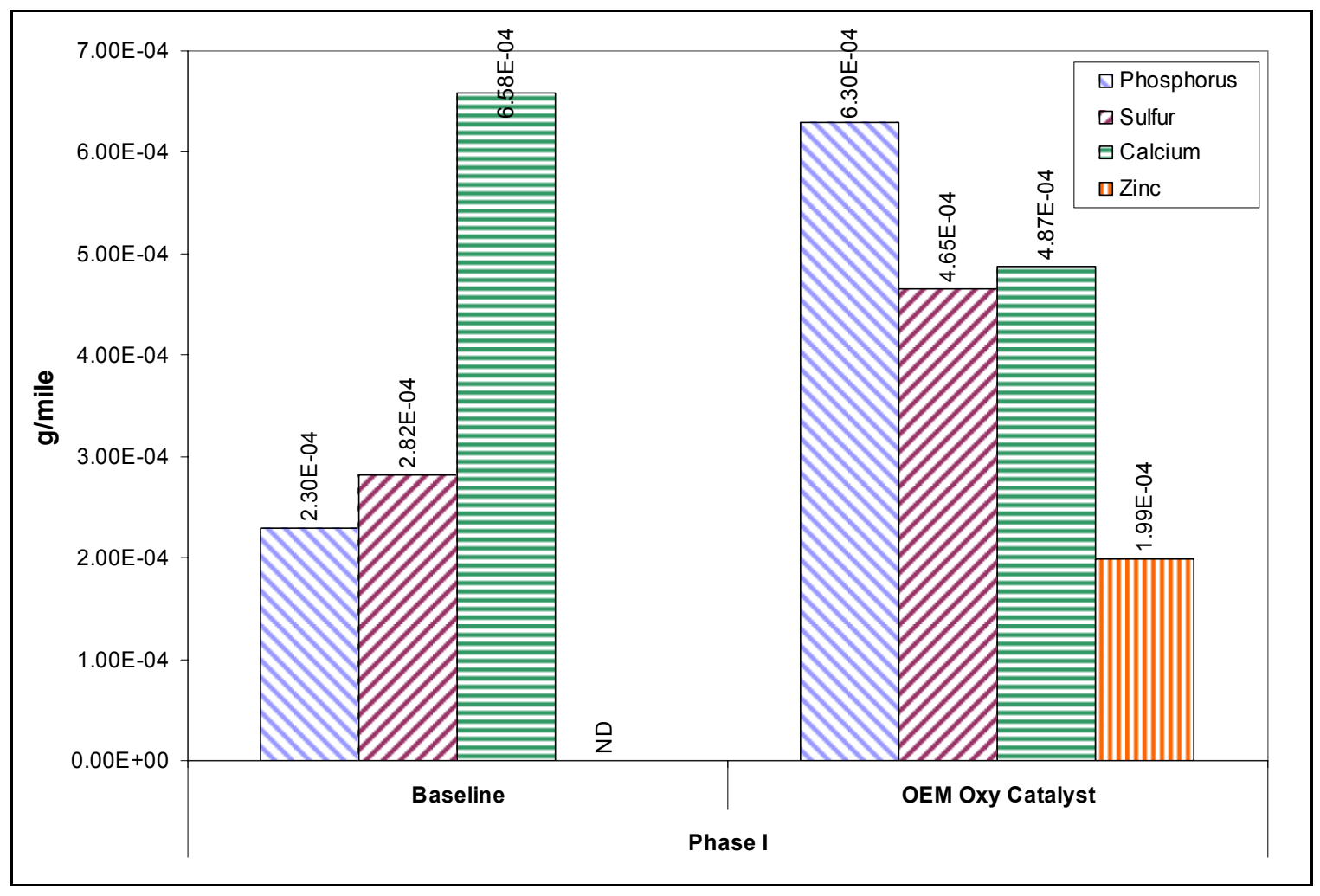

\section{Figure 5.4 Emissions of Lube Oil Additives in Phase I.}

Carbonyl compounds were sampled in 2,4-diphenylhydrazone (DNPH) cartridges. The cartridges were analyzed for formaldehyde, acetaldehyde, acetone, propionaldehyde and acrolein. However, acrolein was not found in any of the samples. Aldehydes have been classified as one of the TAC by CARB. Figure 5.5 shows the quantity of aldehydes emitted from the baseline engine and the reduction achieved by the OEM oxidation catalyst. 


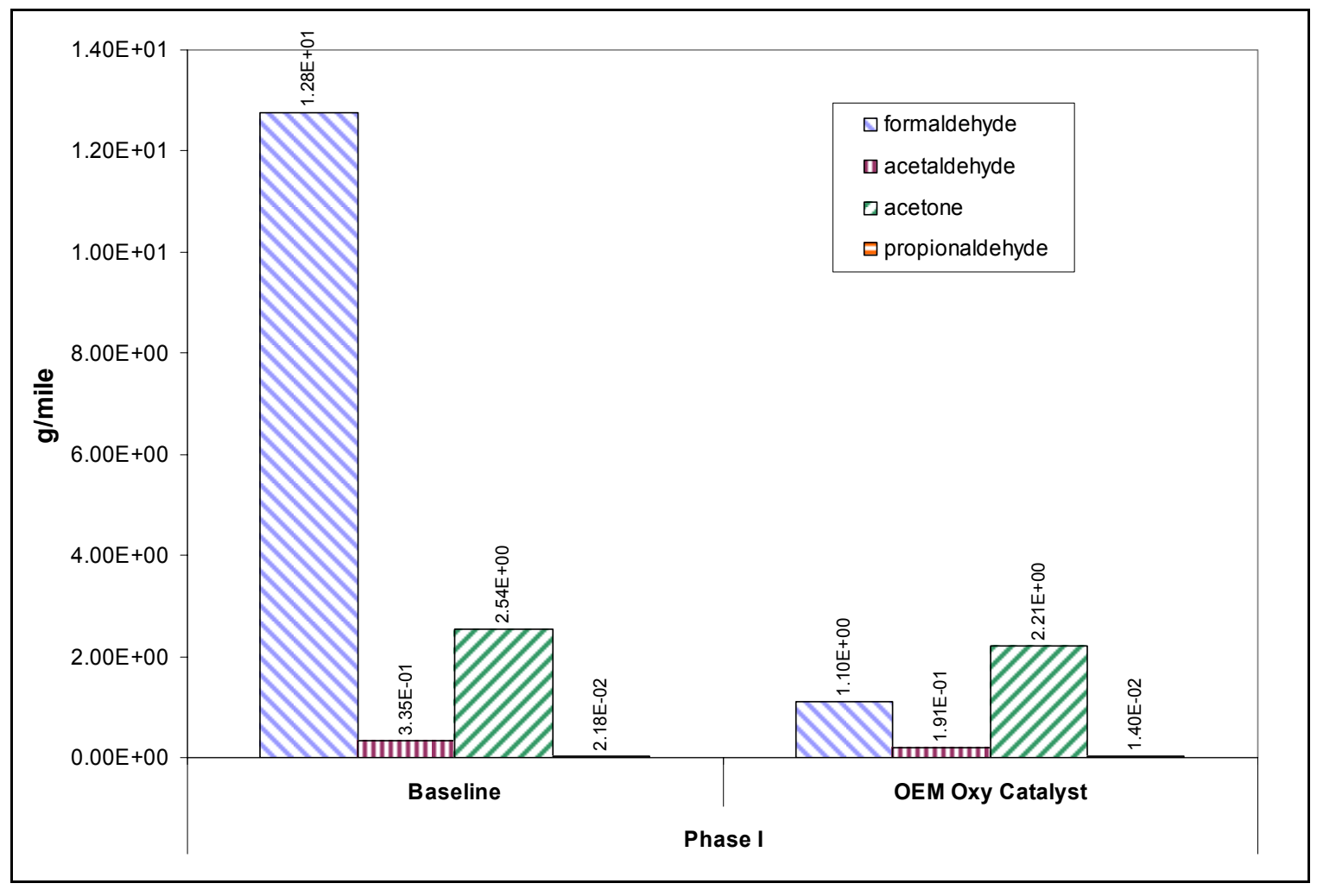

Figure 5.5 Emissions of Carbonyl Compounds in Phase I.

As can be seen from the plot, the OEM oxidation catalyst demonstrated significant reduction in carbonyl emissions which were in the order of $91 \%$ reduction of formaldehyde, $43 \%$ reduction in acetaldehyde, $13 \%$ reduction in acetone and 36\% reduction in propionaldehyde. This indicates that the oxidation catalyst is effective in reducing lower molecular weight hydrocarbons.

Polycyclic aromatic hydrocarbons (PAHs) are a class of hydrocarbons that are formed due to incomplete combustion of diesel fuel and lube oil, and some of them are considered to be highly carcinogenic. Hence, they are classified under TACs by US EPA and CARB. The PAH species in CNG exhaust is suspected to be a contribution of lubrication oil. PAHs generally occur in the atmosphere both as vapor and particle bound organic fraction. PAH species were sampled in a PUF/XAD cartridge and were analyzed by a GC/MS (gas chromatography and mass spectrometer). Figure 5.6 shows the emission of total PAH from the baseline engine and reduction achieved by the use of OEM oxidation catalyst. 


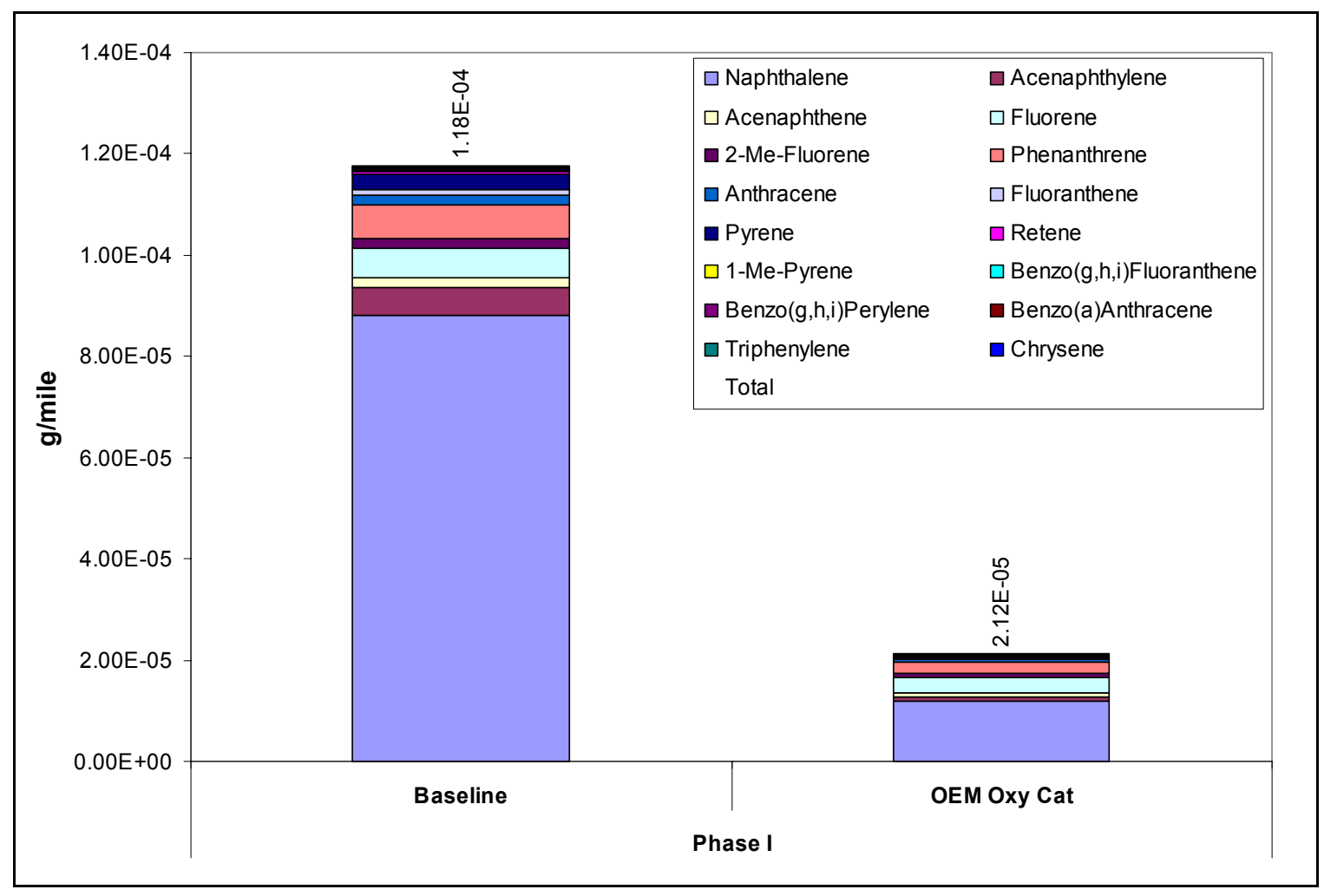

Figure 5.6 Emissions of Polycyclic Aromatic Hydrocarbons in Phase I.

Among thirty two different species of PAH analyzed only fifteen species were identified as contributors and all the remaining species were below the detection limit. Naphthalene which was the most abundant species found in the total PAH was reduced by $86 \%$ by the OEM oxidation catalyst whereas the total PAH emissions were reduced by $82 \%$. Nitro-PAHs which are formed due to the secondary reaction between PAH and the nitrogen were also analyzed during this test and they were found to be below detection limit. McDonald et al. (2004) stated that nitro-PAHs are associated with bacterial mutagencity.

The one-ring aromatic compounds analyzed include benzene, toluene, ortho-, meta-, and para-xylene isomers and ethyl benzene which are collectively identified as BTEX. The BTEX compounds along with 1,3-butadiene were analyzed at the test site after each run, using a field grade GC provided by Environment Canada, as they are highly susceptible to degradation in sunlight and have a very short sample life. The samples were collected in Tedlar bags, and also in stainless steel canisters which were 
analyzed at ERMD, Canada. The results obtained from both bag and canister analysis are shown in Figure 5.7.

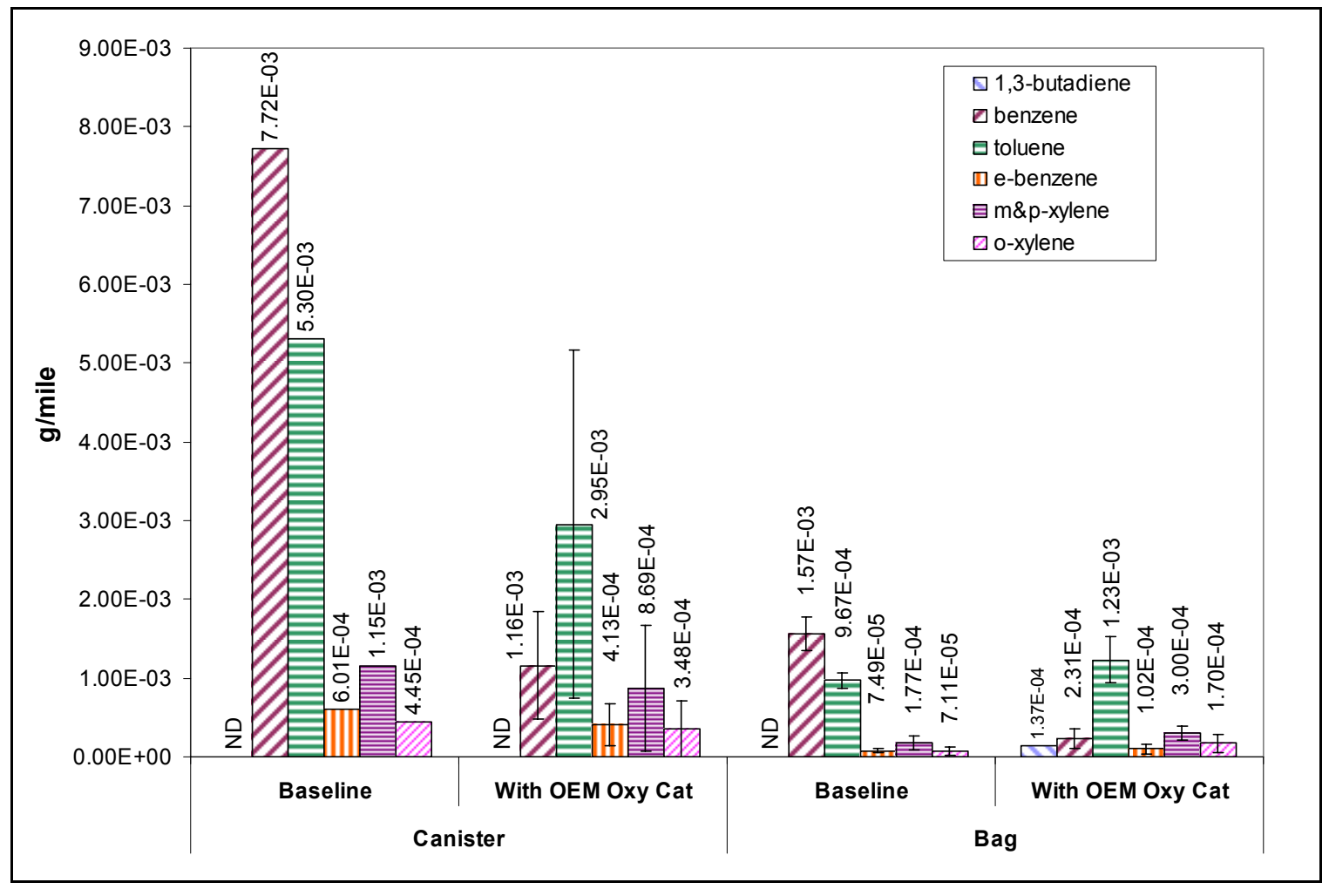

Figure 5.7 Emissions of Toxic Gases in Phase I.

The canister samples which were analyzed at ERMD show that all the species were reduced by the OEM catalyst, whereas the bag results indicate an increase in toluene, e-benzene, m\&p-xylene and o-xylene which do not agree with the canister results. The difference in the values between the bag and canister sample was suspected to be due to reaction between the bag material and the sample. To investigate the problem a sample bag (BAG 1) was filled with a known concentration of toxic gas and analyzed using a field grade GC at ERMD. The reader should note that BAG 1 was of the same material and was made by the same manufacturer as the bags used during Phase I testing. Results indicated a $20 \%$ to $30 \%$ loss of chemical species in BAG 1 . To check these findings, a sample bag (BAG 2) manufactured by a different company, but the same material was filled with the same toxic gas of known concentration. The results for the BAG 2 indicated that less than $0.5 \%$ of the chemical species were lost. Several test runs were performed using BAG 1 and BAG 2 and the results showed that the percentage of 
chemical species lost to BAG 1 reduced with time. This indicated that some type of chemical adsorption was taking place between the bag material and sample in BAG 1 . Over time BAG 1 reached a steady-state and adsorbed smaller percentages of chemical species, verifying the fact that there was adsorption in BAG 1 . Therefore in the Phase 2 testing, bag type 2 was used for sample collection (Burlingame, 2004).

The particles in the diesel exhaust are composed of elemental carbon (soot) and organic compounds adsorbed from fuel and lubricating oil. Whereas exhaust from natural gas fueled engines is considered to be free of elemental carbon due to the simple structure of the fuel molecule consisting of single carbon atom, which is mainly methane consisting of a single carbon atom, when compared to complex molecule of diesel fuel. Figure 5.8 shows that the organic carbon emissions were reduced by $57 \%$ with the use of the oxidation catalyst.

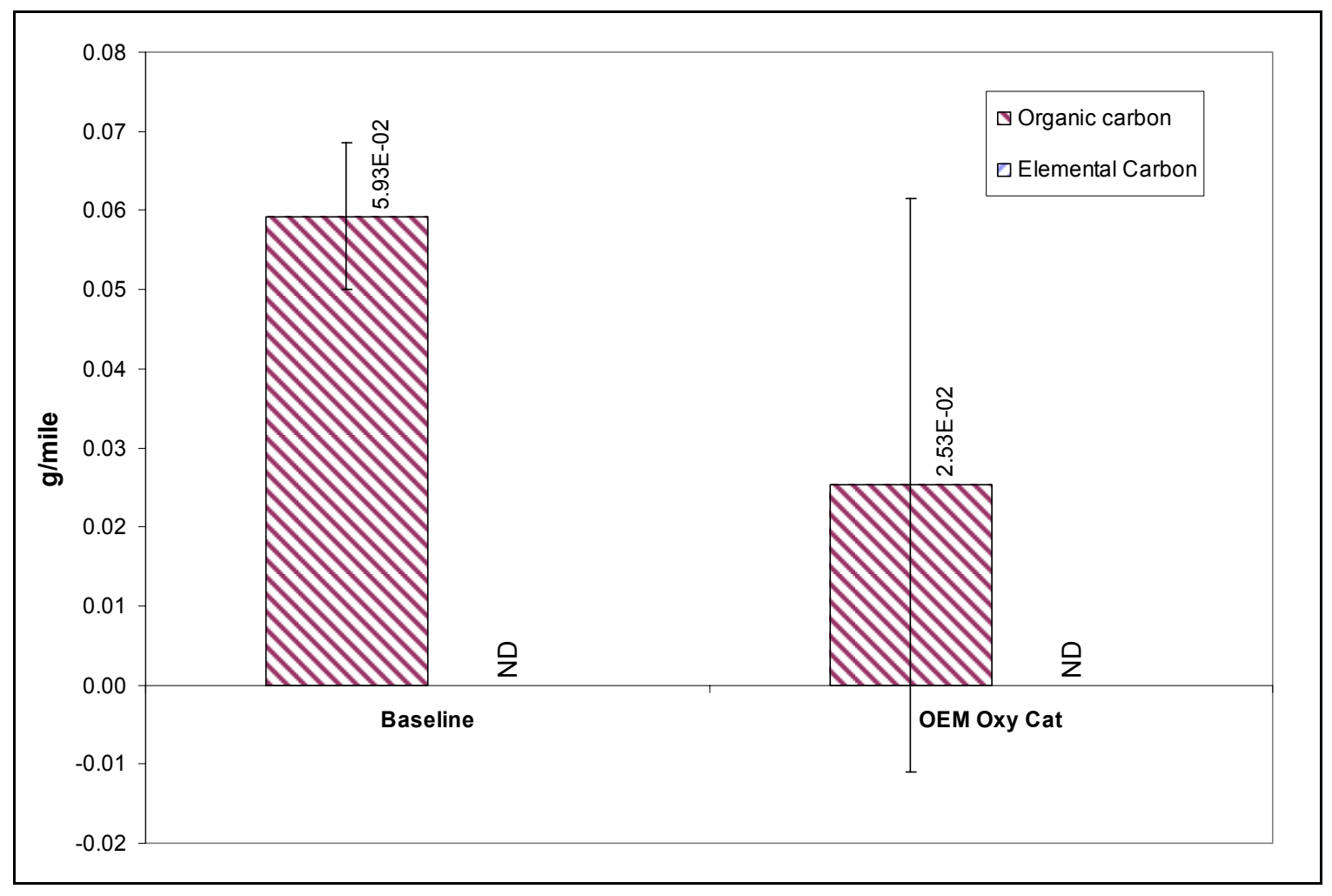

Figure 5.8 Emissions of Elemental and Organic Carbons in Phase I.

Size specific gravimetric analysis of PM was performed during this test along with TPM. The size fractions analyzed included $\mathrm{PM}_{10}, \mathrm{PM}_{2.5}$ and $\mathrm{PM}_{1.0}$. All these samples were collected on a Teflon coated glass fiber filter using cyclonic separators. 
The filters were pre-weighed in an environmentally controlled chamber and post weighed under similar conditions. The size specific PM samples were collected from the primary dilution tunnel without emphasis on the filter face temperature as opposed to TPM sampling. Particulate emissions from $\mathrm{CNG}$ engines are low by mass when compared to the diesel exhaust but the number concentration of nanoparticles is higher by 2 to 3 orders of magnitude compared to diesel engines; hence, the particulate emissions from $\mathrm{CNG}$ are considered to be potentially more harmful as they can reach deep into the lungs delivering toxics. Figure 5.9 shows the emission levels of the particulate matter and the reductions obtained by OEM catalyst. The error bars in Figure 5.9 signifies the variation observed in measuring very low PM mass, which is mainly due to the inherent variability of sampling devices, of flow measuring system, and of the balance used to weigh very low PM mass collected on relatively heavier filter medium. The error bars shown in Figure 5.9 are equal to \pm 2 times the standard deviation observed among three repeats.

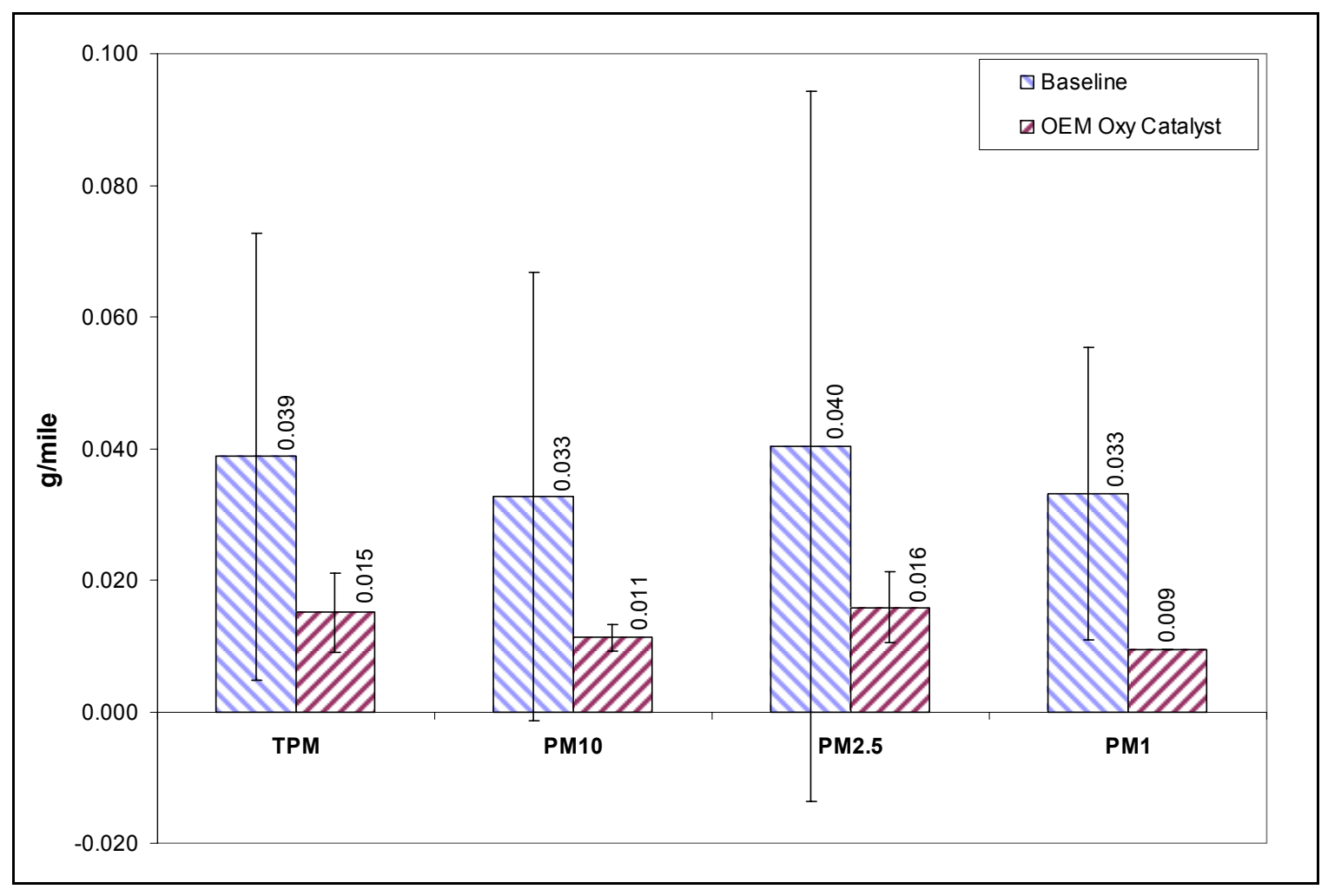

Figure 5.9 Size Classified PM Emissions in Phase I. 
A reduction of $61 \%$ was observed in TPM emissions with the installation of the OEM catalyst and a reduction of $60 \%$ to $70 \%$ was observed in the other PM size fractions with the use of oxidation catalyst.

\subsubsection{Particle Sizing Using SMPS}

Complete data of particle concentrations of different sizes from the baseline engine and from the engine equipped with oxidation catalyst running on a CBD cycle were measured using a Scanning Mobility Particle Sizer and a mini dilution tunnel. Before tracking particles of different sizes of interest, a full size distribution was measured with and without OEM oxidation catalyst by maintaining the vehicle at a constant speed of $20 \mathrm{mph}$ for the entire duration of SMPS sampling. A speed of $20 \mathrm{mph}$ was chosen as it was the maximum speed the vehicle would reach on a CBD cycle, which was the official duty cycle used for measuring the emissions. Three samples consisting of 220 seconds up-scan and 30 seconds down-scan, at a dilution ratio of 1:30, were collected to check for sample repeatability. The results are shown in Figure 5.10-5.11. It is evident from the particle size distribution curve that baseline engine emits maximum particles in the size range of $100 \mathrm{~nm}$ at concentrations level equal to $6 \times 10^{5}$ particles $/ \mathrm{cm}^{3}$ when tested at a steady-state speed of $20 \mathrm{mph}$. These particles maybe composed of solid carbonaceous particles formed due to burning of lubrication oil leaking into the combustion chamber. The concentrations of these particles were considerably higher than the background particles. Particle size distribution measured from the exhaust of the CNG engine operating with the OEM oxidation catalyst showed particles in the size range of $42-47 \mathrm{~nm}$ at a concentration of $1 \times 10^{6}$ particles $/ \mathrm{cm}^{3}$ during cold start period before reaching the light off temperature of the oxidation catalyst. While the concentration of these particles reduced to $1.4 \times 10^{5}$ particles $/ \mathrm{cm}^{3}$ during hot test when the exhaust temperature was stabilized at approximately $500{ }^{\circ} \mathrm{C}$, which took about 300 seconds from the start of the engine. These nanoparticles may be composed of semivolatile particles due to the presence of heavy hydrocarbons, and some inorganic ash. Inorganic ash containing calcium oxides or even metallic ash is emitted due to the combustion of lubrication oil, since calcium and zinc are used as special additives in the lube oil 


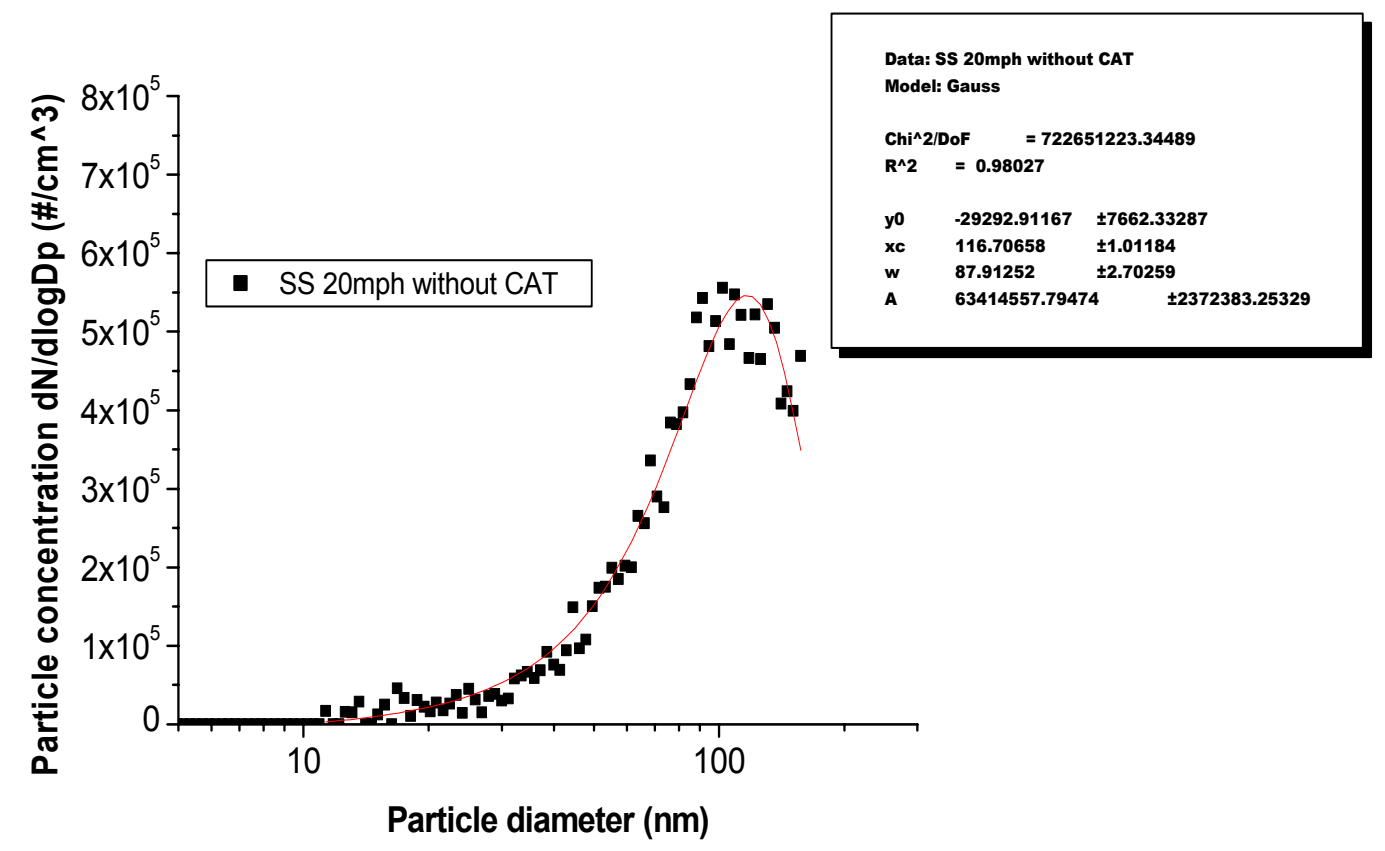

Figure 5.10 Phase I Steady-state Particle Size Distribution for the Baseline Engine

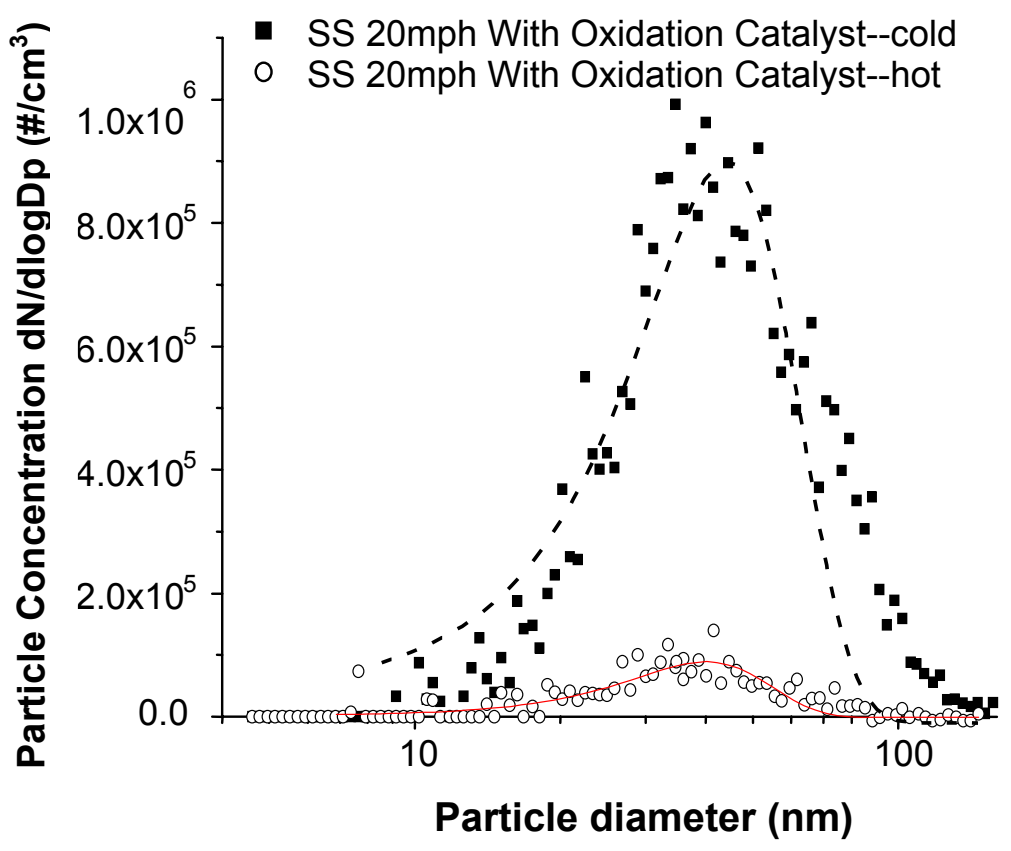

Figure 5.11 Phase I Particle Size Distribution with the OEM Oxidation Catalyst 
Upon completion of the Phase I testing and during the installation of the new exhaust aftertreatment device it was discovered that the OEM oxidation catalyst was structurally damaged and was disintegrating inside the can. It was suspected that pulverized catalyst support material would have contributed for such high particle concentration. Five particle sizes $8 \mathrm{~nm}, 19 \mathrm{~nm}, 31 \mathrm{~nm}, 44 \mathrm{~nm}$ and $84 \mathrm{~nm}$ were chosen from the steady-state data for comparing the emission of these particles during transient (QCBD) tests. All the particle size measurements were made at a dilution ratio of 1:20 and the results are shown in the charts below.

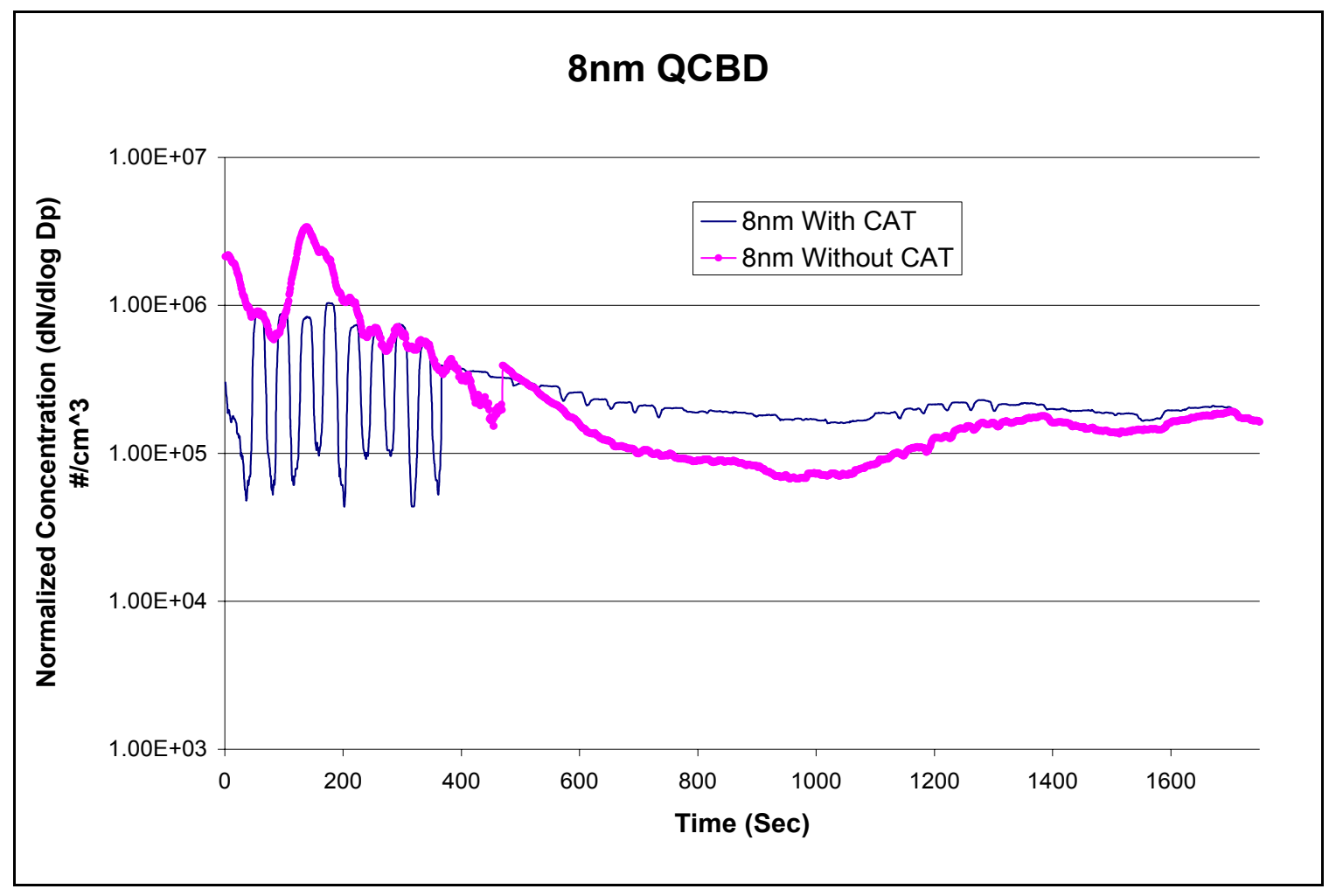

Figure 5.12 Concentration of 8nm Particles from a QCBD test with and without the OEM Oxidation Catalyst

The $8 \mathrm{~nm}$ particle did not vary with the transient cycle as shown in the figure above while the $19 \mathrm{~nm}$ particle showed variation of concentration in sympathy with CBD test cycle as shown in the figure below. These particles are most likely condensed water and heavy lube oil based hydrocarbons. Particles of this size are of major health concern since these particles penetrate very deep into the lungs and get deposited in the alveolar region and may cause inflammation. These particles were reduced in concentration by a factor of 10 when an oxidation catalyst was used. 


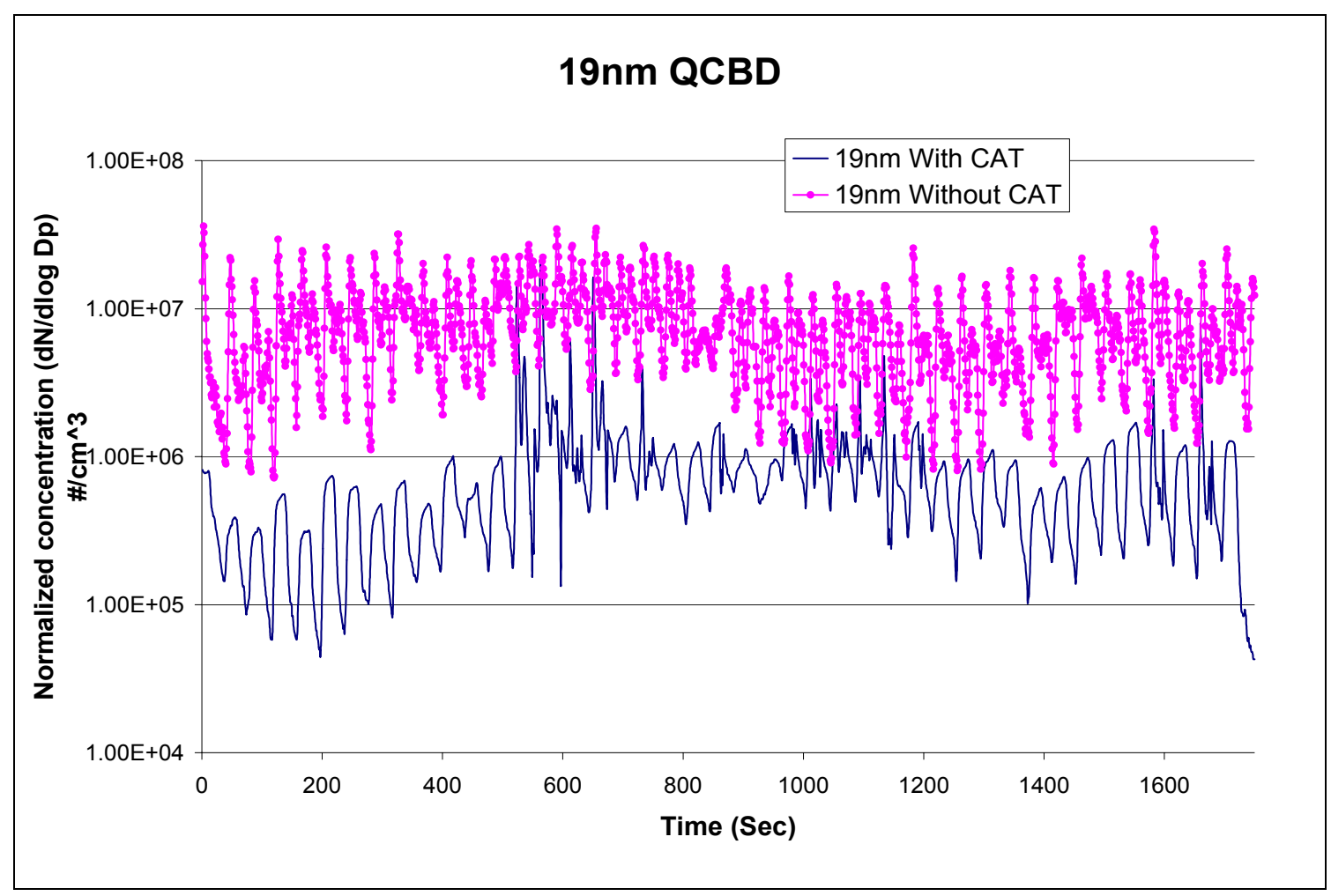

Figure 5.13 Concentration of 19nm Particles from a QCBD test with and without the OEM Oxidation Catalyst

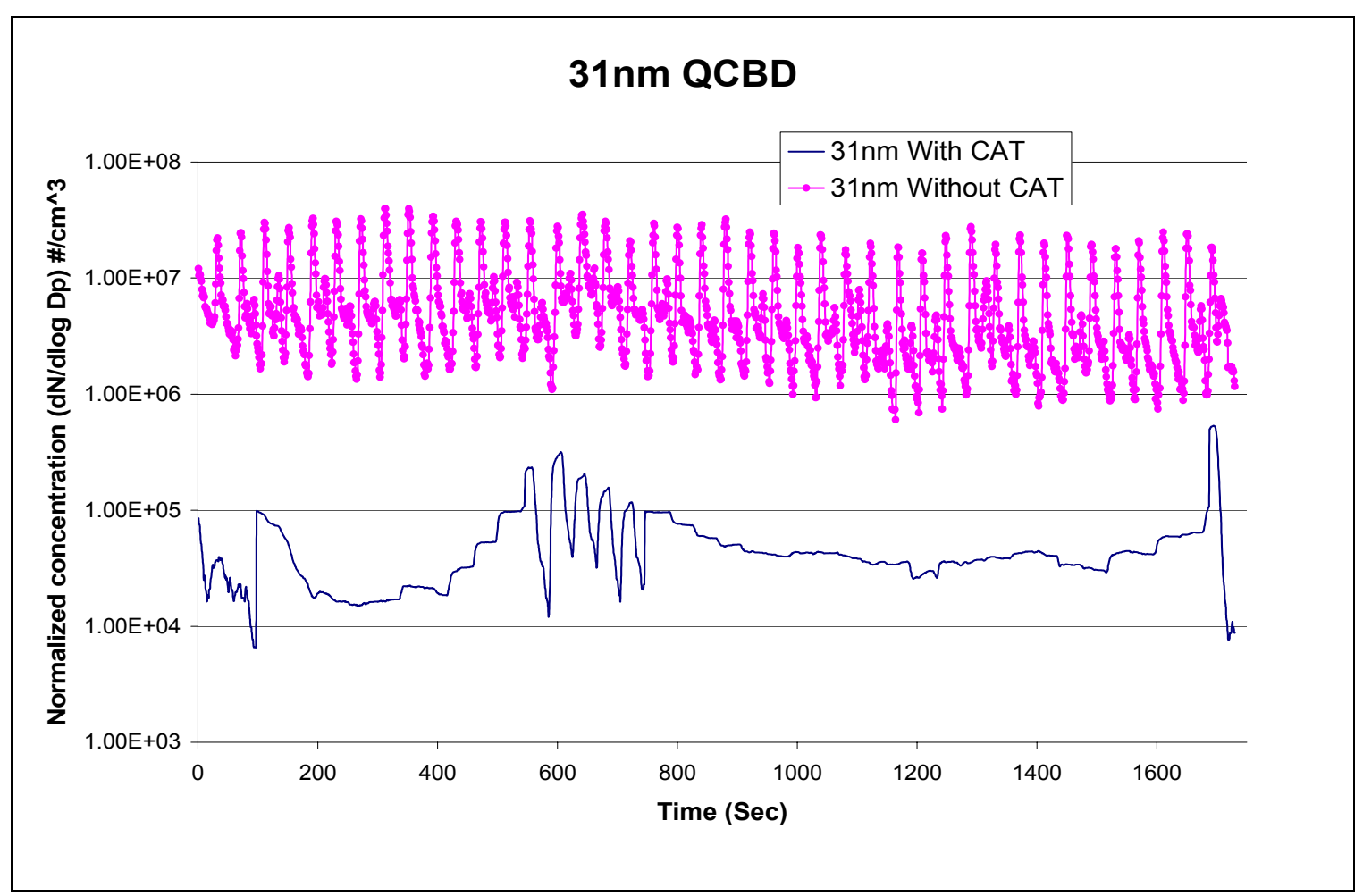

Figure 5.14 Concentration of 31nm Particles from a QCBD test with and without the OEM Oxidation Catalyst 
Particles of size $31 \mathrm{~nm}$ were reduced by two orders of magnitude with the use of oxidation catalyst as shown in the figure above. The trace of $44 \mathrm{~nm}$ particles as shown below presents an interesting insight to the formation of nanoparticles with the variation of dilution ratio. The concentration of $44 \mathrm{~nm}$ particles with the use of oxidation catalyst at a dilution ratio of 1:30 was found to be higher than what was found with in a dilution ratio of 1:20. This could be due to an increase in saturation ratio with increase in dilution ratio that leads to self nucleation of volatile compounds and some of these compounds may even grow to form particles in the range of accumulation mode due to condensation. A decrease in the concentration by a factor 1000 was observed with the use of oxidation catalyst when sampled at a dilution ratio of 1:20.

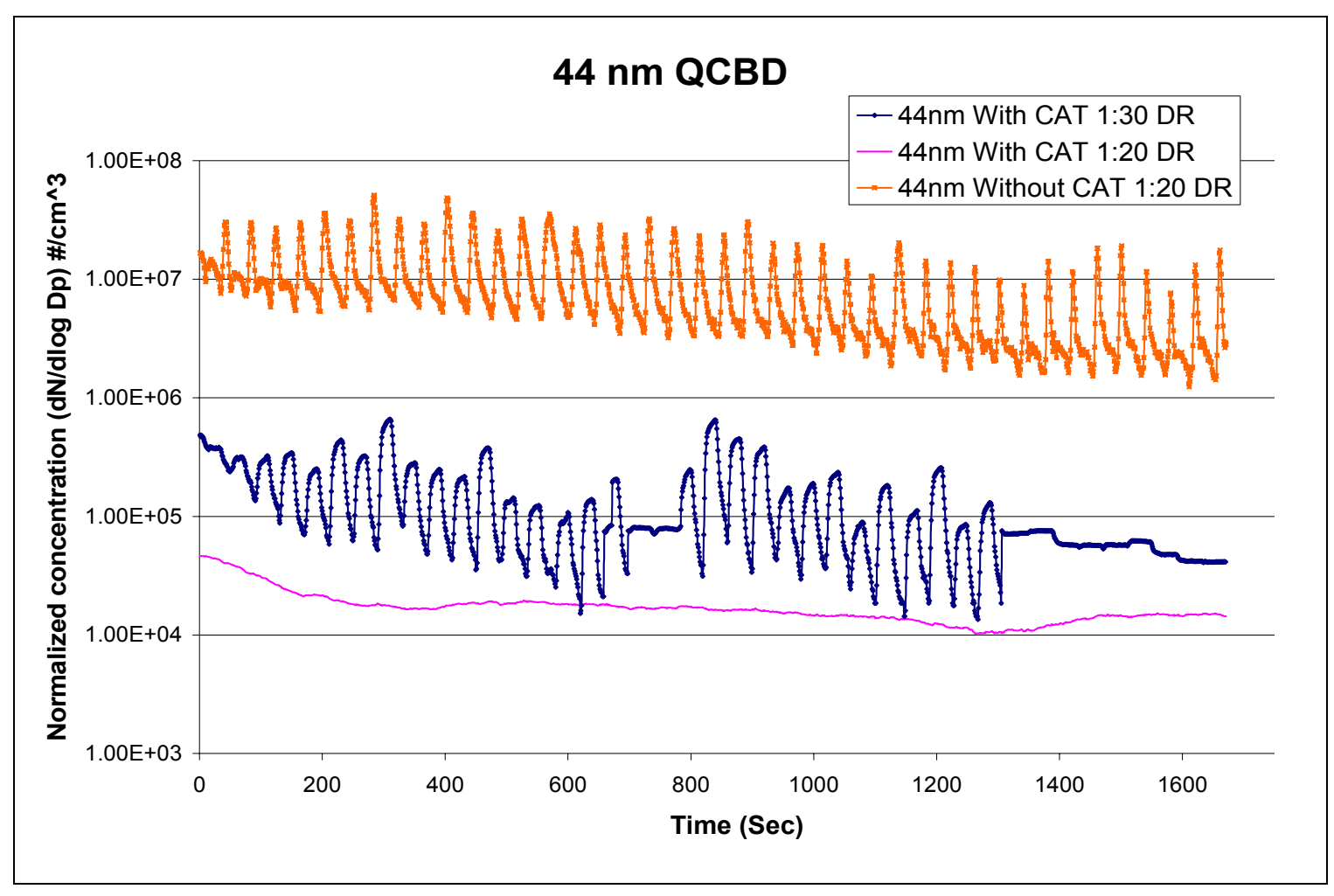

Figure 5.15 Concentration of 44nm Particles from a QCBD test with and without OEM Oxidation Catalyst 


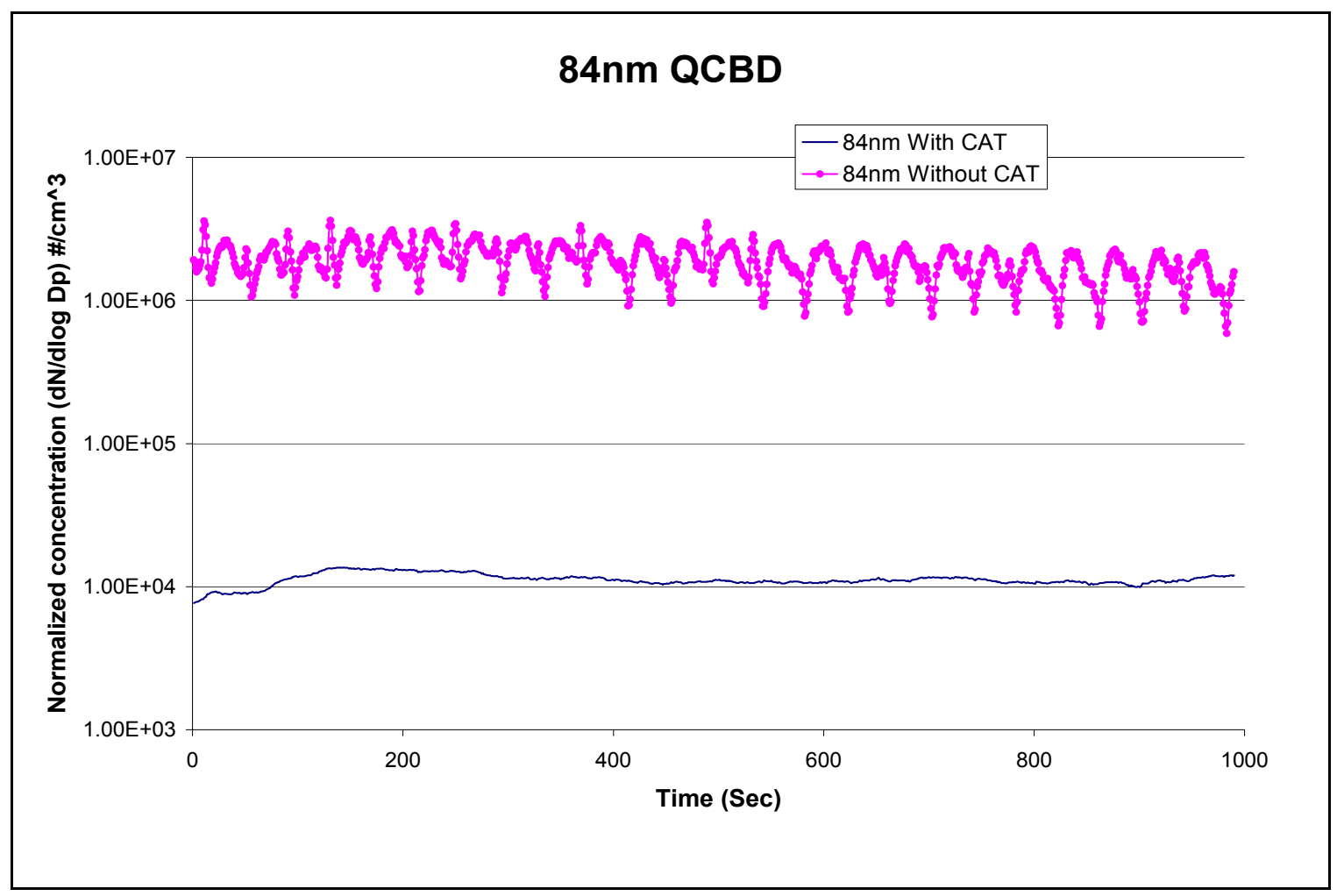

\section{Figure 5.16 Concentration of 84nm Particles from a QCBD test with and without OEM Oxidation Catalyst}

The concentration trace of $84 \mathrm{~nm}$ particles showed a decrease in the order of magnitude of 100 with the use of OEM oxidation catalyst. The oxidation catalyst aided in eliminating all the accumulation mode particles in the size range of 100nm and shifted the maximum concentration of the particle to the size range of $40-45 \mathrm{~nm}$, but the catalyst seems to have little effect on nanoparticles in the size range below 20nm. Comparisons between the steady-state results suggest that the use of an oxidation catalyst effectively reduced the concentrations of the larger size particles which contributed towards a decrease in mass emissions.

With the regulated and non-regulated emissions data obtained from the baseline engine and the engine equipped with the OEM oxidation catalyst it was evident that there was a need for an efficient exhaust aftertreatment system which would address the issue of reducing PM and other toxic air contaminants effectively to the background levels. An advanced after treatment device was developed by WVU along with Lubrizol-ECS. The new exhaust aftertreatment system comprised a particulate trap and an oxidation catalyst 
arranged in series. The emission reduction potential of the new exhaust aftertreatment device was tested in the Phase II. The design of the aftertreatment system and the emissions results from Phase II testing are discussed in the following section.

\subsection{Phase II: Emissions Results}

West Virginia University and Lubrizol-ECS teamed up in designing an aftertreatment device to address the reduction of nano particle emissions and various other toxic organic compounds typically found in $\mathrm{CNG}$ engines based on the emissions data obtained during Phase I testing. The novel aftertreatment system consisted of a catalyzed particulate trap and an oxidation catalyst arranged in series. Conventionally, an exhaust aftertreatment system consisting of a particulate trap and an oxidation catalyst, a typical arrangement would be an oxidation catalyst followed by a particulate trap. However, the novelty of WVU-Lubrizol exhaust aftertreatment device was that the particulate trap was placed before the oxidation catalyst. This particular configuration was used to reduce the majority of nanoparticles emitted from natural gas vehicles by oxidizing the heavier organics of lower volatility. Exploiting the higher exhaust temperature of the natural gas engines a catalyzed PM filter would not only trap ash particles and negligible amount of elemental ions, its regeneration would be quite effective. Any gas phase organics leaving the catalyzed filter would be oxidized in the downstream oxidation catalytic converter. Hence, the nanoparticle emissions (primarily nucleated heavy organics) would be significantly reduced.

\subsubsection{Design and Formulation of WVU-Lubrizol Aftertreatment Device}

The oxidation catalyst used was a Platinum (Pt) and Palladium (Pt:Pd::1:3) catalyst with a loading of $350 \mathrm{~g} / \mathrm{ft}^{3}$, and the washcoat system was supported on a Corning EX20 Large Frontal Area Substrate with a cell density of 400 cells/in ${ }^{2}$. The substrate had a nominal diameter of 10.5 inches, and length of 6 inches and a total volume of approximately 8.5 liters or $520 \mathrm{in}^{3}$. The catalyst system served in oxidizing carbon monoxide, total hydrocarbons as well as any hydrocarbon aerosols that might pass the diesel particulate filter which was located upstream. The oxidation catalyst was packaged into a separate converter which allowed it to be readily removed to determine the cost effectiveness of the diesel particulate filter as well as the combination of the DPF and oxidation catalyst (Tadrous, 2004). 
The catalyzed particulate filter was a Lubrizol's commercially available DPF known under the trade name Purifilter ${ }^{\mathrm{TM}}$. The Purifilter $^{\mathrm{TM}}$ uses Platinum $(\mathrm{Pt})$ and base metal catalyst with a washcoat system that is supported on a wall flow monolithic silicon carbide diesel particulate filter substrate.

The catalyst system serves to oxidize carbon monoxide and the particle bound heavier hydrocarbons in the soluble organic fraction (SOF) of the particulate much like an oxidation catalyst but effective in oxidizing long-chain $\left(>\mathrm{C}_{12}\right)$ heavier hydrocarbons. In addition the catalyst serves in combustion of the insoluble carbon portion of the diesel particulate. The Purifilter ${ }^{\mathrm{TM}}$ will operate passively under acceptable exhaust restrictions when $25 \%$ of the duty cycle exceeds a minimum exhaust temperature over $280{ }^{\circ} \mathrm{C}$.

The catalyzed filter is integrated into the design of a replacement muffler, which would install in place of the original vehicle silencer. Each Purifilter ${ }^{\mathrm{TM}}$ features a removable filter centerbody to facilitate periodic maintenance and inspection. The inlet and outlet sections can be configured to a variety of inlet / outlet locations and sizes to facilitate installation.

A Purifilter ${ }^{\mathrm{TM}}$ model $\mathrm{SC} 17 \mathrm{H}$ was chosen for the $\mathrm{CNG}$ application due to the excellent thermal stability of the Pt/base metal catalyst system and solid state chemical properties of the silicon carbide. The DPF had a nominal diameter of 10.5 inches, and length of 12 inches with a total volume of approximately 17liters. The high Pt Loading was selected to promote durability.

Unlike cordierite, Silicon Carbide is thermally conductive. This allows heat to be dissipated quickly and effectively and minimizes the chance of localized hot spots within the filter that could result in melting of the substrate or thermal deterioration by solid state reaction of ash components with the substrate. Such solid state interactions can result in a loss of porosity or the development of pin holes in the filter wall (Tadrous, 2004).

\subsubsection{Reduction of Emissions by WVU-Lubrizol Aftertreatment Device}

Phase II of this project involved the verification of emission reduction potential of the newly designed exhaust aftertreatment device by WVU-Lubrizol. The novel aftertreatment device was installed on the same bus which was tested during Phase I. The 
reduction in both regulated and non-regulated emissions was verified by operating the bus on the QCBD cycle following the same sampling protocol as in Phase I testing.

\subsubsection{Regulated Emissions}

The results of the regulated emissions from the bus equipped with the new aftertreatment device are presented along with the baseline emissions and the OEM catalyst emissions in order to compare the emission reduction potential of the WVULubrizol aftertreatment device with respect to the baseline emission levels obtained during Phase I. The regulated emissions result is shown in the following figure.

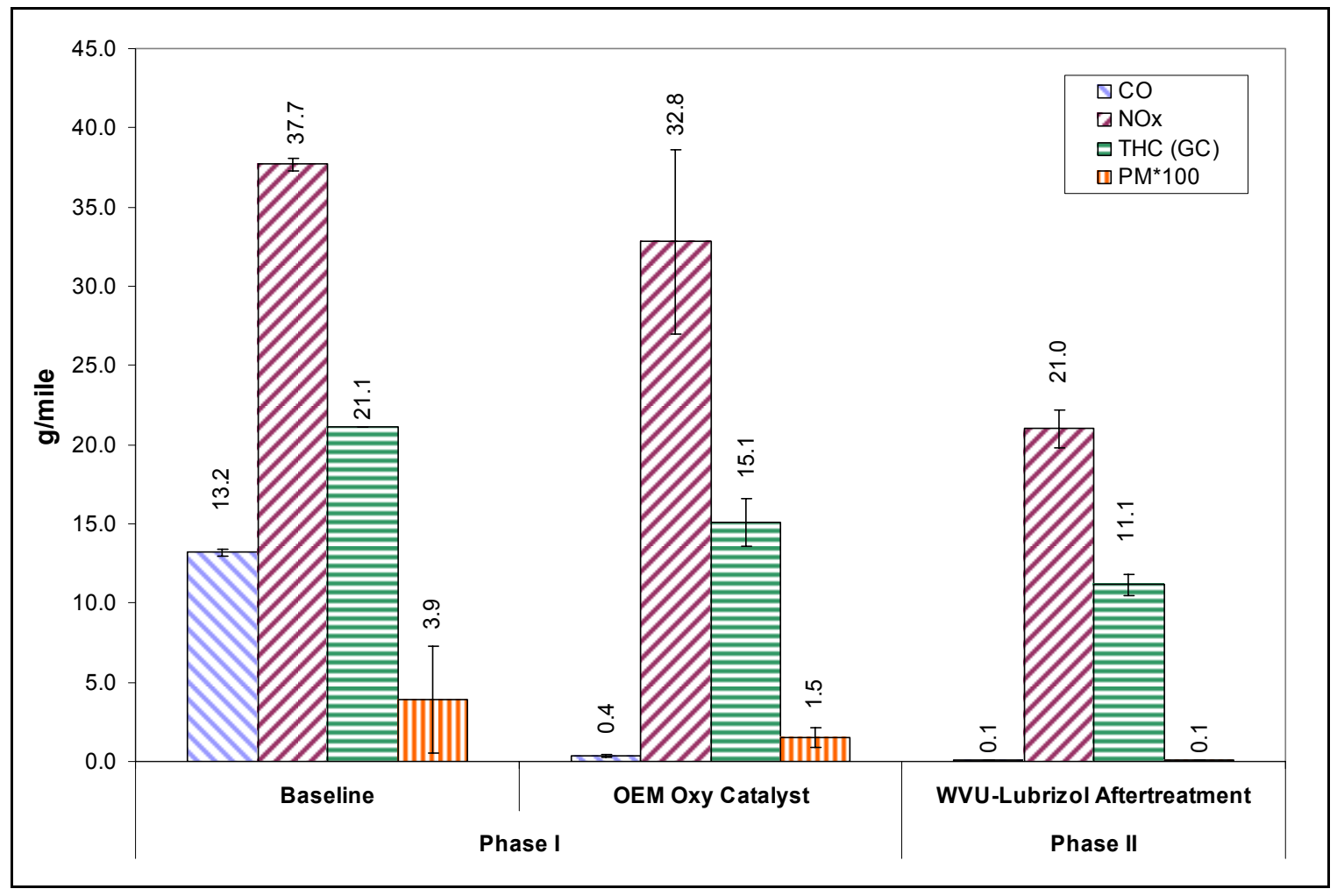

Figure 5.17 Regulated Emissions from Phase II vs Phase I.

It should be noted that TPM emissions values are multiplied by a factor of 100 for visualization purposes. The percentage reductions in emissions achieved by the use of WVU-Lubrizol aftertreatment device in comparison to the baseline and OEM catalyst are shown in the table below. 
Table 5.2 Reduction of Regulated Emissions Achieved by WVU-Lubrizol Aftertreatment Device

\begin{tabular}{|c|c|c|}
\hline & WVU-Lubrizol Trap vs. Baseline & WVU-Lubrizol Trap vs. OEM Catalyst \\
\hline CO & $99.0 \%$ & $65.8 \%$ \\
\hline NOx & $44.3 \%$ & $36.0 \%$ \\
\hline GCHC & $47.2 \%$ & $26.0 \%$ \\
\hline TPM & $98.2 \%$ & $95.3 \%$ \\
\hline
\end{tabular}

The WVU-Lubrizol trap exhibited superior emissions reduction characteristics when compared to the OEM oxidation catalyst, and the TPM mass emissions were drastically reduced which qualified the design of the novel exhaust aftertreatment device for what it was intended. The reduction of NOx with WVU-Lubrizol exhaust aftertreatment device could be attributed to the shift in the engine performance as Phase II and Phase I emissions were measured during different periods, and to the retention of exhaust gas in the cylinder due to increased exhaust backpressures as a result of using the WVULubrizol exhaust aftertreatment device. The exhaust gases retained in the cylinder displaces the oxygen in the intake air with inert gases that reduces the formation of NOx. Engine fuel consumption data is provided in Appendix C.

The methane and non-methane hydrocarbon emission levels were analyzed with a GC and results are shown in Figure 5.18. It was observed that the WVU-Lubrizol trap reduced the total hydrocarbon emissions by $47 \%$ when compared to baseline emissions, and by $26 \%$ when compared to OEM oxidation catalyst. However, an increase in nonmethane hydrocarbons was noticed with the use of the new aftertreatment device. 


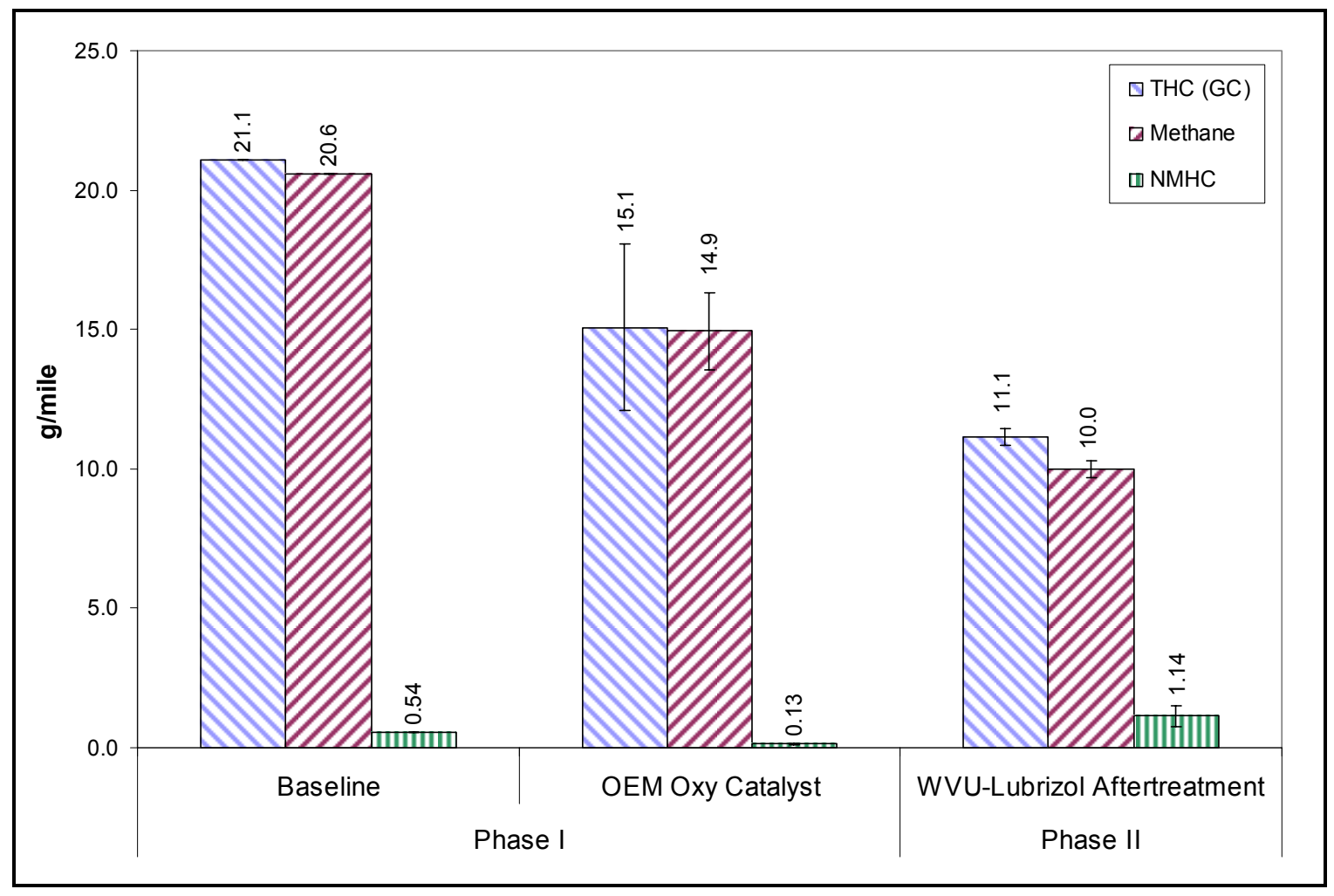

\section{Figure 5.18 Emissions of Methane and NMHCs from Phase II vs Phase I.}

\subsubsection{Non-Regulated Emissions}

All the non-regulated emissions that were sampled during the Phase I were also measured during Phase II with WVU-Lubrizol aftertreatment device in place. The nonregulated emissions were not corrected for background emissions because of the very low emission levels observed in CNG engines.

In the second phase of testing, PM samples were subjected to an elemental analysis. The analysis yielded a reading of "none detected" for all the engine wear elements, and also for elements associated with lubrication oil. The elemental analysis results are shown in Figure 5.19. 


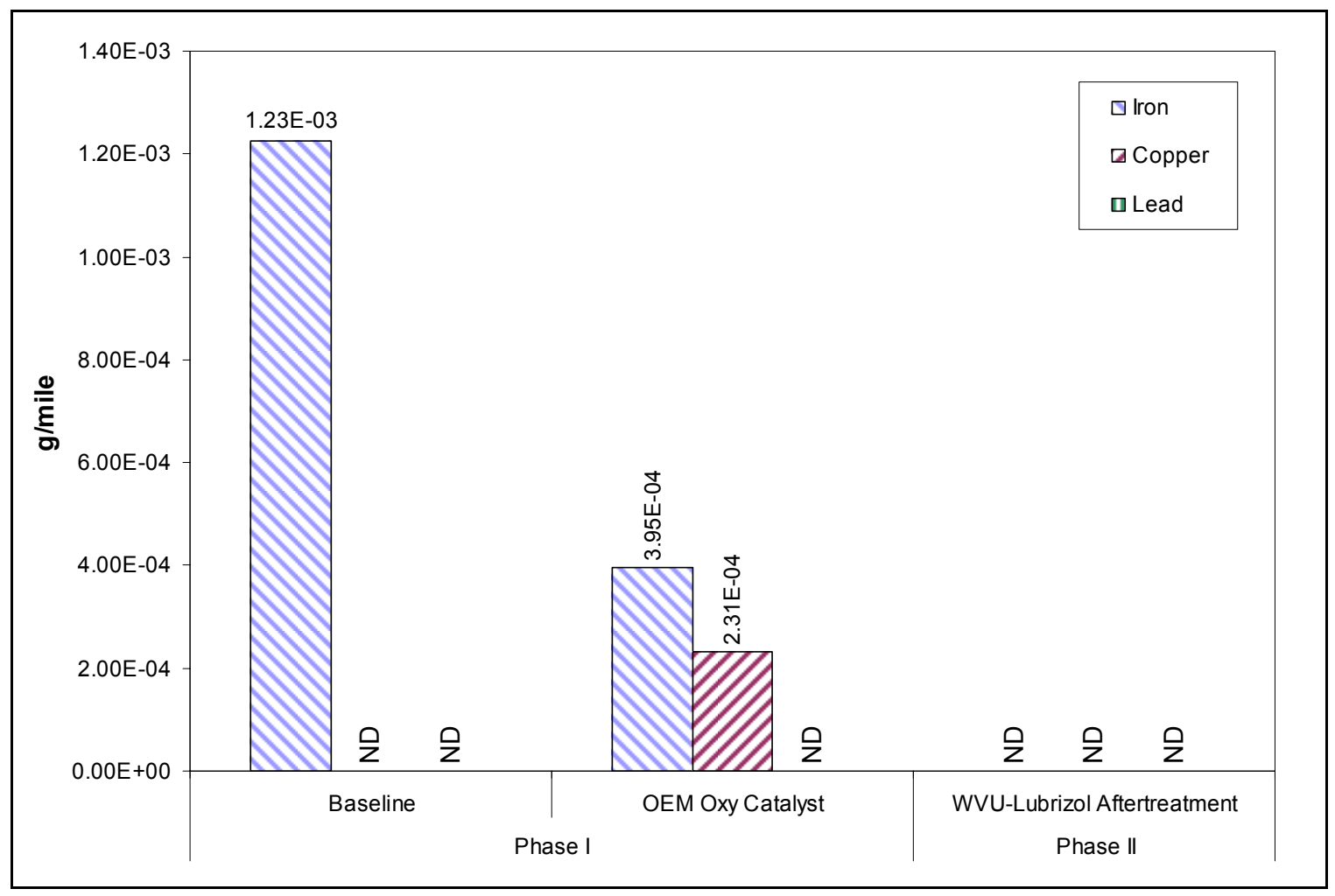

Figure 5.19 Emission of Engine Wear Elements from Phase II vs. Phase I.

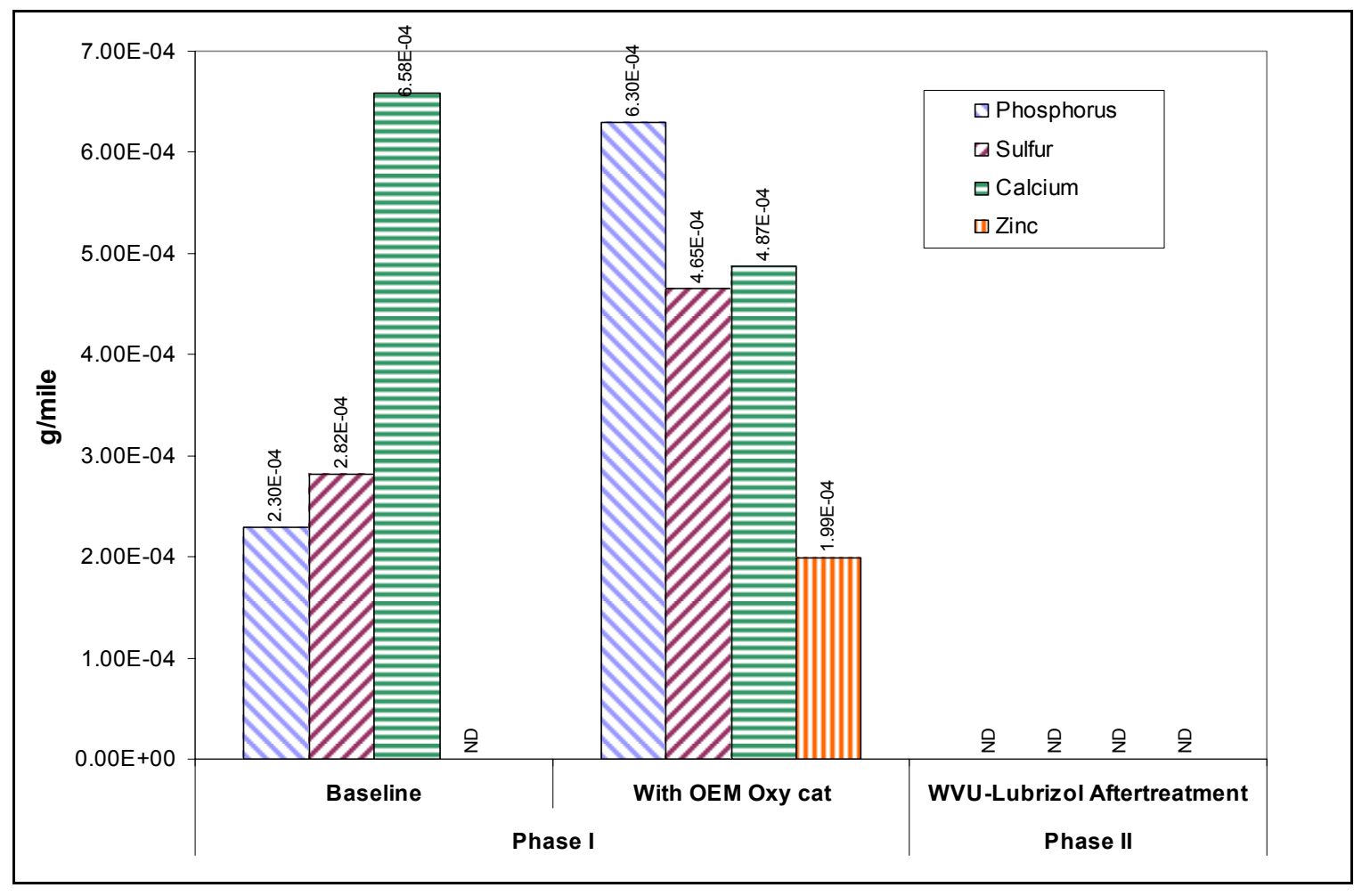

Figure 5.20 Emissions of Lube Oil Elements from Phase II vs. Phase I. 
Carbonyl samples were collected on DNPH cartridges, which were then analyzed for formaldehyde, acetaldehyde, acetone, propionaldehyde and acrolein. As shown in Figure 5.21. The oxidation catalyst significantly reduced the formaldehyde emissions, but appeared to have no effect on the acetone and propionaldehyde. The WVU-Lubrizol particulate trap and the oxidation catalyst system reduced all the carbonyl species to the background levels. This indicates that the oxidation catalyst and the catalyzed particulate filter were successful in oxidizing the carbonyls better than the oxidation catalyst alone.

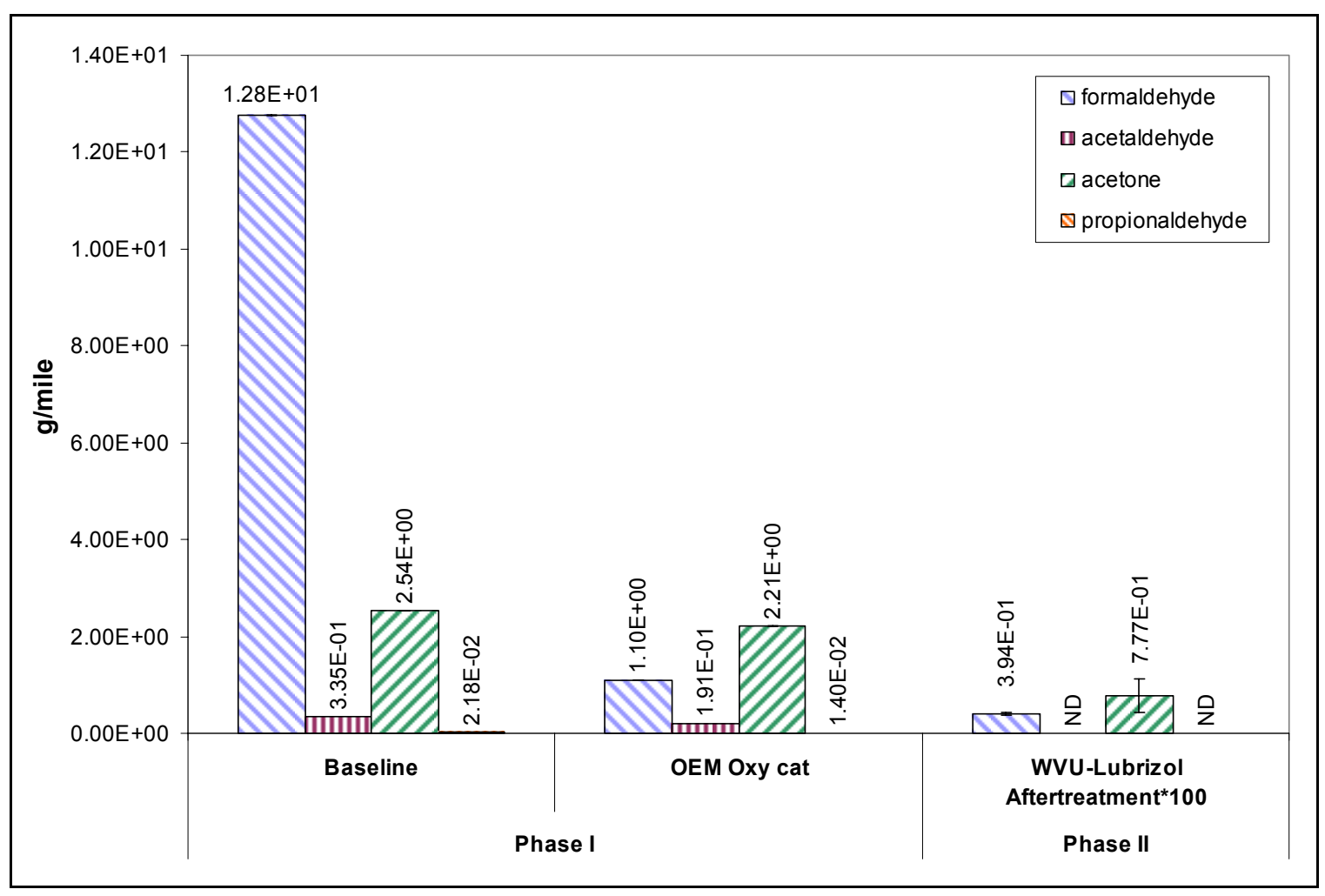

\section{Figure 5.21 Emissions of Carbonyl Compounds from Phase II vs. Phase I.}

Note: The carbonyl emission levels from the WVU-Lubrizol trap is multiplied by a factor of 100 for better visualization of the results.

Polycyclic Aromatic Hydrocarbon (PAH) emission levels were reduced significantly with the use of the WVU-Lubrizol catalyst (see Figure 5.22). The total PAH emissions levels were reduced by $80 \%$ compared to baseline emissions. However, an increase of $8 \%$ was observed when compared to emission values of OEM oxidation catalyst. This could be attributed to higher background values as the reported values are not background corrected. Naphthalene being the predominant PAH was reduced by $82 \%$ compared to baseline emissions. Since all the PAH compounds are considered to be 
carcinogenic, the WVU-Lubrizol aftertreatment device was successful in reducing emissions of these compounds in comparison to the baseline emission values. There were no detectable levels of nitro-PAH emissions from any of the three test configurations.

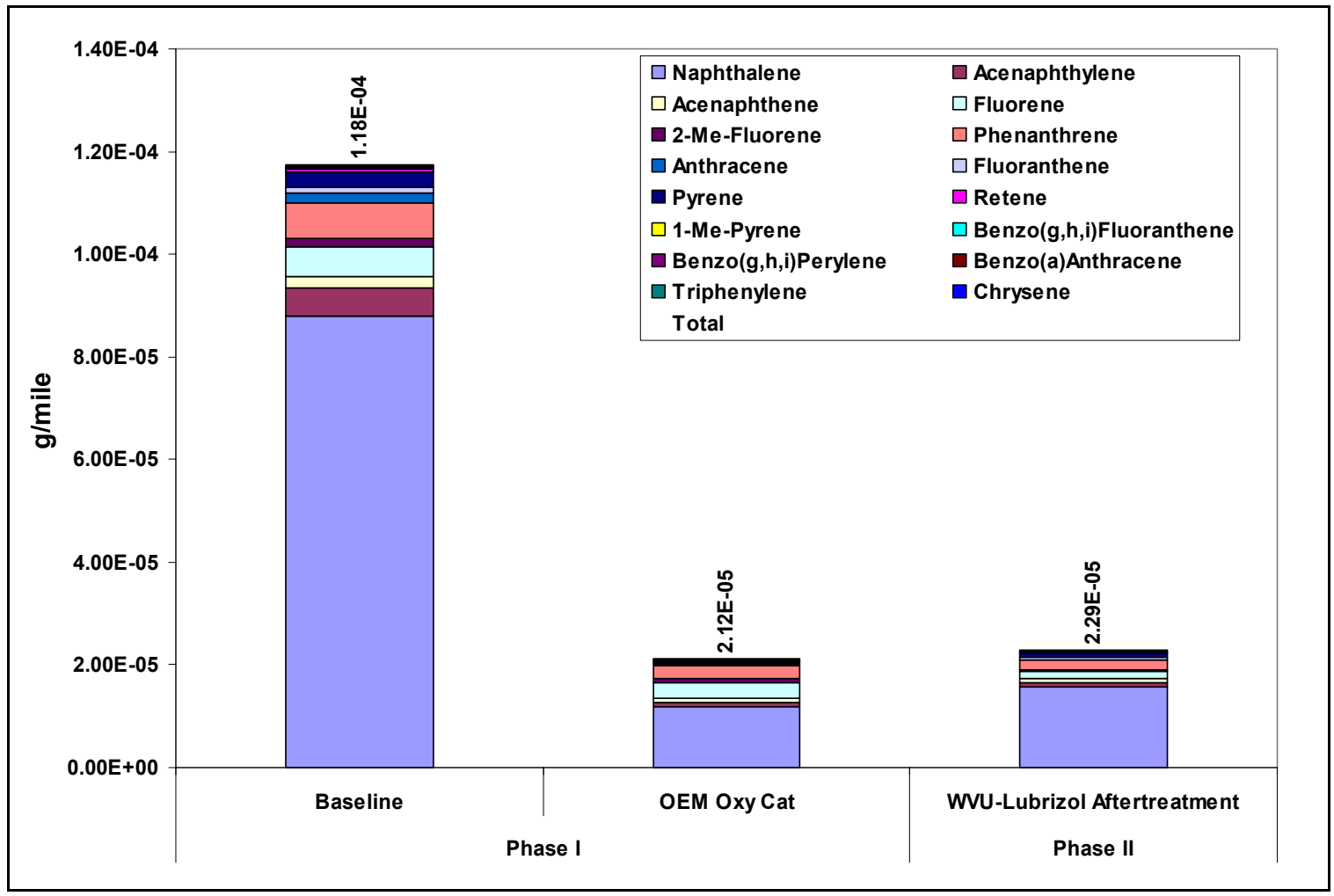

Figure 5.22 Emissions of Polycyclic Aromatic Hydrocarbons from Phase II vs. Phase I.

The toxic gas analysis included 1,3 butadiene, benzene, toluene, ethyl benzene, xylene. Both bag and canister samples were collected from the primary dilution tunnel with the bags being analyzed at the test site whereas the canister samples were analyzed in the lab at Environment Canada. Tedlar bags, which were determined to be inert for toxic gases during Phase I tests were used in Phase II toxic gas sampling. The results are shown in Figure 5.23.

The total carbon analysis results showed that WVU-Lubrizol aftertreatment device reduced the emissions of organic carbon by $72 \%$ and $34 \%$ compared to the baseline and OEM catalyst, respectively. Elemental carbon was not detected in any of the tests (see Figure 5.24). 


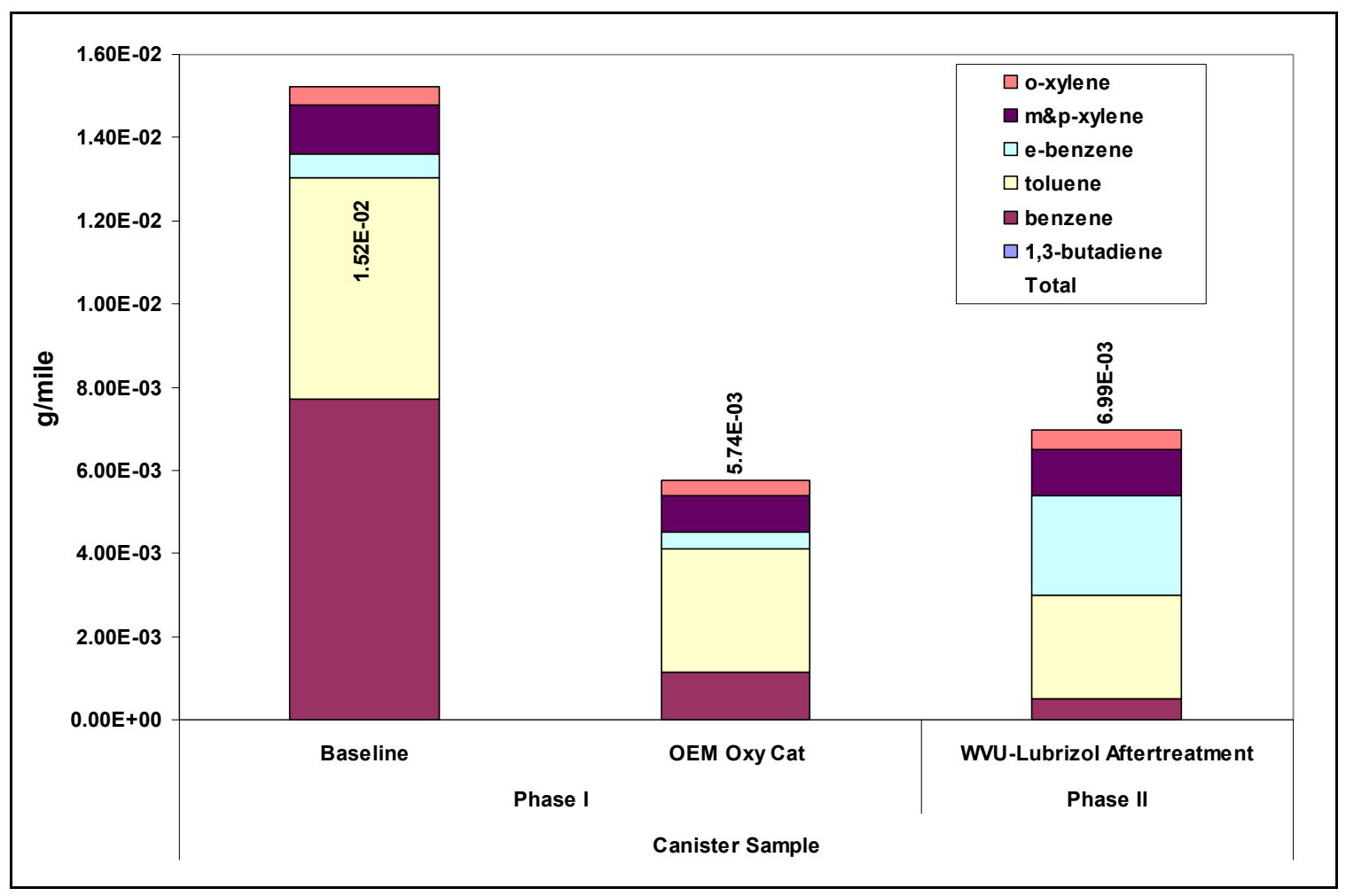

Figure 5.23 Emissions of Toxic Gases from Phase II vs. Phase I.

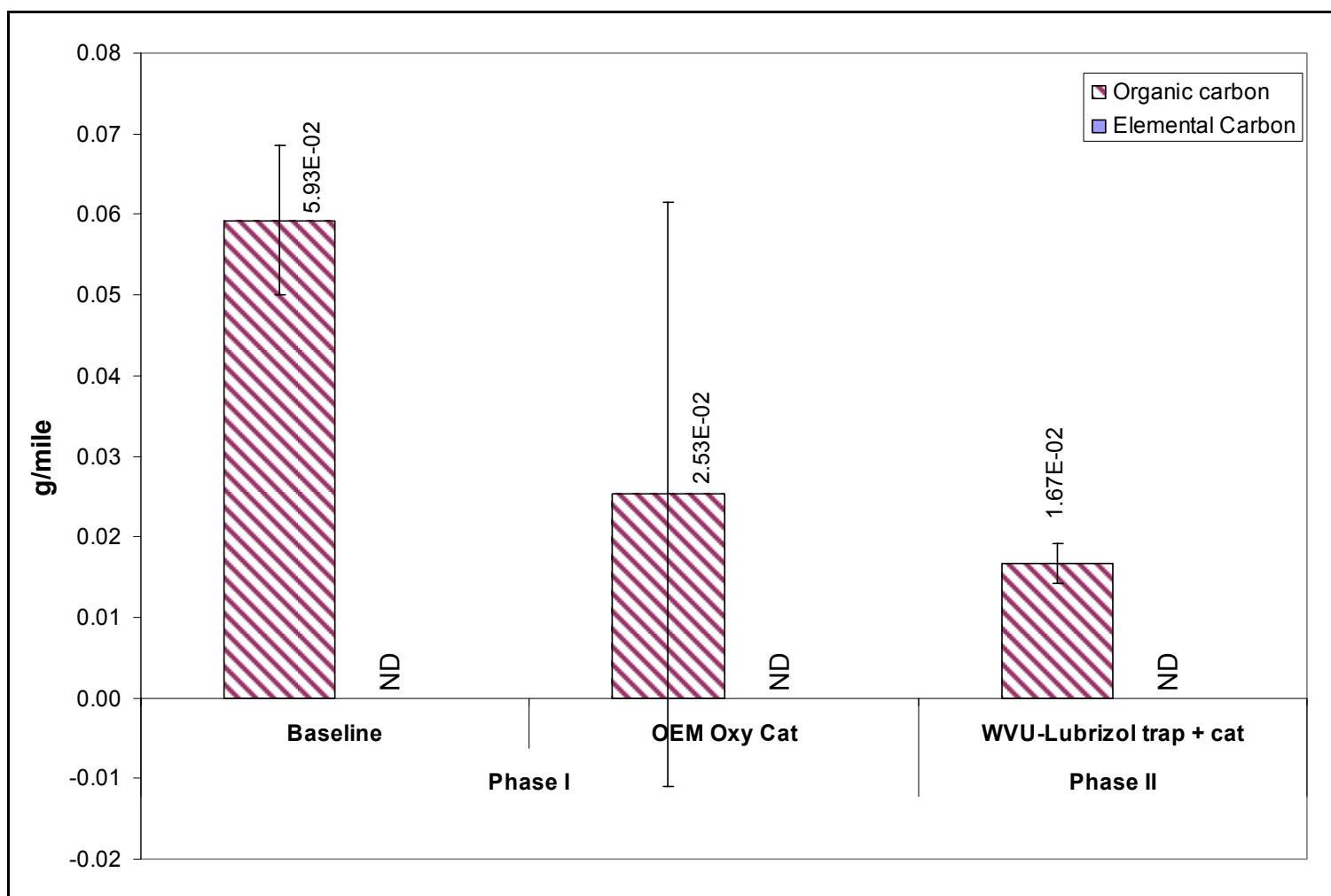

Figure 5.24 Emissions of Elemental and Organic Carbons from Phase II vs. Phase I. 
Significant reductions in size classified PM emissions were observed with the use of new WVU-Lubrizol aftertreatment device (see Figure 5.25). Results of distance specific mass emissions of $\mathrm{PM}_{10}, \mathrm{PM}_{2.5}, \mathrm{PM}_{1.0}$ and TPM are corrected for background emissions, and represent an average of three repetitive tests in Figure 5.25.

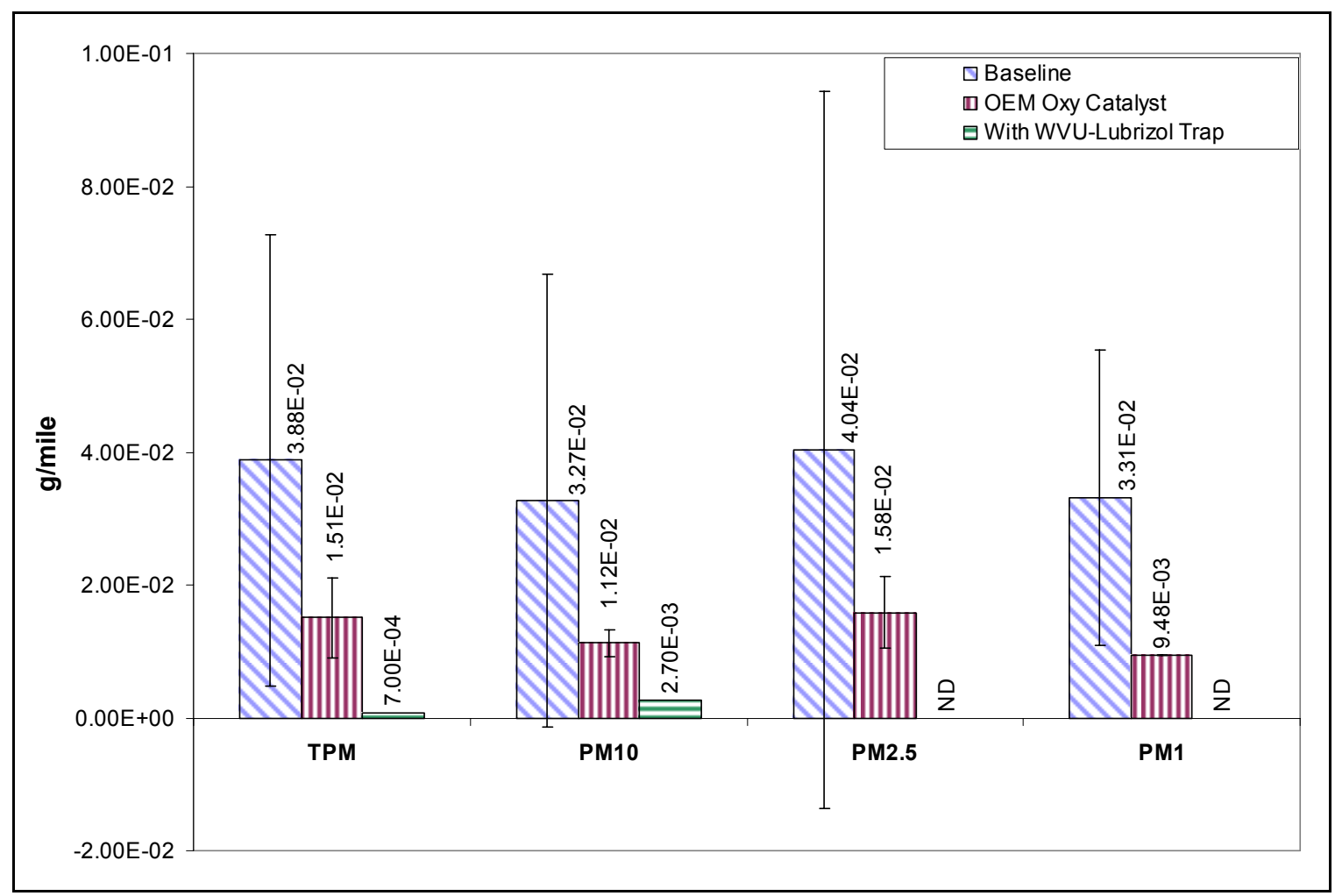

\section{Figure 5.25 Size Classified PM Emissions from Phase II vs. Phase I.}

The PM mass emissions measured in different size ranges indicated a profound decrease with the use of WVU-Lubrizol aftertreatment device, the TPM was reduced by $98 \%$ compared to baseline and by $95 \%$ compared to emissions with oxidation catalyst. Distance specific mass emissions of $\mathrm{PM}_{2.5}$ and $\mathrm{PM}_{1.0}$ were below detection limit, hence, confirming the superior PM reduction characteristics of the WVU-Lubrizol aftertreatment device.

\subsubsection{Particle Sizing Using SMPS}

During Phase II testing, PM concentrations and size distribution measurements were performed on the engine equipped with WVU Lubrizol aftertreatment device, and the data was collected over three Quad-CBD cycles and two background samples. A constant dilution ratio of 1:30 was maintained for all the tests. The vehicle was run at a 
constant speed of $25 \mathrm{mph}$ to obtain a complete particle size distribution which is shown in Figure 5.26. It shows that there was no clear size distribution of PM emissions and also the number of particles detected was very small.

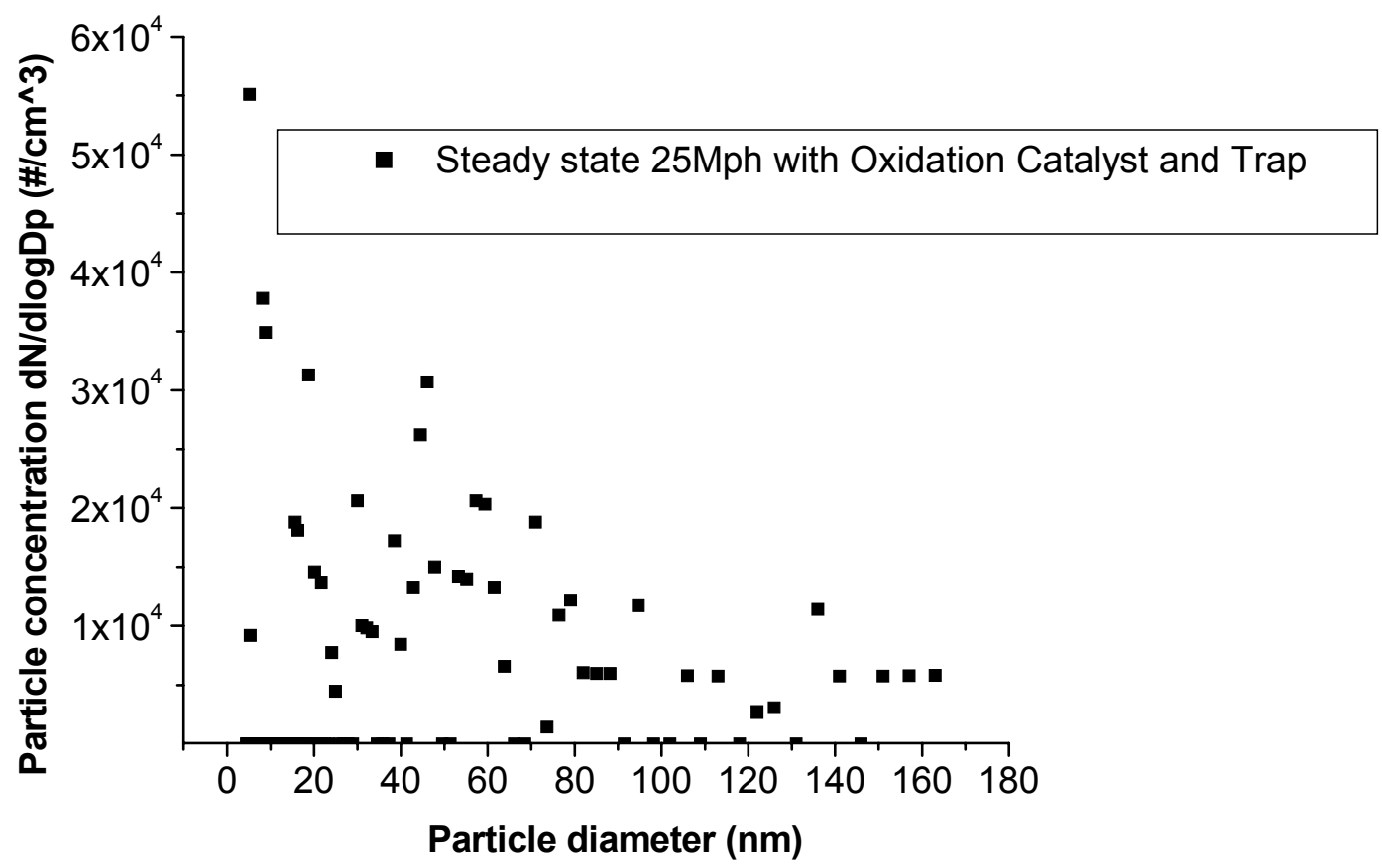

Figure 5.26 Particle Size Distributions with Oxidation Catalyst and Particulate Trap for $25 \mathrm{mph}$ Steady-state Test

The particle sizing data from all the three repeats of the steady-state tests did not present a clear size distribution and all of them matched background particle concentration which is shown in the Figure 5.27.

Three different particle sizes are usually chosen over the normal distribution. Since the particle size distribution was not very comprehensible, three peaks from the particle size distribution were selected and particle diameters corresponding to those peaks were tracked during the Quad-CBD runs. 


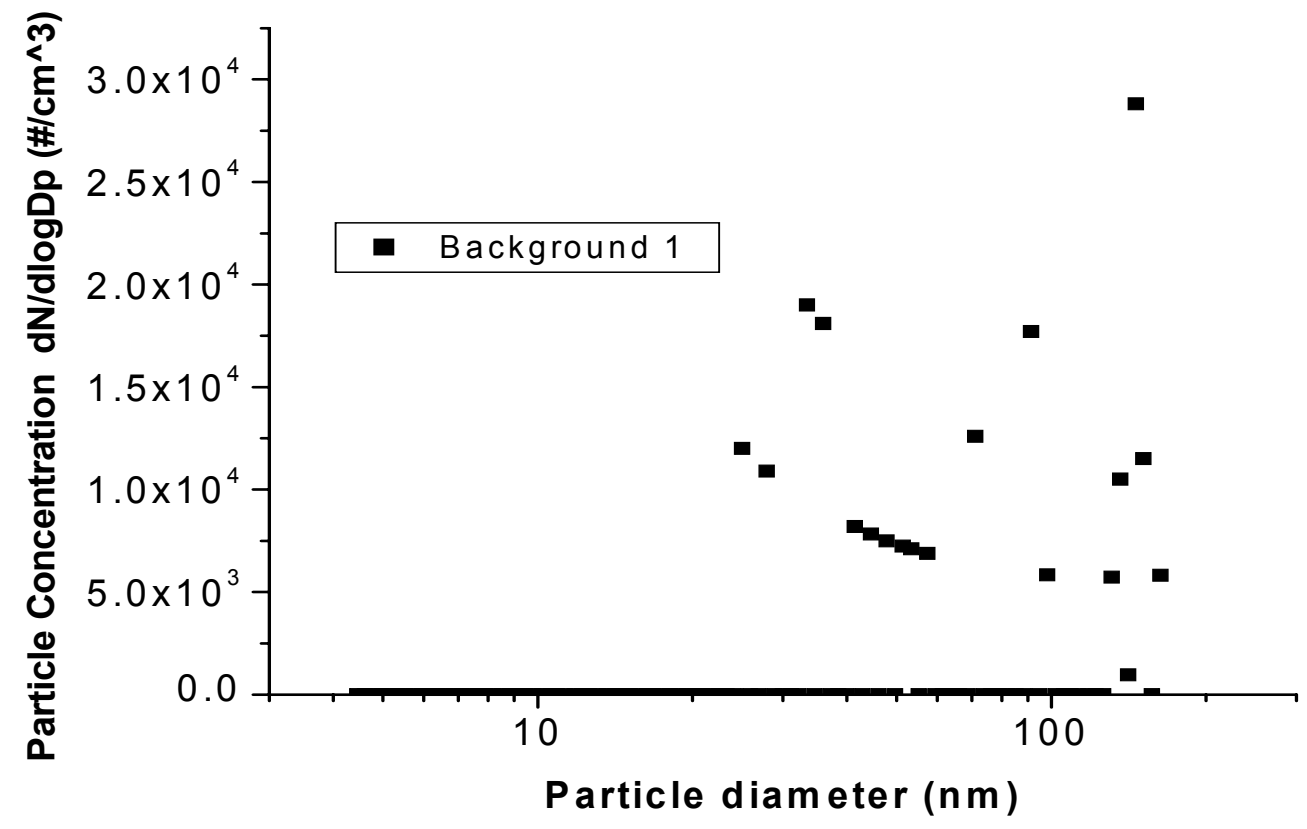

\section{Figure 5.27 Background Particle Size Distributions}

Since the oxidation catalyst and PM trap made a significant difference to the particle size distribution, the effect of the new oxidation catalyst on the particle size distributions was investigated. The vehicle was run through another steady-state with the exhaust connected to the dilution tunnel after the particulate trap, effectively by-passing the oxidation catalyst. Particle size distributions for cold and hot starts were measured and a shift in the particle size towards the nuclei mode was noted for the hot start data as seen in Figure 5.28. 


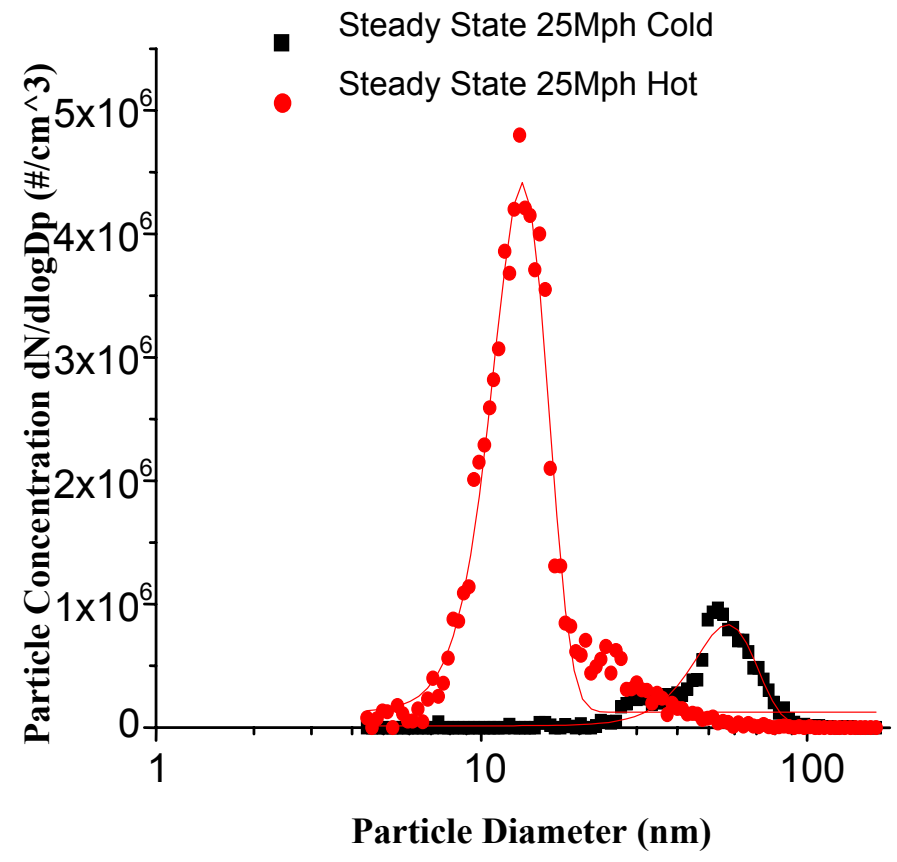

Figure 5.28 Particle Size Distributions Particulate Trap @ 25Mph

It is evident from Figure 5.28 that the concentration of PM during the cold and hot start did not change significantly, but there was a shift in the particle size from $53.3 \mathrm{~nm}$ during cold start to $13.3 \mathrm{~nm}$ during the hot start. During cold start conditions the particles of size $53.3 \mathrm{~nm}$ with a concentration of $1 \times 10^{6}$ particle $/ \mathrm{cm}^{3}$, which was well above the background level. The possibility of these particles containing solid carbon is very low owing to the fact that catalyzed particulate traps are highly efficient in removing solid particles. The larger sized PM during cold start is attributed to the lack of oxidation of heavy organics which escape through a trap that has not achieved the required light-off temperature.

A hot steady-state test, followed the cold test, and particle size distributions were measured. The median diameter obtained from the hot test was $13.3 \mathrm{~nm}$ having a concentration of $4.8 \times 10^{6}$ particles $/ \mathrm{cm}^{3}$. Since the particulate trap is effective in controlling solid particles including inorganic ash, it is likely that the $13.3 \mathrm{~nm}$ particles are nucleated volatile organics. Volatile vapors at super-saturated conditions tend to undergo homogeneous nucleation at reduced temperature in the absence of solid particles to 
adsorb onto. The source of these volatile vapors could be from burning lube oil in the combustion chamber.

Three particles of size $46.9 \mathrm{~nm}, 91.11 \mathrm{~nm}$ and $136 \mathrm{~nm}$ were chosen from the steadystate particle size distribution data corresponding to peak concentrations. These particles were tracked during the quad CBD transient testing from the vehicle equipped with WVU Lubrizol aftertreatment device and the concentration of these particles are shown in Figure 5.29-5.31.

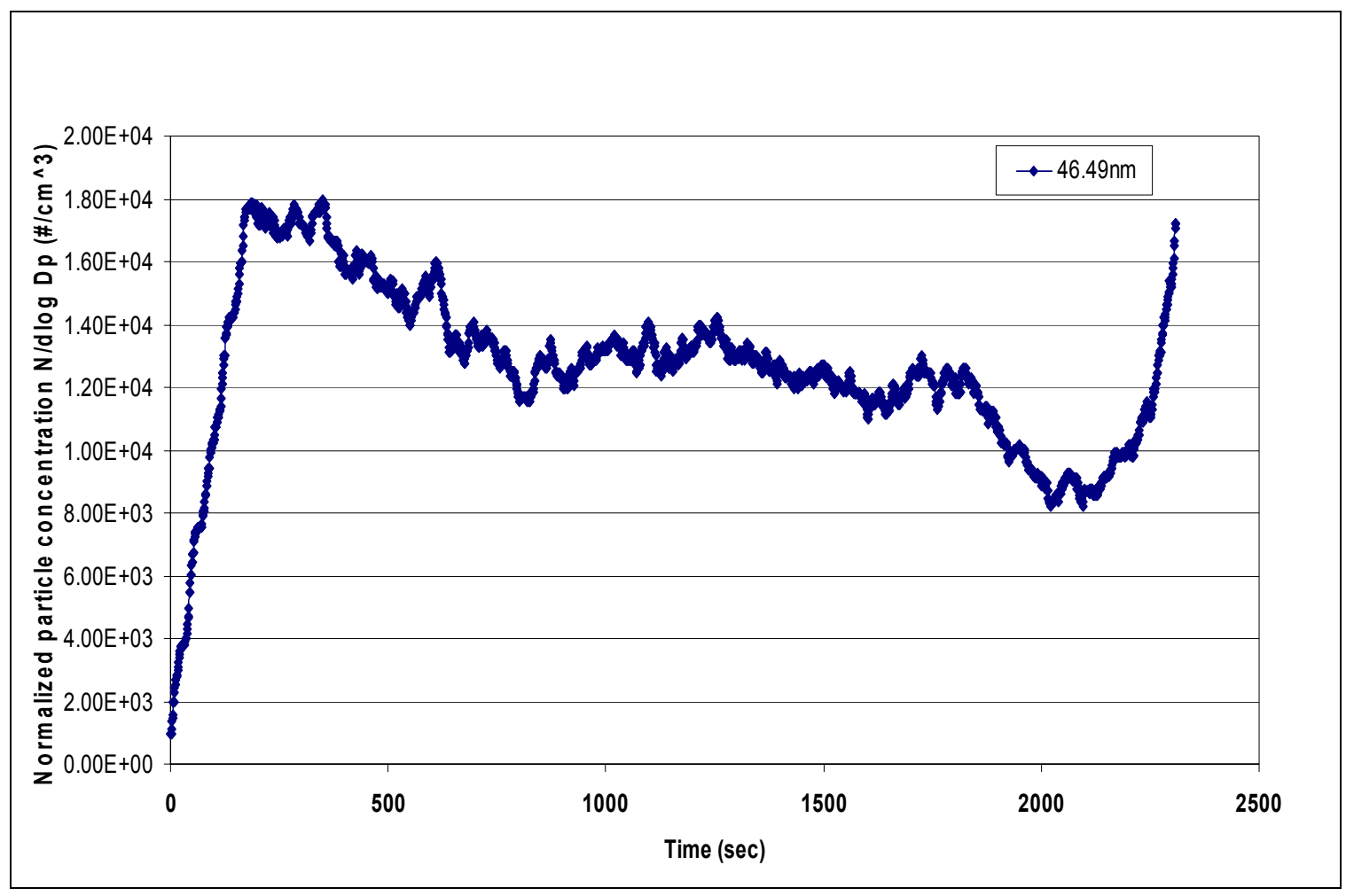

Figure 5.29 Concentration of $46.49 \mathrm{~nm}$ Particles from the Vehicle equipped with WVU-Lubrizol Exhaust Aftertreatment Device, over QCBD cycle. 


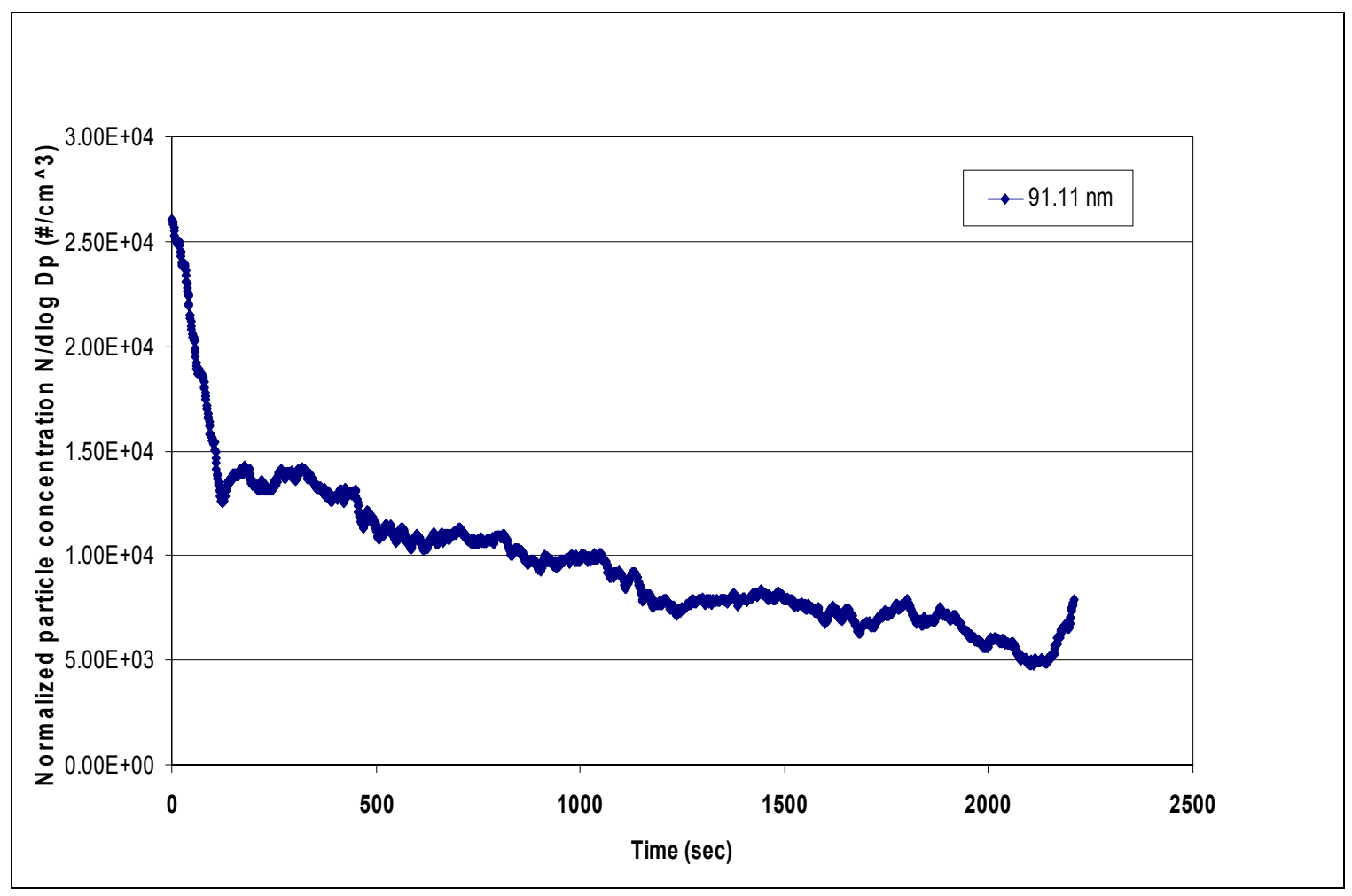

Figure 5.30 Concentration of $91.11 \mathrm{~nm}$ Particles from the Vehicle Equipped with WVU-Lubrizol ExhaustAftertreatment Device, over QCBD cycle.

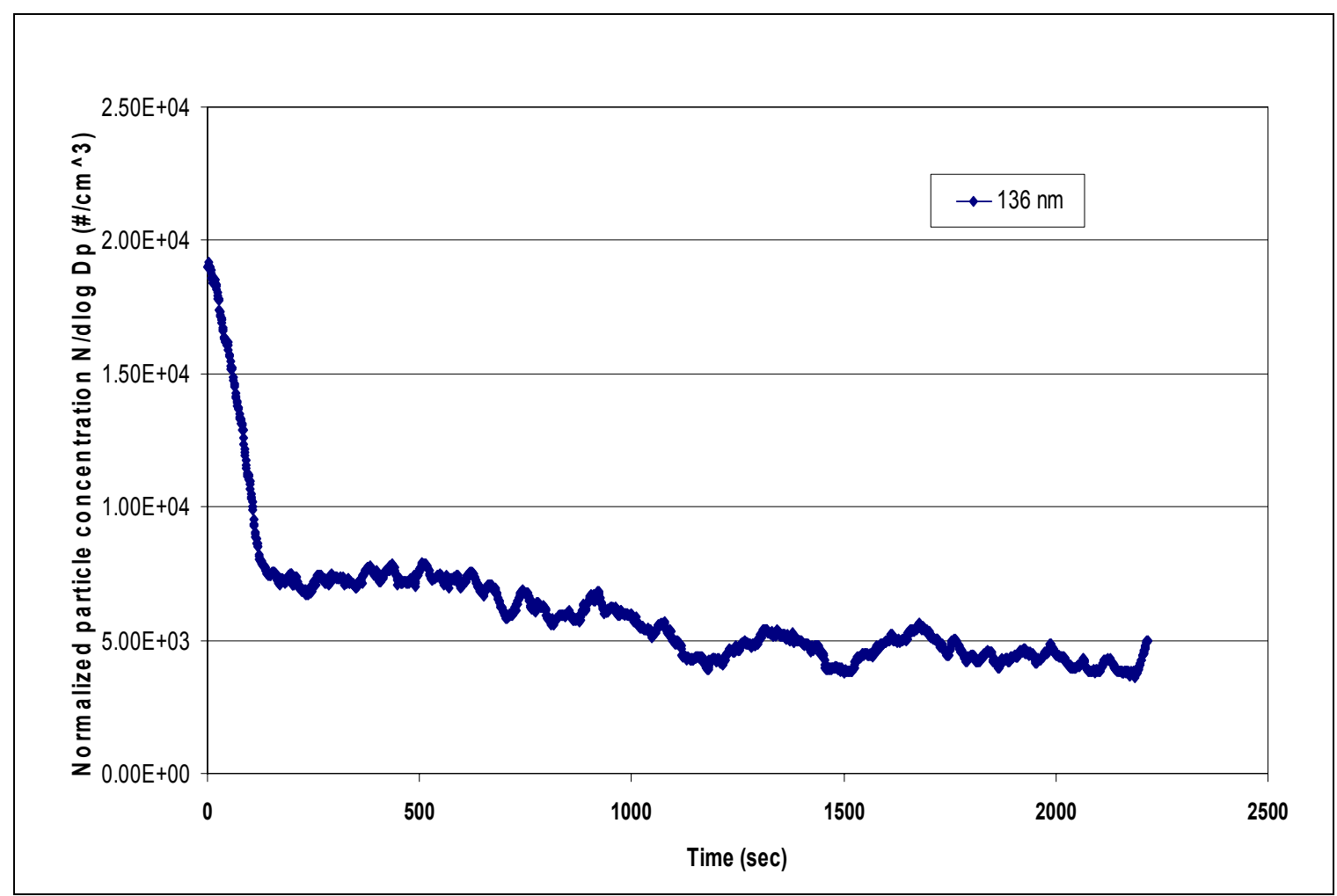

Figure 5.31 Concentration of 136nm Particles from the Vehicle Equipped with WVU-Lubrizol Exhaust Aftertreatment Device, over QCBD cycle. 
It is evident from these results that the concentration all three particle sizes, chosen from the steady-state data with the WVU-Lubrizol aftertreatment device in place, did not respond in sympathy with the transient operation of the vehicle. The measured concentrations were similar to background levels. The two particle sizes chosen from the steady-state operation of the vehicle retrofitted with only the particulate trap followed the transients and the results are shown in Figure 5.32-5.33.

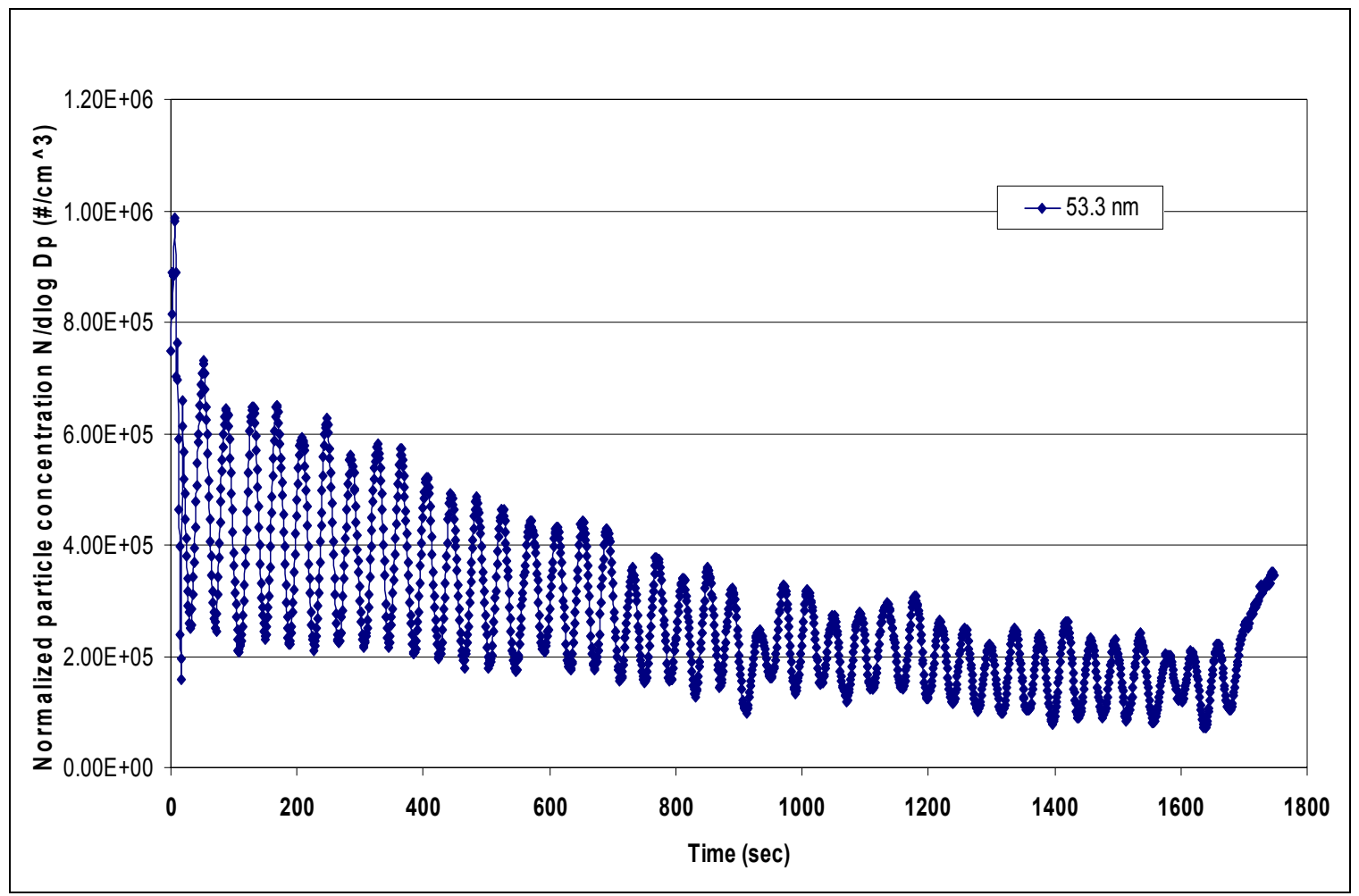

Figure 5.32 Concentrations of 53.3nm Particles from the Vehicle Equipped with only the Particulate Trap, over QCBD cycle. 


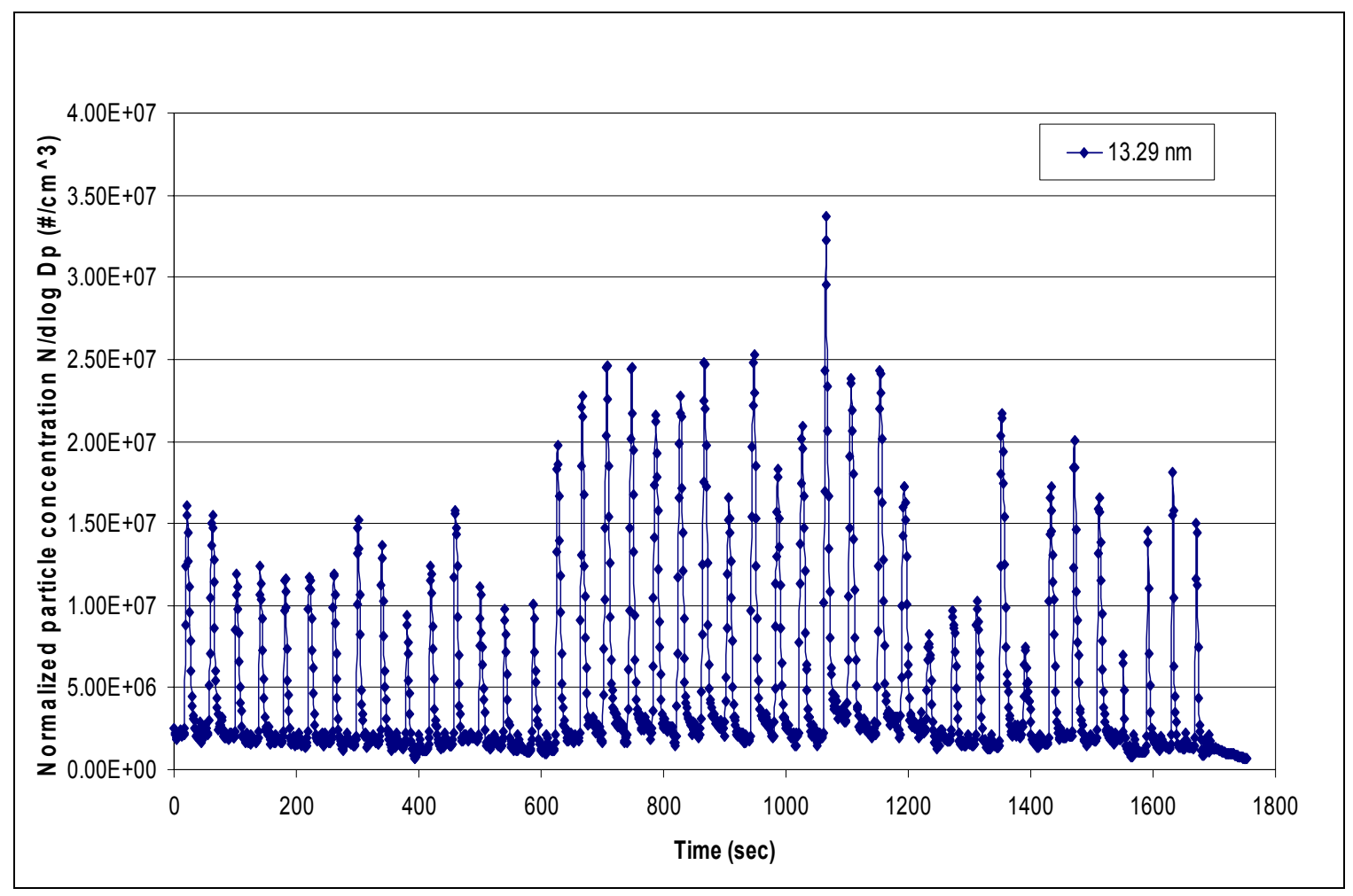

Figure 5.33 Concentrations of $13.29 \mathrm{~nm}$ Particles from the vehicle equipped with only the Particulate Trap, over QCBD cycle.

The concentration of $53.3 \mathrm{~nm}$ particles varied in accordance with the transient operation of the vehicle and was reduced by $25 \%$ when compared to the cold start steadystate particle distribution data (see Figure 5.32). The particles of size $13.3 \mathrm{~nm}$ were emitted in high numbers during acceleration. These particles which are mostly volatile organics can be eliminated using an oxidation catalyst. The formation of these nanoparticles from the volatile organic compounds by homogeneous nucleation, demonstrates the effectiveness of a particulate trap in reducing solid particles.

Variation in the concentration of particles of size $19 \mathrm{~nm}$ from the vehicle with three different aftertreatment configurations is shown in Figure 5.34. 


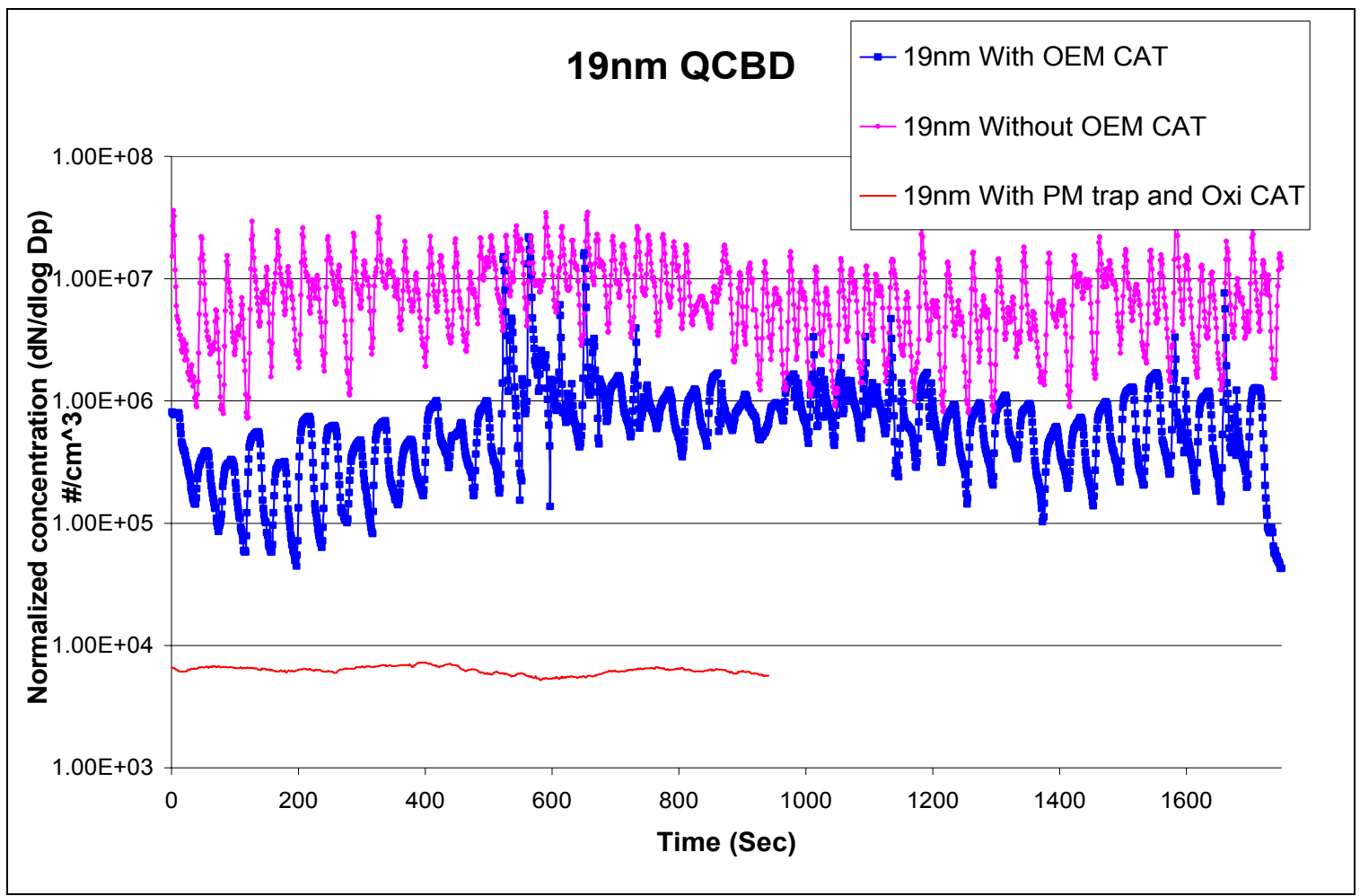

Figure 5.34 Variation in the concentration of $19 \mathrm{~nm}$ Particles for three different vehicle configurations, over QCBD cycle.

The comparison clearly illustrates the fact that although the OEM catalyst drops the concentration of the nanoparticles by an order of magnitude, it does not totally eliminate them, whereas a particulate trap together with an oxidation catalyst reduces the nanoparticle concentrations equal to background levels.

\subsection{Phase III: Emissions Results.}

The transit bus on which the WVU-Lubrizol aftertreatment device was installed and tested during the Phase II experiments was returned back to its regular revenue service. The performance of the exhaust aftertreatment device was demonstrated in the field for six months. Infield demonstration of the device, after its development phase, was an integral part of the total design and development cycle. The new aftertreatment device was subjected to the rigors of the real world to verify whether there were any changes in the drivability, vehicle handling, change in the engine power, and any structural failure of the device. To control the regeneration cycle of the particulate trap a closed loop control system was used to de-rate the engine and alarm the driver to 
slowdown when the backpressure on the engine would exceed a certain threshold limit. This control system was also verified to perform its design function.

After six months of in-field demonstration the exhaust aftertreatment device was tested once again to verify any deterioration in the emission reduction performance. Visual inspections were made to determine if any external damage or leaks had developed in the catalytic trap and oxidation catalyst housing.

\subsubsection{Regulated Emissions}

The WVU-Lubrizol aftertreatment device had accumulated about 32,828 miles during the demonstration period. The device performed satisfactorily without any instances of breakdown or change in vehicle performance, which included fuel consumption, engine power, drivability, and maintenance due to the new device. The exhaust aftertreatment device was retested and measurements of both regulated and nonregulated emissions were made along with PM sizing. In Phase III, the regulated emissions from the WVU-Lubrizol emission reduction system were compared with the baseline emissions (vehicle without any aftertreatment system) measured in Phase III in order to account for the shift in the emission performance of the engine over the period of six months. In the case of non-regulated emissions the Phase III results were compared with the Phase I and II results to determine any deterioration in the performance of the exhaust aftertreatment device. A comparison of regulated emissions between baseline engine and the engine with WVU-Lubrizol aftertreatment device is shown in Figure 5.35.

The results indicate that carbon monoxide was reduced by $99 \%$, NOx was reduced by $15 \%$, total hydrocarbons were reduced by $16 \%$ and the TPM mass was reduced by $90 \%$. The emissions reductions in Phase III were comparable with the emissions reduction observed in Phase II test with the newly installed WVU-Lubrizol aftertreatment system. Table 5.2 illustrates the percentage reductions of regulated emissions observed during Phase II and Phase III tests with WVU-Lubrizol aftertreatment device against the baseline engine. 


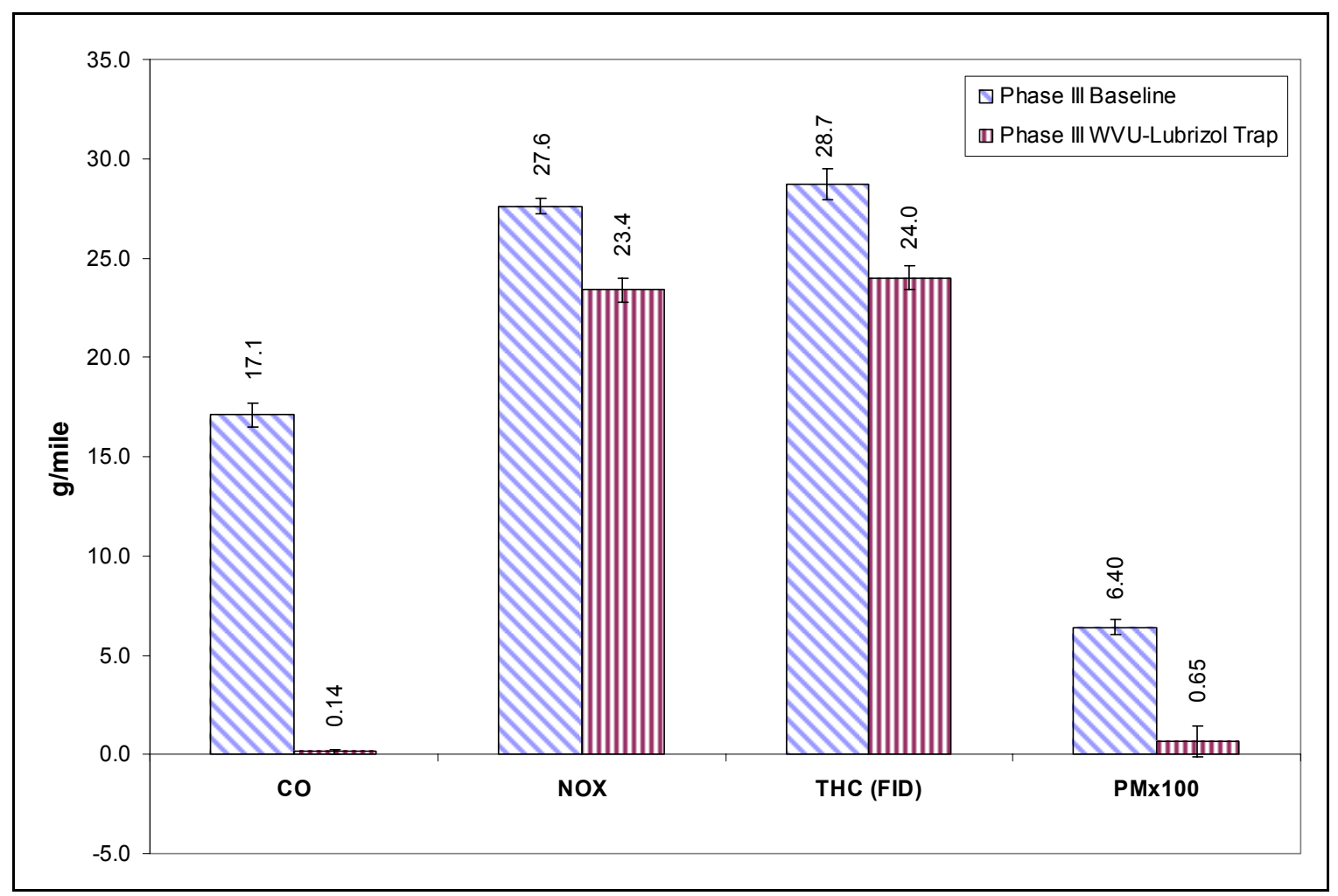

Figure 5.35 Regulated Emissions in Phase III Testing

A $15 \%$ reduction in the emissions of NOx by the WVU-Lubrizol exhaust aftertreatment device was observed although the system was not designed to reduce oxides of nitrogen. Such reductions are attributed to the reducing atmospheres, created by increased fueling rates, where NOx is reduced to nitrogen by oxidizing the excess hydrocarbons and, in part, to increased exhaust backpressures by the particulate filter. High exhaust backpressures increase the retention of exhaust gases in the cylinder inhibiting the in-cylinder formation of NOx by displacing excess oxygen in the intake air with inert gases.

Table 5.3 Reduction in Emissions Observed in New and Aged Exhaust Aftertreatment Device

\begin{tabular}{|c|c|c|c|c|c|c|}
\hline \multirow{2}{*}{$\begin{array}{c}\text { Regulated } \\
\text { Emissions }\end{array}$} & \multicolumn{3}{|c|}{ Phase II (g/mile) } & \multicolumn{3}{c|}{ Phase III (g/mile) } \\
\cline { 2 - 7 } & Baseline & $\begin{array}{c}\text { WVU-Lubrizol } \\
\text { Trap }\end{array}$ & $\begin{array}{c}\% \\
\text { Reduction }\end{array}$ & Baseline & $\begin{array}{c}\text { WVU-Lubrizol } \\
\text { Trap }\end{array}$ & $\begin{array}{c}\% \\
\text { Reduction }\end{array}$ \\
\hline $\mathrm{CO}$ & $1.32 \mathrm{E}+01$ & $1.30 \mathrm{E}-01$ & $99 \%$ & $1.71 \mathrm{E}+01$ & $1.40 \mathrm{E}-01$ & $99 \%$ \\
\hline $\mathrm{NOx}$ & $3.77 \mathrm{E}+01$ & $2.10 \mathrm{E}+01$ & $44 \%$ & $2.76 \mathrm{E}+01$ & $2.34 \mathrm{E}+01$ & $15 \%$ \\
\hline $\mathrm{GCHC}$ & $2.11 \mathrm{E}+01$ & $1.11 \mathrm{E}+01$ & $47 \%$ & $2.87^{\mathrm{a}} \mathrm{E}+01$ & $2.40^{\mathrm{a}} \mathrm{E}+01$ & $16 \%$ \\
\hline $\mathrm{PM}^{*} 100$ & $3.90 \mathrm{E}+00$ & $7.00 \mathrm{E}-02$ & $98 \%$ & $6.40 \mathrm{E}+00$ & $6.50 \mathrm{E}-01$ & $90 \%$ \\
\hline
\end{tabular}

Note: (a) refers to total hydrocarbons (THC) measured using flame ionization detector (FIDHC) 


\subsubsection{Non-Regulated Emissions}

The performance of the WVU-Lubrizol aftertreatment device after six months of in-use demonstration period was evaluated by comparing the results of non-regulated emissions from Phase III with Phase II tests.

Elemental analysis was performed to detect emissions of metals associated with the engine wear, fuel and lube oil additives. X-ray Fluorescence spectrometer was used for elemental analysis. Samples from the newly installed WVU-Lubrizol aftertreatment device as well as from the same device after an in-field demonstration yielded a result of "none detected" for all the elements analyzed (see Table 5.4)

Table 5.4 Result from X-Ray Fluorescence Elemental Analysis

\begin{tabular}{|c|c|c|c|c|}
\hline \multirow{2}{*}{ Elements } & \multicolumn{2}{|c|}{ Phase I (g/mile) } & Phase II (g/mile) & Phase III (g/mile) \\
\cline { 2 - 5 } & Baseline & OEM Oxy cat & WVU-Lubrizol Trap & WVU-Lubrizol Trap \\
\hline Aluminum-Al & $4.30 \mathrm{E}-04$ & $9.23 \mathrm{E}-04$ & $0.00 \mathrm{E}+00$ & $0.00 \mathrm{E}+00$ \\
\hline Silicon-Si & $1.36 \mathrm{E}-03$ & $1.47 \mathrm{E}-03$ & $0.00 \mathrm{E}+00$ & $0.00 \mathrm{E}+00$ \\
\hline Phosphorus-P & $2.30 \mathrm{E}-04$ & $6.30 \mathrm{E}-04$ & $0.00 \mathrm{E}+00$ & $0.00 \mathrm{E}+00$ \\
\hline Sulfur-S & $2.82 \mathrm{E}-04$ & $4.65 \mathrm{E}-04$ & $0.00 \mathrm{E}+00$ & $0.00 \mathrm{E}+00$ \\
\hline Chlorine-Cl & $0.00 \mathrm{E}+00$ & $3.27 \mathrm{E}-04$ & $0.00 \mathrm{E}+00$ & $0.00 \mathrm{E}+00$ \\
\hline Potassium-K & $5.26 \mathrm{E}-04$ & $2.32 \mathrm{E}-04$ & $0.00 \mathrm{E}+00$ & $0.00 \mathrm{E}+00$ \\
\hline Calcium-Ca & $6.58 \mathrm{E}-04$ & $4.87 \mathrm{E}-04$ & $0.00 \mathrm{E}+00$ & $0.00 \mathrm{E}+00$ \\
\hline Titanium-Ti & $0.00 \mathrm{E}+00$ & $2.99 \mathrm{E}-04$ & $0.00 \mathrm{E}+00$ & $0.00 \mathrm{E}+00$ \\
\hline Chromium-Cr & $0.00 \mathrm{E}+00$ & $1.78 \mathrm{E}-04$ & $0.00 \mathrm{E}+00$ & $0.00 \mathrm{E}+00$ \\
\hline Manganese-Mn & $9.53 \mathrm{E}-05$ & $0.00 \mathrm{E}+00$ & $0.00 \mathrm{E}+00$ & $0.00 \mathrm{E}+00$ \\
\hline Iron-Fe & $1.23 \mathrm{E}-03$ & $3.95 \mathrm{E}-04$ & $0.00 \mathrm{E}+00$ & $0.00 \mathrm{E}+00$ \\
\hline Cobalt-Co & $7.38 \mathrm{E}-05$ & $7.63 \mathrm{E}-05$ & $0.00 \mathrm{E}+00$ & $0.00 \mathrm{E}+00$ \\
\hline Barium-Ba & $1.06 \mathrm{E}-04$ & $1.35 \mathrm{E}-04$ & $0.00 \mathrm{E}+00$ & $0.00 \mathrm{E}+00$ \\
\hline Nickel-Ni & $0.00 \mathrm{E}+00$ & $3.10 \mathrm{E}-05$ & $0.00 \mathrm{E}+00$ & $0.00 \mathrm{E}+00$ \\
\hline Copper-Cu & $0.00 \mathrm{E}+00$ & $2.31 \mathrm{E}-04$ & $0.00 \mathrm{E}+00$ & $0.00 \mathrm{E}+00$ \\
\hline Zinc-Zn & $0.00 \mathrm{E}+00$ & $1.99 \mathrm{E}-04$ & $0.00 \mathrm{E}+00$ & $0.00 \mathrm{E}+00$ \\
\hline Lanthanum-La & $1.75 \mathrm{E}-04$ & $1.18 \mathrm{E}-04$ & $0.00 \mathrm{E}+00$ & $0.00 \mathrm{E}+00$ \\
\hline Neodymium-Nd & $2.48 \mathrm{E}-04$ & $0.00 \mathrm{E}+00$ & $0.00 \mathrm{E}+00$ & $0.00 \mathrm{E}+00$ \\
\hline
\end{tabular}

As mentioned earlier there was an increased emission of silicon and aluminum from oxidation catalyst in the Phase I test due to the structural deterioration of the catalyst substrate. The result in the table confirms the performance of the WVU-Lubrizol did not decrease after accumulating 32,828 miles over a period of six months. 
The reduction of carbonyl compounds from the WVU-Lubrizol aftertreatment device after the demonstration period were compared with Phase I and Phase II results to verify any deterioration in the performance of the novel aftertreatment device (see Figure 5.36).

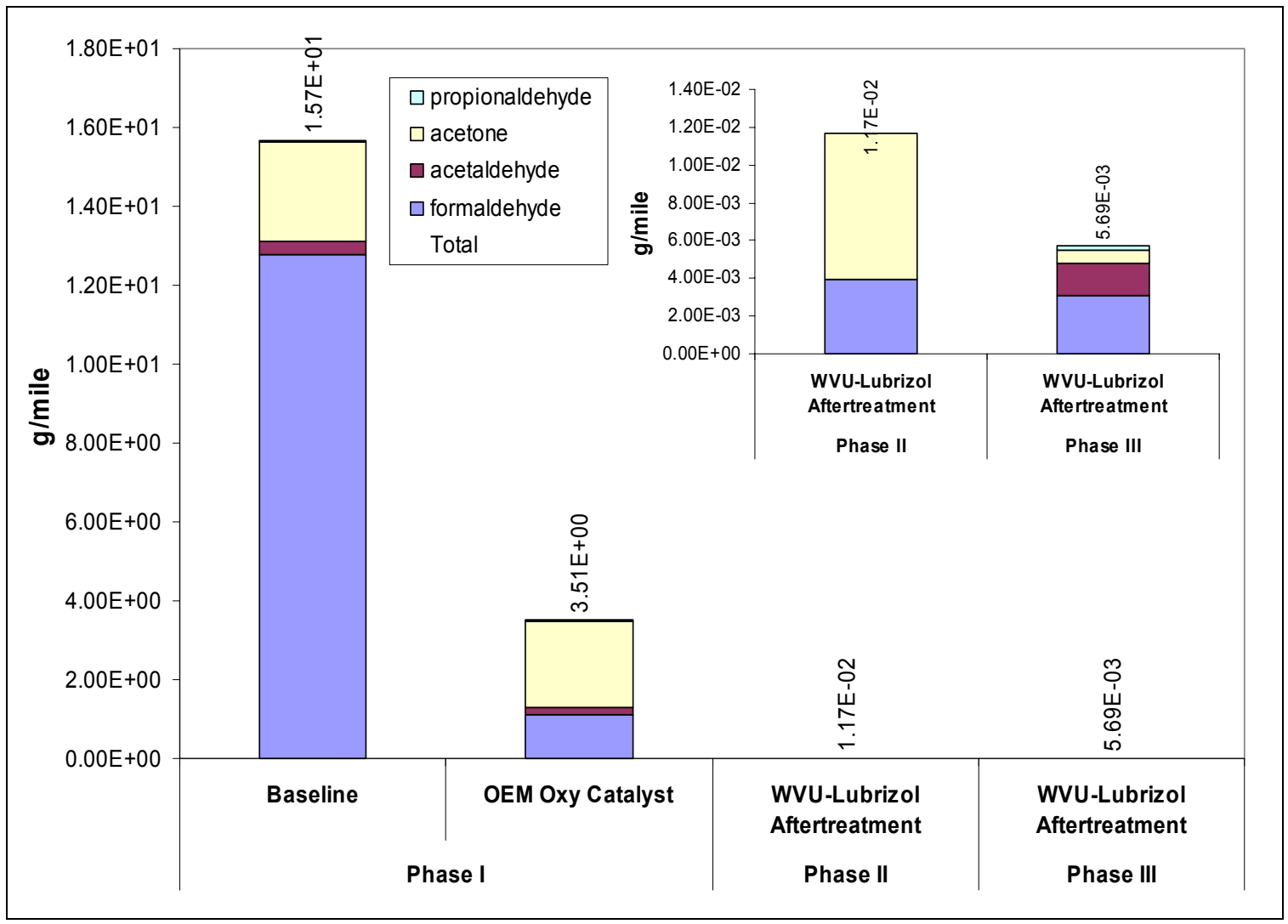

Figure 5.36 Emissions of Carbonyl Compounds in Phase III compared to Phase I and Phase II.

The results indicate that the performance of the aged aftertreatment device improved when compared to reductions that were achieved by the newly installed device. Emissions of acetaldehyde and acetone were reduced by $22 \%$ and $90 \%$, respectively by the aged aftertreatment device when compared to the new device. Total carbonyl emissions were reduced by $51 \%$ by the aged aftertreatment device in comparison to the newly installed device.

Polycyclic aromatic hydrocarbons which are considered as carcinogenic were analyzed in the Phase III tests to verify any change in the reduction of these compounds by the aged aftertreatment device. The results comparing the PAH emissions from Phase I, Phase II and Phase III is shown in Figure 5.37. 


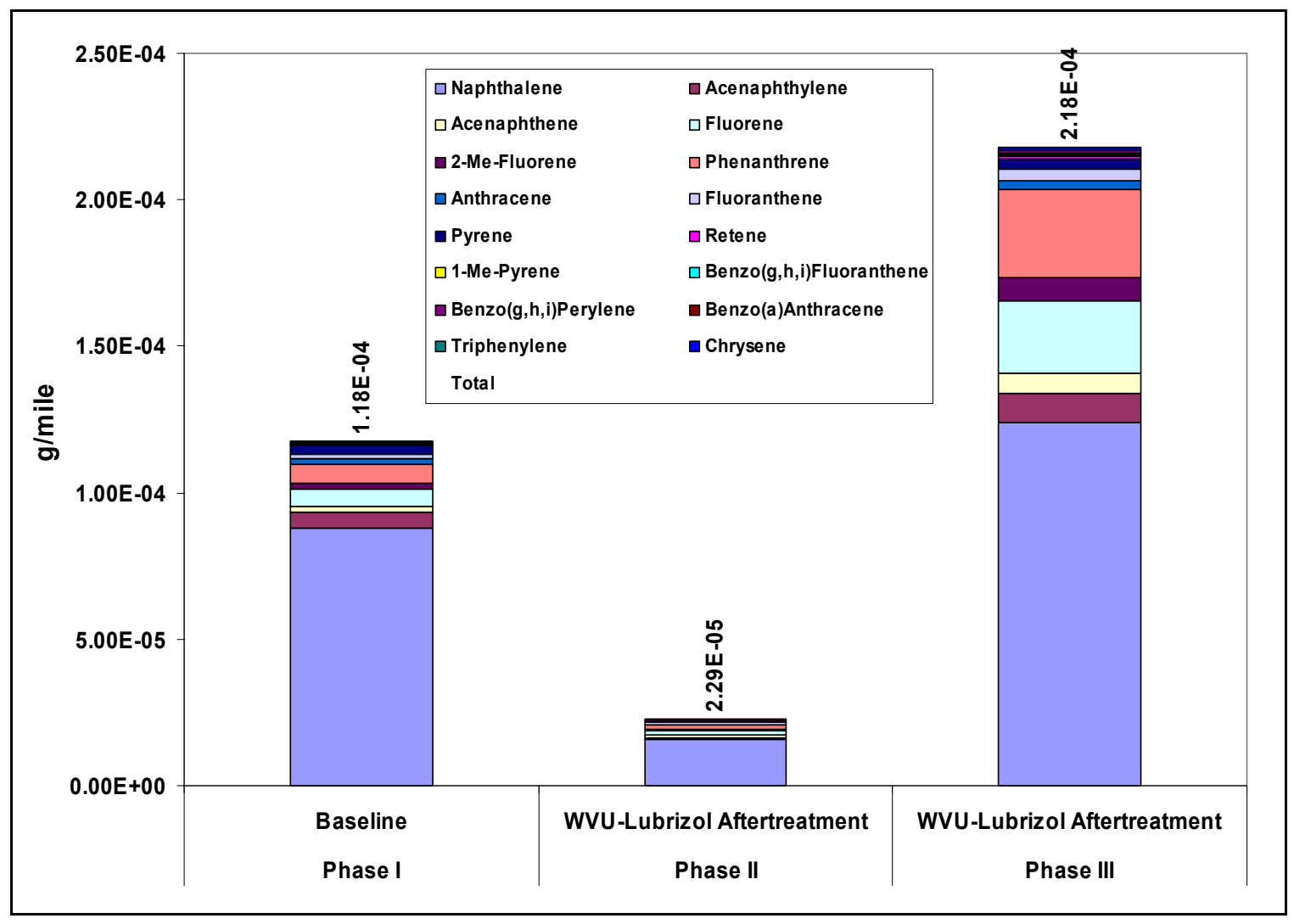

Figure 5.37 Emissions of Polycyclic Aromatic Hydrocarbons in Phase III compared to Phase I and Phase II.

Results indicate that the total PAH emissions increased from the aged WVULubrizol aftertreatment device in comparison to the new device. Particularly emissions of naphthalene, fluorene and phenanthrene, increased in the Phase III testing. It should be noted that even though the PAH emissions show an increase, the absolute value of distance specific emissions are extremely small. It is likely that errors associated with sampling and the detection of low concentrations of PAHs could have contributed to the difference in Phase II and Phase III results. It should be noted that PAH samples collected during Phase I and Phase II testing was a composite sample of three quad CBDs collected on a single media, whereas in Phase III separate media were used for each quad CBD.

The toxic gases, which included 1,3 butadiene, benzene, toluene, ethyl-benzene, m\&p xylene and o-xylene were sampled in same kind of Tedlar bags that were used during Phase II testing. Figure 5.38 shows a comparison of toxic gas emissions from Phase II and Phase III bag samples. 


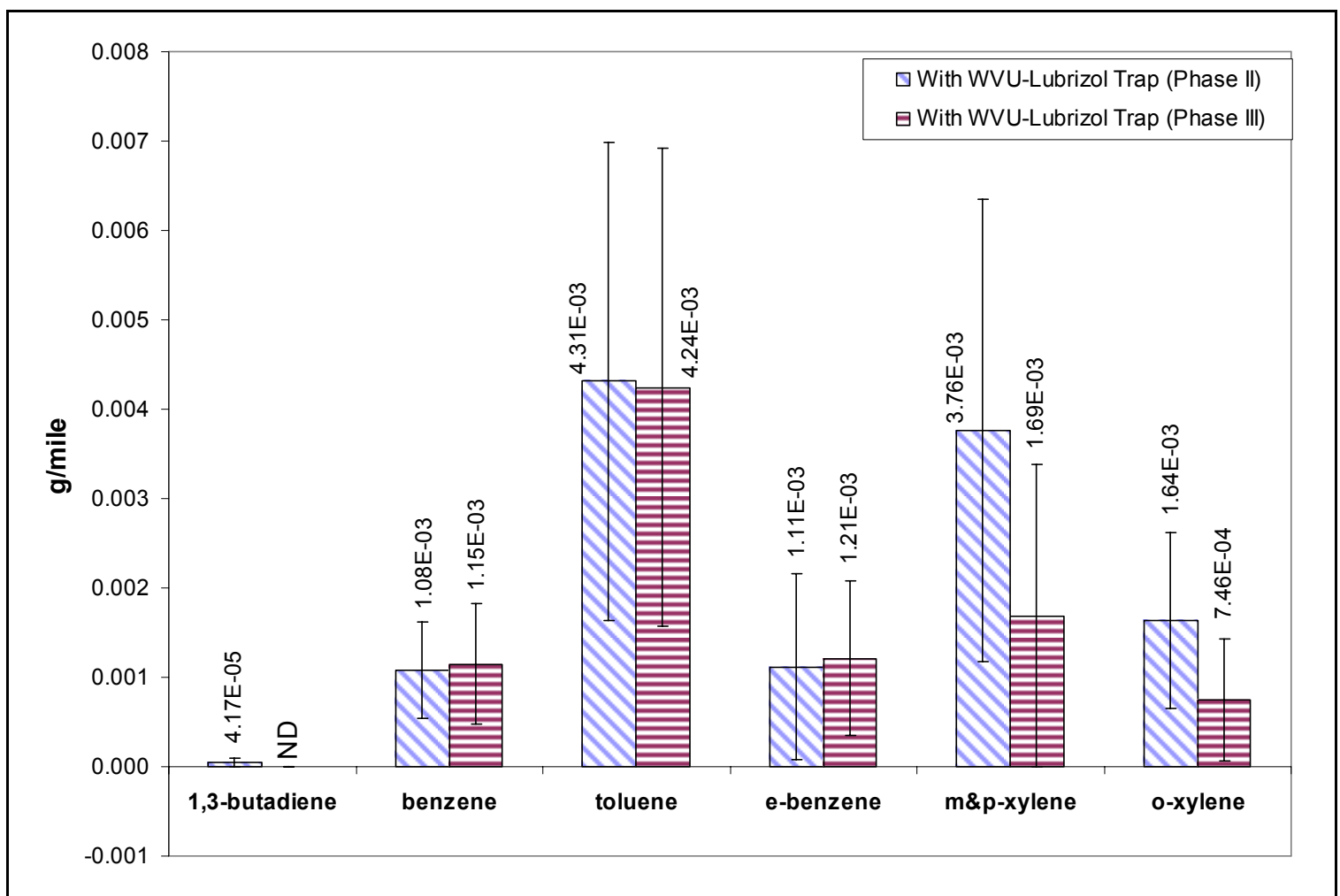

Figure 5.38 Emissions of Toxic Gases from Onsite Analysis in Phase III compared to Phase II.

Emissions of toluene were reduced by $11 \%$, m\&p xylene and o-xylene were reduced by $59 \%$ when compared to Phase II results. The emission reduction of benzene and ethyl-benzene was equal to or better than the Phase II results. The Phase III onsite analysis of toxic emissions were not compared with Phase I baseline emissions because the Tedlar bags used in Phase I reacted with the gas yielding lower values. Emissions of toxic gases determined from the canister samples in Phase III were compared with baseline emissions from Phase I, and with newly installed WVU-Lubrizol aftertreatment device in Phase II. The comparison of results is shown in Figure 5.39. 


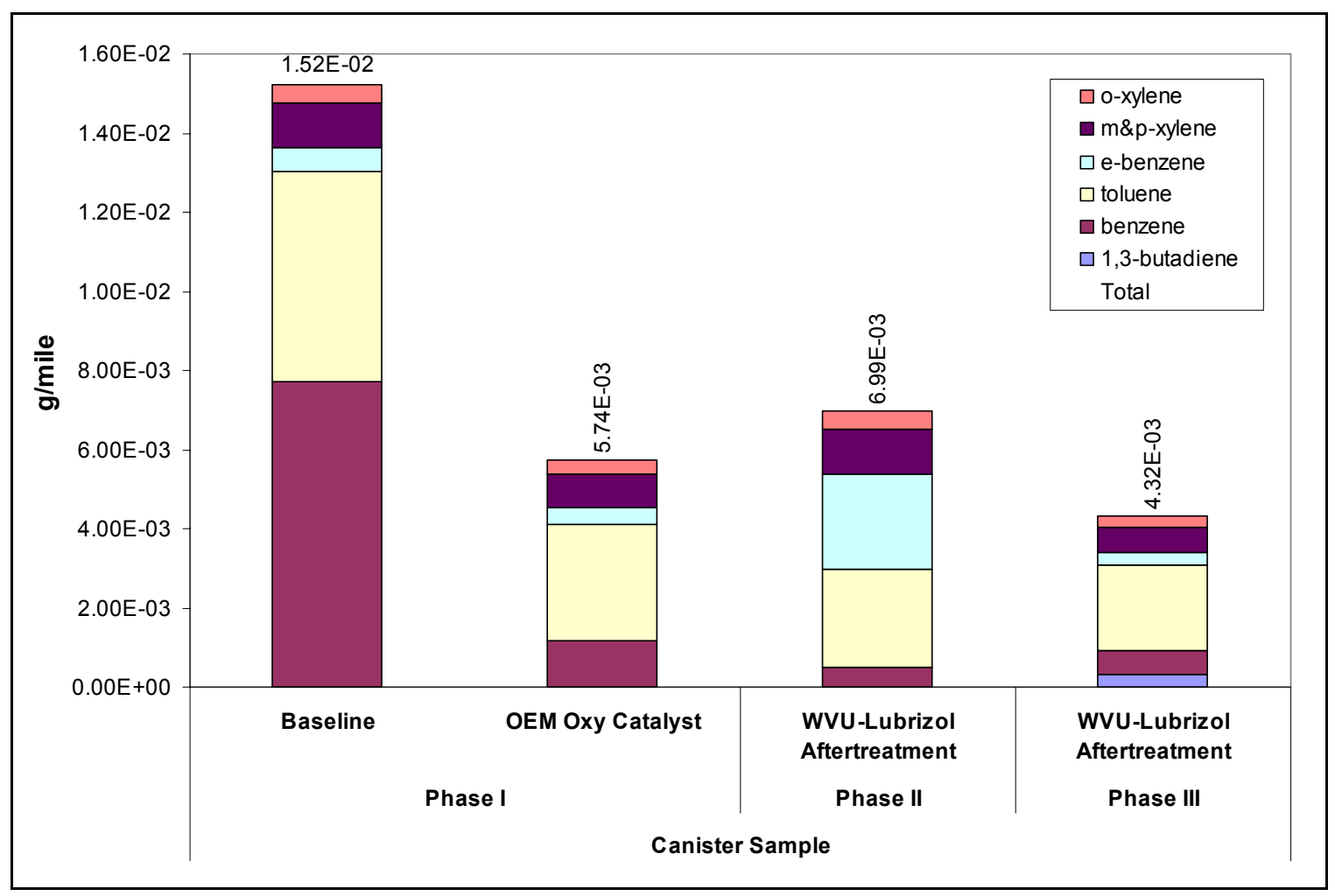

Figure 5.39 Emissions of Toxic Gases Analyzed from Canister Samples from Phase III compared to Phase I and Phase II.

The reductions in the toxic gas emissions achieved by post demonstration WVULubrizol aftertreatment device with respect to the baseline and newly installed exhaust aftertreatment device are shown in Table 5.5.

Table 5.5 Reduction of Toxic Emissions from Post-Use WVU-Lubrizol Trap Compared to Baseline and Pre-Use Trap

\begin{tabular}{|c|c|c|c|c|c|}
\hline Toxics & $\begin{array}{c}\text { Baseline } \\
(\mathrm{g} / \mathrm{mile})\end{array}$ & $\begin{array}{c}\text { Pre Use WVU- } \\
\text { Lubrizol Trap } \\
(\mathrm{g} / \mathrm{mile})\end{array}$ & $\begin{array}{c}\text { Post Use WVU- } \\
\text { Lubrizol Trap } \\
(\mathrm{g} / \mathrm{mile})\end{array}$ & $\begin{array}{c}\text { Post Use vs. } \\
\text { Baseline }\end{array}$ & $\begin{array}{c}\text { Post vs. Pre } \\
\text { Use }\end{array}$ \\
\hline 1,3-Butadiene & $0.00 \mathrm{E}+00$ & $0.00 \mathrm{E}+00$ & $3.08 \mathrm{E}-04$ & - & - \\
\hline Benzene & $7.72 \mathrm{E}-03$ & $5.03 \mathrm{E}-04$ & $6.19 \mathrm{E}-04$ & $92 \%$ & $-23 \%$ \\
\hline Toluene & $5.30 \mathrm{E}-03$ & $2.48 \mathrm{E}-03$ & $2.17 \mathrm{E}-03$ & $59 \%$ & $13 \%$ \\
\hline e-Benzene & $6.01 \mathrm{E}-04$ & $2.41 \mathrm{E}-03$ & $3.13 \mathrm{E}-04$ & $48 \%$ & $87 \%$ \\
\hline M\&p-Xylene & $1.15 \mathrm{E}-03$ & $1.10 \mathrm{E}-03$ & $6.32 \mathrm{E}-04$ & $45 \%$ & $43 \%$ \\
\hline o-Xylene & $4.45 \mathrm{E}-04$ & $4.92 \mathrm{E}-04$ & $2.83 \mathrm{E}-04$ & $36 \%$ & $43 \%$ \\
\hline
\end{tabular}

An increase in the emissions of benzene, by 23\%, from aged WVU-Lubrizol aftertreatment was observed when compared to Phase II results, while emissions of other 
toxics were further reduced by the aged aftertreatment device indicating improved performance. It is not clear why benzene emissions increased in Phase III testing.

Elemental and organic carbon analysis was conducted on $\mathrm{PM}_{2.5}$ samples, which were collected on a $47 \mathrm{~mm}$ pre-fired quartz filter. EC-OC emissions from all three phases are shown in Figure 5.40. Results indicate there was no trace of elemental carbon in any of the tests. Additionally emissions of organic carbon were successfully reduced by the oxidation catalyst. The Phase II and Phase III results indicate no change in the emission of the organic carbon confirming no deterioration in the emission performance of the aged aftertreatment device.

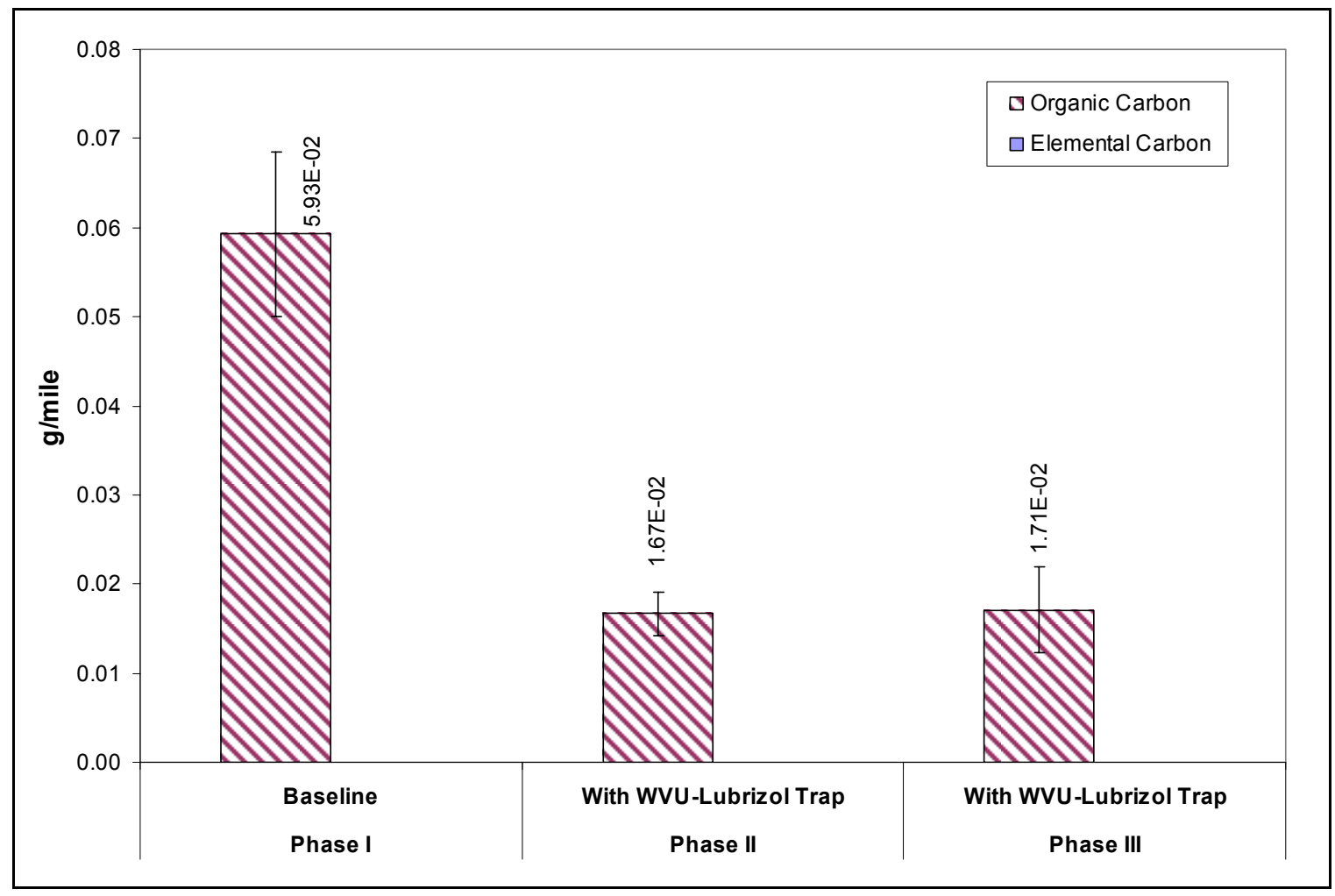

Figure 5.40 Emission of Elemental and Organic Carbons in Phase III compared to Phase I and Phase II.

Gravimetric analysis of size specific particulate matter was performed during Phase III and the results were compared with the baseline PM emissions of Phase III, PM emissions of the newly installed WVU-Lubrizol aftertreatment device (Phase II) and the baseline PM emissions of Phase I. The result is shown in Figure 5.41. 


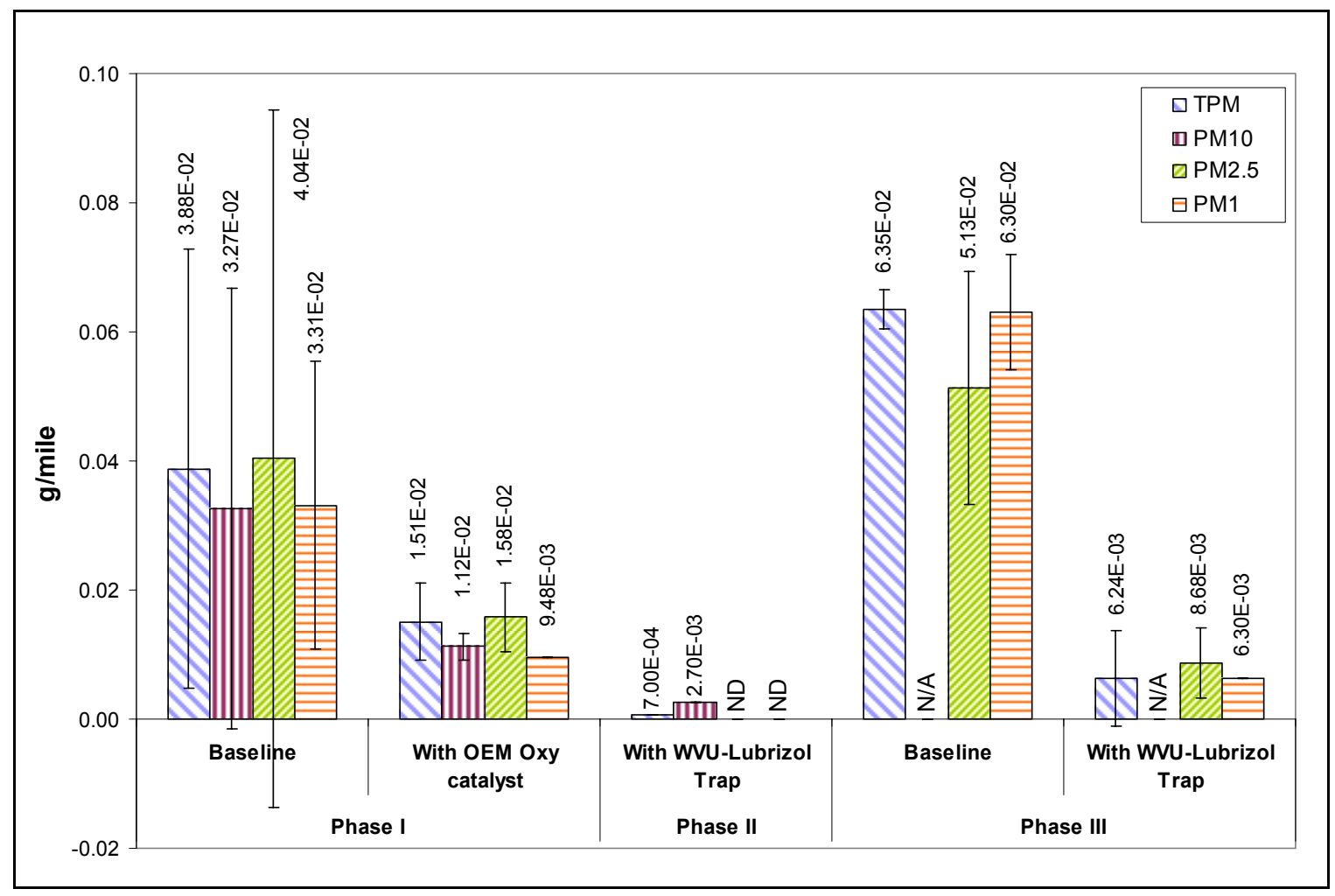

Figure 5.41 Comparison of Size Classified PM Emissions from different Phases

The aged WVU-Lubrizol aftertreatment device showed a reduction of $90 \%$ in TPM emissions when compared to Phase III baseline emissions, while other PM size fractions were reduced on an average by $89 \%$. Reductions in various size fractions of PM emissions achieved by the new aftertreatment device (Phase II) in comparison to Phase I baseline emissions were in the following order $98 \%$ reduction in TPM, 92\% reduction in $\mathrm{PM}_{10}$ emissions, and $\mathrm{PM}_{2.5}$ and $\mathrm{PM}_{1.0}$ emissions were reduced below detection limits. Although particulate matter in the size range of $2.5 \mu \mathrm{m}$ and $1 \mu \mathrm{m}$ were detected in Phase III testing the novel aftertreatment device was still considered a success based on the reduction in PM levels when compared to the engine equipped with OEM catalyst only.

\subsubsection{Particle Sizing Using SMPS}

The performance of the six month old WVU-Lubrizol aftertreatment device was validated by comparing the size distribution of PM to that of the baseline engine and background values. The particle size distribution was measured by running the vehicle, with and without the exhaust aftertreatment device, at a steady state speed of 25 and 35 
mph for a period of 20 minutes. The particle size distribution from the engine exhaust and background air are shown in Figures 5.42-5.45.

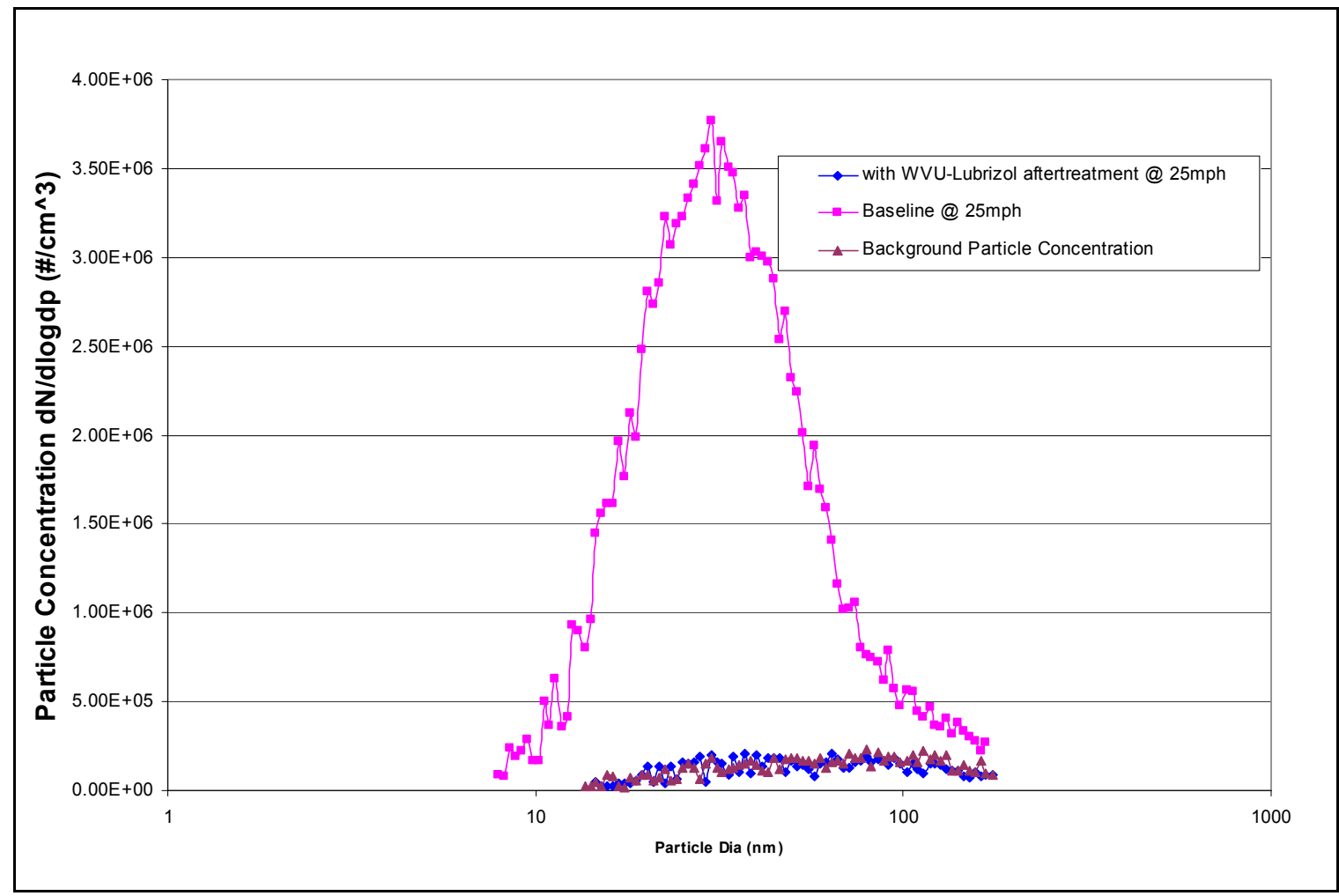

Figure 5.42 Particle Size Distribution with WVU-Lubrizol Exhaust Aftertreatment (a) 25mph compared to Baseline Values. 


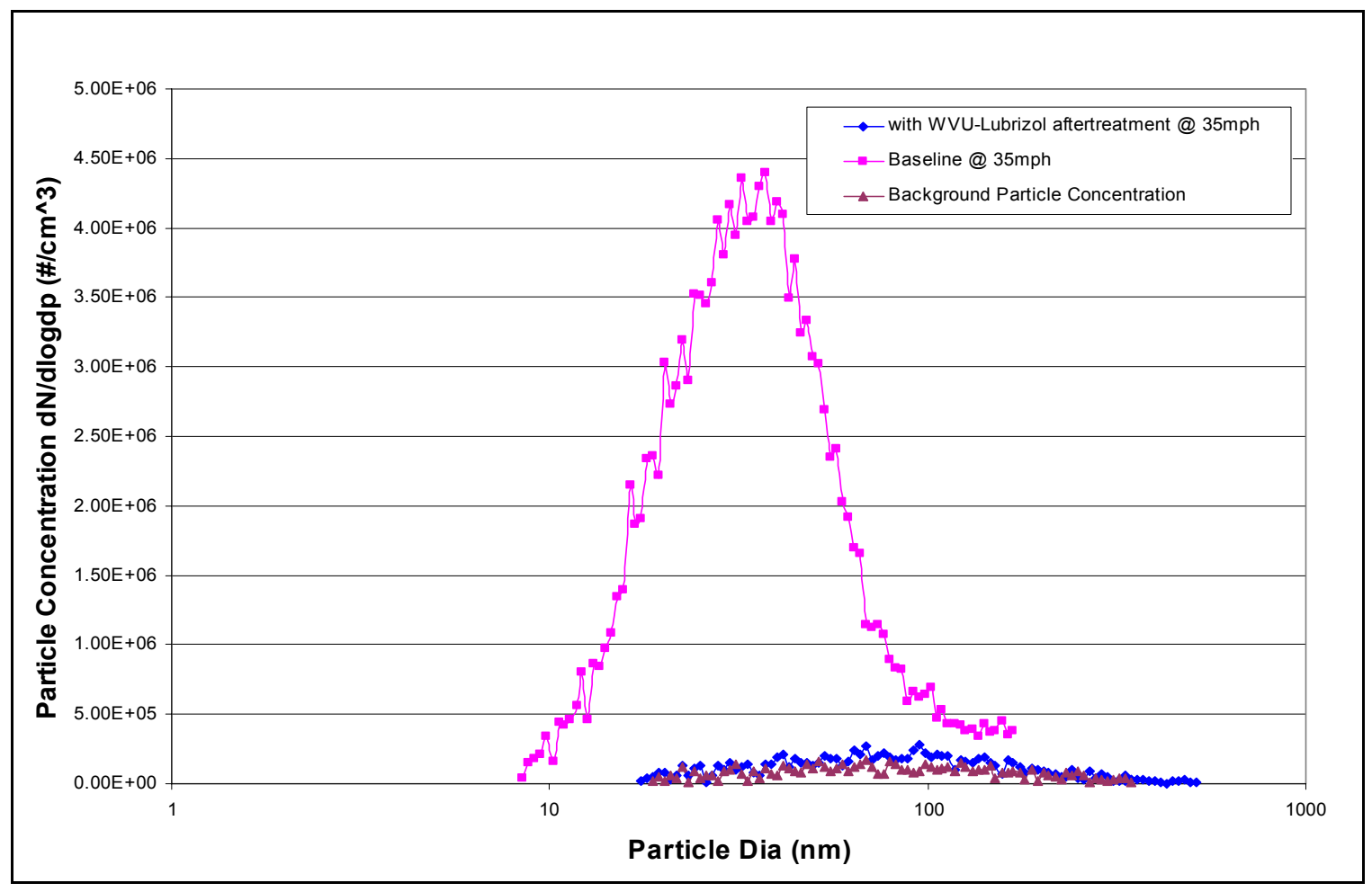

Figure 5.43 Particle Size Distribution with WVU-Lubrizol Exhaust Aftertreatment (a) 35 mph compared to Background and Baseline Values.

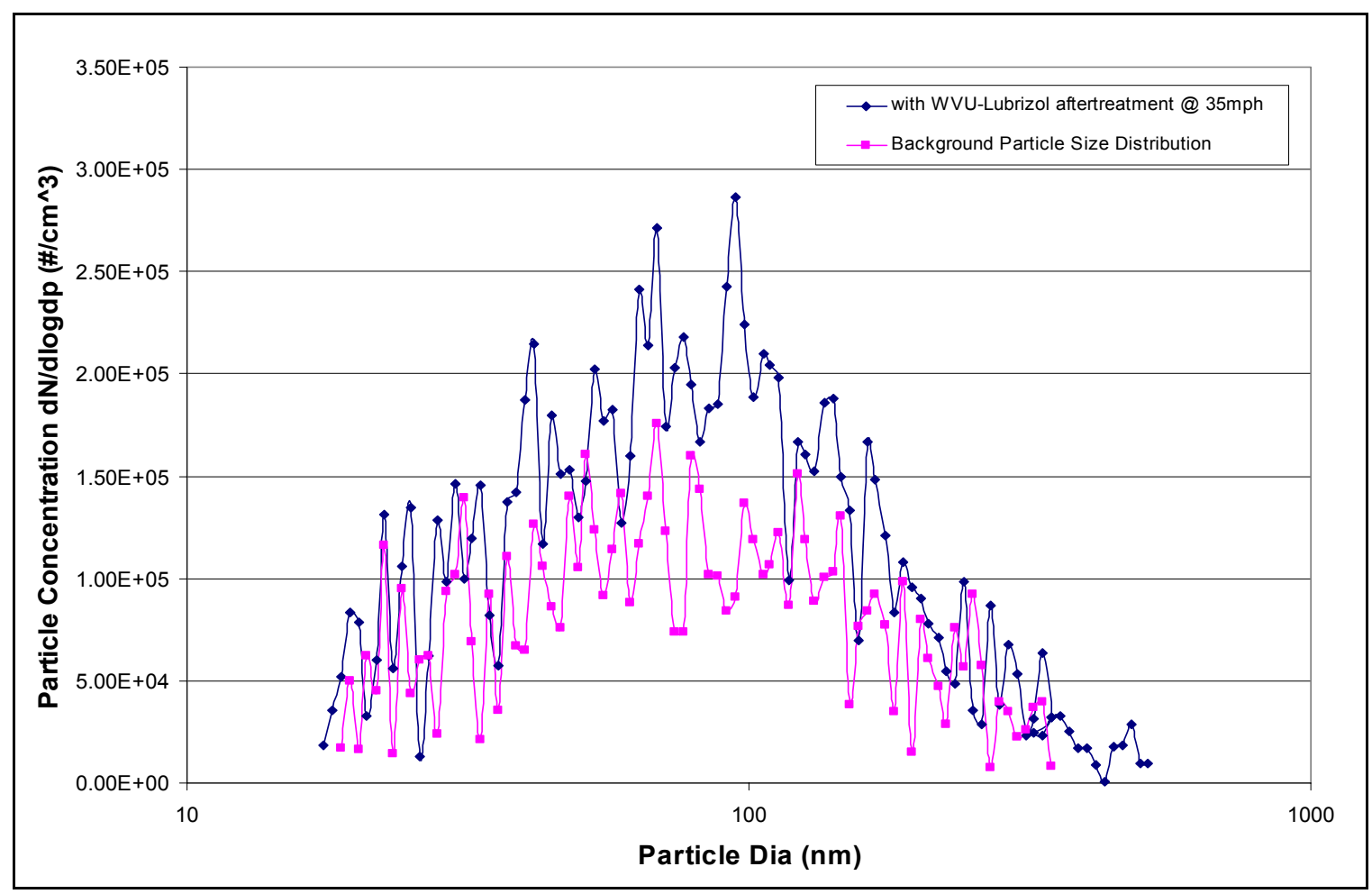

Figure 5.44 Particle Size Distribution with WVU-Lubrizol Exhaust Aftertreatment (a) 35mph compared to Background Values. 


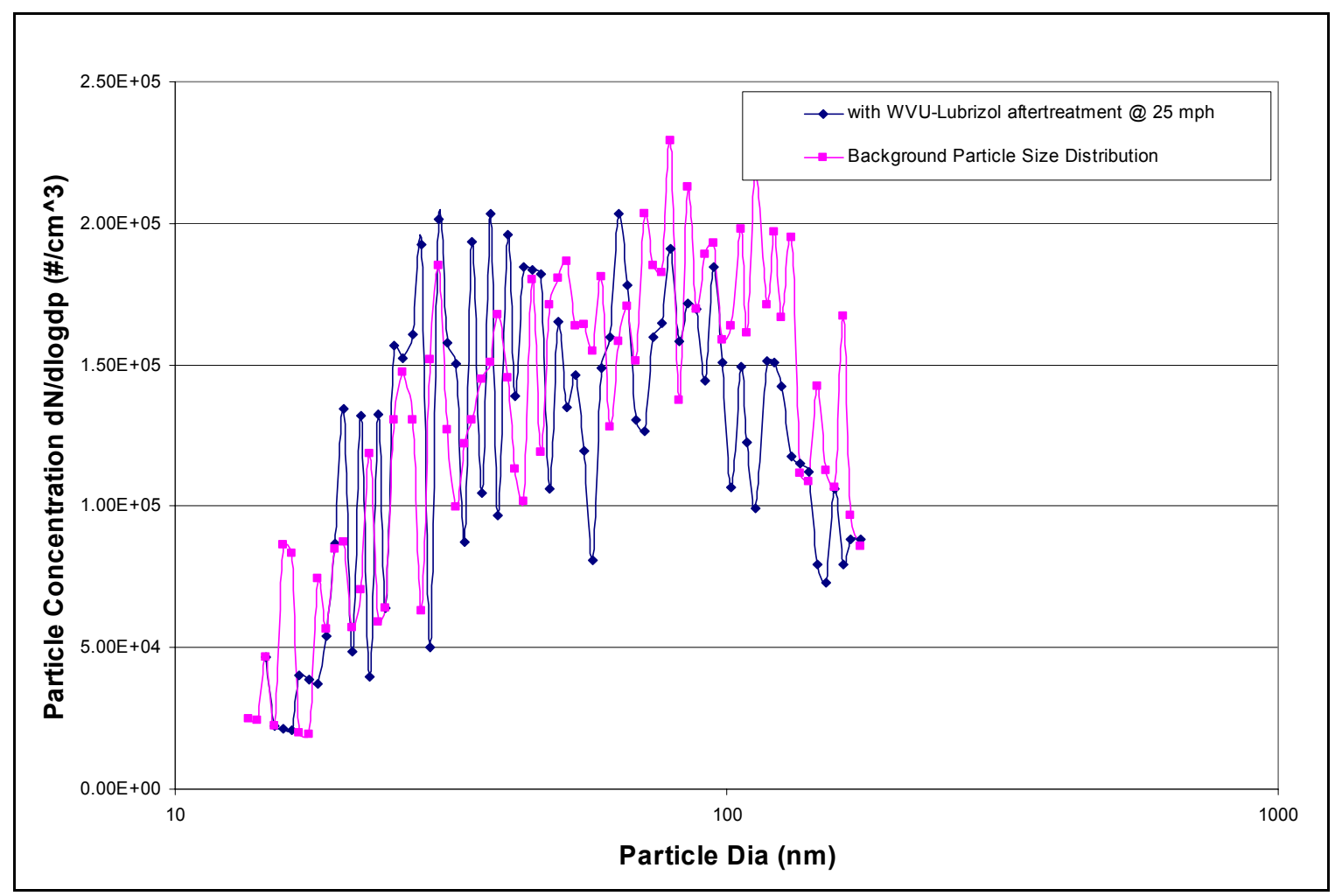

Figure 5.45 Particle Size Distribution with WVU-Lubrizol Exhaust Aftertreatment (a) 25mph compared to Background Values.

PM size distribution shown in Figures 5.43 and 5.44 are not smooth. This is attributed to the significantly low concentrations of PM in the exhaust stream as a result of using WVU-Lubrizol aftertreatment device.

It is evident from the above charts that the newly designed aftertreatment device was successful in bringing down the PM emissions from CNG engines to levels typical of background concentrations. All particle sizing was done at a constant dilution ratio of 1:30 using a mini dilution tunnel. Three particle sizes corresponding to peak concentrations from the steady-state particle size distribution of baseline engine were chosen in order to track their concentrations during transient operation. Charts comparing the concentrations of the following particle sizes $16.8 \mathrm{~nm} ; 35.9 \mathrm{~nm}$ and $59.4 \mathrm{~nm}$ between baseline engine and the engine equipped with WVU-Lubrizol aftertreatment device over one complete QCBD cycle are shown in Figure 5.46-5.48. 


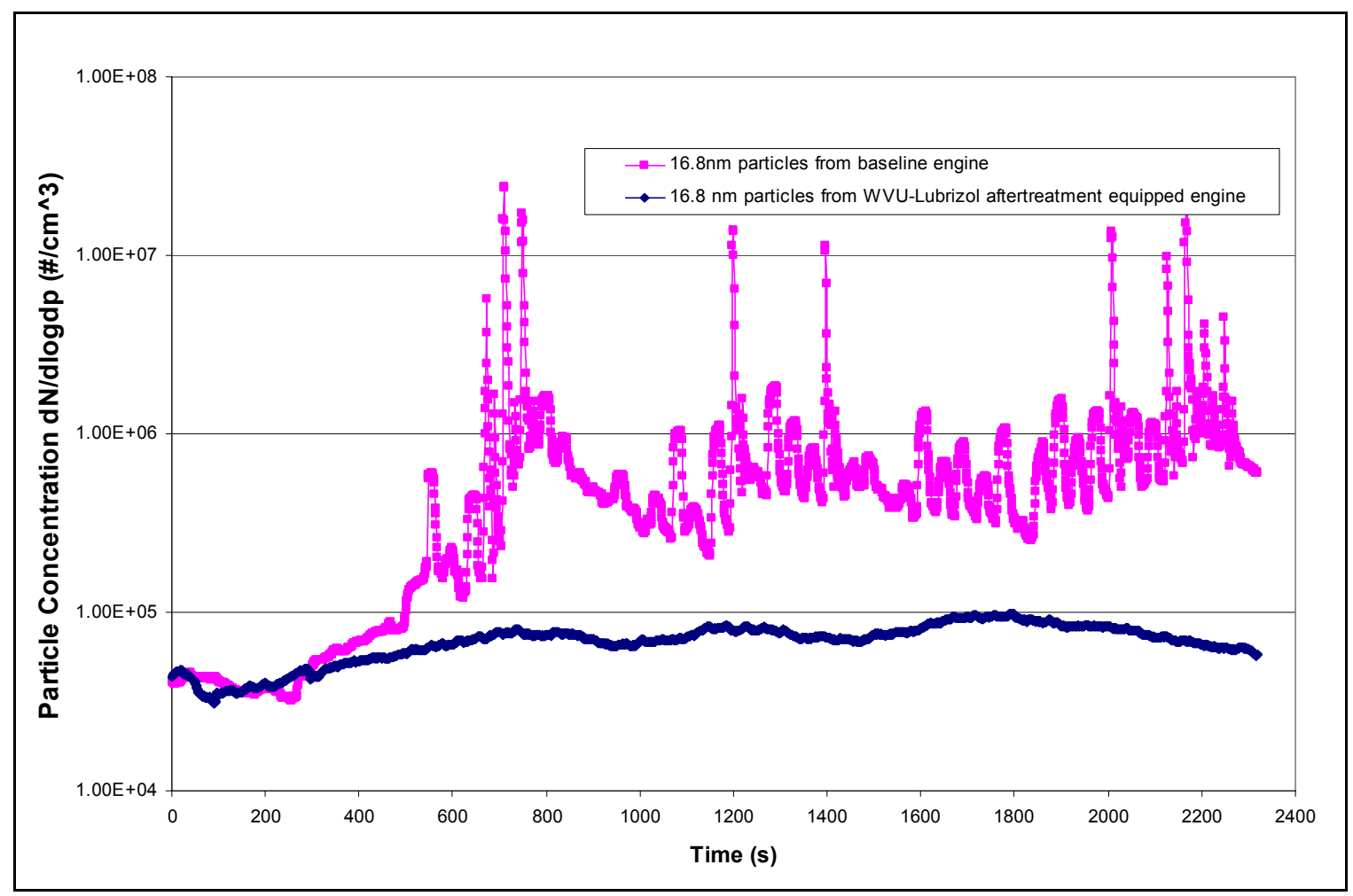

Figure 5.46 Concentration of $16.8 \mathrm{~nm}$ Particle with WVU-Lubrizol Exhaust Aftertreatment compared to Baseline Values.

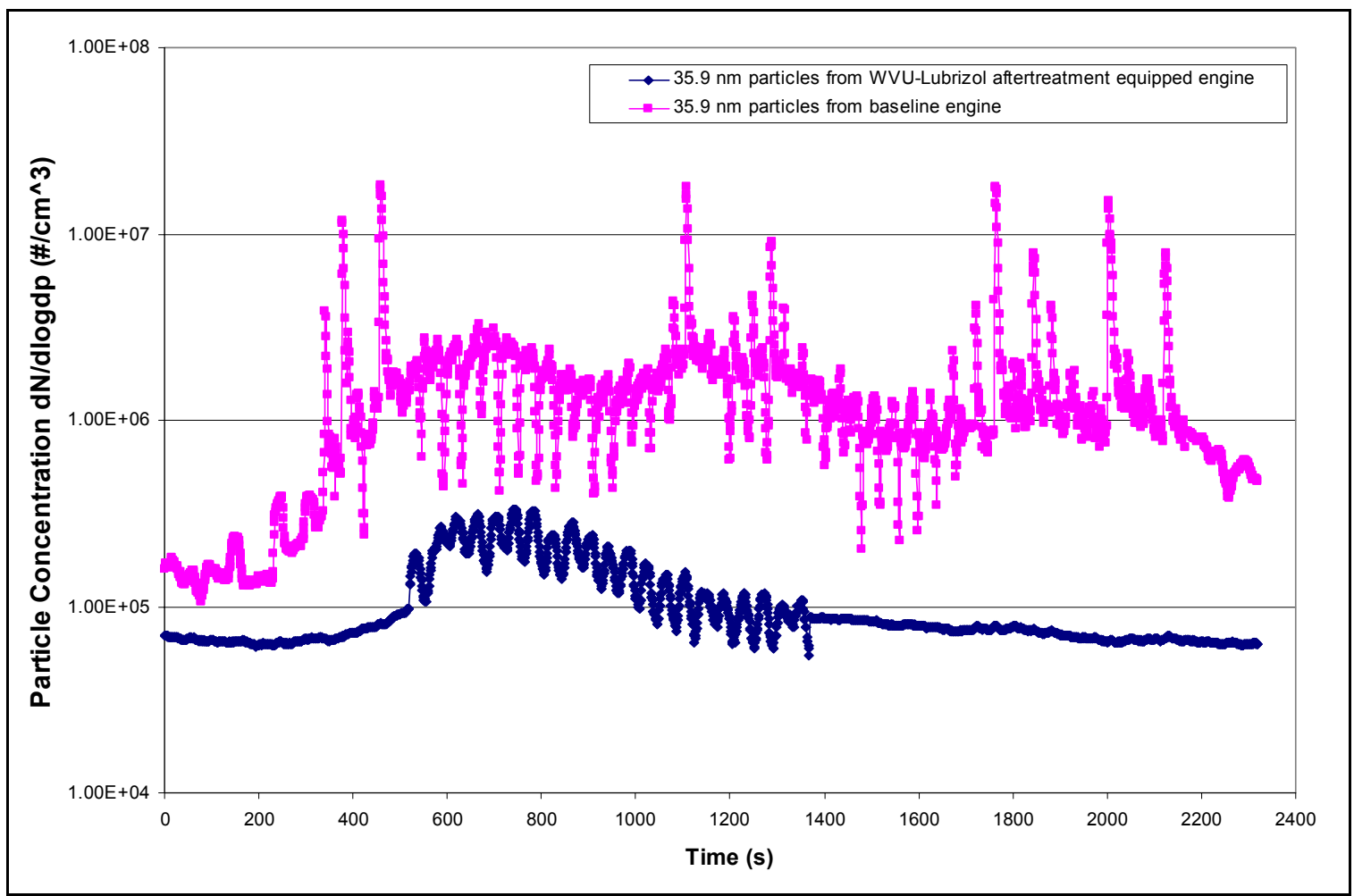

Figure 5.47 Concentration of 35.9nm Particle with WVU-Lubrizol Exhaust Aftertreatment compared to Baseline Values. 


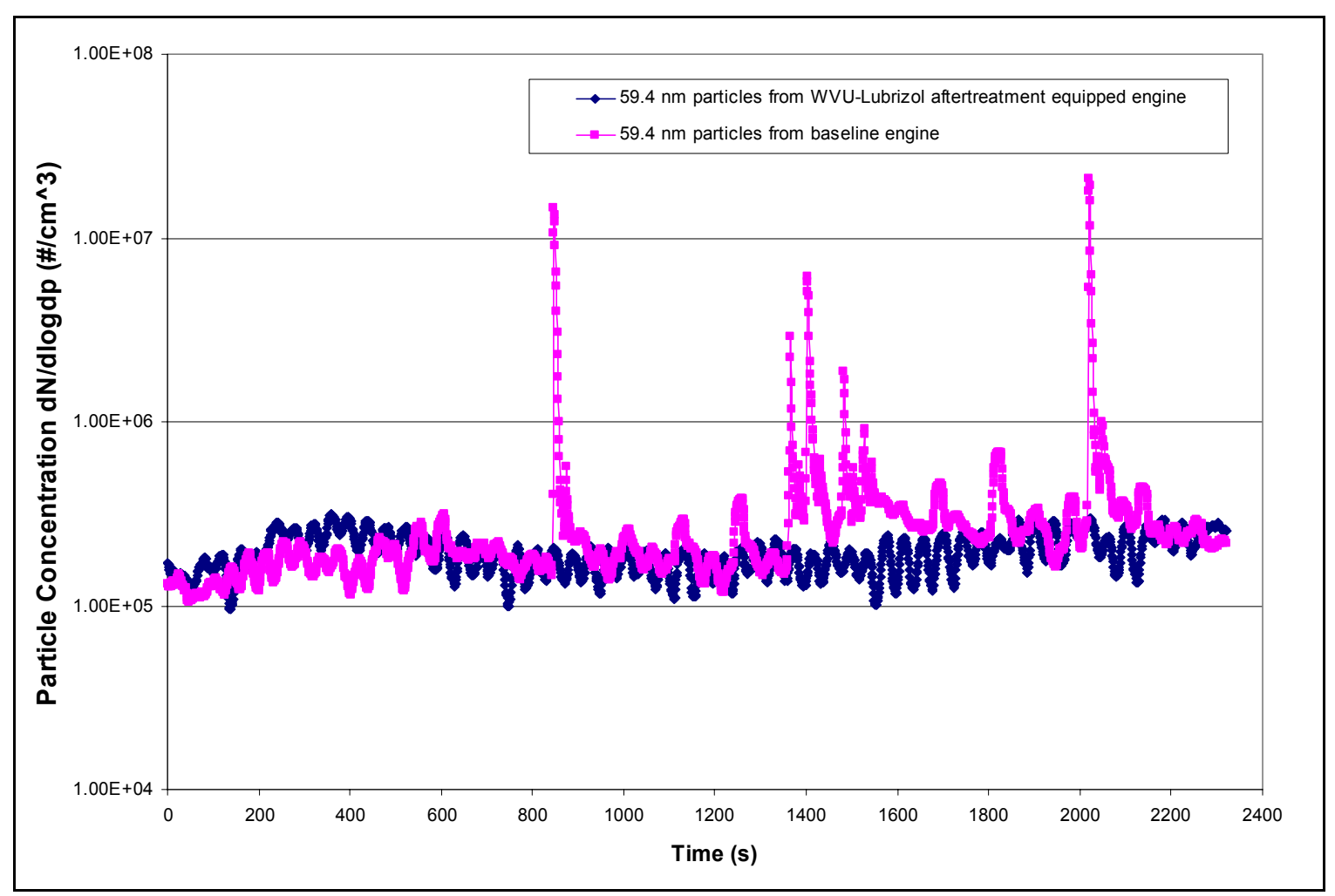

Figure 5.48 Concentration of 59.4nm Particle with WVU-Lubrizol Exhaust Aftertreatment compared to Baseline Values.

The following observations were made from the particle size distribution data collected from different exhaust configurations tested in all the three phases.

- The baseline engine out concentration of nanoparticle emissions was higher than the background concentration by an order of magnitude.

- The use of the OEM oxidation catalyst reduced the number concentration of the nanoparticles in the size range of $50-80 \mathrm{~nm}$. However, concentration of particles in the size range of $8-40 \mathrm{~nm}$ was still equal to the baseline emissions. This indicated that the OEM oxidation catalyst was unable to oxidize some of the heavier organics, which subsequently underwent homogenous nucleation and/or adsorption onto the ash and other additives, emitted from lube oil combustion, to form smaller nanoparticles.

- The use of WVU-Lubrizol aftertreatment device in Phase II showed that the nanoparticle concentration was reduced down to the background levels. This signifies that the combination of the catalyzed particulate trap and the oxidation 
catalyst was highly effective; the ash and other insolubles from the lube oil additives were trapped by the filter, and the volatile organics leaving the trap were oxidized by the catalyst; thereby, reducing the formation of nanoparticles.

- The previous observation was confirmed by measurement of the particle concentrations from the particulate filter, which showed peak concentrations at $13 \mathrm{~nm}$. This increase was likely due to the homogenous nucleation of the vapor phase heavy organics leaving the filter. In addition, the size signifies the absence of solid particles on which the volatile hydrocarbons would adsorb generally and grow in size.

- The Phase III results showed that the WVU-Lubrizol aftertreatment device performed effectively after the six months of in-field demonstration, and reduced the nanoparticle concentrations to levels found in the background. It was observed that the time resolved nanoparticles emissions trace followed the QCBD cycle, speed vs. time trace, when the concentrations were above $1 \times 10^{5}$ particles $/ \mathrm{cm}^{3}$. The spikes observed in the QCBD particle trace for baseline engines were reduced by the WVU-Lubrizol aftertreatment device effectively reducing the total number of particles. 


\section{CONCLUSIONS AND RECOMMENDATIONS}

\subsection{Conclusions}

The main objective of this study was to design an efficient, and durable exhaust aftertreatment device to reduce emissions of toxic pollutants and nanoparticles from natural gas fueled urban transit buses. Previous comparative studies, which involved complete speciation of emissions from engines equipped with and without exhaust aftertreatment devices and operating on different fuels, have shown that $\mathrm{CNG}$ engines were neither as clean nor harmless, as widely believed.

The new exhaust aftertreatment device was designed for an 8.3litre (Cummins $\left.\mathrm{C} 8.3 \mathrm{G}^{+}\right) \mathrm{CNG}$ engine, certified as ULEV by CARB. The exhaust aftertreatment device consisted of a DPF and an oxidation catalyst, arranged in series, with catalyzed DPF installed upstream of the oxidation catalyst. This new arrangement was effective in reducing the number concentration of nanoparticles and other toxic gaseous emissions. All emissions were sampled from a "clean tunnel" that was specifically designed, fabricated, and qualified for this project. The transit bus was tested in three different configurations, over three phases using West Virginia University's transportable chassis dynamometer. The exhaust speciation data from the 'baseline' engine, without any aftertreatment device, formed a basis for the design of the new aftertreatment device. Emissions from the existing engine with OEM oxidation catalyst were also measured to justify the need for a catalyzed particulate filter. The new WVU-Lubrizol aftertreatment device was tested for emissions in Phase II and showed significant reductions in both regulated and non-regulated emissions, compared to baseline engine and the engine equipped with OEM catalyst. The transit bus was returned to its regular revenue service for in-field demonstration of the new aftertreatment device. The new aftertreatment device which had accumulated 32,828 miles over a period of six months, was retested for emissions in Phase III. During the field evaluation period the engine parameters were continuously monitored to check for any deterioration in the engine performance, and no such cases were reported, making the new aftertreatment device suitable for retrofit applications.

Consolidated, comparative results of regulated and non-regulated emissions from all three phases, and the conclusions derived from them, are discussed below. 


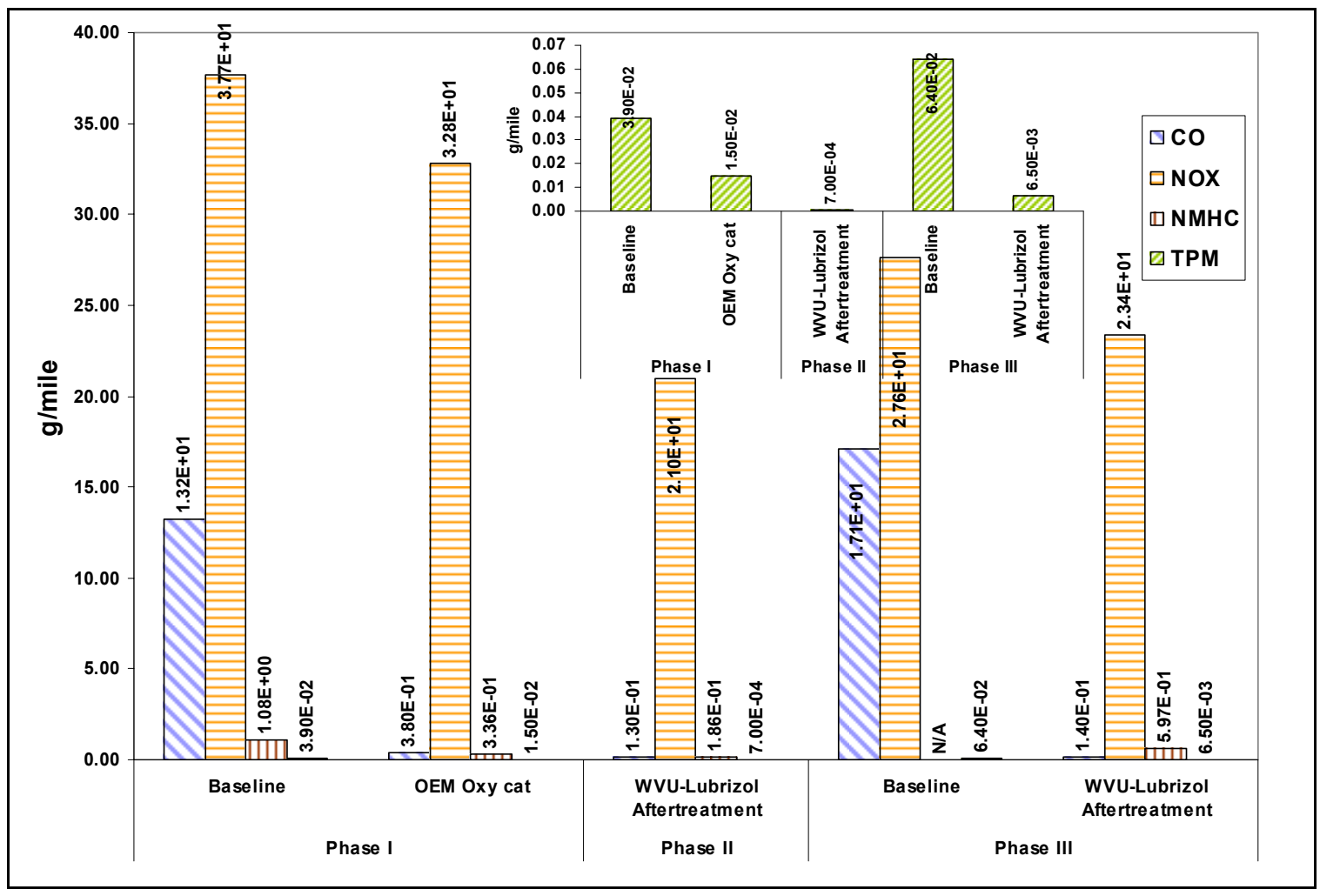

Figure 6.1 Regulated Emissions from all three phases of test

Significant reductions of $\mathrm{CO}$, hydrocarbons, and PM emissions were achieved by WVU-Lubrizol aftertreatment device when compared to baseline emissions. The PM emissions from WVU-Lubrizol equipped engine were reduced by 90-99\%, when compared to the Phase I results, illustrating the advantage of including the catalyzed particulate filter. The percentage reduction achieved by using the WVU-Lubrizol aftertreatment device compared to the baseline engine, in regulated emissions is shown in Table 6.1.

Table 6.1 Reduction in Regulated Emissions compared to Baseline values

\begin{tabular}{|c|c|c|c|c|c|}
\hline \multirow{2}{*}{$\begin{array}{l}\text { Emission } \\
\text { Reduction }\end{array}$} & \multicolumn{2}{|c|}{ Phase I } & \multirow{2}{*}{$\begin{array}{c}\text { Phase II } \\
\text { WVU-Lubrizol } \\
\text { vs. Baseline }\end{array}$} & \multicolumn{2}{|c|}{ Phase III } \\
\hline & $\begin{array}{c}\text { Baseline } \\
\text { g/mile }\end{array}$ & \begin{tabular}{|c|} 
OEM \\
vs. Baseline
\end{tabular} & & $\begin{array}{l}\text { Baseline } \\
\text { g/mile }\end{array}$ & $\begin{array}{l}\text { WVU-Lubrizol } \\
\text { vs. Baseline }\end{array}$ \\
\hline $\mathrm{CO}$ & $1.32 \mathrm{E}+01$ & $97 \%$ & $99 \%$ & $1.71 \mathrm{E}+01$ & $99 \%$ \\
\hline NOx & $3.77 \mathrm{E}+01$ & $13 \%$ & $44 \%$ & $2.76 \mathrm{E}+01$ & $15 \%$ \\
\hline NMHC & $1.08 \mathrm{E}+00$ & $69 \%$ & $83 \%$ & $2.87 \mathrm{E}+01^{*}$ & $16 \%^{*}$ \\
\hline TPM & 3.90E-02 & $62 \%$ & $98 \%$ & $6.40 \mathrm{E}-02$ & $90 \%$ \\
\hline
\end{tabular}

Note: $*=$ THC analyzed by FID analyzer. 


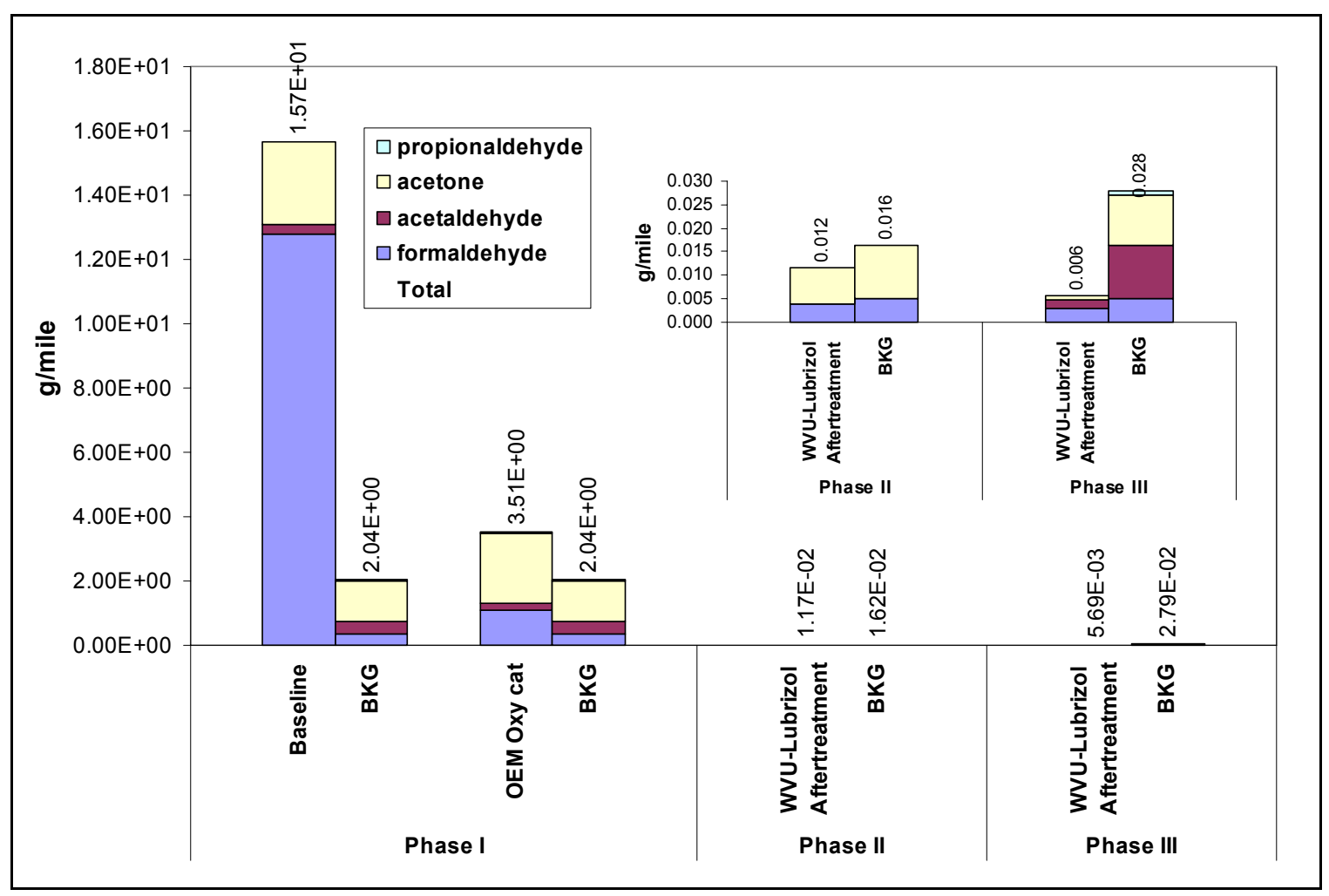

\section{Figure 6.2 Emissions of Carbonyl compounds}

Figure 6.2 represents the reductions achieved in the emissions of carbonyls by using the WVU-Lubrizol aftertreatment device. The percentage reductions in carbonyl emissions achieved by WVU-Lubrizol aftertreatment device are shown in Table 6.2, illustrating its superior performance compared to baseline engine with and without OEM catalyst. No deterioration in the performance of aged aftertreatment device was observed.

Table 6.2 Reduction in Carbonyl Emissions compared to Baseline values

\begin{tabular}{|c|c|c|c|c|}
\hline \multirow{2}{*}{ Carbonyls } & \multicolumn{2}{|c|}{ Phase I } & Phase II & Phase III \\
\cline { 2 - 5 } & $\begin{array}{c}\text { Baseline } \\
\text { g/mile }\end{array}$ & $\begin{array}{c}\text { OEM vs. } \\
\text { Baseline }\end{array}$ & $\begin{array}{c}\text { WVU-Lubrizol vs. } \\
\text { Baseline }\end{array}$ & $\begin{array}{c}\text { WVU-Lubrizol vs. } \\
\text { Baseline }\end{array}$ \\
\hline Formaldehyde & $1.28 \mathrm{E}+01$ & $91 \%$ & $100 \%$ & $100 \%$ \\
\hline Acetaldehyde & $3.35 \mathrm{E}-01$ & $43 \%$ & $100 \%$ & $100 \%$ \\
\hline Acetone & $2.54 \mathrm{E}+00$ & $13 \%$ & $100 \%$ & $100 \%$ \\
\hline Propionaldehyde & $2.18 \mathrm{E}-02$ & $36 \%$ & $100 \%$ & $99 \%$ \\
\hline
\end{tabular}

Polycyclic Aromatic Hydrocarbons identified as TACs by CARB were reduced to background levels with the use of WVU-Lubrizol aftertreatment device (see Figure 6.3). 
However, the total PAH emissions during Phase III were higher than the baseline emissions. This was attributed to increased background emissions that were not corrected in the reported emissions. Therefore, it becomes difficult to justify the need for an exhaust aftertreatment device to reduce emissions when the background levels are more than the actual emissions.

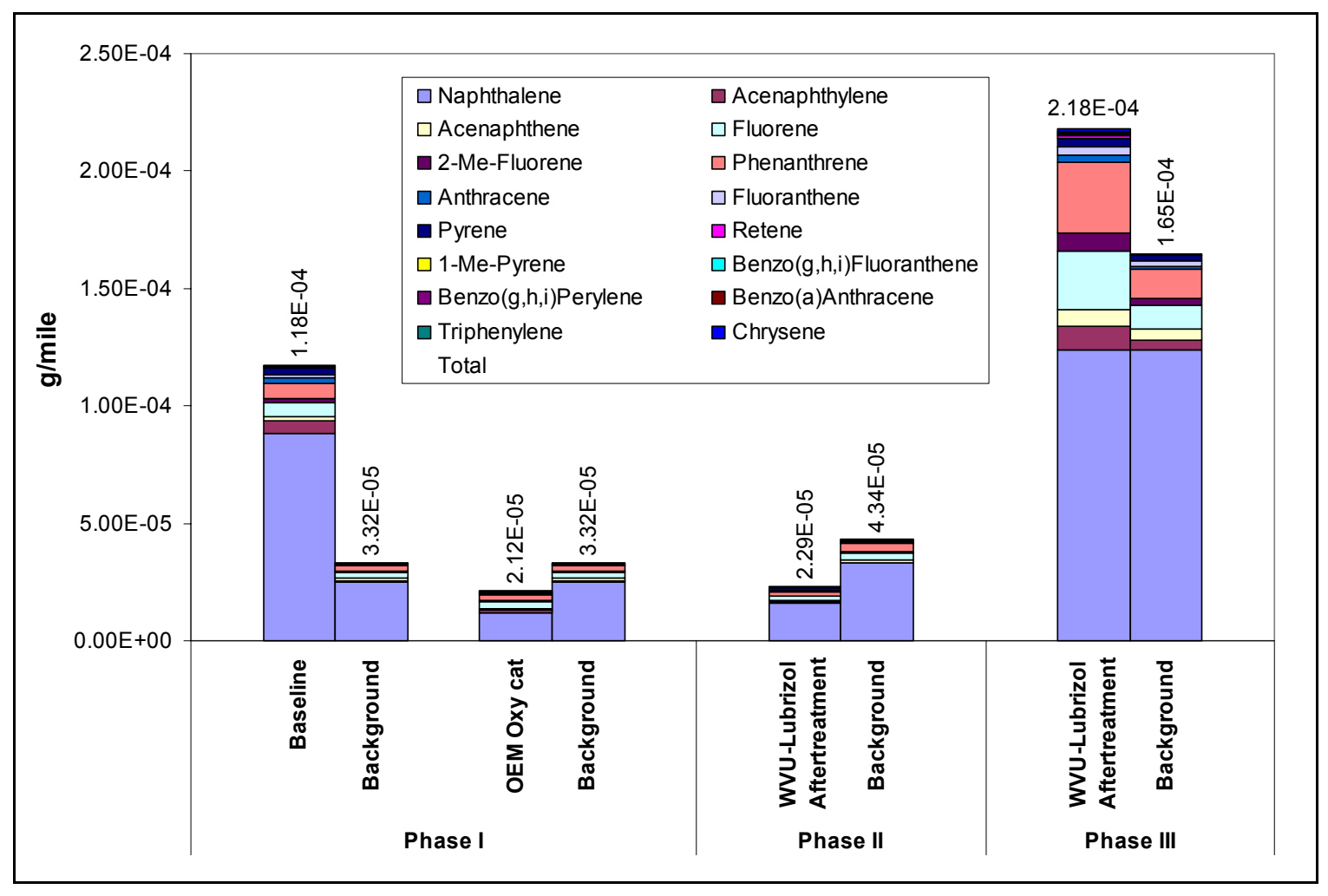

Figure 6.3 Emissions of Polycyclic Aromatic Hydrocarbons

Toxic gas emissions analyzed by different methods, test-site GC and lab analysis, showed that the WVU-Lubrizol aftertreatment device reduced toxic gas emissions below the background levels. This was observed in both test-site and lab analysis results and is shown in Figure 6.4. The Phase III results confirmed that the performance of aged aftertreatment device was better than the new one. 


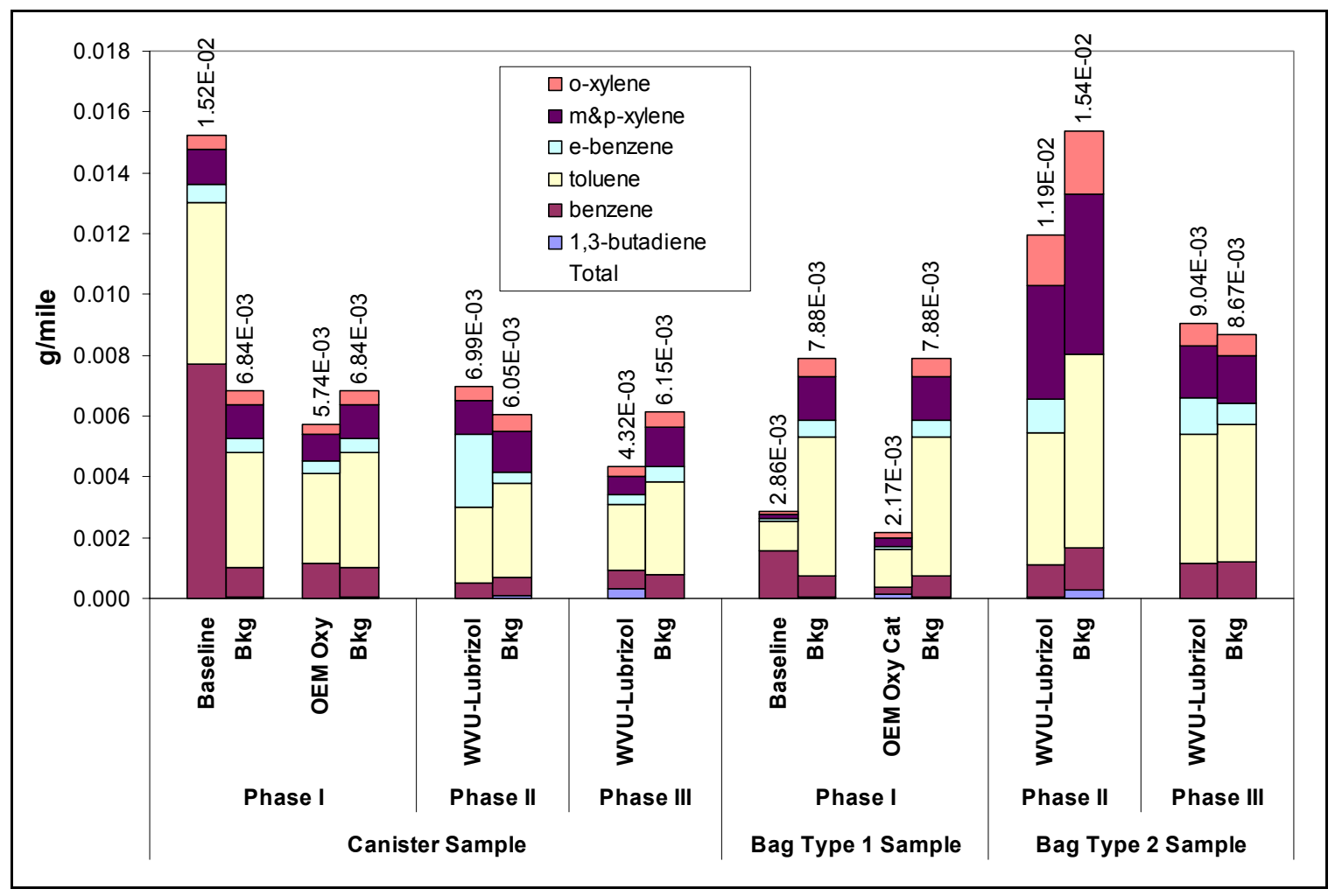

\section{Figure 6.4 Emissions of Toxic Gases}

Emissions of engine wear elements and lube oil additives were reduced below detectable limits by the use of WVU-Lubrizol aftertreatment device. Emissions of elemental carbon were below detection limit during all the tests, while emissions of organic carbons were reduced considerably (in the range of 71\%) by WVU-Lubrizol aftertreatment device.

Among forty-one non-regulated hydrocarbons identified as TACs by CARB, only fifteen were detected, and all of them were reduced below the background levels by the WVU-Lubrizol aftertreatment device (see Figure 6.5) - reinforcing the design objective. It is evident from the results that there was no deterioration in the performance of the aged WVU-Lubrizol aftertreatment device. 


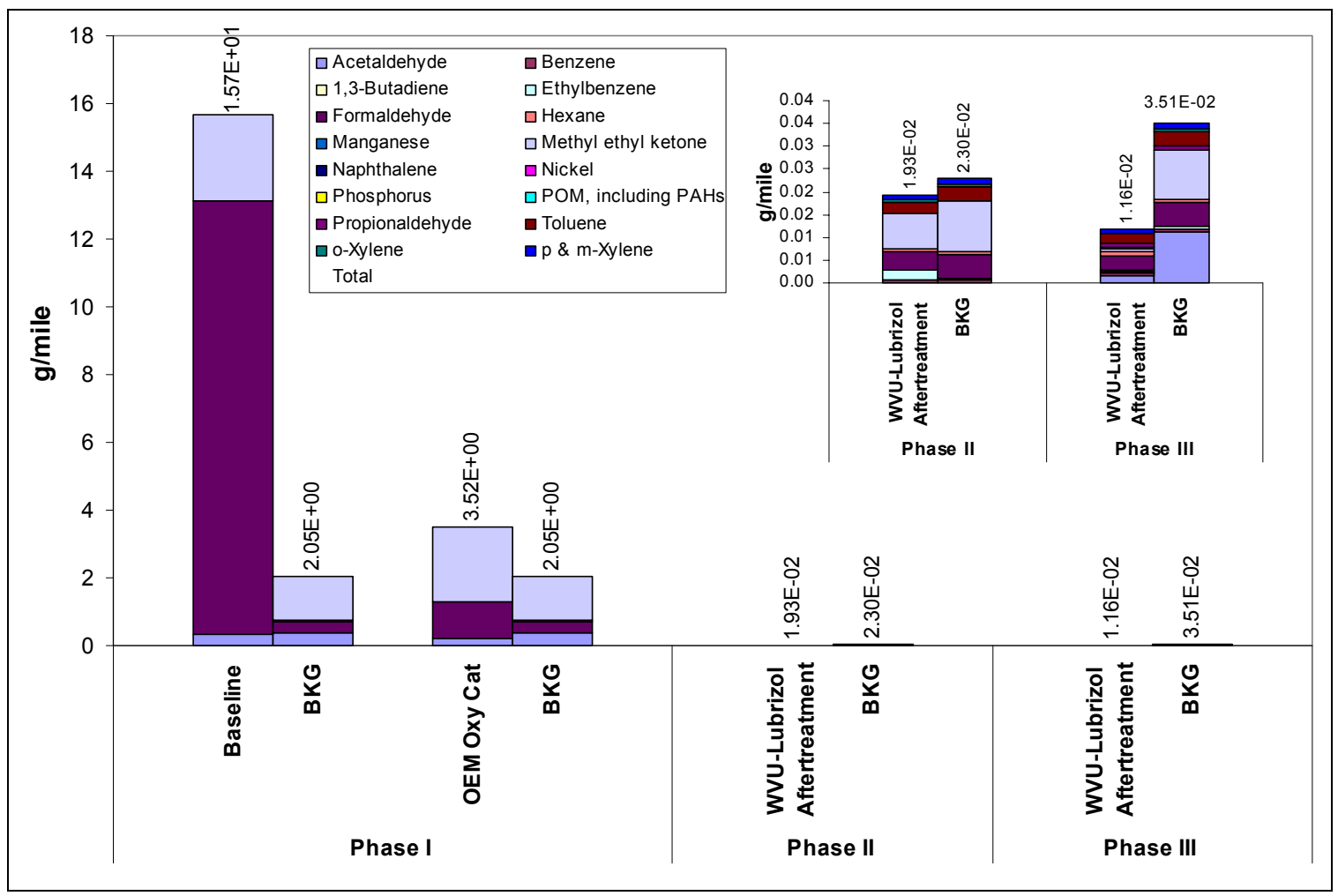

Figure 6.5 Emission of Toxic Air Contaminants

The number concentrations of nano particles were successfully reduced to the background levels by using the WVU-Lubrizol aftertreatment device (see Figure 6.6). The oxidation catalyst placed downstream of the particulate filter played an important role in oxidizing any heavier hydrocarbon escaping the particulate trap which otherwise would undergo homogenous nucleation to form nanoparticles. The particulate trap worked in concert with the oxidation catalyst by trapping the ash and other lube oil additives, which serve as nucleation sites for the heavier hydrocarbons to adsorb and form nanoparticles, even before reaching the super-saturation conditions required for homogeneous nucleation. The steady-state particle size distribution measured from the aged WVU-Lubrizol aftertreatment device is shown in Figure 6.6, along with the background particle size distribution, which validates that there was no deterioration in the performance after six months of in-field demonstration. 


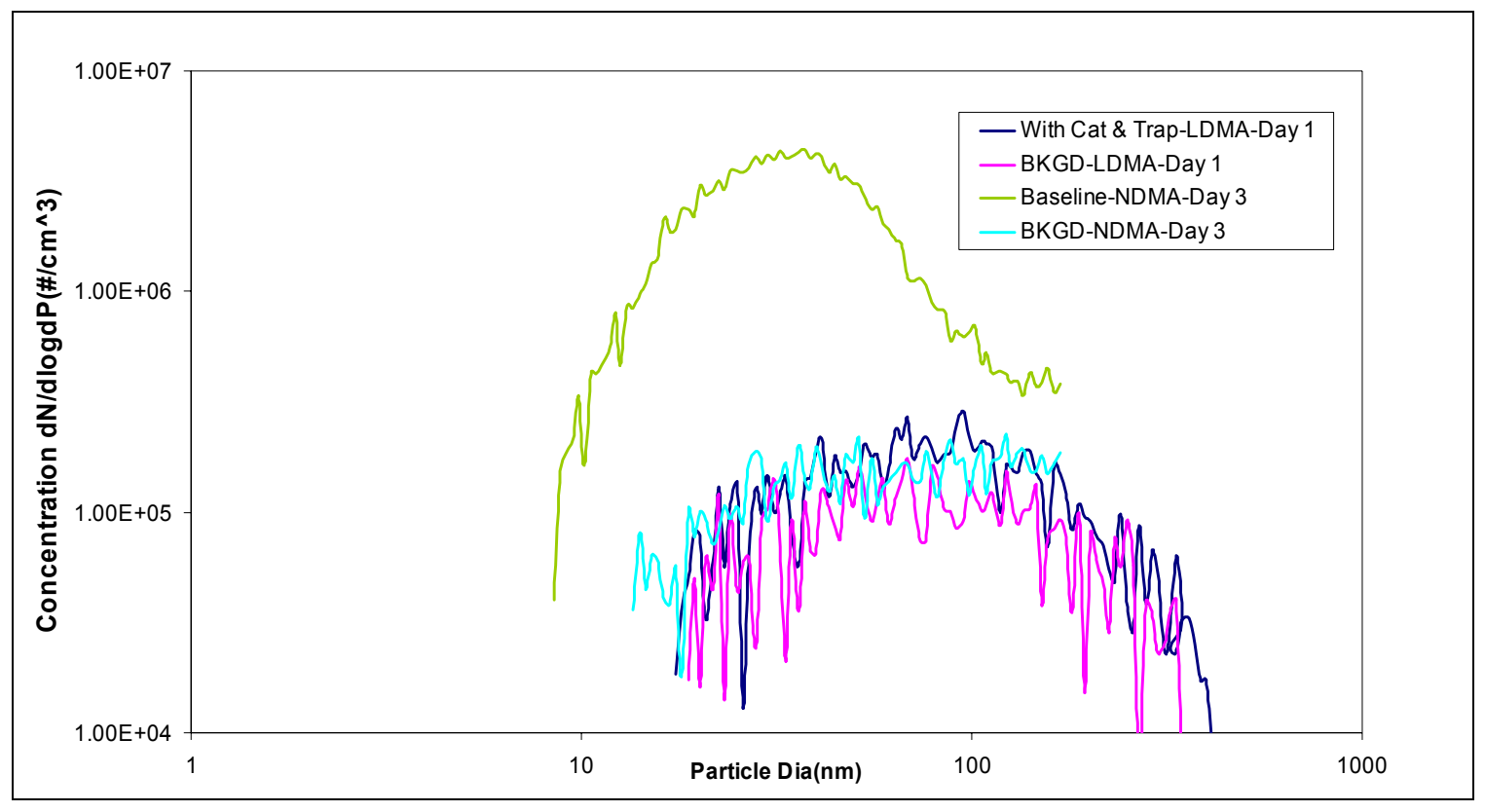

Figure 6.6 Particle Size Distribution @ 35mph with DR=30

\subsection{Recommendations}

Retrofitting is considered a viable solution to extend the useful life of transit buses without overhauling the engine, in order to meet updated emissions regulations. Hence, it becomes imperative to develop reliable and durable exhaust aftertreatment devices to address this issue. In this study, it was found that the OEM oxidation catalyst on the test vehicle underwent structural deterioration well before completing its useful life. Thus indicating that there is scope to improve the durability and maintain consistent emissions reduction efficiencies through its useful life. Following are some of the areas that require further research to understand the formation of nanoparticles and to find the sources of heavier hydrocarbons in $\mathrm{CNG}$ engine emissions.

- Study the effect of lube oil properties, age of the oil, and the amount of oil consumption on the emissions of toxics and nano-particles.

- Need to study the adverse effects of soot and non-combustible lube oil ash accumulating in the new aftertreatment device over extended period of operation.

- Need to develop standardized and robust sampling techniques to measure compounds found at low concentration levels to have repeatable results.

- Analyze the contribution of tunnel background and HEPA filtered dilution air in the measurement of low concentration compounds. 
- Study the effect of different duty cycles and the nature of driving which includes aggressive accelerations and braking, on the emissions reduction potential of the newly designed aftertreatment device.

- Study the reduction in emissions from different configurations of the new aftertreatment device, as this study was limited to single configuration in which the particulate filter was placed upstream of an oxidation catalyst.

- Study the source of oil leak into the cylinder, such as piston ring and liner, intake and exhaust valve stem guides/seals, and the source of oil leak into exhaust manifold - mainly turbocharger and crankcase ventilation. 


\section{LITERATURE CITED}

Ahlvik, P. "DieselNet Technolgy Guide, Alternative Diesel Fuels: Natural Gas.", $<$ www.dieselnet.com>, 2003.

Andersson, J., Preston, H., Warrens, C., Brett, P. "Fuel and Lubricant Effects on Nucleation Mode Particle Emissions from a Euro III Light-Duty Diesel Vehicle." SAE 2004-01-1989, 2004.

Ayala, A., Gebel, E. M., Okamoto, A. R., Reiger, L. P., Kado, Y. N., Cotter, C., Verma, N. "Oxidation Catalyst Effect on CNG Transit Bus Emissions." SAE 2003-01-1900, JSAE 20030101, 2003.

Ayala, A., Kado, N., Okamoto, A. R., Holmen, A. B., Kuzmicky, P., Kobayashi, R., Stiglitz, K. "Diesel and CNG Heavy-duty Transit Bus Emissions over Multiple Driving Schedules: Regulated Pollutants and Project Overview.” SAE 2002-01-1722, 2002.

Bardasz, E., Mackney, D., Britton, N., Kleinschek, G., Olofsson, K., Murray, I., Walker, P. A. "Investigations of Interactions between Lubricant-derived Species and Aftertreatment Systems on a State-of-the-Art Heavy-Duty Engine." SAE 2003-01-1963, JSAE 20030077, 2003.

Baumgard, K., Johnson, H. J. "The Effect of Fuel and Engine Design on Diesel Exhaust Particle Size Distributions.” SAE 960131, 1996.

Burlingame, T. S. "Reduction of Natural Gas Engine Emissions Using a Novel Aftertreatment System." M.S. Thesis, Department of Mechanical and Aerospace Engineering, West Virginia University, Morgantown, WV, 2004.

California Air Resource Board "The California Almanac of Emissions and Air Quality." Planning and Technical Support Division, 2005. 
California Air Resource Board. "Executive Summary: Proposed Identification of Diesel Exhaust as a Toxic Air Contaminant.” Staff Report, 1998.

California Environmental Protection Agency "Proposed Regulation for a Public Transit Bus Fleet Rule and Emissions Standards for New Urban Buses.” Staff Report, 2000.

Carder, D. K. "Performance Evaluation of Exhaust Aftertreatment Devices Used for Emissions Control on Diesel Engines Employed in Underground Coal Mines." M.S. Thesis, Department of Mechanical and Aerospace Engineering, West Virginia University, Morgantown, WV, 1999.

Chatterjee, S., Conway, R., Lanni, T., Frank, B., Tang, S., Rosenblatt, D., Bush, C., Lowell, D., Evans, J., Mclean, R., Levy, J. S. "Performance and Durability Evaluation of Continuously Regenerating Particulate Filters on Diesel Powered Urban Buses at NY City Transit - Part II.” SAE 2002-01-0430, 2002.

Clark, N., Boyce, J.E., Xie, W., Gautam, M. Lyons, D.W., Vertin, K., LeTavec, C.A., Coburn, T.C. "Class 8 Trucks Operating On Ultra-Low Sulfur Diesel with Particulate Filter Systems: Regulated Emissions." SAE 2000-01-2815, 2000.

Clark, N., Gautam, M., Rapp, B., Lyons, D., Graboski, M., McCormick, R., Alleman, T. "Diesel and CNG Transit Bus Emissions Characterization by Two Chassis Dynamometer Laboratories: Results and Issues.” SAE 1999-01-1469, 1999.

Clean Air Strategic Alliance Data Warehouse, Pollutants Monitored. $<$ http://www.casadata.org/pollutants/index.asp $>$.

Code of Federal Regulations. CFR 40 Parts 86 to 99, Washington, D.C., 2004. 
Dockery, D. W., Pope, A. C., Xu, X., John, D., Spengler., Ware, J. H., Fay, M. E., Ferris, B. G., Speizer, F. E. “An Association between Air Pollution and Mortality in Six U.S. Cities.” New Engl. J. Med., vol. 329, pp 1753-1759, 1993.

Environmental Protection Agency. "Technical Support Document: Control of Emissions of Hazardous Air Pollutants from Motor Vehicles and Motor Vehicle Fuels.” EPA0420R-00-023, December 2000.

Ferguson, D. "Design, Fabrication, and Testing of an Emissions Measurement System for a Transportable Heavy-duty Vehicle Emissions Testing Laboratory." M.S. Thesis, Department of Mechanical and Aerospace Engineering, West Virginia University, Morgantown, WV, 1993.

Froelund, K., Yilmaz, E. "Impact of Engine Oil Consumption on Particulate Emissions." $<$ www.osd.org.tr >, 2006.

Gautam, M. "Particulate Matter and NOx Emissions from In-Use Heavy-Duty Diesel Vehicles", World Truck Conference, Invitation Presentation, May 2-4, 1999, Monterey, Ca.

Gautam, M. "Reducing Real-world Exhaust Emissions from Public Transit and Fleet Vehicles", South Coast AQMD Clean Air Technologies 2001, Nov. 5-6, 2001, Anaheim, CA.

Gautam, M., Clark, N., Lyons, D., Long, Jr., T., Howell, A., Loth, J., Palmer, G., and Bata, R. "Design Overview of a Heavy-Duty Mobile Vehicle Emissions Testing Laboratory." ASME DE-Vol.40, Advanced Automotive Technologies, 1991.

Gluck, K. H., Lox, E., Schafer-Sindlinger, A., Kreuzer, T., Muniz, R. S. "Catalyst Development for Stoichiometric and Lean-burn Natural Gas Engines.” SAE 942419, 1994. 
Goto, Y., Sato, Y. "Combustion Improvement and Exhaust Emissions Characteristics in a Direct Injection Natural Gas Engine by Throttling and Exhaust Gas Recirculation." SAE 2001-01-0737, 2001.

Graham, L. "Exhaust Characterization Method.” Environment Canada, 2006.

Gupta, D. "Speciation of Heavy-duty Diesel Exhaust Emissions Under Transient and Steady-state Operating Conditions." M.S. Thesis, Department of Mechanical and Aerospace Engineering, West Virginia University, Morgantown, WV, 1996.

Harayama, N., Niimura, K., and Watanabe, Y. "Effects of Sulfate Adsorption on Performance of Diesel Oxidation Catalysts.” SAE 920852. 1992.

Heywood, J.B. Internal Combustion Engine Fundamentals., McGraw-Hill, Inc. New York, 1988.

Holmen, A. B., Ayala, A. "Ultrafine PM Emissions from Natural Gas, Oxidation-Catalyst Diesel and Particle-Trap Diesel Heavy-Duty Transit Buses.” Environ. Sci. Technol. Vol. 36, 2002, pp. 5041-5050.

Holmen, A. B., Ayala, A., Kado, N., Okamoto, R. “ARB's Study of Emissions from "Late-Model" Diesel and CNG Heacy-duty Transit Buses: Preliminary Nanoparticle Measurement Results." $5^{\text {th }}$ ETH Conference on Nanoparticle Measurement, August 6-8, 2001, Zurich.

Horiuchi, M., Saito, K., Ichihara, S. "The Effects of Flow-through Type Oxidation Catalysts on the Particulate Reduction of 1990's Diesel Engines." SAE 900600, 1990.

Inoue, T., Masuda, Y., Yamamoto, M. "Reduction of Diesel Particulate Matter by Oil Consumption Improvement Utilizing Radioisotope Tracer Techniques." SAE 971630, 1997. 
Institute of Occupational Medicine. "Nanoparticle: An Occupational Hygiene Review." Research Report 274, 2004.

Ling, J. V., Helden, R. V., Riemersma, I. "Comparison of Particle Size Distribution and Emissions from Heavy-duty Deisel Engines and Gas Engines for Urban Buses." $12^{\text {th }}$ International Scientific Symposium on Transport and Air Pollution, Avignon, France., 2003.

Jung, H., Kittleson, D., Zachariah, M. "The Influence of Engine Lubricating Oil on Diesel Nanoparticle Emissions and Kinetics of Oxidation." SAE 2003-01-3179, 2003.

Kado, K. Y., Okamoto, R. A., Kuzmicky, P. A., Kobayashi, R., Ayala, A., Gebel, M. E., Rieger P. L., Maddox, C., and Zafonte, L. "Emissions of Toxic Pollutants from Compressed Natural Gas (CNG) and Low Sulfur Diesel-Fueled Heavy-Duty Transit Buses Tested Over Multiple Driving Cycles.” Environ. Sci. Technol., vol. 39 (19), pp 7638-7649, 2005.

Kittelson, B. D., Johnson, H. J. "Variability in Particle Emissions Measurements in the Heavy-duty Transient Test." SAE 910738, 1991.

Kittelson, D., Abdul-Khalek, A. "Formation of Nanoparticles during Exhaust Dilution." EFI Members Conference: Fuels, Lubricants, Engines, and Emissions, 1999.

Kittleson, B. D. "Diesel Aerosol Sampling Methodology - CRC E-43: Technical Summary and Conclusions." Department of Mechanical Engineering, University of Minnesota, Minneapolis, MN, 2002.

Lanni, T., Chatterjee, S., Conway, R., Windawi, H., Rosenblatt, D., Bush, C., Lowell, D., Evans, J., McLean, R., "Performance and Durability Evaluation of Continuously 
Regenerating Particulate Filters on Diesel Powered Urban Buses at NY City Transit." SAE 2001-01-0511, 2001.

Lanni, T., Frank, P. B., Tang, S., Rosenblatt, D., Lowell, D. "Performance and Emissions Evaluation of Compressed Natural Gas and Clean Diesel Buses at New York City's Metropolitan Transit Authority." SAE 2033-01-0300, 2003.

Lapin, C. A., Gautam, M., Zielinska, B., Wagner, V. O., McClellan, R. O. "Mutagenicity of Emissions from a Natural Gas Fueled Truck." Genetic Toxicology and Environmental Mutagenesis, vol 519, pp 205-209, 2002.

Lev-On, M., LeTavec, C., Uihlein, J., Alleman, T., Lawson, D., Vertin, K., Thompson, G., Gautam, M., Wayne, S., Zeilinska, B., Sagebeil, J., "Chemical Speciation of Exhaust Emissions from Trucks and Buses Fueled on Ultra-Low Sulfur Diesel and CNG." SAE 2002-01-0432, 2002.

Majewski, A. W. "DieselNet Technology Guide: Diesel Particulate Matter.", $<$ www.dieselnet.com>, 2002.

Mathis, U., Kaegi, R., Mohr, M., and Zenobi, R. "TEM analysis of volatile nanoparticles from particle trap equipped diesel and direct-injection spark-ignition vehicles." Atmospheric Environment., Vol 38, pp 4347-4355, 2004.

Mathis, U., Mohr, M., Zenobi, R. "Effect of Organic Compounds in Nanoparticle formation in Diluted Diesel Exhaust.” Atmos. Chem. Phys., vol. 4, 2004, pp. 609-620.

Mayer, A. "VERT: Curtailing Emissions of Diesel Engines in Tunnel Sites." VERT, Report W11/1297. TTM, Switzerland, 1998.

Mayer, A., Evequoz, R., Wyser-Huesi, M., Czerwinski, J., Matter, U., Graf, P. "Particulate Traps Used in City-Buses in Switzerland." SAE 2000-01-1927, 2000. 
McMillian, H. M. "Combustion Analysis and Particulate Mutagenicity Characterization for a Single-Cylinder Diesel Engine Fueled by Fischer-Tropsch Derived Liquids." Phd. Dissertation, Department of Mechanical and Aerospace Engineering, West Virginia University, Morgantown, WV, 2002.

Nagendran, V. "Characterization of Exhaust Emissions from Catalyzed Trap-Equipped Non-Road Heavy-Duty Diesel Engines.” M.S. Thesis, Department of Mechanical and Aerospace Engineering, West Virginia University, Morgantown, WV, 2003.

National Science Foundation. "Emerging Issues in Nanoparticle Aerosol Science and Technology (NAST).” University of California, Los Angeles, 2003.

Newkirk, M. S., Bass, E. A. "Reactivity Comparison of Exhaust Emissions from HeavyDuty Engines Operating on Gasoline, Diesel, and Alternative Fuels." SAE 952442, 1995.

Newkirk, M. S., Smith, L. R., Merritt, P. M. "Heavy-Duty Diesel Hydrocarbon Speciation: Key Issues and Technological Challenges.” SAE 932853. 1993.

Nylund, N., Erkilla, K., Lappi, M., Ikonen, M. “Transit Bus Emission Study: Comparison of Emissions from Diesel and Natural Gas Buses.” Research Report, 2004.

Okamoto, A. R., Kado, Y. N., Kuzmicky, Y. P., Ayala, A., Kobayashi, R. "Unregulated Emissions from Compressed Natural Gas (CNG) Transit Buses Configured with and without Oxidation Catalyst." Enviro. Sci. Technol., vol. 40(1), 2006, pp. 332-341.

Parker, D., O'Conner, S., Lemieux, S., Nolan, K. "CARB Evaporative Emissions Test Program.” SAE 1999-01-3528, 1999. 
Sakurai, H., Tobias, J. H., Park, K., Zarling, D., Docherty, S. K., Kittelson, B. D., McMurry, H. P., Ziemann, J. P. "On-line Measurements of Diesel Nanoparticle Composition and Volatility.” Atmospheric Environment, vol. 37, pp 1199-1210, 2003.

Sharp, C., Howell, S., Jobe, J. "The Effect of Biodiesel Fuels on Transient Emissions from Modern Diesel Engines, Part I: Regulated Emissions and Performance.” SAE paper 2000-01-1967, 2000.

Tadrous, T. "Personal Communication", The Lubrizol Corporation / Engine Control Systems Division, 2004.

Tobias, J. H., Beving, E. D., Ziemann, J. P., Sakurai, H., Zuk, M., McMurry, H. P., Zarling, D., Waytulonis, R., Kittelson, B. D. "Chemical Analysis of Diesel Engine Nanoparticle Using a Nano-DMA/ Thermal Desorption Particle Beam Mass Spectrometer.” Environ. Sci. Technol., vol. 35, pp 2233-2243, 2001.

U.S. Environmental Protection Agency "Motor Vehicles and 1990 Clean Air Act." Office of Mobile Sources, Ann Arbor, MI.

U.S. Environmental Protection Agency. "Emission Standards Reference Guide for Heavy-Duty and Nonroad Engines.” Air and Radiation, 1997.

Ullman, T., Smith, L., Anthony, J., Slodowske, W., Trestrail, B., Cook, A., Bunn, W., Lapin, C., Wright, K., Clark, C. "Comparison of Exhaust Emissions, Including Toxic Air Contaminant, from School Buses in Compressed Natural Gas, Low Emitting Diesel, and Conventional Diesel Engine Configurations.” SAE 2003-01-1381, 2003.

Westport $^{\mathrm{TM}}$ Innovations Inc, High Pressure Direct Injection, $<\underline{\text { http://www.westport.com/tech/hpdi.php }>, 2006 .}$ 
Yilmaz, E. "Sources and Characteristics of Oil Consumption in a Spark-Ignition Engine." PhD Dissertation, Department of Mechanical Engineering, MIT, 2003. 


\section{APPENDIX A: EXHAUST CHARACTERIZATION METHOD}

(Source: Environment Canada, 2005)

\section{Methane and Non-methane Hydrocarbons}

Canister samples were collected for analysis of methane and non-methane hydrocarbons (NMHC). The flow rate selected for sample collection filled the evacuated sample canister to approximately 10 psig over the test duration. Samples were shipped back to the ERMD lab for analysis.

Approximately 165 non-methane hydrocarbons were determined by high-resolution gas chromatography with a flame ionisation detector following cryogenic preconcentration. An Entech M7000 cryogenic concentrator, operating in the microscale purge and trap mode, was used as an inlet to the GC, allowing a sample volume of $200 \mathrm{~mL}$ to be used. A Hewlett Packard 5890 Series II gas chromatograph with a flame ionisation detector was used for the analysis. Data was acquired and sample concentrations were calculated using the Hewlett Packard ChemStation software. This method is referred to as the NMHC method. The complete list of target compounds for this analysis is given in Table A.1. This system is calibrated using external standards.

The preconcentrator system does not allow for the determination of methane and sometimes the $\mathrm{C}_{2}$ hydrocarbons are not well retained on the trap. Methane must be determined using an alternate method and in certain instances, confirmation of the $\mathrm{C}_{2}$ and $\mathrm{C}_{3}$ hydrocarbon concentrations determined using the preconcentrator method is required. The methane analysis and the $\mathrm{C}_{2}$ and $\mathrm{C}_{3}$ hydrocarbon confirmation are accomplished by simple gas loop injection onto a capillary column. The sample loop is flushed with sample and the contents of the loop are injected directly onto the capillary column. This method is referred to as the light hydrocarbon (LHC) method. A Hewlett Packard 5890 Series II gas chromatograph with a flame ionisation detector is used for the analysis. Data is acquired using the Hewlett Packard ChemStation software. This system is calibrated using external standards.

Chromatographic conditions for the NMHC and LHC methods are given in Table A.2. 
Table A. 1 Target compounds for methane and non-methane hydrocarbon analysis.

\begin{tabular}{|c|c|c|c|}
\hline methane & benzene & 1e-1m-cyP & 3e-toluene \\
\hline ethylene & 33-dm-pentane & t-13-dm-cyH & 4e-toluene \\
\hline acetylene & cyclohexane & t-12-dm-cyH & 23-dm-octane \\
\hline ethane & 2m-hexane & n-octane & 135-tm-benzene \\
\hline propylene & 23-dm-pentane & ccc-123-tm-cyP & 2m-nonane \\
\hline propane & 11-dm-cyP & t2-octene & 3e-octane \\
\hline propyne & cyclohexene & 244-tm-hexane & 2e-toluene \\
\hline isobutane & 3m-hexane & ip-cyP & 3m-nonane \\
\hline isobutene/1-butene & c-13-dm-cyP & c2-octene & t-butylbenzene \\
\hline 1,3-butadiene & t-13-dm-cyP & 235-tm-hexane & 124-tm-benzene \\
\hline n-butane & 3e-pentane & 22-dm-heptane & 1-decene \\
\hline t2-butene & t-12-dm-cyP & 24-dm-heptane & $\mathrm{ib}-\mathrm{cyH}$ \\
\hline 1-butyne & 1-heptene & c-12-dm-cyH & t-1m-2p-cyH \\
\hline c2-butene & 224-tm-pentane & 26-dm-heptane & n-decane \\
\hline 12-butadiene & t3-heptene & np-cyP & ib-benzene \\
\hline 3m1-butene & n-heptane & ccc-135-tm-cyH & sb-benzene \\
\hline 2m-butane & c3-heptene & e-cyH & 3-ip-toluene \\
\hline 14-pentadiene & t2-heptene & 25-dm-heptane & 123-tm-benzene \\
\hline 2-butyne & c2-heptene & 33-dm-heptane & 4-ip-toluene \\
\hline 1-pentene & m-cyclohexane & 114-tm-cyH & indan \\
\hline 2m1-butene & 22-dm-hexane & e-benzene & 2-ip-toluene \\
\hline n-pentane & e-cyclopentane & ctt-124-tm-cyH & 13-de-benzene \\
\hline 2m-1,3-butadiene & 25-dm-hexane & 23-dm-heptane & 3-np-toluene \\
\hline t2-pentene & 223-tm-pentane & m\&p-xylene & 4-np-toluene \\
\hline c2-pentene & 24-dm-hexane & 34-dm-heptane & nb-benzene \\
\hline 2m2-butene & ctc-124-tm-cyP & 2m-octane/4m-octane & 14de-benzene \\
\hline 22-dm-butane & 33dm-hexane & 3e-heptane & 13-dm-5e-benzene \\
\hline cyclopentene & ctc-123-tm-cyP & 3m-octane & 12-de-benzene \\
\hline 4m1-pentene & 234-tm-pentane & styrene & 2-np-toluene \\
\hline cyclopentane & toluene & ctc-124-tm-cyH & 14-dm-2e-benzene \\
\hline 23-dm-butane & 233-tm-pentane & 33-de-pentane & 13dm-4e-benzene \\
\hline c/t-4m2-pentene & 23-dm-hexane & o-xylene & 12-dm-4e-benzene \\
\hline 2m-pentane & 112-tm-cyP & 112-tm-cyH & 13-dm-2e-benzene \\
\hline 3m-pentane & 1m-cyHexene & 1-nonene & 12-dm-3e-benzene \\
\hline 2m1-pentene/1-hexene & 2m-heptane & ib-cyP & n-undecane \\
\hline n-hexane & 4m-heptane & t3-nonene & 2mb-benzene \\
\hline t2-hexene & 34-dm-hexane & c3-nonene & 1245-ttm-benzene \\
\hline 2m2-pentene & 3m-heptane & n-nonane & 1235-ttm-benzene \\
\hline t-3m2-pentene & 3e-hexane & t2-nonene & tb-2m-benzene \\
\hline c2-hexene & c-13-dm-cyH & c2-nonene & 1234-ttm-benzene \\
\hline c-3m2-pentene & cct-124-tm-cyP & ip-benzene & n-pentylbenzene \\
\hline 22-dm-pentane & t-14-dm-cyH & 22-dm-octane & $\mathrm{t}-1 \mathrm{~m}-2(4 \mathrm{mp}) \mathrm{cyP}$ \\
\hline m-cyclopentane & 11-dm-cyH & ip-cyH & tb-35-dm-benzene \\
\hline
\end{tabular}




\begin{tabular}{|c|c|c|c|}
\hline 24-dm-pentane & 225-tm-hexane & nb-cyP & tb-4e-benzene \\
\hline 223-tm-butane & 1-octene & 33-dm-octane & naphthalene \\
\hline 1m-cyclopentene & 224-tm-hexane & n-propylbenzene & n-dodecane \\
\hline
\end{tabular}

Table A. 2 Chromatographic conditions for the NMHC and LHC methods.

\begin{tabular}{|l|l|}
\hline Column & $\begin{array}{l}50 \mathrm{~m} \times 0.32 \mathrm{~mm} \times 1.05 \mu \mathrm{m} \text { film thickness; HP-1 (Crosslinked } \\
\text { Methylslicone) }\end{array}$ \\
\hline $\begin{array}{l}\text { Oven Temperature } \\
\text { Program }\end{array}$ & $3 \mathrm{~min} @-50^{\circ} \mathrm{C}, 5^{\circ} / \mathrm{min}$ to $200^{\circ} \mathrm{C}, 2 \mathrm{~min} @ 200^{\circ} \mathrm{C}$ \\
\hline Carrier gas & UHP Helium, EPC @ $11.7 \mathrm{psig}(1.2 \mathrm{~mL} / \mathrm{min}) @ 35^{\circ} \mathrm{C}$ \\
\hline Makeup gas & UHP Helium, Total column plus makeup is $30 \mathrm{~mL} / \mathrm{min}$ \\
\hline Injector & Entech Concentrator \\
\hline Detector & $\begin{array}{l}\text { FID operated at } 300^{\circ} \mathrm{C} . \text { Fuel gases: hydrogen } 30 \mathrm{~mL} / \mathrm{min}, \\
\text { Air } 400 \mathrm{~mL} / \mathrm{min}\end{array}$ \\
\hline Sample size & $200 \mathrm{~mL}$ \\
\hline
\end{tabular}

\begin{tabular}{|c|c|}
\hline Column & GSQ Phase, Fused Silica Capillary, $25 \mathrm{~m}$ x $0.53 \mathrm{~mm}$ \\
\hline $\begin{array}{l}\text { Oven Temperature } \\
\text { Program }\end{array}$ & $\begin{array}{l}1.10 \text { mins } @ 40^{\circ} \mathrm{C}, 25^{\circ} / \mathrm{min} \text { to } 130^{\circ} \text {; hold for } 7.3 \text { min. @ } \\
130^{\circ} \mathrm{C} \text {. }\end{array}$ \\
\hline Carrier gas & Helium: $1.8 \mathrm{~mL} / \mathrm{min} . @ 40^{\circ} \mathrm{C}$ \\
\hline Makeup gas & Total of column and make-up flow of $30 \mathrm{~mL} / \mathrm{min}$ helium \\
\hline Injector & $\begin{array}{l}\text { VICI 6-port gas sampling valve with electric actuator, } \\
\text { maintained at } 100^{\circ} \mathrm{C}\end{array}$ \\
\hline Detector & $\begin{array}{l}\text { FID, maintained at } 180^{\circ} \mathrm{C} \text {. Fuel gases: hydrogen: } 30 \mathrm{~mL} / \mathrm{min} \text {. } \\
\text { air: } 400 \mathrm{~mL} / \mathrm{min} \text {. }\end{array}$ \\
\hline Sample size & $250 \mu \mathrm{L}$ \\
\hline
\end{tabular}

\section{1,3-butadiene and BTEX Field Method}

Tedlar bag samples were collected and immediately analysed for 1,3-butadiene and BTEX (benzene, toluene, ethyl benzene and xylene isomers).

The concentrations in the Tedlar bag samples were determined by high-resolution gas chromatography with a flame ionisation detector following cryogenic preconcentration. An Entech M7000 cryogenic concentrator, operating in the microscale purge and trap mode, was used as an inlet to the GC, allowing a sample volume of 200 to $500 \mathrm{~mL}$ to be used. A Hewlett Packard 5890 Series II gas chromatograph with a flame ionisation detector was used for the analysis. Data was acquired and sample concentrations were calculated using the Hewlett Packard ChemStation software. The complete list of target 
compounds for this analysis is given in Table A.3. This system is calibrated using external standards.

Chromatographic conditions for the methods are given in Table A.4.

Table A. 3 Target compounds for 1,3-butdiene BTEX method.

\begin{tabular}{|l|}
\hline 1,3-butadiene \\
\hline benzene \\
\hline toluene \\
\hline ethyl benzene \\
\hline m\&p-xylene \\
\hline o-xylene \\
\hline
\end{tabular}

Table A. 4 Chromatographic conditions for 1,3-butdiene BTEX method.

\begin{tabular}{|l|l|}
\hline Column & $\begin{array}{l}50 \mathrm{~m} \times 0.32 \mathrm{~mm} \times 1.05 \mu \mathrm{m} \text { film thickness; HP-1 (Crosslinked } \\
\text { Methylslicone) }\end{array}$ \\
\hline $\begin{array}{l}\text { Oven Temperature } \\
\text { Program }\end{array}$ & $\begin{array}{l}3 \mathrm{~min} @ 10^{\circ} \mathrm{C}, 5^{\circ} / \mathrm{min} \text { to } 130^{\circ} \mathrm{C}, 50^{\circ} / \mathrm{min} \text { to } 200^{\circ} \mathrm{C}, 10 \mathrm{~min} @ \\
200^{\circ} \mathrm{C}\end{array}$ \\
\hline Carrier gas & UHP Helium, $12 \mathrm{psig}(1.6 \mathrm{~mL} / \mathrm{min}) @ 40^{\circ} \mathrm{C}$ \\
\hline Makeup gas & UHP Helium, Total column plus makeup is $30 \mathrm{~mL} / \mathrm{min}$ \\
\hline Injector & Entech Concentrator \\
\hline Detector & $\begin{array}{l}\text { FID operated at } 300^{\circ} \mathrm{C} . \text { Fuel gases: hydrogen } 30 \mathrm{~mL} / \mathrm{min}, \text { air } \\
300 \mathrm{~mL} / \mathrm{min}\end{array}$ \\
\hline Sample size & 200 and $500 \mathrm{~mL}$ \\
\hline
\end{tabular}

\section{Carbonyl Compounds and Nitrogen Dioxide}

Samples are collected by drawing dilute exhaust or dilution air at a constant flow rate air through a silica gel Sep-Pak cartridge coated with 2,4-DNPH. The carbonyl compounds selectively react with the 2,4-DNPH forming hydrazones that are retained on the cartridge. $\mathrm{NO}_{2}$ reacts with DNPH to form 2,4-dinitrophenylazide (DNPA) that is also retained on the cartridge. The derivatives are removed from the cartridge using a solvent and the liquid sample that results is analysed by high performance liquid chromatography (HPLC). The DNPH coated silica cartridges were prepared in-house by ERMD. No cartridge blank correction was necessary for these samples.

After sample collection, the derivatives were eluted from each Sep-Pak cartridge and the solution was made up to volume in a graduated centrifuge tube with HPLC grade Acetonitrile (J.T. Baker). An aliquot of this solution was analyzed by reverse phase 
HPLC with UV-Visible detection. A Hewlett Packard 1100 HPLC with a diode-array detector, 100 vial autosampler and the HPLC-3D ChemStation software was used for sample analysis. The ratio of transmitted light intensity at two wavelengths is used as the signal for quantitation. The method reports 24 carbonyl compounds, though 8 of the 24 individual compounds are reported as pairs as they co-elute. External calibration standards were purchased from Radian International (Austin, TX.). Where commercial standards were not available, the hydrazones were synthesized in house and standards prepared. A calibration check mix was run after every 10th sample to monitor detector response and retention time drifts. Near baseline resolution was obtained for the acrolein-acetone-propionaldehyde triplet.

As the DNPA derivative absorbs light at a different wavelength than the carbonyl-DNPH derivatives, it can be determined simultaneously with the carbonyl-DNPH derivatives if a multichannel detector such as a photodiode array is used. It has been reported that DNPA can co-elute with the formaldehyde-DNPH derivative under certain chromatographic conditions, resulting in erroneously high formaldehyde emission rates. Our results have shown that the methods developed have successfully separated these two species, allowing for simultaneous determination under the same chromatographic conditions.

The DNPA signal is monitored at $309 \pm 15 \mathrm{~nm}$ whereas the carbonyl-DNPH derivatives are monitored at $370 \pm 15 \mathrm{~nm}$. The background region is the same for both signals (550 $\pm 30 \mathrm{~nm}$ ). The DNPA peak appears before the formaldehyde-DNPH peak and after the unreacted DNPH peak in the chromatogram.

For the calibration of $\mathrm{NO}_{2}$, standards are made by sampling known concentration gas phase standards of $\mathrm{NO}_{2}$ in UHP nitrogen onto 2,4-DNPH cartridges and preparing liquid samples of the derivative using the standard sample preparation method. Calibration samples in the range of 4 to $100 \mathrm{ug} / \mathrm{mL}$ free $\mathrm{NO}_{2}$ are prepared when extracted with 5.0 $\mathrm{mL}$ acetonitrile. Cartridges are prepared in duplicate for calibration. Additional midrange standards $\left(58 \mathrm{mg} / \mathrm{mL}\right.$ free $\mathrm{NO}_{2}$ ) can be prepared and stored like sampled cartridges for daily calibration checks, to be eluted with samples during sample preparation. 
Table A. 5 Target carbonyl compounds

\begin{tabular}{|l|l|}
\hline \multicolumn{2}{|c|}{ Compounds } \\
\hline Formaldehyde & Isobutyraldehyde \& Butyraldehyde \\
\hline Acetaldehyde & Benzaldehyde \\
\hline 2-3 butanedione & Isovaleraldehyde \\
\hline Acrolein & Trimethylacetaldehyde \& 3m2-Butanone \\
\hline Acetone & Valeraldehyde \\
\hline Propionaldehyde & Acetophenone \\
\hline Methoxyacetone & o-Tolualdehyde \\
\hline Crotonaldehyde & m\&p-Tolualdehyde \\
\hline Methyl Vinyl Ketone & Methyl isobutyl Ketone \\
\hline Methacrolein & Pinacolone \\
\hline Methyl Ethyl Ketone & Hexanaldehyde \\
\hline Isobutyraldehyde \& Butyraldehyde & 2,5-dimethylbenzaldehyde \\
\hline
\end{tabular}

Table A. 6 Analytical Conditions for HPLC analysis of carbonyl derivatives.

\begin{tabular}{|c|c|c|}
\hline Column & \multicolumn{2}{|c|}{2 of Hypersil ODS $2.1 \mathrm{~mm} \times 10 \mathrm{~mm}$} \\
\hline Temperature & \multicolumn{2}{|l|}{$40^{\circ} \mathrm{C}$} \\
\hline Mobile Phase Flow Rate & \multicolumn{2}{|l|}{$0.25 \mathrm{~mL} / \mathrm{min}$} \\
\hline Injection volume & \multicolumn{2}{|l|}{$5 \mu \mathrm{l}$} \\
\hline Diode Array Detector wavelengths & \multicolumn{2}{|c|}{$\begin{array}{l}\text { Signal A: } 370 \pm 15 \mathrm{~nm}, 550 \pm 30 \mathrm{~nm} \\
\text { Signal B: } 309 \pm 15 \mathrm{~nm}, 550 \pm 30 \mathrm{~nm}\end{array}$} \\
\hline \multicolumn{3}{|l|}{ Mobile Phase Gradient } \\
\hline Time [min.] & $\%$ Acetonitrile & \% Methanol/Water Solution \\
\hline 0.00 & 10.0 & 90.0 \\
\hline 24.00 & 30.0 & 70.0 \\
\hline 38.00 & 50.0 & 50.0 \\
\hline 39.00 & 100.0 & 0.0 \\
\hline 42.00 & 100.0 & 0.0 \\
\hline
\end{tabular}

The sample collection and analysis methods are based on the California Air Resources Board Method 1004 and the EPA Compendium Method TO-11. We achieve the same analytical performance as these methods using different equipment.

\section{Semivolatile and Particle-bound Organic Speciation}

\section{Polyurethane Foam (PUF) Clean-up}

Polyurethane foam, Grade 1531, is obtained from Neoprene Canada. PUFs, 3" x 3 3/8", diameter are cut from the sheet material. 2 PUFs are rolled up with tissue paper, inserted 
into a $100 \mathrm{~mL}$ stainless steel pressure vessel and extracted using an Accelerated Solvent Extraction (ASE) system manufactured by Dionex. The system utilizes solvent, pressure and temperature to maximize the extraction efficiency. The parameters that are used to remove potential background contaminants contained in the PUF are as follows: The pressure vessel is filled with acetone and heated to $100^{\circ} \mathrm{C}$ for 5 minutes at a pressure of 1500 psi. The acetone is flushed out, the cell is purged with nitrogen then filled with hexane. The hexane is heated to $100^{\circ} \mathrm{C}$ and held at that temperature for 5 minutes at a pressure of $1500 \mathrm{psi}$. The hexane is flushed out and the cell is purged with nitrogen. The extraction with hexane is repeated one time. Once the cells are cooled to room temperature, the cleaned PUFs are removed, placed into a clean fumehood and allowed to air dry for approximately one hour before they are inserted into precleaned stainless steel sleeves and wrapped with aluminium foil.

\section{XAD Resin Clean-up}

The XAD is initially rinsed with 3 volumes of deionized water before being placed into a soxhlet extraction apparatus. The XAD is subsequently extracted for 16 to 20 hours with methanol. The extraction procedure is then repeated first with dichloromethane then with cyclohexane. The cleaned XAD is then stored in methanol just until use. The wet XAD is allowed to air dry in a clean fumehood for approximately 2 hours before it is dried in an oven at $90^{\circ} \mathrm{C}$ for three to four hours. The cleaned, dried XAD is then transferred to a pre-cleaned amber bottle and sealed with a Teflon lined cap.

\section{Extraction of filters/PUF/XAD Samples}

Aliphatic standards (greater than $99 \%$ purity) from $n-\mathrm{C}_{8}$ to $n-\mathrm{C}_{34}-$ including deuterotetracosane, pristane, phytane and 5- $\alpha$-androstane were purchased from Chiron Laboratories (Trondheim, Norway), Chromatographic Specialties, Ultra Scientific/VWR and Aldrich (Milwaukee, WI). The biomarker standards (greater than 96\% purity, $0.1 \mathrm{mg} / \mathrm{mL}$ ) were purchased from Chiron Laboratories (Trondheim, Norway). They included cholestanes, steranes and hopanes.

High purity PAH standards were purchased from many suppliers including Supelco, US, Eastman Kodak, US, Ultra Scientific, US, Koch-Light Lab, US, K \& K Lab, US, and 
Aldrich, US. Isotope-labelled surrogates were purchased from MSD Isotopes, Canada and CDN Isotopes, Canada.

The top PUF is placed at the bottom of a $71 / 60$ joint soxhlet extraction apparatus followed by the filters, the XAD and topped with the bottom PUF. The sample is spiked with $\mathrm{PAH}$ and nitro-PAH, alkane and biomarker surrogates and allowed to sit for approximately 1 hour while the solvent containing the surrogates evaporates. The 1000 $\mathrm{mL}$ round-bottomed flask is charged with approximately $750 \mathrm{~mL}$ of dichloromethane, connected to the soxhlet apparatus and placed into a heating mantle. The extraction is completed over a 20 -hour period. The extract is allowed to cool then the solvent is concentrated and exchanged to hexane before column clean-up and fractionation.

\section{Column Fractionation}

Sodium sulphate and distilled chromatographic grade solvents including acetone, cyclohexane, toluene, dichloromethane (DCM) and methanol were used without further purification.

Silica gel (Aldrich;100-200 mesh, pore size $150 \AA$, pore $1.2 \mathrm{~cm}^{3} / \mathrm{g}$, and active surface 320 $\mathrm{m}^{2} / \mathrm{g}$ ), was washed and activated prior to use according to the following procedure. A batch of 200-300 g silica gel was placed in a $900 \times 41-\mathrm{mm}$ ID chromatography column with a coarse porosity fritted disk. The column was serially rinsed with 2 volumes of methanol followed by 2 volumes of DCM. The silica gel was dried overnight at $110^{\circ} \mathrm{C}$, then activated at $250^{\circ} \mathrm{C}$ for 24 hours and kept in an oven at that temperature until used.

Approximately $5 \mathrm{~g}$ of $5 \%$ deactivated silica was prepared by adding $5 \%$ water to activated silica $(\mathrm{w} / \mathrm{w})$ and shaking vigorously until no clumps were observed. Next, the deactivated silica was transferred to a $1.5 \mathrm{~cm}$ (id) $\times 25 \mathrm{~cm}$ chromatography column packed at the bottom with glass wool and topped with approximately $1 \mathrm{~g}$ of sodium sulphate. The height of the deactivated silica gel bed was $\sim 4.5 \mathrm{~cm}$. The column was precleaned with $15 \mathrm{~mL}$ of cyclohexane.

A vial was placed under the column and the sample loaded on column with approximately $2 \mathrm{~mL}$ of cyclohexane rinses. An additional $13 \mathrm{~mL}$ of cyclohexane was added to collect paraffins and biomarkers in the first vial (Fraction F1). Prior to the 
column bed going dry the first vial was removed and replaced with a second one. The column was immediately eluted with $15 \mathrm{~mL}$ of cyclohexane/acetone $(50 / 50 \mathrm{v}: \mathrm{v})$. This fraction contained the PAH suite of compounds (Fraction F2). Just as the column bed went dry, the second vial was removed and the column eluted with two $15 \mathrm{~mL}$ aliquots of methanol collected in two separate vials (Fractions F3 and F4).

Fraction F1 was concentrated to $1 \mathrm{~mL}$ or less using the automated solvent evaporator. These fractions were further concentrated to a preinjection volume of $0.1 \mathrm{~mL}$ using nitrogen blowdown in a precalibrated vial or Kuderna-Danish concentrator. Fraction F2 was further processed as described below for PAH analysis. Fractions F3 and F4 were archived for later analysis for polar compounds.

\section{Alkanes and Biomarkers}

Fraction F1 contains the non-polar hydrocarbon compounds. The analysis for $n$ paraffins, pristane, phytane, and biomarkers was performed on a HP 6890GC equipped with a 5972A mass selective detector (MSD). System control and data acquisition was achieved with a HP MS Chemstation (Windows95 series).

A SP-B5 (5\% Phenyl methyl siloxane) fused silica capillary column, $30 \mathrm{~m} \times 0.25$ - $\mathrm{mm}$ id. $(0.25 \mu \mathrm{m}$ film $)$ was used. The chromatographic conditions were as follows:

- carrier gas, helium $(1.5 \mathrm{~mL} / \mathrm{min})$

- injection mode: splitless

- injector \& detector temperatures: $275^{\circ} \mathrm{C}, 280^{\circ} \mathrm{C}$

The following temperature program was used:

- initial temperature $-50^{\circ} \mathrm{C}$, no hold

- ramp to $300^{\circ} \mathrm{c}$ at $6^{\circ} \mathrm{C} / \mathrm{min}$

- 10 min hold at $300^{\circ} \mathrm{C}$

The MSD was operated in scan mode to evaluate the chromatography and in the selected ion monitoring mode (SIM) for quantitative analysis of target compounds:

- $\mathrm{m} / \mathrm{z} 85$ ions for $n$-paraffins, pristane and phytane 
- $\mathrm{m} / \mathrm{z} 177$ and 191 ions for hopanes/triterpanes

- $\mathrm{m} / \mathrm{z} 217$ and 218 ions for steranes

Quantitative measurements of alkanes and biomarkers were achieved using the external standard method. Paraffin concentrations were obtained using the HP Chemstation software. Biomarker concentrations were determined using peak integration listings of $\mathrm{m} / \mathrm{z}$ ion pairs 177/191 and 217/218 from the HP Chemstation software as input data for BIOMQUANT, a dedicated software package written in Visual Basic to handle standard calibration curves and concentration calculations for samples. Pure authentic biomarker standards for the compounds listed in Table A.7 are used for quantitative analysis. The concentration of the other biomarkers were extrapolated as follows:

1. Hopanes: since the stereochemistry of most of the biomarkers of interest is " $\alpha \beta$ ", an average response factor from H15, H17 and H19 was calculated. The standard deviation of this average chromatographic response factor is about $10 \%$. This is the response factor used for all the other hopanes unavailable as standards, except for the homohopane series (homohopane, bis-, tris-, tetra- and pentakis-homohopanes). For the $\alpha \beta$-homohopane-S and $\alpha \beta$-homohopane-R series, the response factor of H21 and $\mathrm{H} 22$, respectively were applied.

2. Steranes: three C27 (carbon number), one C28 and two C29 authentic standards are available. A plot of response factor as a function of carbon number indicated that it was appropriate to use the response factors of the three C27's and two C29's in a linear regression analysis to obtain an equation that could be used to derive chromatographic response factors for the C20, C21, C22, C27, C28 and C29 steranes.

Table A. 7 Authentic standards for biomarker quantitation.

\begin{tabular}{|l|l|}
\hline Hopanes & Steranes \\
\hline aB-Trisnorhopane (H15) & aaa-20S-cholestane (S12) \\
\hline aB-Norhopane (H17) & aBB-20R-cholestane(S13) \\
\hline Ba-Norhopane & aaa-20R-cholestane (S15) \\
\hline aB-hopane (H19) & aBB-20R-methylcholestane (S18) \\
\hline Ba-hopane (H20) & aBB-20R-ethylcholestane (S23) \\
\hline aB-homohopane S (H21) & aaa-20R-ethylcholestane (S25) \\
\hline aB-homohopane R (H22) & \\
\hline BB-hopane (H23) & \\
\hline
\end{tabular}


Table A. 8 Target analytes for the alkane and biomarker suites of compounds

\begin{tabular}{|c|c|c|}
\hline Alkanes & Hopanes & Steranes \\
\hline $\mathrm{n}-\mathrm{C} 13$ & C19 tricyclic terpane $(\mathrm{H} 1)$ & C20 aaa-sterane (S1) \\
\hline $\mathrm{n}-\mathrm{C} 14$ & C20 tricyclic terpane $(\mathrm{H} 2)$ & C21 Baa-sterane (S2) \\
\hline $\mathrm{n}-\mathrm{C} 15$ & C21 tricyclic terpane $(\mathrm{H} 3)$ & C21 aBB-sterane $(\mathrm{S} 3,4)$ \\
\hline $\mathrm{n}-\mathrm{C} 16$ & C22 tricyclic terpane $(\mathrm{H} 4)$ & C21 aaa-sterane $(\mathrm{S} 4,3)$ \\
\hline $\mathrm{n}-\mathrm{C} 17$ & $\begin{array}{l}\text { C23 aB-dimethyl-a- } \\
\text { butylpodocarpane (H5) }\end{array}$ & C22 aBB-sterane (S5) \\
\hline $\begin{array}{l}\text { Pristane } \\
(2,6,10,14- \\
\text { tetramethylpentadecane) }\end{array}$ & $\begin{array}{l}\text { C24 aB-dimethyl-a- } \\
\text { methylbutylpodocarpane (H6) }\end{array}$ & $\begin{array}{l}\text { C27 20S-Ba-diasterane } \\
\text { (S6) }\end{array}$ \\
\hline n-C18 & C25 tricyclic terpane $(\mathrm{H} 7)$ & $\begin{array}{l}\text { C27 20R-Ba-diasterane } \\
\text { (S7) }\end{array}$ \\
\hline $\begin{array}{l}\text { Phytane } \\
(3,7,11,15- \\
\text { tetramethylhexadecane) }\end{array}$ & C26 tricyclic terpane $(\mathrm{H} 8)$ & $\begin{array}{l}\text { C27 20S-aB-diasterane } \\
\text { (S8) }\end{array}$ \\
\hline n-C19 & $\begin{array}{l}\text { C26 tricyclic triterpane 22R } \\
\left(\mathrm{H} 8{ }^{\prime}\right)\end{array}$ & $\begin{array}{l}\text { C27 20R-aB-diasterane } \\
\left(\mathrm{S} 8{ }^{\prime}\right)\end{array}$ \\
\hline $\mathrm{n}-\mathrm{C} 20$ & $\begin{array}{l}\text { C26 tricyclic triterpane } 22 \mathrm{~S} \\
(\mathrm{H} 8 ")\end{array}$ & $\begin{array}{l}\text { C28 20S-Ba-diasterane } \\
\text { (S9) }\end{array}$ \\
\hline $\mathrm{n}-\mathrm{C} 21$ & $\begin{array}{l}\text { C27 tetracyclic terpane } 22 \mathrm{R} \\
\text { (H9) }\end{array}$ & $\begin{array}{l}\text { C28 20R-Ba-diasterane } \\
\text { (S10) }\end{array}$ \\
\hline $\mathrm{n}-\mathrm{C} 22$ & $\begin{array}{l}\text { C27 tetracyclic terpane } 22 \mathrm{~S} \\
\text { (H10) }\end{array}$ & $\begin{array}{l}\mathrm{C} 28 \text { 20R/S?-Ba- } \\
\text { diasterane (S10') }\end{array}$ \\
\hline $\mathrm{n}-\mathrm{C} 23$ & $\begin{array}{l}\text { C28 tetracyclic terpane } 22 \mathrm{R} \\
\text { (H11) }\end{array}$ & $\begin{array}{l}\mathrm{C} 28 \text { 20R/S?-Ba- } \\
\text { diasterane (S10") }\end{array}$ \\
\hline $\mathrm{n}-\mathrm{C} 24$ & $\begin{array}{l}\text { C28 tetracyclic terpane } 22 \mathrm{~S} \\
\text { (H12) }\end{array}$ & $\begin{array}{l}\text { C28 20S-Ba-diasterane } \\
\left(\mathrm{S} 10^{\prime \prime}\right)\end{array}$ \\
\hline $\mathrm{n}-\mathrm{C} 25$ & $\begin{array}{l}\text { C27 aB-Trisnorneohopane Ts } \\
\text { (H13) }\end{array}$ & $\begin{array}{l}\text { C27 20R-Baa-cholestane } \\
\text { (S11) }\end{array}$ \\
\hline n-C26 & C27 aaB-Trisnorhopane(H14) & $\begin{array}{l}\text { C27 20S-aaa-cholestane } \\
\text { (S12) }\end{array}$ \\
\hline $\mathrm{n}-\mathrm{C} 27$ & $\begin{array}{l}\text { C27 Trisnorhopane Tm (H15) } \\
*\end{array}$ & $\begin{array}{l}\text { C27 20R-aBB-cholestane } \\
\text { (S13) }\end{array}$ \\
\hline $\mathrm{n}-\mathrm{C} 28$ & $\begin{array}{l}\text { C30 Tricyclic terpane } 22 \mathrm{R} \\
\left(\mathrm{H} 15^{\prime}\right)\end{array}$ & $\begin{array}{l}\text { C27 20S-aBB-cholestane } \\
(\mathrm{S} 14)\end{array}$ \\
\hline $\mathrm{n}-\mathrm{C} 29$ & $\begin{array}{l}\text { C30 Tricyclic terpane } 22 \mathrm{~S} \\
(\mathrm{H} 15 ")\end{array}$ & $\begin{array}{l}\text { C27 20R-aaa-cholestane } \\
\text { (S15) }\end{array}$ \\
\hline \multirow[t]{3}{*}{$n-C 30$} & C28 aaB-Bisnorhopane (H16) & $\begin{array}{l}\text { C29 20S-Ba-diasterane } \\
\text { (S16) }\end{array}$ \\
\hline & C29 aB-25-norhopane (H17') & $\begin{array}{l}\text { C29 20S-Ba-diasterane } \\
\left(\mathrm{S} 166^{\prime}\right)\end{array}$ \\
\hline & C29 aB-30-norhopane (H17) * & $\begin{array}{l}\text { C28 20S-aaa- } \\
\text { methylcholestane (S17) }\end{array}$ \\
\hline
\end{tabular}




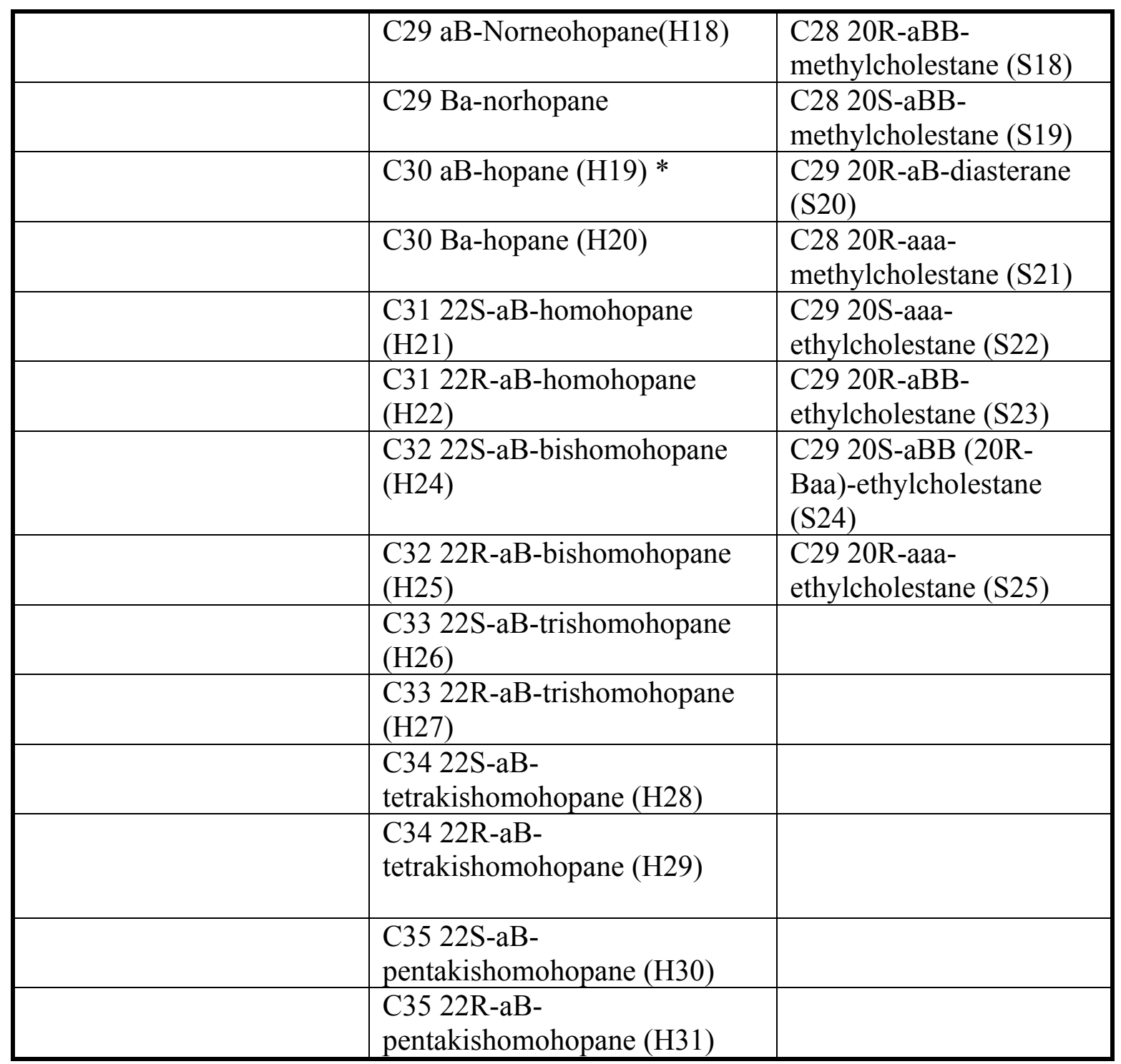

\section{$\mathrm{PAH}$ and $\mathrm{NO}_{2}$-PAH}

F2 contains $\mathrm{PAH}, \mathrm{NO}_{2}-\mathrm{PAH}, \mathrm{PASH}$ and some polar compounds. The F2 fraction was split in half. One half was analysed for PAH while the other half was analysed for $\mathrm{NO}_{2}$ PAH.

\section{PAH Fraction}

The extract was concentrated to approximately $450 \mu \mathrm{L}$ using a gentle stream of nitrogen. $50 \mu \mathrm{L}$ of d10-Floranthene $(10 \mu \mathrm{g} / \mathrm{mL})$ was added as an internal standard and the extract was made up to a final volume of $500 \mu \mathrm{L}$. The extract was analysed for PAH using low 
resolution GC/MS equipped with a $30 \mathrm{M}$ DB-XLB column. The details of the analytical conditions are given in Table A.9. Following PAH analysis the extract was concentrated to less than $50 \mu \mathrm{L}$ and to remove polar interferences it was injected onto a HPLC system with a $250 \times 4.6 \mathrm{~mm}$ silica column. The column was eluted with $5 \%$ dichloromethane in hexane at $1 \mathrm{~mL} / \mathrm{min}$. The fraction containing PASH was collected between 2 and 13 minutes. The extract was concentrated to $30 \mu \mathrm{L}$ before $20 \mu \mathrm{L}$ of d8-DBT was added as an internal standard.

\section{$\mathrm{NO}_{2}$-PAH Fraction}

The extract was blown down just to dryness using a gentle stream of nitrogen and then dissolved in $1 \mathrm{~mL}$ of DMSO. Aliphatic compounds were removed by extracting the DMSO with 3,1 mL aliqouts of hexane. The DMSO was then diluted with $3 \mathrm{~mL}$ of water before the $\mathrm{NO}_{2}-\mathrm{PAH}$ were extracted with $3,3 \mathrm{~mL}$ aliquots of cyclohexane. The extract was then concentrated and made up to a final volume of $100 \mu \mathrm{L}$ which was then injected onto a $250 \times 4.6 \mathrm{~mm}$ silica column contained in an HPLC system. The extract was then separated using a solvent gradient of $5 \%$ dichloromethane in hexane to $100 \%$ dichloromethane. The $\mathrm{NO}_{2}$-PAH were collected over a 17 minute window while the gradient was maintained at $45 \%$ DCM. The $\mathrm{NO}_{2}-\mathrm{PAH}$ fraction was concentrated to approximately $0.5 \mathrm{~mL}$ using a TurboVap before being blown down just to dryness under a gentle stream of nitrogen. $50 \mu \mathrm{L}$ of the internal standard containing d7-2nitrodibenzodioxin and d11-nitrobenzo(a)anthracene was added just before analysis. The samples were analyzed using HRGC/HRMS operating in the negative chemical ionization mode. Methane was used as the reagent gas. The GC is equipped with a DB-5 column. The analytical conditions are summarized in Table A.10.

Table A. 9 PAH analytical conditions

\begin{tabular}{|l|l|}
\hline Instrument & HP 5890 Series II GC interfaced with HP 5970 MSD. \\
\hline Injection & on-column, $1 \mu \mathrm{L}$ \\
\hline Column & $30 \mathrm{~m}$ DB-XLB fused silica, $0.25 \mathrm{~mm}$ ID and $0.25 \mu \mathrm{m}$ film thickness \\
\hline Oven Program & $\begin{array}{l}90^{\circ} \mathrm{C} \text { for } 1 \mathrm{~min}, \text { to } 200^{\circ} \mathrm{C} \text { at } 20^{\circ} \mathrm{C} / \mathrm{min} \text {, to } 250^{\circ} \mathrm{C} \text { at } 2.5^{\circ} \mathrm{C} / \mathrm{min}, \text { then to } \\
280^{\circ} \mathrm{C} \text { at } 1.5^{\circ} \mathrm{C} / \mathrm{min} \text { and hold for } 10 \mathrm{~min}\end{array}$ \\
\hline $\begin{array}{l}\text { Detection } \\
\text { Mode }\end{array}$ & $\begin{array}{l}\text { Electron Impact (EI), Selected Ion Monitoring (SIM); } \\
\text { Scan time } 1 \mathrm{~s} \text { or less, dwell time } 50-100 \mathrm{~ms} / \text { ion }\end{array}$ \\
& A minimum of two characteristic ions per compound are monitored. \\
\hline
\end{tabular}


Table A. $10 \mathrm{NO}_{2}$ PAH analytical conditions

\begin{tabular}{|l|l|}
\hline Instrument & HP 5890 Series II GC interfaced with VG Autospec HRMS \\
\hline Injection & $1 \mu \mathrm{L}$, Splitless, $280^{\circ} \mathrm{C}$ \\
\hline Column & $\begin{array}{l}30 \mathrm{~m} \text { DB-5 fused silica, } 0.25 \mathrm{~mm} \text { ID and } 0.25 \mu \mathrm{m} \text { film } \\
\text { thickness }\end{array}$ \\
\hline Oven Program & $\begin{array}{l}100^{\circ} \mathrm{C} \text { for } 2 \mathrm{~min}, \text { to } 200^{\circ} \mathrm{C} \text { at } 25^{\circ} \mathrm{C} / \mathrm{min} \text {, hold } 1 \mathrm{~min} ., 10 \\
{ }^{\circ} \mathrm{C} / \mathrm{min} \text { to } 240^{\circ} \mathrm{C}, 5^{\circ} \mathrm{C} / \mathrm{min} \text { to } 300^{\circ} \mathrm{C} \text { and hold for } 5.4 \mathrm{~min}\end{array}$ \\
\hline Ionisation Mode & $\begin{array}{l}\mathrm{NCI} \text { using UHP } \operatorname{argon} \text { as reagent gas, Selected Ion } \\
\text { Recording } \\
\text { Source pressure: } 2-4 \times 10^{-5} \text { torr } \\
\text { Source temperature: } 260^{\circ} \mathrm{C}\end{array}$ \\
\hline
\end{tabular}

\section{Identification and Quantitation}

A total of three ion masses (one quantitation ion and two confirmation ions) were monitored for each PAH analyte as shown in Table A.11 and Table A.12. The presence of a target compound in the sample extract was confirmed when all of the following criteria were satisfied:

- Response for the two most abundant characteristic ions must exceed the background noise level by a minimum ratio of 3:1.

- The abundance ratio of the two major characteristic ions must be within $\pm 40 \%$ of the corresponding compound in the external standard solution.

- The third qualifying ion must be present unless the ion is masked by high background interference.

- The peak maxima for the specified characteristic ions must be coincident within 2 scan units.

- Analyte's retention time relative to the closest eluting surrogate must be within $0.1 \mathrm{~min}$ of the relative retention time of the corresponding standard mixture components.

Quantitative measurement of PAH was achieved using the external standard calibration method. 
Table A. 11 Target Analytes and Monitored Ions for PAH Analysis

\begin{tabular}{|c|c|c|c|c|c|c|c|}
\hline Compounds & Abbrev. & MW & Rings & Surrogate & $\begin{array}{c}\text { Quantitation } \\
\text { Ion }\end{array}$ & $\begin{array}{c}\text { Confirmation } \\
\text { Ions }\end{array}$ & $\begin{array}{l}\text { Relative } \\
\text { Intensity }\end{array}$ \\
\hline Naphthalene & NAP & 128 & 2 & NAP- $\mathrm{d}_{8} *$ & 128 & 127,102 & $100,17,7$ \\
\hline Acenaphthylene & $\mathrm{AL}$ & 152 & 3 & AL-d ${ }_{8}^{*}$ & 152 & 151,150 & $100,20,13$ \\
\hline Acenaphthene & $\mathrm{AE}$ & 154 & 3 & AE-d $d_{10}$ & 153 & 154,152 & $100,96,21$ \\
\hline Fluorene & FL & 166 & 3 & FL-d ${ }_{10} *$ & 166 & 165,163 & $100,91,18$ \\
\hline 2-Me-fluorene & MFL & 178 & 3 & & 165 & 180,178 & $100,76,27$ \\
\hline Phenanthrene & PHE & 178 & 3 & ${\text { PHE}-d_{10}}^{*}$ & 178 & 176,179 & $100,19,16$ \\
\hline Anthracene & AN & 178 & 3 & AN-d $d_{10}$ & 178 & 176,179 & $100,18,16$ \\
\hline Fluoranthene & FLT & 202 & 4 & & 202 & 200,101 & $100,21,13$ \\
\hline Pyrene & PY & 202 & 4 & $\mathrm{Py}-\mathrm{d}_{10}$ & 202 & 200,101 & $100,21,13$ \\
\hline Retene & RET & 234 & 3 & & 219 & 234,204 & $100,68,28$ \\
\hline Benzo(a)fluorene & B(a)FL & 216 & 4 & & 216 & 215,108 & $100,77,8$ \\
\hline Benzo(b)fluorene & $\mathrm{B}(\mathrm{b}) \mathrm{FL}$ & 216 & 4 & & 216 & 215,108 & $100,93,9$ \\
\hline 1-Me-pyrene & MPY & 216 & 4 & & 216 & 215,108 & $100,73,7$ \\
\hline Benzo(ghi)fluoranthene & $\mathrm{B}$ (ghi)F & 226 & 5 & & 226 & 224,113 & $100,24,11$ \\
\hline Benz(a)anthracene & $\mathrm{B}(\mathrm{a}) \mathrm{A}$ & 228 & 4 & $\mathrm{~B}(\mathrm{a}) \mathrm{A}-\mathrm{d}_{12}$ & 228 & 226,114 & $100,27,8$ \\
\hline Chrysene & $\mathrm{C}$ & 228 & 4 & $\mathrm{C}-\mathrm{d}_{12} *$ & 228 & 226,114 & $100,29,7$ \\
\hline Triphenylene & $\mathrm{T}$ & 228 & 4 & $\mathrm{~T}-\mathrm{d}_{12} *$ & 228 & 226,114 & $100,29,7$ \\
\hline 7-Me-Benz(a)anthracene & $\mathrm{MB}(\mathrm{a}) \mathrm{A}$ & 242 & 4 & & 242 & 241,239 & $100,38,5$ \\
\hline Benzo(b)fluoranthene & $\mathrm{B}(\mathrm{b}) \mathrm{F}$ & 252 & 5 & $\mathrm{~B}(\mathrm{~b}) \mathrm{FL}-\mathrm{d}_{12} *$ & 252 & 250,126 & $100,24,9$ \\
\hline Benzo(k)fluoranthene & $\mathrm{B}(\mathrm{k}) \mathrm{F}$ & 252 & 5 & & 252 & 250,126 & $100,24,9$ \\
\hline Benzo(e)pyrene & $\mathrm{B}(\mathrm{e}) \mathrm{P}$ & 252 & 5 & $\mathrm{~B}(\mathrm{e}) \mathrm{P}-\mathrm{d}_{12} *$ & 252 & 250,126 & $100,30,8$ \\
\hline Benzo(a)pyrene & $\mathrm{B}(\mathrm{a}) \mathrm{P}$ & 252 & 5 & $\mathrm{~B}(\mathrm{a}) \mathrm{P}-\mathrm{d}_{12}$ & 252 & 250,126 & $100,25,10$ \\
\hline Perylene & PER & 252 & 5 & PER-d $12^{*}$ & 252 & 250,126 & $100,29,10$ \\
\hline 3-Me-cholanthrene & $\mathrm{MCH}$ & 268 & 5 & & 268 & 252,126 & $100,34,10$ \\
\hline Indeno(1,2,3-cd)pyrene & IP & 276 & 6 & IP-d $12 *$ & 276 & 274,138 & $100,21,10$ \\
\hline Dibenz(ah)anthracene & $\mathrm{D}(\mathrm{ah}) \mathrm{A}$ & 278 & 5 & $\mathrm{D}(\mathrm{ah}) \mathrm{A}-\mathrm{d}_{14}$ & 278 & 276,139 & $100,39,7$ \\
\hline
\end{tabular}




\begin{tabular}{|l|l|c|c|c|c|c|c|}
\hline Compounds & Abbrev. & MW & Rings & Surrogate & $\begin{array}{c}\text { Quantitation } \\
\text { Ion }\end{array}$ & $\begin{array}{c}\text { Confirmation } \\
\text { Ions }\end{array}$ & $\begin{array}{c}\text { Relative } \\
\text { Intensity }\end{array}$ \\
\hline Benzo(b)chrysene & $\mathrm{B}(\mathrm{b}) \mathrm{C}$ & 278 & 5 & & 278 & 276,139 & $100,28,6$ \\
\hline Benzo(ghi)perylene & $\mathrm{B}(\mathrm{ghi}) \mathrm{P}$ & 276 & 6 & $\mathrm{~B}(\mathrm{ghi}) \mathrm{P}-\mathrm{d}_{12}$ & 276 & 274,138 & $100,22,11$ \\
\hline Anthanthrene & $\mathrm{ANT}$ & 276 & 6 & & 276 & 274,138 & $100,20,10$ \\
\hline Indeno(123cd)fluoranthene & $\mathrm{IF}$ & 276 & 6 & & 276 & 274,138 & $10,20,17$ \\
\hline Internal Standard & & & & & & & \\
\hline Fluoranthene-d & & 212 & & & & & \\
\hline
\end{tabular}

Note: $\mathrm{Me}=$ Methyl 
Table A. 12 Quantitation Standards and Monitored Ions for Nitro-PAH analysis

\begin{tabular}{|c|c|c|c|}
\hline Compounds & $\begin{array}{c}\text { Quantitation Ion } \\
\text { (M) }\end{array}$ & $\begin{array}{c}\text { Confirmation Ion } \\
(M+1)\end{array}$ & Relative Intensity \\
\hline 2- Nitrofluorene & 211 & 212 & 6.62 \\
\hline \multicolumn{4}{|l|}{ Total Nitro-C13* } \\
\hline 9-Nitoranthracene & 223 & 224 & 6.29 \\
\hline 2-Nitroanthracene & 223 & 224 & 6.29 \\
\hline 9-Nitrophenanthrene & 223 & 224 & 6.29 \\
\hline \multicolumn{4}{|l|}{ Total Nitro-C14* } \\
\hline 2-Nitrofluoranthene & 247 & 248 & 5.36 \\
\hline 3-Nitorfluoranthene & 247 & 248 & 5.36 \\
\hline 4-Nitropyrene & 247 & 248 & 5.36 \\
\hline 1-Nitropyrene & 247 & 248 & 5.36 \\
\hline 2-Nitropyrene & 247 & 248 & 5.36 \\
\hline \multicolumn{4}{|l|}{ Total Nitro-C16* } \\
\hline 7-Nitrobenz(a)anthracene & 273 & 274 & 4.80 \\
\hline 6-Nitrochrysene & 273 & 274 & 4.80 \\
\hline \multicolumn{4}{|l|}{ Total Nitro-C18* } \\
\hline 1-Nitrobenzo(e)pyrene & 297 & 298 & 4.48 \\
\hline 6-Nitrobenzo(a)pyrene & 297 & 298 & 4.48 \\
\hline 4-Nitrobenzo(e)pyrene & 297 & 298 & 4.48 \\
\hline 3-Nitrobenzo(e)pyrene & 297 & 298 & 4.48 \\
\hline 3-Nitrobenzo(a)pyrene & 297 & 298 & 4.48 \\
\hline 1-Nitrobenzo(a)pyrene & 297 & 298 & 4.48 \\
\hline 2-Nitrobenzo(a)pyrene & 297 & 298 & 4.48 \\
\hline \multicolumn{4}{|l|}{ Total Nitro-C20* } \\
\hline 9-Nitrodibenz $(\mathrm{a}, \mathrm{c})$ anthracene & 323 & 324 & 3.98 \\
\hline \multicolumn{4}{|l|}{ Total Nitro-C22* } \\
\hline 1,3-Dinitropyrene & 292 & 293 & 5.31 \\
\hline 1,6-Dinitropyrene & 292 & 293 & 5.31 \\
\hline 1,8-Dinitropyrene & 292 & 293 & 5.31 \\
\hline 7-Nitro-12-Methyl-B(a)A & 287 & 288 & 4.80 \\
\hline 12-Ethyl-6-Nitrochrysene & 301 & 302 & 4.36 \\
\hline \multicolumn{4}{|l|}{ Surrogates: } \\
\hline $\mathrm{d}_{9}-2-$ Nitrofluorene & 220 & 221 & 6.71 \\
\hline $\mathrm{d}_{9}-9-$ Nitroanthracene & 232 & 233 & 6.61 \\
\hline $\mathrm{d}_{9}-3$-Nitrofluoranthene & 256 & 257 & 5.46 \\
\hline $\mathrm{d}_{9}$-1-Nitropyrene & 256 & 257 & 5.46 \\
\hline $\mathrm{d}_{11}-6$-Nitrochrysene & 284 & 285 & 5.18 \\
\hline $\mathrm{d}_{11}-6$-Nitrobenzo(a)pyrene & 308 & 309 & 4.41 \\
\hline $\mathrm{d}_{8}-1,3$-Dinitropyrene & 300 & 301 & 5.35 \\
\hline Compounds & Quantitation Ion & Confirmation Ion & Relative Intensity \\
\hline
\end{tabular}




\begin{tabular}{|l|c|c|c|}
\hline & $\mathbf{( M )}$ & $\mathbf{( M + 1 )}$ & \\
\hline $\mathrm{d}_{8}$-1,6-Dinitropyrene & 300 & 301 & 5.35 \\
\hline $\mathrm{d}_{8}$-1,8-Dinitropyrene & 300 & 301 & 5.35 \\
\hline Internal Standard: & & & \\
\hline $\mathrm{d}_{7}$-2-Nitrodibenzodioxin & 236 & 237 & 7.20 \\
\hline $\mathrm{d} 11-7-N$ itrobenz(a)anthracene & 284 & 285 & 5.18 \\
\hline
\end{tabular}

\section{Organic and Elemental Carbon}

The two quartz filters (one primary particulate matter filter and one secondary adsorbed carbon filter) were submitted for analysis of total organic and elemental carbon using NIOSH Method 5040 Thermal/Optical Transmittance (TOT) method. A $1.5 \mathrm{~cm}^{2}$ punch is taken from each filter sample. This filter punch is heated sequentially at temperatures of $325,475,625$ and $870{ }^{\circ} \mathrm{C}$ in a pure helium atmosphere to evolve volatile carbon. The sample is cooled to $550{ }^{\circ} \mathrm{C}$, the atmosphere is changed to $10 \%$ oxygen in helium and the sample is heated further at $625,700,775,850$ and $910{ }^{\circ} \mathrm{C}$. The carbon dioxide evolved is first quantitatively converted to carbon dioxide by catalytic oxidation then quantitatively converted to methane by catalytic reduction. The methane is quantified using a flame ionisation detector. The transmittance of laser light by the filter sample is monitored throughout the analysis. This transmittance decreases during the volatilization in a helium atmosphere due to the pyrolysis of organic material. When oxygen is added, the transmittance increases as the light absorbing pyrolized carbon is combusted and removed. Organic carbon is defined as that which evolves prior to re-attainment of the initial transmittance and elemental carbon as that material that evolves after the original transmittance has been attained. Analysis results are reported in units of $\mu \mathrm{g} / \mathrm{cm}^{2}$.

\section{Elemental Analysis}

$\mathrm{XRF}$ spectrometry is based on the measurement of fluorescent $\mathrm{x}$-rays produced when an inner shell electron is ejected allowing a higher energy electron to drop into the lower energy orbital to fill the vacancy. The energy of the fluorescent $\mathrm{x}$-ray is characteristic of the emitting element and the area of the fluorescent peak is proportional to the number of atoms in the sample. 
Quantitative determination is made through comparison with thin metal foil and salt standards (Micromatter $\left.{ }^{\circledR}\right)$. With the sample deposited as a thin layer on the filter, matrix effects are substantially reduced, and with small particle diameters, XRF elemental determinations become more accurate due to lower self-absorption of low energy x-rays by large particles.

The x-ray spectrometer is the Kevex EDX-771 with a 200 watt rhodium target tube as an excitation source. The instrument has three modes of excitation: direct, filtered direct and secondary targets. The detector, cooled by liquid nitrogen, is lithium-drifted silicon with a $5 \mathrm{~mm}$ Be window with tantalum collimator having a resolution of $165 \mathrm{eV}$ at $5.9 \mathrm{KeV}$. A 16 position, rotating sample wheel provides for sample changing. . Samples are measured under vacuum for 1000 seconds live time using three excitation conditions to allow for optimal determination of different elements. The analysis parameters are summarized in Table A.13.

Samples are measured in inverted geometry (the deposit side is facing the detector). In this case it is necessary to protect the detector window from material falling onto it by placing a Prolene film between the filter and the detector window.(XRF Prolene, diameter $63.5 \mathrm{~mm}, 4.0 \mathrm{~m}$ thickness, supplied by Chemplex Industries). Filter blanks with their Prolene films are analyzed prior to particulate loading and the resulting spectra saved.

Spectral processing of the samples begins with a correction for variations in the $\mathrm{x}$-ray tube flux using Reference monitors (NIST 1832 and 1833). The background is removed by subtracting the previously analyzed blank filters and their associated Prolene films. Escape and sum peaks are removed, followed by correction for peak interferences. Linear least square Gaussian deconvolution is performed on the remaining net spectra to obtain analytical elemental concentrations that are reported in units of $\mu \mathrm{g} / \mathrm{cm}^{2}$.

Table A. 13 Parameters for XRF analysis.

\begin{tabular}{|c|c|c|c|c|c|}
\hline $\begin{array}{c}\text { Excitation } \\
\text { Condition }\end{array}$ & Tube & $\begin{array}{c}\text { Potential } \\
(\mathbf{k V})\end{array}$ & $\begin{array}{c}\text { Current } \\
(\mathbf{m A})\end{array}$ & Collimator & Transmission Filters \\
\hline 1 & Direct & 60 & 3 & $3 \mathrm{~mm}$ & $1 \mathrm{Mo}, 1 \mathrm{Zr}, 1 \mathrm{Cu}, 2 \mathrm{Gd}$ \\
\hline 2 & Direct & 60 & 3 & $5 \mathrm{~mm}$ & $1 \mathrm{Sn}, 4 \mathrm{Ag}$ \\
\hline 3 & Direct & 6 & 0.5 & $3 \mathrm{~mm}$ & none \\
\hline
\end{tabular}




\section{APPENDIX B: TEST ENGINE AND VEHICLE SPECIFICATION}

\section{Vehicle Information}

Vehicle Type

Vehicle ID Number (VIN)

Vehicle Manufacturer

Vehicle Model Year

Gross Vehicle Weight (GVW)

Vehicle Tested Weight (lb.)

Transmission Type

Transmission Configuration

Number of Axles

\section{$\underline{\text { Engine Information }}$}

Engine Manufacturer

Engine ID Number

Engine Model Year

Engine Model

Engine Displacement

Number of Cylinders

Compression Ratio

Engine Rated Power

Peak Torque

Ignition System

Fuel Injection

Net Weight

Primary Fuel
Transit Bus

2B1569K7XR6031936

Orion

1994

40000 lbs.

$35800 \mathrm{lbs}$

Auto

4 speed

2

Cummins Westport Innovations

45912400

2000

C-Series, Gas plus $(\mathrm{C} 8.3 \mathrm{G}+)$

8.3 liters

6

10:1

280 hp@2400rpm

850 ft-1b@1400rpm

Spark Ignited

Premixed Air/Fuel

$1330 \mathrm{lbs}$

Auto-grade CNG 


\section{APPENDIX C: CONSOLIDATED SPECIATION RESULTS}

\section{Table C. 1 Emissions of Alkanes Measured in Different Phases}

\begin{tabular}{|c|c|c|c|c|c|c|c|c|c|c|}
\hline \multirow{2}{*}{$\begin{array}{l}\text { Alkanes } \\
\text { g/mile }\end{array}$} & \multirow{2}{*}{$\begin{array}{l}\text { Limit of } \\
\text { Detection }\end{array}$} & \multicolumn{3}{|c|}{$\begin{array}{c}\text { Phase I } \\
\text { Baseline \& OEM catalyst }\end{array}$} & \multicolumn{2}{|c|}{\begin{tabular}{|c|} 
Phase II \\
New WVU-Lubrizol Aftertreatment \\
\end{tabular}} & \multicolumn{4}{|c|}{$\begin{array}{c}\text { Phase III } \\
\text { Post Demo WVU-Lubrizol Aftertreatment }\end{array}$} \\
\hline & & \begin{tabular}{|c|} 
QCBD \\
(Baseline)
\end{tabular} & $\begin{array}{c}\text { QCBD } \\
\text { (OEM Catalyst) }\end{array}$ & Background & QCBD & Background & QCBD & $\begin{array}{c}\text { Standard } \\
\text { Deviation }\end{array}$ & Background & $\begin{array}{c}\text { Standard } \\
\text { Deviation }\end{array}$ \\
\hline $\mathrm{n}-\mathrm{C} 10$ & $1.03 \mathrm{E}-06$ & $3.70 \mathrm{E}-05$ & $1.47 \mathrm{E}-05$ & $2.81 \mathrm{E}-05$ & $2.07 \mathrm{E}-05$ & $4.55 \mathrm{E}-05$ & $5.76 \mathrm{E}-04$ & $2.21 \mathrm{E}-04$ & $3.15 \mathrm{E}-04$ & $1.87 \mathrm{E}-05$ \\
\hline $\mathrm{n}-\mathrm{C} 11$ & $1.94 \mathrm{E}-06$ & $4.22 \mathrm{E}-05$ & $1.69 \mathrm{E}-05$ & $4.93 \mathrm{E}-05$ & $2.56 \mathrm{E}-05$ & $6.56 \mathrm{E}-05$ & $2.28 \mathrm{E}-03$ & $1.21 \mathrm{E}-03$ & $6.53 \mathrm{E}-04$ & $1.01 \mathrm{E}-04$ \\
\hline $\mathrm{n}-\mathrm{C} 12$ & $1.37 \mathrm{E}-06$ & $2.98 \mathrm{E}-05$ & $1.50 \mathrm{E}-05$ & $2.81 \mathrm{E}-05$ & $2.08 \mathrm{E}-05$ & $4.47 \mathrm{E}-05$ & $1.46 \mathrm{E}-03$ & $1.09 \mathrm{E}-03$ & $4.61 \mathrm{E}-04$ & $4.11 \mathrm{E}-05$ \\
\hline $\mathrm{n}-\mathrm{C} 13$ & $1.40 \mathrm{E}-06$ & $3.58 \mathrm{E}-05$ & $2.06 \mathrm{E}-05$ & $2.64 \mathrm{E}-05$ & $3.00 \mathrm{E}-05$ & $4.87 \mathrm{E}-05$ & $1.92 \mathrm{E}-04$ & $6.33 \mathrm{E}-05$ & $1.14 \mathrm{E}-04$ & $5.95 \mathrm{E}-05$ \\
\hline $\mathrm{n}-\mathrm{C} 14$ & $1.69 \mathrm{E}-06$ & $4.74 \mathrm{E}-05$ & $3.31 \mathrm{E}-05$ & $3.83 \mathrm{E}-05$ & $4.55 \mathrm{E}-05$ & $5.48 \mathrm{E}-05$ & $3.08 \mathrm{E}-04$ & $1.73 \mathrm{E}-04$ & $1.60 \mathrm{E}-04$ & $8.63 \mathrm{E}-05$ \\
\hline $\mathrm{n}-\mathrm{C} 15$ & $1.62 \mathrm{E}-06$ & $6.29 \mathrm{E}-05$ & $4.75 \mathrm{E}-05$ & $3.77 \mathrm{E}-05$ & $5.66 \mathrm{E}-05$ & $5.51 \mathrm{E}-05$ & $3.73 \mathrm{E}-04$ & $2.02 \mathrm{E}-04$ & $1.33 \mathrm{E}-04$ & $3.18 \mathrm{E}-05$ \\
\hline $\mathrm{n}-\mathrm{C} 16$ & $2.68 \mathrm{E}-06$ & $1.20 \mathrm{E}-04$ & $8.20 \mathrm{E}-05$ & $6.20 \mathrm{E}-05$ & $8.72 \mathrm{E}-05$ & $7.90 \mathrm{E}-05$ & $5.55 \mathrm{E}-04$ & $3.12 \mathrm{E}-04$ & $1.65 \mathrm{E}-04$ & $6.47 \mathrm{E}-07$ \\
\hline $\mathrm{n}-\mathrm{C} 17$ & $1.94 \mathrm{E}-06$ & $1.71 \mathrm{E}-04$ & $1.25 \mathrm{E}-04$ & $7.96 \mathrm{E}-05$ & $1.12 \mathrm{E}-04$ & $9.76 \mathrm{E}-05$ & $6.45 \mathrm{E}-04$ & $3.33 \mathrm{E}-04$ & $1.92 \mathrm{E}-04$ & $1.11 \mathrm{E}-05$ \\
\hline Pristane & $1.44 \mathrm{E}-06$ & $4.16 \mathrm{E}-05$ & $2.21 \mathrm{E}-05$ & $1.39 \mathrm{E}-05$ & $2.73 \mathrm{E}-05$ & $2.32 \mathrm{E}-05$ & $1.98 \mathrm{E}-04$ & $8.35 \mathrm{E}-05$ & $4.98 \mathrm{E}-05$ & $1.18 \mathrm{E}-05$ \\
\hline $\mathrm{n}-\mathrm{C} 18$ & $1.85 \mathrm{E}-06$ & $1.09 \mathrm{E}-04$ & $7.30 \mathrm{E}-05$ & $5.18 \mathrm{E}-05$ & $8.70 \mathrm{E}-05$ & $6.93 \mathrm{E}-05$ & $4.03 \mathrm{E}-04$ & $2.13 \mathrm{E}-04$ & $1.28 \mathrm{E}-04$ & $1.25 \mathrm{E}-05$ \\
\hline Phytane & $1.97 \mathrm{E}-06$ & $3.56 \mathrm{E}-05$ & $2.55 \mathrm{E}-05$ & $1.59 \mathrm{E}-05$ & $2.41 \mathrm{E}-05$ & $2.26 \mathrm{E}-05$ & $1.69 \mathrm{E}-04$ & $7.86 \mathrm{E}-05$ & $6.01 \mathrm{E}-05$ & $3.58 \mathrm{E}-06$ \\
\hline n-C19 & $1.65 \mathrm{E}-06$ & $5.17 \mathrm{E}-05$ & $3.58 \mathrm{E}-05$ & $2.36 \mathrm{E}-05$ & $9.23 \mathrm{E}-05$ & $4.04 \mathrm{E}-05$ & $2.55 \mathrm{E}-04$ & $1.25 \mathrm{E}-04$ & $9.76 \mathrm{E}-05$ & $1.15 \mathrm{E}-05$ \\
\hline $\mathrm{n}-\mathrm{C} 20$ & $1.40 \mathrm{E}-06$ & 5.83E-05 & $3.99 \mathrm{E}-05$ & $2.06 \mathrm{E}-05$ & $8.40 \mathrm{E}-05$ & $3.23 \mathrm{E}-05$ & $2.22 \mathrm{E}-04$ & $1.03 \mathrm{E}-04$ & $9.03 \mathrm{E}-05$ & $3.38 \mathrm{E}-05$ \\
\hline $\mathrm{n}-\mathrm{C} 21$ & $1.01 \mathrm{E}-06$ & $5.88 \mathrm{E}-05$ & $3.99 \mathrm{E}-05$ & $1.73 \mathrm{E}-05$ & $4.11 \mathrm{E}-05$ & $1.89 \mathrm{E}-05$ & $2.15 \mathrm{E}-04$ & $7.80 \mathrm{E}-05$ & $8.28 \mathrm{E}-05$ & $1.33 \mathrm{E}-05$ \\
\hline $\mathrm{n}-\mathrm{C} 22$ & $1.28 \mathrm{E}-06$ & $3.82 \mathrm{E}-05$ & $2.19 \mathrm{E}-05$ & $1.35 \mathrm{E}-05$ & $1.70 \mathrm{E}-05$ & $1.28 \mathrm{E}-05$ & $1.18 \mathrm{E}-04$ & $4.14 \mathrm{E}-05$ & $5.58 \mathrm{E}-05$ & $3.59 \mathrm{E}-06$ \\
\hline $\mathrm{n}-\mathrm{C} 23$ & $1.08 \mathrm{E}-06$ & $1.69 \mathrm{E}-05$ & $8.85 \mathrm{E}-06$ & $8.70 \mathrm{E}-06$ & $7.14 \mathrm{E}-06$ & $7.73 \mathrm{E}-06$ & $6.90 \mathrm{E}-05$ & $2.37 \mathrm{E}-05$ & $5.29 \mathrm{E}-05$ & $6.01 \mathrm{E}-06$ \\
\hline $\mathrm{n}-\mathrm{C} 24$ & $2.78 \mathrm{E}-05$ & $1.12 \mathrm{E}-05$ & $4.68 \mathrm{E}-06$ & $6.69 \mathrm{E}-06$ & $4.59 \mathrm{E}-06$ & $6.81 \mathrm{E}-06$ & $4.36 \mathrm{E}-05$ & $2.84 \mathrm{E}-05$ & $5.73 \mathrm{E}-05$ & $1.58 \mathrm{E}-05$ \\
\hline$n-C 25$ & $8.92 \mathrm{E}-07$ & $1.00 \mathrm{E}-05$ & $4.94 \mathrm{E}-06$ & $6.83 \mathrm{E}-06$ & $4.34 \mathrm{E}-06$ & $6.03 \mathrm{E}-06$ & $4.62 \mathrm{E}-05$ & $3.96 \mathrm{E}-05$ & $6.91 \mathrm{E}-05$ & $1.48 \mathrm{E}-05$ \\
\hline $\mathrm{n}-\mathrm{C} 26$ & $7.47 \mathrm{E}-07$ & $1.06 \mathrm{E}-05$ & $5.21 \mathrm{E}-06$ & $6.42 \mathrm{E}-06$ & $4.08 \mathrm{E}-06$ & $6.03 \mathrm{E}-06$ & $8.08 \mathrm{E}-05$ & - & $7.15 \mathrm{E}-05$ & $8.90 \mathrm{E}-06$ \\
\hline $\mathrm{n}-\mathrm{C} 27$ & $8.47 \mathrm{E}-07$ & $1.35 \mathrm{E}-05$ & $5.47 \mathrm{E}-06$ & $5.76 \mathrm{E}-06$ & $<\mathrm{LOD}$ & $6.03 \mathrm{E}-06$ & $4.37 \mathrm{E}-05$ & $4.37 \mathrm{E}-05$ & $7.86 \mathrm{E}-05$ & 7.89E-06 \\
\hline n-C28 & $5.26 \mathrm{E}-07$ & $1.12 \mathrm{E}-05$ & $4.94 \mathrm{E}-06$ & $5.62 \mathrm{E}-06$ & $<\mathrm{LOD}$ & $1.04 \mathrm{E}-05$ & $3.38 \mathrm{E}-05$ & $3.12 \mathrm{E}-05$ & $7.38 \mathrm{E}-05$ & $3.31 \mathrm{E}-06$ \\
\hline n-C29 & $3.66 \mathrm{E}-07$ & $1.15 \mathrm{E}-05$ & $5.34 \mathrm{E}-06$ & $6.29 \mathrm{E}-06$ & $<\mathrm{LOD}$ & $7.43 \mathrm{E}-06$ & $3.85 \mathrm{E}-05$ & $1.84 \mathrm{E}-05$ & $7.58 \mathrm{E}-05$ & $2.32 \mathrm{E}-06$ \\
\hline $\mathrm{n}-\mathrm{C} 30$ & $3.20 \mathrm{E}-07$ & $1.06 \mathrm{E}-05$ & $3.77 \mathrm{E}-06$ & $4.02 \mathrm{E}-06$ & $<\mathrm{LOD}$ & $5.88 \mathrm{E}-06$ & $2.16 \mathrm{E}-05$ & $1.39 \mathrm{E}-05$ & $5.86 \mathrm{E}-05$ & $3.02 \mathrm{E}-07$ \\
\hline $\mathrm{n}-\mathrm{C} 31$ & $2.52 \mathrm{E}-07$ & $6.60 \mathrm{E}-06$ & $3.12 \mathrm{E}-06$ & $3.48 \mathrm{E}-06$ & $<\mathrm{LOD}$ & $<$ LOD & $2.00 \mathrm{E}-05$ & $1.12 \mathrm{E}-05$ & $5.85 \mathrm{E}-05$ & $7.66 \mathrm{E}-06$ \\
\hline$n-C 32$ & $2.06 \mathrm{E}-07$ & $4.59 \mathrm{E}-06$ & $2.08 \mathrm{E}-06$ & $2.01 \mathrm{E}-06$ & $<$ LOD & $<\mathrm{LOD}$ & $2.05 \mathrm{E}-05$ & - & $3.58 \mathrm{E}-05$ & $2.75 \mathrm{E}-06$ \\
\hline n-C33 & $1.37 \mathrm{E}-07$ & $2.30 \mathrm{E}-06$ & $1.17 \mathrm{E}-06$ & $1.34 \mathrm{E}-06$ & $<\mathrm{LOD}$ & $<\mathrm{LOD}$ & $<\mathrm{LOD}$ & - & $2.89 \mathrm{E}-05$ & $4.53 \mathrm{E}-06$ \\
\hline$n-C 34$ & $9.15 \mathrm{E}-08$ & $1.15 \mathrm{E}-06$ & $6.51 \mathrm{E}-07$ & $8.03 \mathrm{E}-07$ & $<$ LOD & $<$ LOD & $<$ LOD & - & $1.60 \mathrm{E}-05$ & $1.16 \mathrm{E}-06$ \\
\hline $\mathrm{n}-\mathrm{C} 36$ & $9.15 \mathrm{E}-08$ & $<\mathrm{LOD}$ & $<\mathrm{LOD}$ & $<\mathrm{LOD}$ & $<\mathrm{LOD}$ & $<\mathrm{LOD}$ & $<\mathrm{LOD}$ & - & $<\mathrm{LOD}$ & - \\
\hline
\end{tabular}


Table C. 2 Emissions of Hopanes Measured in Different Phases

\begin{tabular}{|c|c|c|c|c|c|c|c|c|c|c|}
\hline \multirow{2}{*}{$\begin{array}{c}\text { Hopanes } \\
\text { g/mile }\end{array}$} & \multirow{2}{*}{$\begin{array}{l}\text { Limit of } \\
\text { Detection }\end{array}$} & \multicolumn{3}{|c|}{$\begin{array}{c}\text { Phase I } \\
\text { Baseline and OEM Catalyst }\end{array}$} & \multicolumn{2}{|c|}{\begin{tabular}{|c|} 
Phase II \\
New WVU-Lubrizol \\
Aftertreatment
\end{tabular}} & \multicolumn{4}{|c|}{$\begin{array}{c}\text { Phase III } \\
\text { Post Demo WVU-Lubrizol } \\
\text { Aftertreatment }\end{array}$} \\
\hline & & $\begin{array}{c}\text { QCBD } \\
\text { (Baseline) }\end{array}$ & \begin{tabular}{|c|} 
QCBD \\
(OEM \\
Catalyst)
\end{tabular} & Background & $\mathrm{d}$ QCBD & Background & $\mathrm{d}$ QCBD & $\begin{array}{c}\text { Standard } \\
\text { Deviation }\end{array}$ & Background & $\begin{array}{l}\text { Standard } \\
\text { Deviation }\end{array}$ \\
\hline C19 tricyclic terpane $(\mathrm{H} 1)$ & $2.55 \mathrm{E}-08$ & $2.85 \mathrm{E}-07$ & $2.03 \mathrm{E}-07$ & $1.08 \mathrm{E}-07$ & $1.61 \mathrm{E}-07$ & \begin{tabular}{l|l}
7 & $2.20 \mathrm{E}-07$ \\
\end{tabular} & $1.82 \mathrm{E}-06$ & - & $<$ LOD & - \\
\hline C20 tricyclic terpane $(\mathrm{H} 2)$ & $1.20 \mathrm{E}-08$ & $9.85 \mathrm{E}-07$ & $3.04 \mathrm{E}-07$ & $3.38 \mathrm{E}-07$ & $2.44 \mathrm{E}-07$ & $\begin{array}{ll}7 & 3.19 \mathrm{E}-07 \\
\end{array}$ & $3.33 \mathrm{E}-06$ & $2.50 \mathrm{E}-06$ & $<$ LOD & - \\
\hline C21 tricyclic terpane $(\mathrm{H} 3)$ & $1.77 \mathrm{E}-08$ & $1.82 \mathrm{E}-06$ & 7.10E-07 & $5.41 \mathrm{E}-07$ & $4.32 \mathrm{E}-07$ & $7 \quad 4.97 \mathrm{E}-07$ & $4.70 \mathrm{E}-06$ & $1.61 \mathrm{E}-06$ & $1.25 \mathrm{E}-06$ & - \\
\hline C22 tricyclic terpane $(\mathrm{H} 4)$ & 5.84E-09 & $6.87 \mathrm{E}-07$ & $2.93 \mathrm{E}-07$ & $2.06 \mathrm{E}-07$ & $1.73 \mathrm{E}-07$ & $<\mathrm{LOD}$ & $<\mathrm{LOD}$ & - & $<\mathrm{LOD}$ & - \\
\hline C23 aB-dimethyl-a-butylpodocarpane (H5) & 7.47E-08 & $4.96 \mathrm{E}-06$ & $2.13 \mathrm{E}-06$ & $1.12 \mathrm{E}-06$ & $9.58 \mathrm{E}-07$ & $\begin{array}{l}7 \\
\end{array} 8.10 \mathrm{E}-07$ & $1.11 \mathrm{E}-05$ & $4.77 \mathrm{E}-06$ & $3.08 \mathrm{E}-06$ & $7.36 \mathrm{E}-07$ \\
\hline C24 aB-dimethyl-a-methylbutylpodocarpane (H6) & $3.45 \mathrm{E}-08$ & $2.56 \mathrm{E}-06$ & 1.09E-06 & $5.05 \mathrm{E}-07$ & $4.82 \mathrm{E}-07$ & $7 \quad 3.90 \mathrm{E}-07$ & $5.82 \mathrm{E}-06$ & $2.18 \mathrm{E}-06$ & $1.30 \mathrm{E}-06$ & - \\
\hline C24 aB-dimethyl-a-methylbutylpodocarpane (H6') & $1.84 \mathrm{E}-08$ & $<$ LOD & $<\mathrm{LOD}$ & $<\mathrm{LOD}$ & $<\mathrm{LOD}$ & $<\mathrm{LOD}$ & $<\mathrm{LOD}$ & - & $<\mathrm{LOD}$ & - \\
\hline C25 tricyclic terpane $(\mathrm{H} 7)$ & $1.66 \mathrm{E}-08$ & $1.64 \mathrm{E}-06$ & 5.79E-07 & $2.89 \mathrm{E}-07$ & $2.60 \mathrm{E}-07$ & $<\mathrm{LOD}$ & $3.60 \mathrm{E}-06$ & $1.61 \mathrm{E}-06$ & $<\mathrm{LOD}$ & - \\
\hline C25 tricyclic terpane $\left(\mathrm{H} 7^{\prime}\right)$ & $3.69 \mathrm{E}-08$ & $<\mathrm{LOD}$ & $<\mathrm{LOD}$ & $<\mathrm{LOD}$ & $<\mathrm{LOD}$ & $<\mathrm{LOD}$ & $<\mathrm{LOD}$ & - & $<\mathrm{LOD}$ & - \\
\hline C26 tricyclic terpane (H8) & $1.20 \mathrm{E}-08$ & $1.62 \mathrm{E}-06$ & $5.48 \mathrm{E}-07$ & $3.02 \mathrm{E}-07$ & $2.74 \mathrm{E}-07$ & \begin{tabular}{|l|l|}
7 & $2.92 \mathrm{E}-07$ \\
\end{tabular} & $3.65 \mathrm{E}-06$ & $1.45 \mathrm{E}-06$ & $1.12 \mathrm{E}-06$ & - \\
\hline C26 tricyclic triterpane 22R (H8') & $1.20 \mathrm{E}-08$ & $6.11 \mathrm{E}-07$ & $1.77 \mathrm{E}-07$ & $8.78 \mathrm{E}-08$ & $<\mathrm{LOD}$ & $<\mathrm{LOD}$ & $<\mathrm{LOD}$ & - & $<$ LOD & - \\
\hline C26 tricyclic triterpane $22 \mathrm{~S}(\mathrm{H} 8 ")$ & $7.05 \mathrm{E}-09$ & $0.00 \mathrm{E}+00$ & $<\mathrm{LOD}$ & $<\mathrm{LOD}$ & $<\mathrm{LOD}$ & $<\mathrm{LOD}$ & $<\mathrm{LOD}$ & - & $<\mathrm{LOD}$ & - \\
\hline C27 tetracyclic terpane 22R (H9) & $1.02 \mathrm{E}-08$ & $4.29 \mathrm{E}-07$ & 7.91E-08 & $<$ LOD & $<$ LOD & $<\mathrm{LOD}$ & $<$ LOD & - & $<$ LOD & - \\
\hline C27 tetracyclic terpane 22S (H10) & $8.95 \mathrm{E}-09$ & $4.49 \mathrm{E}-07$ & 7.54E-08 & $<\mathrm{LOD}$ & $<$ LOD & $<\mathrm{LOD}$ & $<$ LOD & - & $<\mathrm{LOD}$ & - \\
\hline C28 tetracyclic terpane 22R (H11) & 7.93E-09 & $4.48 \mathrm{E}-07$ & 7.34E-08 & $<$ LOD & $<$ LOD & $<\mathrm{LOD}$ & $4.67 \mathrm{E}-07$ & - & $<$ LOD & - \\
\hline C28 tetracyclic terpane $22 \mathrm{~S}(\mathrm{H} 12)$ & $3.66 \mathrm{E}-08$ & $4.68 \mathrm{E}-07$ & $9.32 \mathrm{E}-08$ & $<\mathrm{LOD}$ & $<\mathrm{LOD}$ & $<\mathrm{LOD}$ & $2.08 \mathrm{E}-07$ & - & $<\mathrm{LOD}$ & - \\
\hline C27 aB-Trisnorneohopane Ts (H13) & $2.63 \mathrm{E}-08$ & $1.01 \mathrm{E}-06$ & $2.68 \mathrm{E}-07$ & $2.11 \mathrm{E}-07$ & $1.82 \mathrm{E}-07$ & $<\mathrm{LOD}$ & $2.46 \mathrm{E}-06$ & - & $2.75 \mathrm{E}-06$ & - \\
\hline C27 Trisnorhopane Tm $(\mathrm{H} 15) *$ & $2.63 \mathrm{E}-08$ & $1.44 \mathrm{E}-06$ & $2.78 \mathrm{E}-07$ & $2.01 \mathrm{E}-07$ & $1.47 \mathrm{E}-07$ & $7<\mathrm{LOD}$ & $2.50 \mathrm{E}-06$ & - & $<\mathrm{LOD}$ & - \\
\hline
\end{tabular}

Note: $<\mathrm{LOD}=$ Below Level of Detection 
Contd....

\begin{tabular}{|c|c|c|c|c|c|c|c|c|c|c|}
\hline \multirow{2}{*}{$\begin{array}{l}\text { Hopanes } \\
\text { g/mile }\end{array}$} & \multirow{2}{*}{$\begin{array}{l}\text { Limit of } \\
\text { Detection }\end{array}$} & \multicolumn{3}{|c|}{$\begin{array}{c}\text { Phase I } \\
\text { Baseline \& OEM Catalyst }\end{array}$} & \multicolumn{2}{|c|}{$\begin{array}{c}\text { Phase II } \\
\text { New WVU-Lubrizol } \\
\text { Aftertreatment }\end{array}$} & \multicolumn{4}{|c|}{$\begin{array}{c}\text { Phase III } \\
\text { Post Demo WVU-Lubrizol } \\
\text { Aftertreatment }\end{array}$} \\
\hline & & $\begin{array}{c}\text { QCBD } \\
\text { (Baseline) }\end{array}$ & $\begin{array}{l}\text { QCBD } \\
\text { (OEM } \\
\text { Catalyst) }\end{array}$ & Background & QCBD & Background & QCBD & $\begin{array}{c}\text { Standard } \\
\text { Deviation }\end{array}$ & Background & $\begin{array}{c}\text { Standard } \\
\text { Deviation }\end{array}$ \\
\hline C30 Tricyclic terpane 22R (H15') & $2.63 \mathrm{E}-08$ & $<\mathrm{LOD}$ & $3.12 \mathrm{E}-08$ & $<\mathrm{LOD}$ & $<\mathrm{LOD}$ & $<\mathrm{LOD}$ & $<\mathrm{LOD}$ & - & $<\mathrm{LOD}$ & - \\
\hline C30 Tricyclic terpane 22S (H15") & $7.97 \mathrm{E}-09$ & $3.80 \mathrm{E}-07$ & $3.69 \mathrm{E}-08$ & $<\mathrm{LOD}$ & $<\mathrm{LOD}$ & $<\mathrm{LOD}$ & $5.34 \mathrm{E}-07$ & - & $<\mathrm{LOD}$ & - \\
\hline C28 aaB-Bisnorhopane (H16) & $2.92 \mathrm{E}-08$ & $5.95 \mathrm{E}-07$ & $6.61 \mathrm{E}-08$ & $<\mathrm{LOD}$ & $<\mathrm{LOD}$ & $<\mathrm{LOD}$ & $3.56 \mathrm{E}-07$ & - & $<\mathrm{LOD}$ & - \\
\hline C29 aB-25-norhopane (H17') & $6.81 \mathrm{E}-08$ & $<\mathrm{LOD}$ & $<\mathrm{LOD}$ & $<\mathrm{LOD}$ & $<\mathrm{LOD}$ & $<$ LOD & $<$ LOD & - & $<\mathrm{LOD}$ & - \\
\hline C29 aB-30-norhopane (H17) * & $5.54 \mathrm{E}-08$ & $2.14 \mathrm{E}-06$ & $3.93 \mathrm{E}-07$ & 4.11E-07 & $2.77 \mathrm{E}-07$ & $4.20 \mathrm{E}-07$ & 6.09E-06 & $2.80 \mathrm{E}-06$ & $5.54 \mathrm{E}-06$ & $3.13 \mathrm{E}-06$ \\
\hline C29 aB-Norneohopane(H18) & $1.46 \mathrm{E}-08$ & $4.75 \mathrm{E}-07$ & $1.12 \mathrm{E}-07$ & $1.02 \mathrm{E}-07$ & $<\mathrm{LOD}$ & $<\mathrm{LOD}$ & $1.78 \mathrm{E}-06$ & - & $<\mathrm{LOD}$ & - \\
\hline C29 Ba-norhopane & $1.46 \mathrm{E}-08$ & $6.77 \mathrm{E}-07$ & $6.85 \mathrm{E}-08$ & $<$ LOD & $<$ LOD & $<$ LOD & $4.35 \mathrm{E}-07$ & - & $<$ LOD & - \\
\hline C30 Ba-hopane (H20) & $1.09 \mathrm{E}-07$ & $<\mathrm{LOD}$ & $<$ LOD & $<\mathrm{LOD}$ & $<\mathrm{LOD}$ & $<$ LOD & $<\mathrm{LOD}$ & - & $<$ LOD & - \\
\hline C31 22S-aB-homohopane (H21) & $2.16 \mathrm{E}-08$ & $1.07 \mathrm{E}-06$ & $1.48 \mathrm{E}-07$ & $2.03 \mathrm{E}-07$ & $<\mathrm{LOD}$ & $<\mathrm{LOD}$ & $6.90 \mathrm{E}-06$ & - & $4.24 \mathrm{E}-06$ & $4.03 \mathrm{E}-06$ \\
\hline C31 22R-aB-homohopane (H22) & $1.68 \mathrm{E}-08$ & $7.92 \mathrm{E}-07$ & 7.90E-08 & $1.24 \mathrm{E}-07$ & $<\mathrm{LOD}$ & $<\mathrm{LOD}$ & $3.00 \mathrm{E}-06$ & $2.38 \mathrm{E}-06$ & $3.03 \mathrm{E}-06$ & $2.73 \mathrm{E}-06$ \\
\hline C32 22S-aB-bishomohopane (H24) & $5.56 \mathrm{E}-06$ & $<\mathrm{LOD}$ & $<$ LOD & $<\mathrm{LOD}$ & $<\mathrm{LOD}$ & $<\mathrm{LOD}$ & $4.23 \mathrm{E}-06$ & - & $2.83 \mathrm{E}-06$ & $2.29 \mathrm{E}-06$ \\
\hline C32 22R-aB-bishomohopane (H25) & $6.14 \mathrm{E}-08$ & $2.66 \mathrm{E}-07$ & 4.67E-08 & 7.24E-08 & $<\mathrm{LOD}$ & $<$ LOD & $3.29 \mathrm{E}-06$ & - & $3.21 \mathrm{E}-06$ & - \\
\hline C33 22S-aB-trishomohopane (H26) & 4.94E-08 & $2.36 \mathrm{E}-07$ & $4.52 \mathrm{E}-08$ & $<$ LOD & $<\mathrm{LOD}$ & $<\mathrm{LOD}$ & $3.71 \mathrm{E}-06$ & - & $3.38 \mathrm{E}-06$ & - \\
\hline C33 22R-aB-trishomohopane (H27) & $4.72 \mathrm{E}-08$ & $1.54 \mathrm{E}-07$ & $2.57 \mathrm{E}-08$ & $<$ LOD & $<$ LOD & $<$ LOD & $2.33 \mathrm{E}-06$ & - & $<$ LOD & - \\
\hline C34 22S-aB-tetrakishomohopane (H28) & $2.84 \mathrm{E}-08$ & $1.46 \mathrm{E}-07$ & $<$ LOD & $<\mathrm{LOD}$ & $<$ LOD & $<$ LOD & $2.63 \mathrm{E}-06$ & - & $<$ LOD & - \\
\hline C34 22R-aB-tetrakishomohopane (H29) & $2.84 \mathrm{E}-08$ & 7.33E-08 & $<$ LOD & $<$ LOD & $<$ LOD & $<$ LOD & $1.66 \mathrm{E}-06$ & - & $<$ LOD & - \\
\hline C35 22S-aB-pentakishomohopane (H30) & $2.84 \mathrm{E}-08$ & $<\mathrm{LOD}$ & $<\mathrm{LOD}$ & $<\mathrm{LOD}$ & $<\mathrm{LOD}$ & $<\mathrm{LOD}$ & $2.56 \mathrm{E}-06$ & - & $<\mathrm{LOD}$ & - \\
\hline C35 22R-aB-pentakishomohopane (H31) & $2.84 \mathrm{E}-08$ & $<\mathrm{LOD}$ & $<\mathrm{LOD}$ & $<\mathrm{LOD}$ & $<\mathrm{LOD}$ & $<\mathrm{LOD}$ & $1.97 \mathrm{E}-06$ & - & $<\mathrm{LOD}$ & - \\
\hline
\end{tabular}

Note: $<$ LOD $=$ Below Level of Detection 
Table C. 3 Emissions of Steranes Measured in Different Phases

\begin{tabular}{|c|c|c|c|c|c|c|c|c|c|c|}
\hline \multirow{2}{*}{$\begin{array}{l}\text { Steranes } \\
\mathrm{g} / \mathrm{mile}\end{array}$} & \multirow{2}{*}{$\begin{array}{l}\text { Limit of } \\
\text { Detection }\end{array}$} & \multicolumn{3}{|c|}{$\begin{array}{c}\text { Phase I } \\
\text { Baseline \& OEM Catalyst }\end{array}$} & \multicolumn{2}{|c|}{\begin{tabular}{|c|} 
Phase II \\
$\begin{array}{c}\text { New WVU-Lubrizol } \\
\text { Aftertreatment }\end{array}$ \\
\end{tabular}} & \multicolumn{4}{|c|}{$\begin{array}{c}\text { Phase III } \\
\text { Post Demo WVU-Lubrizol Aftertreatment }\end{array}$} \\
\hline & & $\begin{array}{c}\text { QCBD } \\
\text { (Baseline) }\end{array}$ & $\begin{array}{c}\text { QCBD } \\
\text { (OEM Catalyst) }\end{array}$ & Background & QCBD & Background & QCBD & $\begin{array}{c}\text { Standard } \\
\text { Deviation }\end{array}$ & Background & $\begin{array}{l}\text { Standard } \\
\text { Deviation }\end{array}$ \\
\hline C20 aaa-sterane (S1) & $2.94 \mathrm{E}-08$ & $4.28 \mathrm{E}-07$ & $1.60 \mathrm{E}-07$ & $1.28 \mathrm{E}-07$ & $1.83 \mathrm{E}-07$ & $<\mathrm{LOD}$ & $<\mathrm{LOD}$ & - & $<\mathrm{LOD}$ & - \\
\hline C21 Baa-sterane (S2) & $1.88 \mathrm{E}-08$ & $8.03 \mathrm{E}-07$ & $2.88 \mathrm{E}-07$ & $2.20 \mathrm{E}-07$ & $<\mathrm{LOD}$ & $<\mathrm{LOD}$ & $2.82 \mathrm{E}-06$ & $1.52 \mathrm{E}-06$ & $<\mathrm{LOD}$ & - \\
\hline C21 aBB-sterane $(\mathrm{S} 3,4)$ & $5.84 \mathrm{E}-08$ & $2.20 \mathrm{E}-06$ & $8.37 \mathrm{E}-07$ & $5.36 \mathrm{E}-07$ & $6.08 \mathrm{E}-07$ & $5.84 \mathrm{E}-07$ & $6.47 \mathrm{E}-06$ & $3.24 \mathrm{E}-06$ & $2.33 \mathrm{E}-06$ & 5.59E-07 \\
\hline C21 aaa-sterane $(\mathrm{S} 4,3)$ & $1.91 \mathrm{E}-08$ & $8.76 \mathrm{E}-07$ & $2.94 \mathrm{E}-07$ & $1.45 \mathrm{E}-07$ & $1.85 \mathrm{E}-07$ & $<\mathrm{LOD}$ & $2.73 \mathrm{E}-06$ & - & $<\mathrm{LOD}$ & - \\
\hline C22 aBB-sterane (S5) & $2.02 \mathrm{E}-08$ & $1.26 \mathrm{E}-06$ & $4.93 \mathrm{E}-07$ & $2.34 \mathrm{E}-07$ & $2.68 \mathrm{E}-07$ & $<\mathrm{LOD}$ & $3.09 \mathrm{E}-06$ & $1.97 \mathrm{E}-06$ & $<\mathrm{LOD}$ & - \\
\hline C27 20S-Ba-diasterane (S6) & $1.71 \mathrm{E}-08$ & $9.18 \mathrm{E}-07$ & $2.02 \mathrm{E}-07$ & $1.16 \mathrm{E}-07$ & $<\mathrm{LOD}$ & $<\mathrm{LOD}$ & $2.07 \mathrm{E}-06$ & - & $<\mathrm{LOD}$ & - \\
\hline C27 20R-Ba-diasterane (S7) & $8.78 \mathrm{E}-09$ & $4.70 \mathrm{E}-07$ & $1.12 \mathrm{E}-07$ & $5.78 \mathrm{E}-08$ & $<\mathrm{LOD}$ & $<\mathrm{LOD}$ & $<\mathrm{LOD}$ & - & $<\mathrm{LOD}$ & - \\
\hline C27 20S-aB-diasterane (S8) & $1.70 \mathrm{E}-08$ & $3.02 \mathrm{E}-07$ & $6.24 \mathrm{E}-08$ & $<\mathrm{LOD}$ & $<$ LOD & $<\mathrm{LOD}$ & $2.34 \mathrm{E}-07$ & - & $<$ LOD & - \\
\hline C27 20R-aB-diasterane (S8') & $6.83 \mathrm{E}-09$ & $5.44 \mathrm{E}-07$ & 9.94E-08 & $5.66 \mathrm{E}-08$ & $<\mathrm{LOD}$ & $<\mathrm{LOD}$ & $<\mathrm{LOD}$ & - & $<\mathrm{LOD}$ & - \\
\hline C28 20S-Ba-diasterane (S9) & $1.04 \mathrm{E}-08$ & $6.46 \mathrm{E}-07$ & $1.55 \mathrm{E}-08$ & $7.25 \mathrm{E}-08$ & $<\mathrm{LOD}$ & $<\mathrm{LOD}$ & $1.49 \mathrm{E}-06$ & - & $<\mathrm{LOD}$ & - \\
\hline C28 20R-Ba-diasterane (S10) & 8.49E-09 & $5.58 \mathrm{E}-07$ & $1.36 \mathrm{E}-08$ & $6.33 \mathrm{E}-08$ & $<\mathrm{LOD}$ & $<\mathrm{LOD}$ & $<\mathrm{LOD}$ & - & $<\mathrm{LOD}$ & - \\
\hline C28 20R/S?-Ba-diasterane (S10') & $6.79 \mathrm{E}-09$ & $3.62 \mathrm{E}-07$ & $8.78 \mathrm{E}-09$ & $4.10 \mathrm{E}-08$ & $<\mathrm{LOD}$ & $<\mathrm{LOD}$ & $<\mathrm{LOD}$ & - & $<\mathrm{LOD}$ & - \\
\hline C28 20R/S?-Ba-diasterane (S10") & 7.03E-09 & $5.38 \mathrm{E}-07$ & $<\mathrm{LOD}$ & $<\mathrm{LOD}$ & $<\mathrm{LOD}$ & $<\mathrm{LOD}$ & $<\mathrm{LOD}$ & - & $<\mathrm{LOD}$ & - \\
\hline C28 20S-Ba-diasterane (S10"'a) & $1.06 \mathrm{E}-08$ & $5.12 \mathrm{E}-07$ & $<\mathrm{LOD}$ & $<\mathrm{LOD}$ & $<\mathrm{LOD}$ & $<\mathrm{LOD}$ & $<\mathrm{LOD}$ & - & $<\mathrm{LOD}$ & - \\
\hline C27 20R-Baa-cholestane (S11) & $5.93 \mathrm{E}-09$ & $2.67 \mathrm{E}-07$ & $<\mathrm{LOD}$ & $<\mathrm{LOD}$ & $<\mathrm{LOD}$ & $<\mathrm{LOD}$ & $<$ LOD & - & $<\mathrm{LOD}$ & - \\
\hline C27 20S-aaa-cholestane (S12) & $1.19 \mathrm{E}-08$ & $1.00 \mathrm{E}-06$ & $1.64 \mathrm{E}-08$ & $7.67 \mathrm{E}-08$ & $<\mathrm{LOD}$ & $<\mathrm{LOD}$ & $2.09 \mathrm{E}-06$ & - & $<\mathrm{LOD}$ & - \\
\hline
\end{tabular}


Contd........

\begin{tabular}{|c|c|c|c|c|c|c|c|c|c|c|}
\hline \multirow{2}{*}{$\begin{array}{l}\text { Steranes } \\
\mathrm{g} / \mathrm{mile}\end{array}$} & \multirow{2}{*}{$\begin{array}{l}\text { Limit of } \\
\text { Detection }\end{array}$} & \multicolumn{3}{|c|}{$\begin{array}{c}\text { Phase I } \\
\text { Baseline \& OEM Catalyst }\end{array}$} & \multicolumn{2}{|c|}{\begin{tabular}{|c|} 
Phase II \\
New WVU-Lubrizol \\
Aftertreatment
\end{tabular}} & \multicolumn{4}{|c|}{$\begin{array}{c}\text { Phase III } \\
\text { Post Demo WVU-Lubrizol } \\
\text { Aftertreatment }\end{array}$} \\
\hline & & $\begin{array}{c}\text { QCBD } \\
\text { (Baseline) }\end{array}$ & \begin{tabular}{|c|} 
QCBD \\
(OEM \\
Catalyst)
\end{tabular} & Background & QCBD & Background & QCBD & \begin{tabular}{|c|} 
Standard \\
Deviation
\end{tabular} & Background & $\begin{array}{l}\text { Standard } \\
\text { Deviation }\end{array}$ \\
\hline C27 20R-aBB-cholestane (S13) & $2.59 \mathrm{E}-08$ & $1.22 \mathrm{E}-06$ & $3.00 \mathrm{E}-08$ & $1.40 \mathrm{E}-07$ & $1.51 \mathrm{E}-07$ & $<\mathrm{LOD}$ & 4.49E-06 & - & $2.30 \mathrm{E}-06$ & $1.49 \mathrm{E}-06$ \\
\hline C27 20S-aBB-cholestane (S14) & $2.07 \mathrm{E}-08$ & $6.83 \mathrm{E}-07$ & $1.94 \mathrm{E}-08$ & $9.07 \mathrm{E}-08$ & $<$ LOD & $<$ LOD & $3.22 \mathrm{E}-06$ & - & $<$ LOD & - \\
\hline C27 20R-aaa-cholestane (S15) & $1.20 \mathrm{E}-08$ & $8.09 \mathrm{E}-07$ & $1.07 \mathrm{E}-08$ & 5.01E-08 & $<\mathrm{LOD}$ & $<\mathrm{LOD}$ & $2.39 \mathrm{E}-06$ & - & $<$ LOD & - \\
\hline C29 20S-Ba-diasterane (S16) & $2.40 \mathrm{E}-08$ & $1.03 \mathrm{E}-06$ & $2.16 \mathrm{E}-08$ & $1.01 \mathrm{E}-07$ & $<\mathrm{LOD}$ & $<$ LOD & $3.37 \mathrm{E}-06$ & - & $2.38 \mathrm{E}-06$ & - \\
\hline C29 20S-Ba-diasterane (S16') & 7.49E-09 & $5.30 \mathrm{E}-07$ & $<$ LOD & $<$ LOD & $<\mathrm{LOD}$ & $<$ LOD & $1.90 \mathrm{E}-06$ & - & $<$ LOD & - \\
\hline C28 20S-aaa-methylcholestane (S17) & $1.96 \mathrm{E}-08$ & $2.89 \mathrm{E}-07$ & $<$ LOD & $<\mathrm{LOD}$ & $<\mathrm{LOD}$ & $<\mathrm{LOD}$ & $1.49 \mathrm{E}-06$ & - & $<$ LOD & - \\
\hline C28 20R-aBB-methylcholestane (S18) & $6.20 \mathrm{E}-09$ & $9.30 \mathrm{E}-07$ & $1.10 \mathrm{E}-08$ & $5.14 \mathrm{E}-08$ & $<\mathrm{LOD}$ & $<$ LOD & $1.95 \mathrm{E}-06$ & - & $<\mathrm{LOD}$ & - \\
\hline C28 20S-aBB-methylcholestane (S19) & $8.24 \mathrm{E}-09$ & $5.72 \mathrm{E}-07$ & $1.18 \mathrm{E}-08$ & $5.51 \mathrm{E}-08$ & $<\mathrm{LOD}$ & $<\mathrm{LOD}$ & $2.25 \mathrm{E}-06$ & - & $<\mathrm{LOD}$ & - \\
\hline C29 20R-aB-diasterane (S20) & $6.76 \mathrm{E}-08$ & $6.04 \mathrm{E}-07$ & $1.35 \mathrm{E}-08$ & $6.28 \mathrm{E}-08$ & $<\mathrm{LOD}$ & $<\mathrm{LOD}$ & $2.40 \mathrm{E}-06$ & - & $<\mathrm{LOD}$ & - \\
\hline C28 20R-aaa-methylcholestane (S21) & $6.95 \mathrm{E}-09$ & $4.26 \mathrm{E}-07$ & $<$ LOD & $<$ LOD & $<\mathrm{LOD}$ & $<$ LOD & $<$ LOD & - & $<\mathrm{LOD}$ & - \\
\hline C29 20S-aaa-ethylcholestane (S22) & 5.29E-08 & $5.52 \mathrm{E}-07$ & $1.65 \mathrm{E}-08$ & 7.71E-08 & $<\mathrm{LOD}$ & $<\mathrm{LOD}$ & $2.05 \mathrm{E}-06$ & - & $<$ LOD & - \\
\hline C29 20R-aBB-ethylcholestane (S23) & $9.53 \mathrm{E}-09$ & 9.43E-07 & $2.30 \mathrm{E}-08$ & $1.07 \mathrm{E}-07$ & $<\mathrm{LOD}$ & $<\mathrm{LOD}$ & $3.03 \mathrm{E}-06$ & - & $<\mathrm{LOD}$ & - \\
\hline C29 20S-aBB (20R-Baa)-ethylcholestane (S24) & $7.51 \mathrm{E}-09$ & $5.51 \mathrm{E}-07$ & $2.09 \mathrm{E}-08$ & $9.76 \mathrm{E}-08$ & $<$ LOD & $<\mathrm{LOD}$ & $2.75 \mathrm{E}-06$ & - & $<\mathrm{LOD}$ & - \\
\hline C29 20R-aaa-ethylcholestane (S25) & $6.16 \mathrm{E}-09$ & 7.91E-07 & $1.70 \mathrm{E}-08$ & $7.95 \mathrm{E}-08$ & $<\mathrm{LOD}$ & $<\mathrm{LOD}$ & $1.86 \mathrm{E}-06$ & - & $<\mathrm{LOD}$ & - \\
\hline
\end{tabular}

Note: $<\mathrm{LOD}=$ Below Level of Detection 
Table C. 4 Emissions of Polycyclic Aromatic Hydrocarbons Measured in Different Phases

\begin{tabular}{|c|c|c|c|c|c|c|c|c|c|c|}
\hline \multirow{2}{*}{$\begin{array}{c}\text { Polycyclic Aromatic } \\
\text { Hydrocarbons } \\
\text { g/mile }\end{array}$} & \multirow{2}{*}{$\begin{array}{l}\text { Limit of } \\
\text { Detection }\end{array}$} & \multicolumn{3}{|c|}{$\begin{array}{c}\text { Phase I } \\
\text { Baseline \& OEM Catalyst }\end{array}$} & \multicolumn{2}{|c|}{$\begin{array}{c}\text { Phase II } \\
\text { New WVU-Lubrizol } \\
\text { Aftertreatment }\end{array}$} & \multicolumn{4}{|c|}{$\begin{array}{c}\text { Phase III } \\
\text { Post Demo WVU-Lubrizol Aftertreatment }\end{array}$} \\
\hline & & $\begin{array}{c}\text { QCBD } \\
\text { (Baseline) }\end{array}$ & $\begin{array}{c}\text { QCBD } \\
\text { (OEM Catalyst) } \\
\end{array}$ & Background & QCBD & Background & QCBD & $\begin{array}{c}\text { Standard } \\
\text { Deviation }\end{array}$ & Background & $\begin{array}{l}\text { Standard } \\
\text { Deviation }\end{array}$ \\
\hline Naphthalene & $5.68 \mathrm{E}-06$ & $8.80 \mathrm{E}-05$ & $1.19 \mathrm{E}-05$ & $2.46 \mathrm{E}-05$ & $1.57 \mathrm{E}-05$ & $3.33 \mathrm{E}-05$ & $1.24 \mathrm{E}-04$ & $1.53 \mathrm{E}-05$ & $1.24 \mathrm{E}-04$ & $3.36 \mathrm{E}-05$ \\
\hline Acenaphthylene & $6.67 \mathrm{E}-09$ & $5.46 \mathrm{E}-06$ & $8.90 \mathrm{E}-07$ & $8.15 \mathrm{E}-07$ & $7.52 \mathrm{E}-07$ & $<\mathrm{LOD}$ & $1.01 \mathrm{E}-05$ & $2.72 \mathrm{E}-06$ & $4.32 \mathrm{E}-06$ & $6.55 \mathrm{E}-07$ \\
\hline Acenaphthene & $7.56 \mathrm{E}-08$ & $2.03 \mathrm{E}-06$ & $7.53 \mathrm{E}-07$ & $1.02 \mathrm{E}-06$ & $7.98 \mathrm{E}-07$ & $8.88 \mathrm{E}-07$ & 6.97E-06 & $1.85 \mathrm{E}-06$ & $4.54 \mathrm{E}-06$ & $2.01 \mathrm{E}-07$ \\
\hline Fluorene & 4.69E-07 & $5.97 \mathrm{E}-06$ & $3.00 \mathrm{E}-06$ & $2.54 \mathrm{E}-06$ & $1.41 \mathrm{E}-06$ & $3.07 \mathrm{E}-06$ & $2.47 \mathrm{E}-05$ & 5.99E-06 & $1.02 \mathrm{E}-05$ & $3.14 \mathrm{E}-06$ \\
\hline 2-Me-Fluorene & $7.56 \mathrm{E}-08$ & $1.71 \mathrm{E}-06$ & $7.53 \mathrm{E}-07$ & $6.80 \mathrm{E}-07$ & $3.98 \mathrm{E}-07$ & $7.43 \mathrm{E}-07$ & $7.80 \mathrm{E}-06$ & $1.86 \mathrm{E}-06$ & $3.03 \mathrm{E}-06$ & $7.80 \mathrm{E}-07$ \\
\hline Phenanthrene & $3.94 \mathrm{E}-07$ & $6.70 \mathrm{E}-06$ & $2.44 \mathrm{E}-06$ & $2.28 \mathrm{E}-06$ & $1.76 \mathrm{E}-06$ & $3.27 \mathrm{E}-06$ & $3.01 \mathrm{E}-05$ & $9.21 \mathrm{E}-06$ & $1.25 \mathrm{E}-05$ & $1.80 \mathrm{E}-06$ \\
\hline Anthracene & $3.56 \mathrm{E}-08$ & $1.97 \mathrm{E}-06$ & $3.57 \mathrm{E}-07$ & $1.63 \mathrm{E}-07$ & $1.11 \mathrm{E}-07$ & $3.86 \mathrm{E}-07$ & $3.05 \mathrm{E}-06$ & $7.36 \mathrm{E}-07$ & $1.12 \mathrm{E}-06$ & $3.91 \mathrm{E}-07$ \\
\hline Fluoranthene & $1.02 \mathrm{E}-07$ & $1.19 \mathrm{E}-06$ & $2.87 \mathrm{E}-07$ & $3.35 \mathrm{E}-07$ & 5.89E-07 & $5.97 \mathrm{E}-07$ & $3.70 \mathrm{E}-06$ & $1.15 \mathrm{E}-06$ & $2.47 \mathrm{E}-06$ & $7.31 \mathrm{E}-07$ \\
\hline Pyrene & 9.79E-08 & $3.02 \mathrm{E}-06$ & $4.35 \mathrm{E}-07$ & $4.03 \mathrm{E}-07$ & $8.34 \mathrm{E}-07$ & $6.27 \mathrm{E}-07$ & 3.69E-06 & $1.30 \mathrm{E}-06$ & $2.10 \mathrm{E}-06$ & $6.45 \mathrm{E}-07$ \\
\hline Retene & $5.78 \mathrm{E}-08$ & $4.90 \mathrm{E}-07$ & $1.80 \mathrm{E}-07$ & $2.78 \mathrm{E}-07$ & $1.38 \mathrm{E}-07$ & $3.31 \mathrm{E}-07$ & 1.09E-06 & $3.08 \mathrm{E}-07$ & $5.93 \mathrm{E}-07$ & $2.21 \mathrm{E}-08$ \\
\hline Benzo(a)Fluorene & $1.11 \mathrm{E}-08$ & $<\mathrm{LOD}$ & $<\mathrm{LOD}$ & $<\mathrm{LOD}$ & $<\mathrm{LOD}$ & $<\mathrm{LOD}$ & $<\mathrm{LOD}$ & - & $<\mathrm{LOD}$ & - \\
\hline Benzo(b)Fluorene & $1.11 \mathrm{E}-08$ & $<\mathrm{LOD}$ & $<\mathrm{LOD}$ & $<\mathrm{LOD}$ & $<\mathrm{LOD}$ & $<\mathrm{LOD}$ & $<\mathrm{LOD}$ & - & $<\mathrm{LOD}$ & - \\
\hline 1-Me-Pyrene & $1.11 \mathrm{E}-08$ & $2.74 \mathrm{E}-07$ & $8.44 \mathrm{E}-08$ & $3.97 \mathrm{E}-08$ & $6.23 \mathrm{E}-08$ & $<\mathrm{LOD}$ & 4.09E-07 & - & $<\mathrm{LOD}$ & - \\
\hline Benzo(g,h,i)Fluoranthene & $2.22 \mathrm{E}-08$ & $1.35 \mathrm{E}-07$ & $1.67 \mathrm{E}-08$ & $<\mathrm{LOD}$ & $1.27 \mathrm{E}-07$ & $<\mathrm{LOD}$ & $3.93 \mathrm{E}-07$ & $3.06 \mathrm{E}-08$ & $2.87 \mathrm{E}-07$ & - \\
\hline Benzo(a)Anthracene & $2.22 \mathrm{E}-08$ & $<\mathrm{LOD}$ & $<\mathrm{LOD}$ & $<\mathrm{LOD}$ & $<\mathrm{LOD}$ & $<\mathrm{LOD}$ & $<\mathrm{LOD}$ & - & $<\mathrm{LOD}$ & - \\
\hline Triphenylene & $8.90 \mathrm{E}-09$ & $1.05 \mathrm{E}-07$ & $1.74 \mathrm{E}-08$ & $<\mathrm{LOD}$ & $<\mathrm{LOD}$ & $<\mathrm{LOD}$ & $<\mathrm{LOD}$ & - & $<\mathrm{LOD}$ & - \\
\hline
\end{tabular}

Note: $<\mathrm{LOD}=$ Below Level of Detection 
Contd.....

\begin{tabular}{|c|c|c|c|c|c|c|c|c|c|c|}
\hline \multirow{2}{*}{$\begin{array}{l}\text { Polycyclic Aromatic } \\
\text { Hydrocarbons } \\
\text { g/mile }\end{array}$} & \multirow{2}{*}{$\begin{array}{l}\text { Limit of } \\
\text { Detection }\end{array}$} & \multicolumn{3}{|c|}{$\begin{array}{c}\text { Phase I } \\
\text { Baseline \& OEM Catalyst }\end{array}$} & \multicolumn{2}{|c|}{$\begin{array}{c}\text { Phase II } \\
\text { New WVU-Lubrizol } \\
\text { Aftertreatment }\end{array}$} & \multicolumn{4}{|c|}{$\begin{array}{c}\text { Phase III } \\
\text { Post Demo WVU-Lubrizol Aftertreatment }\end{array}$} \\
\hline & & $\begin{array}{c}\text { QCBD } \\
\text { (Baseline) }\end{array}$ & $\begin{array}{c}\text { QCBD } \\
\text { (OEM Catalyst) }\end{array}$ & Background & QCBD & Background & QCBD & \begin{tabular}{|c|} 
Standard \\
Deviation
\end{tabular} & Background & $\begin{array}{l}\text { Standard } \\
\text { Deviation }\end{array}$ \\
\hline Chrysene & $2.00 \mathrm{E}-08$ & $1.21 \mathrm{E}-07$ & $2.60 \mathrm{E}-08$ & $<\mathrm{LOD}$ & $<\mathrm{LOD}$ & $<\mathrm{LOD}$ & $9.42 \mathrm{E}-07$ & - & $<\mathrm{LOD}$ & - \\
\hline 7-Me-Benzo(a)Anthracene & $2.22 \mathrm{E}-08$ & $1.30 \mathrm{E}-07$ & $2.58 \mathrm{E}-08$ & $<\mathrm{LOD}$ & $7.12 \mathrm{E}-08$ & $<\mathrm{LOD}$ & $<\mathrm{LOD}$ & - & $<\mathrm{LOD}$ & - \\
\hline Benzo(b)Fluoranthene & $4.45 \mathrm{E}-08$ & $<$ LOD & $<$ LOD & $<$ LOD & $<\mathrm{LOD}$ & $<\mathrm{LOD}$ & $<$ LOD & - & $<\mathrm{LOD}$ & - \\
\hline Benzo(k)Fluoranthene & $4.45 \mathrm{E}-08$ & $<\mathrm{LOD}$ & $<\mathrm{LOD}$ & $<\mathrm{LOD}$ & $<\mathrm{LOD}$ & $<\mathrm{LOD}$ & $<\mathrm{LOD}$ & - & $<\mathrm{LOD}$ & - \\
\hline Benzo(e)Pyrene & $4.45 \mathrm{E}-08$ & $<$ LOD & $<$ LOD & $<$ LOD & $<\mathrm{LOD}$ & $<$ LOD & $<$ LOD & - & $<$ LOD & - \\
\hline Benzo(a)Pyrene & $1.33 \mathrm{E}-07$ & $<\mathrm{LOD}$ & $<$ LOD & $<\mathrm{LOD}$ & $<\mathrm{LOD}$ & $<\mathrm{LOD}$ & $<\mathrm{LOD}$ & - & $<\mathrm{LOD}$ & - \\
\hline Perylene & $1.11 \mathrm{E}-07$ & $<\mathrm{LOD}$ & $<$ LOD & $<\mathrm{LOD}$ & $<$ LOD & $<\mathrm{LOD}$ & $<\mathrm{LOD}$ & - & $<$ LOD & - \\
\hline 2-Me-Cholanthrene & $6.67 \mathrm{E}-08$ & $<\mathrm{LOD}$ & $<$ LOD & $<\mathrm{LOD}$ & $<\mathrm{LOD}$ & $<\mathrm{LOD}$ & $<\mathrm{LOD}$ & - & $<\mathrm{LOD}$ & - \\
\hline Indeno(1,2,3-cd)Fluoranthene & $4.45 \mathrm{E}-08$ & $<$ LOD & $<$ LOD & $<\mathrm{LOD}$ & $<\mathrm{LOD}$ & $<\mathrm{LOD}$ & $<\mathrm{LOD}$ & - & $<\mathrm{LOD}$ & - \\
\hline Indeno(1,2,3-cd)Pyrene & $6.67 \mathrm{E}-08$ & $<$ LOD & $<$ LOD & $<$ LOD & $<\mathrm{LOD}$ & $<\mathrm{LOD}$ & $8.69 \mathrm{E}-07$ & $1.47 \mathrm{E}-08$ & $<\mathrm{LOD}$ & - \\
\hline Dibenzo(a,c)\&(a,h)Anthracene & $6.67 \mathrm{E}-08$ & $<\mathrm{LOD}$ & $<$ LOD & $<\mathrm{LOD}$ & $<\mathrm{LOD}$ & $<\mathrm{LOD}$ & $<\mathrm{LOD}$ & - & $<\mathrm{LOD}$ & - \\
\hline Benzo(b)Chrysene & $6.67 \mathrm{E}-08$ & $<\mathrm{LOD}$ & $<$ LOD & $<\mathrm{LOD}$ & $<\mathrm{LOD}$ & $<\mathrm{LOD}$ & $<\mathrm{LOD}$ & - & $<\mathrm{LOD}$ & - \\
\hline Benzo(g,h,i)Perylene & $4.45 \mathrm{E}-08$ & $1.91 \mathrm{E}-07$ & $<$ LOD & $<$ LOD & $7.12 \mathrm{E}-08$ & $2.41 \mathrm{E}-07$ & $9.06 \mathrm{E}-07$ & - & $<\mathrm{LOD}$ & - \\
\hline Anthanthrene & $6.67 \mathrm{E}-08$ & $<$ LOD & $<$ LOD & $<$ LOD & $<\mathrm{LOD}$ & $<\mathrm{LOD}$ & $<$ LOD & - & $<$ LOD & - \\
\hline
\end{tabular}

Note: $<\mathrm{LOD}=$ Below Level of Detection 
Table C. 5 Emissions of Methane and Non-Methane Hydrocarbons Measured in Different Phases

\begin{tabular}{|c|c|c|c|c|c|c|c|c|c|c|c|c|c|c|}
\hline \multirow{2}{*}{$\begin{array}{c}\text { Methane and } \\
\text { Non-Methane } \\
\text { Hydrocarbons } \\
\text { g/mile }\end{array}$} & \multirow{2}{*}{$\begin{array}{l}\text { Limit of } \\
\text { Detection }\end{array}$} & \multicolumn{5}{|c|}{$\begin{array}{c}\text { Phase I } \\
\text { Baseline \& OEM Catalyst }\end{array}$} & \multicolumn{4}{|c|}{$\begin{array}{c}\text { Phase II } \\
\text { New WVU-Lubrizol Aftertreatment }\end{array}$} & \multicolumn{4}{|c|}{\begin{tabular}{|c|} 
Phase III \\
Post Demo WVU-Lubrizol Aftertreatment
\end{tabular}} \\
\hline & & $\begin{array}{c}\text { QCBD } \\
\text { (Baseline) }\end{array}$ & \begin{tabular}{|c|} 
QCBD \\
(OEM \\
Catalyst)
\end{tabular} & $\begin{array}{c}\text { Standard } \\
\text { Deviation }\end{array}$ & Backgroun & $\begin{array}{l}\text { Standard } \\
\text { Deviation }\end{array}$ & QCBD & $\begin{array}{l}\text { Standard } \\
\text { Deviation }\end{array}$ & Background & $\begin{array}{c}\text { Standard } \\
\text { Deviation }\end{array}$ & QCBD & $\begin{array}{c}\text { Standard } \\
\text { Deviation }\end{array}$ & Background & $\begin{array}{l}\text { Standard } \\
\text { Deviation }\end{array}$ \\
\hline methane & $6.70 \mathrm{E}-03$ & $1.89 \mathrm{E}+01$ & $1.49 \mathrm{E}+01$ & 5.89E-01 & $4.67 \mathrm{E}-01$ & $2.28 \mathrm{E}-02$ & $1.51 \mathrm{E}+01$ & $2.34 \mathrm{E}+00$ & 7.62E-01 & 1.99E-02 & $2.37 \mathrm{E}+01$ & $3.88 \mathrm{E}-01$ & $5.67 \mathrm{E}-01$ & $9.36 \mathrm{E}-03$ \\
\hline ethylene & $6.70 \mathrm{E}-05$ & 3.22E-01 & $3.31 \mathrm{E}-02$ & $3.16 \mathrm{E}-03$ & $1.91 \mathrm{E}-03$ & $9.41 \mathrm{E}-04$ & $4.36 \mathrm{E}-03$ & $3.77 \mathrm{E}-04$ & $2.06 \mathrm{E}-03$ & $1.42 \mathrm{E}-03$ & $2.79 \mathrm{E}-03$ & $1.51 \mathrm{E}-04$ & $2.20 \mathrm{E}-03$ & $7.51 \mathrm{E}-04$ \\
\hline acetylene & $6.70 \mathrm{E}-05$ & 3.88E-02 & $2.41 \mathrm{E}-04$ & $8.17 \mathrm{E}-05$ & $1.22 \mathrm{E}-03$ & $6.89 \mathrm{E}-04$ & $1.05 \mathrm{E}-03$ & $2.22 \mathrm{E}-04$ & $1.25 \mathrm{E}-03$ & $5.55 \mathrm{E}-04$ & $1.14 \mathrm{E}-03$ & $6.11 \mathrm{E}-05$ & $1.59 \mathrm{E}-03$ & 4.79E-04 \\
\hline ethane & $6.70 \mathrm{E}-05$ & 4.84E-01 & $2.34 \mathrm{E}-01$ & $1.19 \mathrm{E}-02$ & $2.46 \mathrm{E}-03$ & $6.24 \mathrm{E}-04$ & $1.41 \mathrm{E}-01$ & $2.38 \mathrm{E}-02$ & $3.10 \mathrm{E}-03$ & $8.28 \mathrm{E}-04$ & $4.96 \mathrm{E}-01$ & $3.84 \mathrm{E}-03$ & $4.00 \mathrm{E}-03$ & $2.45 \mathrm{E}-04$ \\
\hline propylene & $6.70 \mathrm{E}-05$ & $2.53 \mathrm{E}-02$ & $<\mathrm{LOD}$ & $0.00 \mathrm{E}+00$ & $5.89 \mathrm{E}-04$ & $3.04 \mathrm{E}-04$ & $6.53 \mathrm{E}-04$ & $2.33 \mathrm{E}-04$ & $7.50 \mathrm{E}-04$ & $6.06 \mathrm{E}-04$ & $6.64 \mathrm{E}-04$ & $4.06 \mathrm{E}-05$ & $8.52 \mathrm{E}-04$ & $4.21 \mathrm{E}-04$ \\
\hline propane & $6.70 \mathrm{E}-05$ & $6.53 \mathrm{E}-02$ & $2.11 \mathrm{E}-02$ & $2.54 \mathrm{E}-03$ & $5.08 \mathrm{E}-03$ & $3.33 \mathrm{E}-03$ & $7.16 \mathrm{E}-03$ & $6.27 \mathrm{E}-04$ & $3.40 \mathrm{E}-03$ & $1.17 \mathrm{E}-03$ & $4.11 \mathrm{E}-02$ & $9.52 \mathrm{E}-04$ & $6.17 \mathrm{E}-03$ & $3.48 \mathrm{E}-03$ \\
\hline propyne & $6.70 \mathrm{E}-05$ & 5.39E-03 & $1.58 \mathrm{E}-03$ & $1.18 \mathrm{E}-03$ & $1.11 \mathrm{E}-04$ & - & $1.28 \mathrm{E}-04$ & - & $1.11 \mathrm{E}-04$ & - & $9.19 \mathrm{E}-05$ & - & $1.15 \mathrm{E}-04$ & - \\
\hline isobutane & $6.70 \mathrm{E}-05$ & $<\mathrm{LOD}$ & $<\mathrm{LOD}$ & $0.00 \mathrm{E}+00$ & $1.16 \mathrm{E}-03$ & $3.59 \mathrm{E}-04$ & $1.42 \mathrm{E}-03$ & $2.66 \mathrm{E}-04$ & $1.25 \mathrm{E}-03$ & 5.39E-04 & $6.59 \mathrm{E}-03$ & $1.67 \mathrm{E}-04$ & 1.19E-03 & $2.24 \mathrm{E}-04$ \\
\hline isobutene/1-butene & $6.70 \mathrm{E}-05$ & $1.20 \mathrm{E}-02$ & $1.16 \mathrm{E}-03$ & $4.34 \mathrm{E}-04$ & $4.30 \mathrm{E}-04$ & $1.28 \mathrm{E}-04$ & $1.47 \mathrm{E}-03$ & $1.17 \mathrm{E}-03$ & $5.55 \mathrm{E}-04$ & $3.17 \mathrm{E}-04$ & $1.02 \mathrm{E}-03$ & $1.97 \mathrm{E}-04$ & $4.56 \mathrm{E}-04$ & $1.15 \mathrm{E}-04$ \\
\hline 13-butadiene & $6.70 \mathrm{E}-05$ & $<$ LOD & $<\mathrm{LOD}$ & $0.00 \mathrm{E}+00$ & $9.59 \mathrm{E}-05$ & - & $<\mathrm{LOD}$ & - & $2.47 \mathrm{E}-04$ & - & $<\mathrm{LOD}$ & - & $1.89 \mathrm{E}-04$ & - \\
\hline n-butane & $6.70 \mathrm{E}-05$ & 4.39E-02 & $5.77 \mathrm{E}-03$ & $9.00 \mathrm{E}-04$ & $3.08 \mathrm{E}-03$ & $2.17 \mathrm{E}-03$ & $2.57 \mathrm{E}-03$ & $4.82 \mathrm{E}-04$ & $2.57 \mathrm{E}-03$ & $1.23 \mathrm{E}-03$ & $7.41 \mathrm{E}-03$ & $3.92 \mathrm{E}-04$ & $2.04 \mathrm{E}-03$ & $3.82 \mathrm{E}-04$ \\
\hline t2-butene & $6.70 \mathrm{E}-05$ & 5.30E-04 & $<\mathrm{LOD}$ & $0.00 \mathrm{E}+00$ & $<\mathrm{LOD}$ & - & $2.23 \mathrm{E}-04$ & $8.86 \mathrm{E}-05$ & $2.36 \mathrm{E}-04$ & - & $<\mathrm{LOD}$ & - & $<\mathrm{LOD}$ & - \\
\hline c2-butene & $6.70 \mathrm{E}-05$ & $1.23 \mathrm{E}-03$ & $1.29 \mathrm{E}-03$ & $1.51 \mathrm{E}-05$ & $5.46 \mathrm{E}-04$ & $1.84 \mathrm{E}-04$ & $<\mathrm{LOD}$ & - & $1.90 \mathrm{E}-04$ & 7.69E-05 & $2.15 \mathrm{E}-04$ & $1.14 \mathrm{E}-04$ & $<\mathrm{LOD}$ & - \\
\hline 3m1-butene & $6.70 \mathrm{E}-05$ & 5.74E-04 & $<\mathrm{LOD}$ & $0.00 \mathrm{E}+00$ & $<\mathrm{LOD}$ & - & $<\mathrm{LOD}$ & - & $<\mathrm{LOD}$ & - & $<\mathrm{LOD}$ & - & $<\mathrm{LOD}$ & - \\
\hline 2m-butane & $6.70 \mathrm{E}-05$ & $1.21 \mathrm{E}-02$ & $4.56 \mathrm{E}-03$ & $1.39 \mathrm{E}-03$ & $4.33 \mathrm{E}-03$ & $2.50 \mathrm{E}-03$ & $3.03 \mathrm{E}-03$ & $1.15 \mathrm{E}-03$ & $3.60 \mathrm{E}-03$ & $1.71 \mathrm{E}-03$ & $5.28 \mathrm{E}-03$ & $9.73 \mathrm{E}-04$ & $5.14 \mathrm{E}-03$ & $2.76 \mathrm{E}-03$ \\
\hline 1-pentene & $6.70 \mathrm{E}-05$ & $1.84 \mathrm{E}-03$ & $1.72 \mathrm{E}-04$ & $1.03 \mathrm{E}-04$ & $1.20 \mathrm{E}-04$ & - & $<\mathrm{LOD}$ & - & $<\mathrm{LOD}$ & - & $<\mathrm{LOD}$ & - & $<\mathrm{LOD}$ & - \\
\hline 2m1-butene & $6.70 \mathrm{E}-05$ & 7.92E-04 & $9.35 \mathrm{E}-05$ & - & $<\mathrm{LOD}$ & - & $<\mathrm{LOD}$ & - & $1.10 \mathrm{E}-04$ & - & $1.62 \mathrm{E}-04$ & - & $1.01 \mathrm{E}-04$ & - \\
\hline n-pentane & $6.70 \mathrm{E}-05$ & $9.75 \mathrm{E}-03$ & $2.70 \mathrm{E}-03$ & $6.02 \mathrm{E}-04$ & $2.38 \mathrm{E}-03$ & $9.03 \mathrm{E}-04$ & $2.32 \mathrm{E}-03$ & $3.75 \mathrm{E}-04$ & $1.96 \mathrm{E}-03$ & $4.03 \mathrm{E}-04$ & $2.18 \mathrm{E}-03$ & $3.58 \mathrm{E}-04$ & $1.42 \mathrm{E}-03$ & $3.60 \mathrm{E}-04$ \\
\hline 2m-13-butadiene & $6.70 \mathrm{E}-05$ & $6.12 \mathrm{E}-04$ & $1.17 \mathrm{E}-04$ & - & $5.31 \mathrm{E}-04$ & $1.59 \mathrm{E}-04$ & $<\mathrm{LOD}$ & - & $1.27 \mathrm{E}-04$ & $6.15 \mathrm{E}-06$ & $<\mathrm{LOD}$ & - & $1.70 \mathrm{E}-04$ & $7.58 \mathrm{E}-05$ \\
\hline t2-pentene & $6.70 \mathrm{E}-05$ & 7.47E-04 & $5.24 \mathrm{E}-04$ & $1.53 \mathrm{E}-04$ & $<\mathrm{LOD}$ & - & $<\mathrm{LOD}$ & - & $<\mathrm{LOD}$ & - & $<\mathrm{LOD}$ & - & $<\mathrm{LOD}$ & - \\
\hline c2-pentene & $6.70 \mathrm{E}-05$ & $2.30 \mathrm{E}-04$ & $<\mathrm{LOD}$ & $0.00 \mathrm{E}+00$ & $<\mathrm{LOD}$ & - & $<\mathrm{LOD}$ & - & $<\mathrm{LOD}$ & - & $<\mathrm{LOD}$ & - & $<\mathrm{LOD}$ & - \\
\hline 2m2-butene & $6.70 \mathrm{E}-05$ & $6.24 \mathrm{E}-04$ & $1.73 \mathrm{E}-04$ & $1.43 \mathrm{E}-05$ & $<\mathrm{LOD}$ & - & $1.75 \mathrm{E}-04$ & $1.18 \mathrm{E}-05$ & $<\mathrm{LOD}$ & - & $<\mathrm{LOD}$ & - & $<\mathrm{LOD}$ & - \\
\hline 22-dm-butane & $6.70 \mathrm{E}-05$ & $<\mathrm{LOD}$ & $4.34 \mathrm{E}-04$ & $2.11 \mathrm{E}-04$ & $3.81 \mathrm{E}-04$ & $2.87 \mathrm{E}-04$ & $2.17 \mathrm{E}-04$ & $6.19 \mathrm{E}-05$ & $3.12 \mathrm{E}-04$ & $1.45 \mathrm{E}-04$ & $6.22 \mathrm{E}-04$ & $3.71 \mathrm{E}-05$ & $3.77 \mathrm{E}-04$ & $3.08 \mathrm{E}-05$ \\
\hline
\end{tabular}


Contd...

\begin{tabular}{|c|c|c|c|c|c|c|c|c|c|c|c|c|c|c|}
\hline \multirow{2}{*}{$\begin{array}{l}\text { Non-Methane } \\
\text { Hydrocarbons } \\
\text { g/mile }\end{array}$} & \multirow{2}{*}{$\begin{array}{l}\text { Limit of } \\
\text { Detection }\end{array}$} & \multicolumn{5}{|c|}{$\begin{array}{c}\text { Phase I } \\
\text { Baseline \& OEM Catalyst }\end{array}$} & \multicolumn{4}{|c|}{$\begin{array}{c}\text { Phase II } \\
\text { New WVU-Lubrizol Aftertreatment }\end{array}$} & \multicolumn{4}{|c|}{$\begin{array}{c}\text { Phase III } \\
\text { Post Demo WVU-Lubrizol } \\
\text { Aftertreatment }\end{array}$} \\
\hline & & $\begin{array}{c}\mathrm{QCBD} \\
\text { (Baseline) }\end{array}$ & $\begin{array}{c}\text { QCBD } \\
\text { (OEM } \\
\text { Catalyst) }\end{array}$ & $\begin{array}{c}\text { Standard } \\
\text { Deviation }\end{array}$ & Background & $\begin{array}{c}\text { Standard } \\
\text { Deviation }\end{array}$ & QCBD & $\begin{array}{c}\text { Standard } \\
\text { Deviation }\end{array}$ & Backgro & $\begin{array}{c}\text { Standard } \\
\text { Deviation }\end{array}$ & QCBD & $\begin{array}{c}\text { Standard } \\
\text { Deviation }\end{array}$ & Backgr & $\begin{array}{c}\text { Standard } \\
\text { Deviation }\end{array}$ \\
\hline cyclopentene & $6.70 \mathrm{E}-05$ & $7.75 \mathrm{E}-04$ & $1.61 \mathrm{E}-04$ & $3.16 \mathrm{E}-07$ & $<\mathrm{LOD}$ & - & $<\mathrm{LOD}$ & - & $<\mathrm{LOD}$ & - & $<\mathrm{LOD}$ & - & $<\mathrm{LOD}$ & - \\
\hline $4 \mathrm{~m} 1$-pentene & $6.70 \mathrm{E}-05$ & $5.00 \mathrm{E}-04$ & $4.85 \mathrm{E}-04$ & $6.58 \mathrm{E}-05$ & $2.46 \mathrm{E}-04$ & $8.39 \mathrm{E}-05$ & $1.52 \mathrm{E}-04$ & $4.57 \mathrm{E}-05$ & $1.93 \mathrm{E}-04$ & - & $2.92 \mathrm{E}-04$ & $2.14 \mathrm{E}-05$ & $2.01 \mathrm{E}-04$ & $2.86 \mathrm{E}-05$ \\
\hline cyclopentane & $6.70 \mathrm{E}-05$ & $8.40 \mathrm{E}-04$ & $7.90 \mathrm{E}-04$ & $6.36 \mathrm{E}-04$ & $1.65 \mathrm{E}-04$ & $1.12 \mathrm{E}-04$ & $1.56 \mathrm{E}-04$ & $6.65 \mathrm{E}-05$ & $1.68 \mathrm{E}-04$ & $8.83 \mathrm{E}-05$ & $2.47 \mathrm{E}-04$ & $9.76 \mathrm{E}-05$ & $2.72 \mathrm{E}-04$ & $1.16 \mathrm{E}-04$ \\
\hline 23-dm-butane & $6.70 \mathrm{E}-05$ & $1.23 \mathrm{E}-03$ & $4.98 \mathrm{E}-04$ & $1.91 \mathrm{E}-04$ & 7.61E-04 & $6.21 \mathrm{E}-04$ & $4.59 \mathrm{E}-04$ & $2.82 \mathrm{E}-04$ & $4.21 \mathrm{E}-04$ & $2.38 \mathrm{E}-04$ & $6.67 \mathrm{E}-04$ & $2.97 \mathrm{E}-04$ & $6.33 \mathrm{E}-04$ & $2.91 \mathrm{E}-04$ \\
\hline MTBE & $6.70 \mathrm{E}-05$ & $4.67 \mathrm{E}-04$ & $<\mathrm{LOD}$ & - & $<\mathrm{LOD}$ & - & $<\mathrm{LOD}$ & - & $2.67 \mathrm{E}-04$ & $4.56 \mathrm{E}-05$ & $<\mathrm{LOD}$ & - & $<\mathrm{LOD}$ & - \\
\hline $2 \mathrm{~m}$-pentane & $6.70 \mathrm{E}-05$ & $3.12 \mathrm{E}-03$ & $1.18 \mathrm{E}-03$ & $5.02 \mathrm{E}-04$ & $2.63 \mathrm{E}-03$ & $2.80 \mathrm{E}-03$ & $9.16 \mathrm{E}-04$ & $2.83 \mathrm{E}-04$ & $1.16 \mathrm{E}-03$ & $5.70 \mathrm{E}-04$ & $2.27 \mathrm{E}-03$ & $1.28 \mathrm{E}-03$ & $1.24 \mathrm{E}-03$ & $1.96 \mathrm{E}-04$ \\
\hline $\mathrm{c} / \mathrm{t}-4 \mathrm{~m} 2$-pentene & $6.70 \mathrm{E}-05$ & $1.73 \mathrm{E}-03$ & $1.50 \mathrm{E}-03$ & $3.33 \mathrm{E}-04$ & $1.72 \mathrm{E}-03$ & - & $<\mathrm{LOD}$ & - & $<\mathrm{LOD}$ & - & $2.61 \mathrm{E}-04$ & $3.13 \mathrm{E}-06$ & $<\mathrm{LOD}$ & - \\
\hline $3 \mathrm{~m}$-pentane & $6.70 \mathrm{E}-05$ & $2.44 \mathrm{E}-03$ & $1.80 \mathrm{E}-03$ & $4.10 \mathrm{E}-04$ & $2.78 \mathrm{E}-03$ & $2.36 \mathrm{E}-03$ & $5.88 \mathrm{E}-04$ & $1.36 \mathrm{E}-04$ & $6.97 \mathrm{E}-04$ & $3.41 \mathrm{E}-04$ & $1.76 \mathrm{E}-03$ & $1.51 \mathrm{E}-03$ & $1.53 \mathrm{E}-03$ & $2.31 \mathrm{E}-04$ \\
\hline 2m1-pentene & $6.70 \mathrm{E}-05$ & $<\mathrm{LOD}$ & $<\mathrm{LOD}$ & - & $<\mathrm{LOD}$ & - & $<\mathrm{LOD}$ & - & $<\mathrm{LOD}$ & $\# \mathrm{~N} / \mathrm{A}$ & $<\mathrm{LOD}$ & - & $<\mathrm{LOD}$ & - \\
\hline 1-hexene & $6.70 \mathrm{E}-05$ & $<\mathrm{LOD}$ & $<\mathrm{LOD}$ & - & $<\mathrm{LOD}$ & - & $<\mathrm{LOD}$ & - & $<\mathrm{LOD}$ & $\# \mathrm{~N} / \mathrm{A}$ & $<\mathrm{LOD}$ & - & $<\mathrm{LOD}$ & - \\
\hline n-hexane & $6.70 \mathrm{E}-05$ & $3.96 \mathrm{E}-03$ & $9.62 \mathrm{E}-04$ & $3.32 \mathrm{E}-04$ & $8.25 \mathrm{E}-04$ & $5.32 \mathrm{E}-04$ & $5.27 \mathrm{E}-04$ & $1.38 \mathrm{E}-04$ & $6.61 \mathrm{E}-04$ & $3.25 \mathrm{E}-04$ & $7.28 \mathrm{E}-04$ & $1.37 \mathrm{E}-04$ & 7.33E-04 & $3.23 \mathrm{E}-04$ \\
\hline t2-hexene & $6.70 \mathrm{E}-05$ & $1.70 \mathrm{E}-04$ & $<\mathrm{LOD}$ & - & $<\mathrm{LOD}$ & - & $<\mathrm{LOD}$ & - & $<\mathrm{LOD}$ & - & $<\mathrm{LOD}$ & - & $<\mathrm{LOD}$ & - \\
\hline 2m2-pentene & $6.70 \mathrm{E}-05$ & $3.20 \mathrm{E}-04$ & $1.04 \mathrm{E}-04$ & $1.52 \mathrm{E}-05$ & $1.27 \mathrm{E}-04$ & - & 7.53E-04 & $0.00 \mathrm{E}+00$ & $<\mathrm{LOD}$ & - & $1.40 \mathrm{E}-04$ & - & $1.39 \mathrm{E}-04$ & - \\
\hline$t$-3m2-pentene & $6.70 \mathrm{E}-05$ & $1.93 \mathrm{E}-04$ & $<\mathrm{LOD}$ & - & $<\mathrm{LOD}$ & - & $<\mathrm{LOD}$ & - & $1.44 \mathrm{E}-03$ & - & $<\mathrm{LOD}$ & - & $<\mathrm{LOD}$ & - \\
\hline c2-hexene & $6.70 \mathrm{E}-05$ & $<\mathrm{LOD}$ & $<\mathrm{LOD}$ & - & $<\mathrm{LOD}$ & - & $<\mathrm{LOD}$ & - & $<\mathrm{LOD}$ & - & $<\mathrm{LOD}$ & - & $<\mathrm{LOD}$ & - \\
\hline c-3m2-pentene & $6.70 \mathrm{E}-05$ & $<\mathrm{LOD}$ & $3.55 \mathrm{E}-04$ & $1.24 \mathrm{E}-04$ & $<\mathrm{LOD}$ & - & $2.86 \mathrm{E}-04$ & - & $<\mathrm{LOD}$ & - & $3.66 \mathrm{E}-04$ & 9.15E-05 & $1.21 \mathrm{E}-04$ & $4.70 \mathrm{E}-05$ \\
\hline 22-dm-pentane & $6.70 \mathrm{E}-05$ & 7.47E-05 & $<$ LOD & - & $<\mathrm{LOD}$ & - & $<\mathrm{LOD}$ & - & $<\mathrm{LOD}$ & - & $<\mathrm{LOD}$ & - & $<\mathrm{LOD}$ & - \\
\hline m-cyclopentane & $6.70 \mathrm{E}-05$ & $1.72 \mathrm{E}-03$ & $6.81 \mathrm{E}-04$ & $3.54 \mathrm{E}-04$ & $9.22 \mathrm{E}-04$ & $6.92 \mathrm{E}-04$ & $5.20 \mathrm{E}-04$ & $1.86 \mathrm{E}-04$ & $6.72 \mathrm{E}-04$ & $3.54 \mathrm{E}-04$ & $5.12 \mathrm{E}-04$ & $2.56 \mathrm{E}-05$ & $7.11 \mathrm{E}-04$ & $2.95 \mathrm{E}-04$ \\
\hline 24-dm-pentane & $6.70 \mathrm{E}-05$ & $4.15 \mathrm{E}-04$ & $3.23 \mathrm{E}-04$ & $1.78 \mathrm{E}-04$ & $5.23 \mathrm{E}-04$ & $2.50 \mathrm{E}-04$ & $2.80 \mathrm{E}-04$ & $1.37 \mathrm{E}-04$ & $3.25 \mathrm{E}-04$ & $1.65 \mathrm{E}-04$ & $3.57 \mathrm{E}-04$ & $1.35 \mathrm{E}-05$ & 4.48E-04 & $2.11 \mathrm{E}-04$ \\
\hline 223-tm-butane & $6.70 \mathrm{E}-05$ & $<\mathrm{LOD}$ & $<\mathrm{LOD}$ & - & $<\mathrm{LOD}$ & - & $<\mathrm{LOD}$ & - & $<\mathrm{LOD}$ & - & $<\mathrm{LOD}$ & - & $<\mathrm{LOD}$ & - \\
\hline $1 \mathrm{~m}$-cyclopentene & $6.70 \mathrm{E}-05$ & $1.48 \mathrm{E}-04$ & $1.98 \mathrm{E}-04$ & - & $<\mathrm{LOD}$ & - & $<\mathrm{LOD}$ & - & $<\mathrm{LOD}$ & - & $<\mathrm{LOD}$ & - & $<\mathrm{LOD}$ & - \\
\hline benzene & $6.70 \mathrm{E}-05$ & 7.72E-03 & $1.16 \mathrm{E}-03$ & $3.43 \mathrm{E}-04$ & $9.80 \mathrm{E}-04$ & $5.60 \mathrm{E}-04$ & $8.14 \mathrm{E}-04$ & $2.72 \mathrm{E}-04$ & 8.01E-04 & 3.69E-04 & 7.85E-04 & $3.12 \mathrm{E}-05$ & 9.33E-04 & $3.12 \mathrm{E}-04$ \\
\hline 33-dm-pentane & $6.70 \mathrm{E}-05$ & $1.37 \mathrm{E}-04$ & $2.12 \mathrm{E}-04$ & $1.92 \mathrm{E}-05$ & $<\mathrm{LOD}$ & - & $<\mathrm{LOD}$ & - & $<\mathrm{LOD}$ & - & $<\mathrm{LOD}$ & - & $<\mathrm{LOD}$ & - \\
\hline cyclohexane & $6.70 \mathrm{E}-05$ & $1.93 \mathrm{E}-03$ & $5.16 \mathrm{E}-04$ & $2.12 \mathrm{E}-04$ & $5.68 \mathrm{E}-04$ & $3.34 \mathrm{E}-04$ & $2.92 \mathrm{E}-04$ & $9.14 \mathrm{E}-05$ & $5.79 \mathrm{E}-04$ & 4.84E-04 & $1.25 \mathrm{E}-03$ & $6.11 \mathrm{E}-04$ & $1.80 \mathrm{E}-03$ & - \\
\hline
\end{tabular}

Note: $<\mathrm{LOD}=$ Below Level of Detection 
Contd...

\begin{tabular}{|c|c|c|c|c|c|c|c|c|c|c|c|c|c|c|}
\hline \multirow{2}{*}{$\begin{array}{l}\text { Non-Methane Hydrocarbons } \\
\text { g/mile }\end{array}$} & \multirow{2}{*}{$\begin{array}{l}\text { Limit of } \\
\text { Detection }\end{array}$} & \multicolumn{5}{|c|}{$\begin{array}{c}\text { Phase I } \\
\text { Baseline \& OEM Catalyst }\end{array}$} & \multicolumn{4}{|c|}{$\begin{array}{c}\text { Phase II } \\
\text { New WVU-Lubrizol Aftertreatment }\end{array}$} & \multicolumn{4}{|c|}{$\begin{array}{c}\text { Phase III } \\
\text { Post Demo WVU-Lubrizol Aftertreatment }\end{array}$} \\
\hline & & $\begin{array}{c}\text { QCBD } \\
\text { (Baseline) }\end{array}$ & \begin{tabular}{|c|} 
QCBD \\
(OEM \\
Catalyst)
\end{tabular} & $\begin{array}{l}\text { Standard } \\
\text { Deviation }\end{array}$ & Background & $\mid \begin{array}{c}\text { Standard } \\
\text { Deviation }\end{array}$ & QCBD & $\begin{array}{c}\text { Standard } \\
\text { Deviation }\end{array}$ & Background & $\mid \begin{array}{c}\text { Standard } \\
\text { Deviation }\end{array}$ & QCBD & $\left|\begin{array}{c}\text { Standard } \\
\text { Deviation }\end{array}\right|$ & Background & $\begin{array}{l}\text { Standard } \\
\text { Deviation }\end{array}$ \\
\hline 2m-hexane & $6.70 \mathrm{E}-05$ & $1.16 \mathrm{E}-03$ & $5.26 \mathrm{E}-04$ & $2.53 \mathrm{E}-04$ & $5.42 \mathrm{E}-04$ & $4.17 \mathrm{E}-04$ & $3.36 \mathrm{E}-04$ & $1.11 \mathrm{E}-04$ & $3.78 \mathrm{E}-04$ & $1.84 \mathrm{E}-04$ & $2.80 \mathrm{E}-04$ & $2.80 \mathrm{E}-05$ & 4.39E-04 & $2.03 \mathrm{E}-04$ \\
\hline 23-dm-pentane & $6.70 \mathrm{E}-05$ & $1.09 \mathrm{E}-03$ & $5.55 \mathrm{E}-04$ & $4.04 \mathrm{E}-04$ & $5.59 \mathrm{E}-04$ & 4.49E-04 & $3.87 \mathrm{E}-04$ & $1.46 \mathrm{E}-04$ & $4.47 \mathrm{E}-04$ & $2.40 \mathrm{E}-04$ & $3.54 \mathrm{E}-04$ & $4.97 \mathrm{E}-05$ & $5.31 \mathrm{E}-04$ & 2.78E-04 \\
\hline 11-dm-cyP & $6.70 \mathrm{E}-05$ & $1.95 \mathrm{E}-04$ & $<$ LOD & - & $1.83 \mathrm{E}-04$ & $5.68 \mathrm{E}-05$ & $<$ LOD & - & $<\mathrm{LOD}$ & - & $2.28 \mathrm{E}-04$ & $4.95 \mathrm{E}-05$ & $1.46 \mathrm{E}-04$ & 5.19E-06 \\
\hline cyclohexene & $6.70 \mathrm{E}-05$ & $6.85 \mathrm{E}-04$ & $<$ LOD & - & $<\mathrm{LOD}$ & - & $2.45 \mathrm{E}-04$ & - & $<\mathrm{LOD}$ & - & $<\mathrm{LOD}$ & - & $<\mathrm{LOD}$ & - \\
\hline 3m-hexane & $6.70 \mathrm{E}-05$ & $1.53 \mathrm{E}-03$ & $1.30 \mathrm{E}-03$ & 4.70E-04 & $7.92 \mathrm{E}-04$ & $7.14 \mathrm{E}-04$ & $4.33 \mathrm{E}-04$ & $0.00 \mathrm{E}+00$ & 5.52E-04 & $2.06 \mathrm{E}-04$ & $2.66 \mathrm{E}-04$ & $2.05 \mathrm{E}-05$ & 4.77E-04 & $2.18 \mathrm{E}-04$ \\
\hline c-13-dm-cyP & $6.70 \mathrm{E}-05$ & $3.15 \mathrm{E}-04$ & $1.77 \mathrm{E}-04$ & $6.60 \mathrm{E}-05$ & $2.65 \mathrm{E}-04$ & - & $2.04 \mathrm{E}-04$ & - & $1.89 \mathrm{E}-04$ & - & $8.68 \mathrm{E}-05$ & $4.05 \mathrm{E}-06$ & $1.22 \mathrm{E}-04$ & $5.09 \mathrm{E}-05$ \\
\hline 3e-pentane/t-13-dm-cyP & $6.70 \mathrm{E}-05$ & $5.67 \mathrm{E}-04$ & $2.29 \mathrm{E}-04$ & 1.04E-04 & $3.31 \mathrm{E}-04$ & - & $2.35 \mathrm{E}-04$ & - & $2.26 \mathrm{E}-04$ & - & $1.88 \mathrm{E}-04$ & $8.11 \mathrm{E}-06$ & $3.18 \mathrm{E}-04$ & - \\
\hline t-12-dm-cyP/1-heptene & $6.70 \mathrm{E}-05$ & $1.74 \mathrm{E}-03$ & $<\mathrm{LOD}$ & - & $<\mathrm{LOD}$ & - & $<\mathrm{LOD}$ & - & $<$ LOD & - & $<\mathrm{LOD}$ & - & $<\mathrm{LOD}$ & - \\
\hline 224-tm-pentane & $6.70 \mathrm{E}-05$ & $7.89 \mathrm{E}-04$ & $1.20 \mathrm{E}-03$ & $5.62 \mathrm{E}-04$ & $1.44 \mathrm{E}-03$ & $1.09 \mathrm{E}-03$ & $1.18 \mathrm{E}-03$ & 4.64E-04 & $1.44 \mathrm{E}-03$ & $8.46 \mathrm{E}-04$ & $1.36 \mathrm{E}-03$ & $3.85 \mathrm{E}-04$ & $1.32 \mathrm{E}-03$ & 4.44E-04 \\
\hline t3-heptene & $6.70 \mathrm{E}-05$ & $<\mathrm{LOD}$ & $<\mathrm{LOD}$ & - & $<\mathrm{LOD}$ & - & $<\mathrm{LOD}$ & - & $<\mathrm{LOD}$ & - & $<\mathrm{LOD}$ & - & $<\mathrm{LOD}$ & - \\
\hline n-heptane & $6.70 \mathrm{E}-05$ & $1.85 \mathrm{E}-03$ & $7.52 \mathrm{E}-04$ & 3.09E-04 & $5.31 \mathrm{E}-04$ & $3.47 \mathrm{E}-04$ & $3.42 \mathrm{E}-04$ & $1.10 \mathrm{E}-04$ & $3.72 \mathrm{E}-04$ & $1.52 \mathrm{E}-04$ & $2.82 \mathrm{E}-04$ & $9.08 \mathrm{E}-06$ & $3.78 \mathrm{E}-04$ & $1.21 \mathrm{E}-04$ \\
\hline c3-heptene & $6.70 \mathrm{E}-05$ & $<\mathrm{LOD}$ & $<\mathrm{LOD}$ & - & $<\mathrm{LOD}$ & - & $<\mathrm{LOD}$ & - & $<\mathrm{LOD}$ & - & $<\mathrm{LOD}$ & - & $<\mathrm{LOD}$ & - \\
\hline t2-heptene & $6.70 \mathrm{E}-05$ & $<\mathrm{LOD}$ & $1.72 \mathrm{E}-04$ & $8.15 \mathrm{E}-05$ & $<\mathrm{LOD}$ & - & $<\mathrm{LOD}$ & - & $<\mathrm{LOD}$ & - & $2.22 \mathrm{E}-04$ & $1.05 \mathrm{E}-04$ & $9.86 \mathrm{E}-05$ & - \\
\hline c2-heptene & $6.70 \mathrm{E}-05$ & $<\mathrm{LOD}$ & $<\mathrm{LOD}$ & - & $<\mathrm{LOD}$ & - & $<\mathrm{LOD}$ & - & $<\mathrm{LOD}$ & - & $<\mathrm{LOD}$ & - & $<\mathrm{LOD}$ & - \\
\hline m-cyclohexane/22-dm-hexane & $6.70 \mathrm{E}-05$ & $2.65 \mathrm{E}-03$ & $6.29 \mathrm{E}-04$ & $2.80 \mathrm{E}-04$ & $6.85 \mathrm{E}-04$ & $4.22 \mathrm{E}-04$ & $2.32 \mathrm{E}-04$ & $6.61 \mathrm{E}-05$ & $3.40 \mathrm{E}-04$ & $2.08 \mathrm{E}-04$ & $2.68 \mathrm{E}-04$ & $2.65 \mathrm{E}-05$ & $3.49 \mathrm{E}-04$ & $1.70 \mathrm{E}-04$ \\
\hline 25-dm-hexane/e-cyP & $6.70 \mathrm{E}-05$ & $2.81 \mathrm{E}-04$ & $1.95 \mathrm{E}-04$ & 6.79E-05 & $3.64 \mathrm{E}-04$ & - & $1.57 \mathrm{E}-04$ & $4.74 \mathrm{E}-05$ & $2.03 \mathrm{E}-04$ & $1.10 \mathrm{E}-04$ & $2.03 \mathrm{E}-04$ & $3.47 \mathrm{E}-05$ & $2.37 \mathrm{E}-04$ & $1.04 \mathrm{E}-04$ \\
\hline 24-dm-hexane/223-tm-pentane & $6.70 \mathrm{E}-05$ & $<\mathrm{LOD}$ & $2.17 \mathrm{E}-04$ & 5.74E-05 & $3.48 \mathrm{E}-04$ & - & $2.99 \mathrm{E}-04$ & $1.15 \mathrm{E}-04$ & $2.59 \mathrm{E}-04$ & $1.47 \mathrm{E}-04$ & $2.32 \mathrm{E}-04$ & $3.59 \mathrm{E}-05$ & $2.40 \mathrm{E}-04$ & $9.38 \mathrm{E}-05$ \\
\hline 33-dm-hexane/ctc124-tm-cyP & $6.70 \mathrm{E}-05$ & $2.02 \mathrm{E}-04$ & $1.65 \mathrm{E}-04$ & $6.74 \mathrm{E}-05$ & $1.19 \mathrm{E}-04$ & - & $<$ LOD & - & $<\mathrm{LOD}$ & - & $2.01 \mathrm{E}-04$ & $1.27 \mathrm{E}-04$ & $<\mathrm{LOD}$ & - \\
\hline ctc123-tm-cyP & $6.70 \mathrm{E}-05$ & $2.34 \mathrm{E}-04$ & $1.88 \mathrm{E}-04$ & $3.41 \mathrm{E}-05$ & $1.65 \mathrm{E}-04$ & - & $1.23 \mathrm{E}-04$ & - & $<\mathrm{LOD}$ & - & $2.89 \mathrm{E}-04$ & $4.59 \mathrm{E}-05$ & $<\mathrm{LOD}$ & - \\
\hline 234-tm-pentane & $6.70 \mathrm{E}-05$ & $2.39 \mathrm{E}-04$ & $2.59 \mathrm{E}-04$ & $1.31 \mathrm{E}-04$ & $3.49 \mathrm{E}-04$ & $2.93 \mathrm{E}-04$ & $3.55 \mathrm{E}-04$ & $1.28 \mathrm{E}-04$ & 4.11E-04 & $2.49 \mathrm{E}-04$ & $2.61 \mathrm{E}-04$ & $4.68 \mathrm{E}-05$ & 3.79E-04 & $2.29 \mathrm{E}-04$ \\
\hline toluene/233-tm-pentane & $6.70 \mathrm{E}-05$ & $5.30 \mathrm{E}-03$ & $2.95 \mathrm{E}-03$ & $1.10 \mathrm{E}-03$ & $3.78 \mathrm{E}-03$ & $2.91 \mathrm{E}-03$ & $2.84 \mathrm{E}-03$ & $9.60 \mathrm{E}-04$ & $3.48 \mathrm{E}-03$ & $1.79 \mathrm{E}-03$ & $2.17 \mathrm{E}-03$ & $2.86 \mathrm{E}-04$ & $3.08 \mathrm{E}-03$ & $1.45 \mathrm{E}-03$ \\
\hline 23-dm-hexane & $6.70 \mathrm{E}-05$ & $8.42 \mathrm{E}-05$ & $1.33 \mathrm{E}-04$ & $2.00 \mathrm{E}-05$ & $2.20 \mathrm{E}-04$ & - & $1.23 \mathrm{E}-04$ & - & $1.71 \mathrm{E}-04$ & - & $1.40 \mathrm{E}-04$ & - & $1.57 \mathrm{E}-04$ & - \\
\hline 2m-heptane & $6.70 \mathrm{E}-05$ & $6.83 \mathrm{E}-04$ & $3.44 \mathrm{E}-04$ & $9.34 \mathrm{E}-05$ & $3.10 \mathrm{E}-04$ & - & $1.33 \mathrm{E}-04$ & $4.14 \mathrm{E}-05$ & $1.73 \mathrm{E}-04$ & $6.26 \mathrm{E}-05$ & $3.46 \mathrm{E}-04$ & - & $2.27 \mathrm{E}-04$ & $1.61 \mathrm{E}-04$ \\
\hline
\end{tabular}

Note: $<\mathrm{LOD}=$ Below Level of Detection 
Contd...

\begin{tabular}{|c|c|c|c|c|c|c|c|c|c|c|c|c|c|c|}
\hline \multirow{2}{*}{$\begin{array}{l}\text { Non-Methane Hydrocarbons } \\
\text { g/mile }\end{array}$} & \multirow{2}{*}{$\begin{array}{c}\text { Limit of } \\
\text { Detection }\end{array}$} & \multicolumn{5}{|c|}{$\begin{array}{c}\text { Phase I } \\
\text { Baseline \& OEM Catalyst }\end{array}$} & \multicolumn{4}{|c|}{$\begin{array}{c}\text { Phase II } \\
\text { New WVU-Lubrizol Aftertreatment }\end{array}$} & \multicolumn{4}{|c|}{$\begin{array}{c}\text { Phase III } \\
\text { Post Demo WVU-Lubrizol Aftertreatment }\end{array}$} \\
\hline & & $\begin{array}{c}\mathrm{QCBD} \\
\text { (Baseline) }\end{array}$ & $\begin{array}{c}\text { QCBD } \\
\text { (OEM } \\
\text { Catalyst) }\end{array}$ & $\begin{array}{c}\text { Standard } \\
\text { Deviation }\end{array}$ & Background & Standard & QCBD & $\begin{array}{c}\text { Standard } \\
\text { Deviation }\end{array}$ & Background & $\begin{array}{l}\text { Standard } \\
\text { Deviation }\end{array}$ & QCBD & $\begin{array}{c}\text { Standard } \\
\text { Deviation }\end{array}$ & Background & $\begin{array}{l}\text { Standard } \\
\text { Deviation }\end{array}$ \\
\hline $4 \mathrm{~m}$-C7/1m-cyHexene & $6.70 \mathrm{E}-05$ & $<$ LOD & $<\mathrm{LOD}$ & - & $<$ LOD & - & $<$ LOD & - & $<$ LOD & - & $<$ LOD & - & $<$ LOD & - \\
\hline 34-dm-hexane & $6.70 \mathrm{E}-05$ & $1.49 \mathrm{E}-04$ & $1.97 \mathrm{E}-04$ & $5.99 \mathrm{E}-05$ & $1.46 \mathrm{E}-04$ & - & $<\mathrm{LOD}$ & - & $<\mathrm{LOD}$ & - & $1.49 \mathrm{E}-04$ & $4.65 \mathrm{E}-06$ & $8.95 \mathrm{E}-05$ & - \\
\hline 3m-heptane/3e-hexane & $6.70 \mathrm{E}-05$ & $3.57 \mathrm{E}-04$ & $1.72 \mathrm{E}-04$ & $4.61 \mathrm{E}-05$ & $3.01 \mathrm{E}-04$ & - & $2.08 \mathrm{E}-04$ & $41.36 \mathrm{E}-04$ & $2.11 \mathrm{E}-04$ & $1.28 \mathrm{E}-04$ & $1.23 \mathrm{E}-04$ & $2.30 \mathrm{E}-05$ & $2.31 \mathrm{E}-04$ & - \\
\hline cct-124-tm-cyP & $6.70 \mathrm{E}-05$ & $<$ LOD & $<$ LOD & - & $<$ LOD & - & $<\mathrm{LOD}$ & - & $<\mathrm{LOD}$ & - & $6.21 \mathrm{E}-04$ & $9.47 \mathrm{E}-05$ & $4.62 \mathrm{E}-04$ & $1.20 \mathrm{E}-04$ \\
\hline t-14-dm-cyH & $6.70 \mathrm{E}-05$ & $1.66 \mathrm{E}-04$ & $1.40 \mathrm{E}-04$ & $4.20 \mathrm{E}-05$ & $7.97 \mathrm{E}-05$ & - & $<\mathrm{LOD}$ & - & $<\mathrm{LOD}$ & - & $<\mathrm{LOD}$ & - & $<\mathrm{LOD}$ & - \\
\hline 225-tm-hexane & $6.70 \mathrm{E}-05$ & $2.01 \mathrm{E}-04$ & $1.77 \mathrm{E}-04$ & $9.41 \mathrm{E}-06$ & $2.47 \mathrm{E}-04$ & - & $1.43 \mathrm{E}-04$ & $44.71 \mathrm{E}-05$ & $1.58 \mathrm{E}-04$ & $5.57 \mathrm{E}-05$ & $1.06 \mathrm{E}-04$ & $1.23 \mathrm{E}-05$ & $1.62 \mathrm{E}-04$ & $6.69 \mathrm{E}-05$ \\
\hline 1-octene & $6.70 \mathrm{E}-05$ & $<$ LOD & $<\mathrm{LOD}$ & - & $<\mathrm{LOD}$ & - & $<\mathrm{LOD}$ & - & $<\mathrm{LOD}$ & - & $1.10 \mathrm{E}-04$ & $1.11 \mathrm{E}-05$ & $<\mathrm{LOD}$ & - \\
\hline $1 \mathrm{e} 1 \mathrm{~m}-\mathrm{cyP}$ & $6.70 \mathrm{E}-05$ & $1.84 \mathrm{E}-04$ & $2.14 \mathrm{E}-04$ & $1.04 \mathrm{E}-06$ & $2.34 \mathrm{E}-04$ & - & $<\mathrm{LOD}$ & - & $<\mathrm{LOD}$ & - & $1.08 \mathrm{E}-04$ & $3.28 \mathrm{E}-05$ & $1.58 \mathrm{E}-04$ & - \\
\hline n-octane/t12-dm-cyH & $6.70 \mathrm{E}-05$ & $8.23 \mathrm{E}-04$ & $2.22 \mathrm{E}-04$ & $8.69 \mathrm{E}-05$ & $2.35 \mathrm{E}-04$ & $1.34 \mathrm{E}-04$ & $3.07 \mathrm{E}-04$ & 4 1.12E-04 & $3.81 \mathrm{E}-04$ & $1.56 \mathrm{E}-04$ & $1.76 \mathrm{E}-04$ & $1.20 \mathrm{E}-05$ & $3.00 \mathrm{E}-04$ & $1.59 \mathrm{E}-04$ \\
\hline t2-octene & $6.70 \mathrm{E}-05$ & $<\mathrm{LOD}$ & $1.90 \mathrm{E}-04$ & $2.53 \mathrm{E}-05$ & $1.34 \mathrm{E}-04$ & - & $<\mathrm{LOD}$ & - & $<\mathrm{LOD}$ & - & $1.37 \mathrm{E}-04$ & $5.13 \mathrm{E}-06$ & $<\mathrm{LOD}$ & - \\
\hline ccc-123-tm-cyP & $6.70 \mathrm{E}-05$ & $<\mathrm{LOD}$ & $<\mathrm{LOD}$ & - & $<\mathrm{LOD}$ & - & $<\mathrm{LOD}$ & - & $<\mathrm{LOD}$ & - & $2.89 \mathrm{E}-04$ & $1.28 \mathrm{E}-04$ & $1.01 \mathrm{E}-04$ & - \\
\hline c2-octene & $6.70 \mathrm{E}-05$ & $<\mathrm{LOD}$ & $<\mathrm{LOD}$ & - & $1.03 \mathrm{E}-04$ & - & $<\mathrm{LOD}$ & - & $<\mathrm{LOD}$ & - & $<\mathrm{LOD}$ & - & $<\mathrm{LOD}$ & - \\
\hline ip-cyP & $6.70 \mathrm{E}-05$ & $5.26 \mathrm{E}-04$ & $1.93 \mathrm{E}-04$ & $9.09 \mathrm{E}-05$ & $<\mathrm{LOD}$ & - & $<$ LOD & - & $<\mathrm{LOD}$ & - & $<$ LOD & - & $<\mathrm{LOD}$ & - \\
\hline 235-tm-hexane & $6.70 \mathrm{E}-05$ & $<\mathrm{LOD}$ & $<\mathrm{LOD}$ & - & $<\mathrm{LOD}$ & - & $<\mathrm{LOD}$ & - & $<\mathrm{LOD}$ & - & $<\mathrm{LOD}$ & - & $<\mathrm{LOD}$ & - \\
\hline 24-dm-heptane & $6.70 \mathrm{E}-05$ & $<\mathrm{LOD}$ & $<\mathrm{LOD}$ & - & $<$ LOD & - & $<$ LOD & - & $<\mathrm{LOD}$ & - & $<$ LOD & - & $<\mathrm{LOD}$ & - \\
\hline 26-dm-heptane/c12-dm-cyH & $6.70 \mathrm{E}-05$ & $1.51 \mathrm{E}-04$ & $2.94 \mathrm{E}-04$ & $1.03 \mathrm{E}-04$ & $<\mathrm{LOD}$ & - & $<\mathrm{LOD}$ & - & $<\mathrm{LOD}$ & - & $1.48 \mathrm{E}-04$ & - & $<\mathrm{LOD}$ & - \\
\hline np-cyP & $6.70 \mathrm{E}-05$ & $<\mathrm{LOD}$ & $<\mathrm{LOD}$ & - & $<\mathrm{LOD}$ & - & $<\mathrm{LOD}$ & - & $<\mathrm{LOD}$ & - & $<\mathrm{LOD}$ & - & $<\mathrm{LOD}$ & - \\
\hline ccc-135-tm-cyH & $6.70 \mathrm{E}-05$ & $<\mathrm{LOD}$ & $<$ LOD & - & $<\mathrm{LOD}$ & - & $<\mathrm{LOD}$ & - & $<\mathrm{LOD}$ & - & $<\mathrm{LOD}$ & - & $<\mathrm{LOD}$ & - \\
\hline 25-dm-heptane/35-dm-heptane & $6.70 \mathrm{E}-05$ & $7.19 \mathrm{E}-05$ & $<\mathrm{LOD}$ & - & $<\mathrm{LOD}$ & - & $<\mathrm{LOD}$ & - & $<\mathrm{LOD}$ & - & $<\mathrm{LOD}$ & - & $<\mathrm{LOD}$ & - \\
\hline 33-dm-heptane & $6.70 \mathrm{E}-05$ & 9.77E-05 & $1.01 \mathrm{E}-04$ & $1.22 \mathrm{E}-05$ & $1.64 \mathrm{E}-04$ & - & $2.32 \mathrm{E}-04$ & - & $9.97 \mathrm{E}-05$ & - & $7.94 \mathrm{E}-05$ & - & $1.41 \mathrm{E}-03$ & - \\
\hline 114-tm-cyH & $6.70 \mathrm{E}-05$ & $<\mathrm{LOD}$ & $1.15 \mathrm{E}-04$ & - & $<\mathrm{LOD}$ & - & $<\mathrm{LOD}$ & - & $<\mathrm{LOD}$ & - & $<\mathrm{LOD}$ & - & $<\mathrm{LOD}$ & - \\
\hline e-benzene & $6.70 \mathrm{E}-05$ & $6.01 \mathrm{E}-04$ & $4.13 \mathrm{E}-04$ & $1.34 \mathrm{E}-04$ & $4.35 \mathrm{E}-04$ & $3.32 \mathrm{E}-04$ & $3.97 \mathrm{E}-04$ & $41.27 \mathrm{E}-04$ & $4.56 \mathrm{E}-04$ & $2.28 \mathrm{E}-04$ & $2.78 \mathrm{E}-04$ & $3.29 \mathrm{E}-05$ & $5.32 \mathrm{E}-04$ & - \\
\hline ctt-124-tm-cyH & $6.70 \mathrm{E}-05$ & $<$ LOD & $<\mathrm{LOD}$ & - & $<$ LOD & - & $<\mathrm{LOD}$ & - & $<\mathrm{LOD}$ & - & $<\mathrm{LOD}$ & - & $<\mathrm{LOD}$ & - \\
\hline 23-dm-heptane & $6.70 \mathrm{E}-05$ & $<\mathrm{LOD}$ & $<\mathrm{LOD}$ & - & $<\mathrm{LOD}$ & - & $<\mathrm{LOD}$ & - & $<\mathrm{LOD}$ & - & $1.76 \mathrm{E}-04$ & - & $<\mathrm{LOD}$ & - \\
\hline m\&p-xylene/34-dm-heptane & $6.70 \mathrm{E}-05$ & $1.15 \mathrm{E}-03$ & $8.69 \mathrm{E}-04$ & $3.98 \mathrm{E}-04$ & $1.15 \mathrm{E}-03$ & $9.49 \mathrm{E}-04$ & $1.02 \mathrm{E}-03$ & $33.83 \mathrm{E}-04$ & $1.31 \mathrm{E}-03$ & $8.01 \mathrm{E}-04$ & $7.16 \mathrm{E}-04$ & $42.36 \mathrm{E}-04$ & $1.34 \mathrm{E}-03$ & 9.08E-04 \\
\hline $2 \mathrm{~m}$-octane & $6.70 \mathrm{E}-05$ & $2.21 \mathrm{E}-04$ & $1.25 \mathrm{E}-04$ & - & $2.89 \mathrm{E}-04$ & - & $<\mathrm{LOD}$ & - & $<\mathrm{LOD}$ & - & $<\mathrm{LOD}$ & - & $1.14 \mathrm{E}-04$ & - \\
\hline
\end{tabular}

Note: $<$ LOD $=$ Below Level of Detection 
Contd...

\begin{tabular}{|c|c|c|c|c|c|c|c|c|c|c|c|c|c|c|}
\hline \multirow{2}{*}{$\begin{array}{l}\text { Non-Methane } \\
\text { Hydrocarbons } \\
\text { g/mile }\end{array}$} & \multirow{2}{*}{$\begin{array}{l}\text { Limit of } \\
\text { Detection }\end{array}$} & \multicolumn{5}{|c|}{$\begin{array}{c}\text { Phase I } \\
\text { Baseline \& OEM Catalyst }\end{array}$} & \multicolumn{4}{|c|}{$\begin{array}{c}\text { Phase II } \\
\text { New WVU-Lubrizol Aftertreatment }\end{array}$} & \multicolumn{4}{|c|}{$\begin{array}{c}\text { Phase III } \\
\text { Post Demo WVU-Lubrizol Aftertreatment }\end{array}$} \\
\hline & & $\begin{array}{c}\text { QCBD } \\
\text { (Baseline) }\end{array}$ & $\begin{array}{c}\text { QCBD } \\
\text { OEM } \\
\text { Catalyst }\end{array}$ & $\begin{array}{c}\text { Standard } \\
\text { Deviation }\end{array}$ & Background & $\begin{array}{l}\text { Standard } \\
\text { Deviation }\end{array}$ & QCBD & $\begin{array}{c}\text { Standard } \\
\text { Deviation }\end{array}$ & Background & $\begin{array}{l}\text { Standard } \\
\text { Deviation }\end{array}$ & QCBD & $\begin{array}{l}\text { Standard } \\
\text { Deviation }\end{array}$ & Background & $\begin{array}{l}\text { Standard } \\
\text { Deviation }\end{array}$ \\
\hline $3 \mathrm{~m}$-octane & $6.70 \mathrm{E}-05$ & 1.77E-04 & $1.60 \mathrm{E}-04$ & $6.27 \mathrm{E}-05$ & $1.51 \mathrm{E}-04$ & $1.70 \mathrm{E}-05$ & $2.50 \mathrm{E}-04$ & $1.18 \mathrm{E}-04$ & $2.35 \mathrm{E}-04$ & $8.21 \mathrm{E}-05$ & $2.75 \mathrm{E}-04$ & 1.94E-04 & 5.43E-04 & 4.97E-04 \\
\hline ctc-124-tm-cyH & $6.70 \mathrm{E}-05$ & 3.13E-04 & $4.80 \mathrm{E}-04$ & $1.10 \mathrm{E}-04$ & $2.31 \mathrm{E}-04$ & - & $<\mathrm{LOD}$ & - & 2.92E-04 & $1.39 \mathrm{E}-04$ & $6.10 \mathrm{E}-04$ & 9.41E-05 & $9.11 \mathrm{E}-04$ & 7.91E-04 \\
\hline 33-de-C5 & $6.70 \mathrm{E}-05$ & $<\mathrm{LOD}$ & $<\mathrm{LOD}$ & - & $<\mathrm{LOD}$ & - & $<\mathrm{LOD}$ & - & $<\mathrm{LOD}$ & - & $<\mathrm{LOD}$ & - & $<\mathrm{LOD}$ & - \\
\hline o-xylene & 6.70E-05 & 4.45E-04 & $3.48 \mathrm{E}-04$ & $1.80 \mathrm{E}-04$ & $4.50 \mathrm{E}-04$ & 3.60E-04 & $4.00 \mathrm{E}-04$ & $1.28 \mathrm{E}-04$ & $5.42 \mathrm{E}-04$ & 3.08E-04 & $2.76 \mathrm{E}-04$ & 6.15E-05 & $5.25 \mathrm{E}-04$ & 3.28E-04 \\
\hline 1-nonene & $6.70 \mathrm{E}-05$ & 3.02E-04 & $1.14 \mathrm{E}-04$ & $5.74 \mathrm{E}-05$ & $8.86 \mathrm{E}-05$ & - & $<\mathrm{LOD}$ & - & $1.14 \mathrm{E}-04$ & - & $<\mathrm{LOD}$ & - & $<\mathrm{LOD}$ & - \\
\hline 112-tm-cyH & $6.70 \mathrm{E}-05$ & $<\mathrm{LOD}$ & $<$ LOD & - & $<\mathrm{LOD}$ & - & $<\mathrm{LOD}$ & - & $<\mathrm{LOD}$ & - & $<\mathrm{LOD}$ & - & $<\mathrm{LOD}$ & - \\
\hline t3-nonene & 6.70E-05 & $1.12 \mathrm{E}-04$ & $3.22 \mathrm{E}-04$ & $4.31 \mathrm{E}-05$ & $<\mathrm{LOD}$ & - & $1.94 \mathrm{E}-04$ & - & $<\mathrm{LOD}$ & - & $1.81 \mathrm{E}-04$ & 7.04E-05 & $<\mathrm{LOD}$ & - \\
\hline c3-nonene/ib-cyP & $6.70 \mathrm{E}-05$ & $<\mathrm{LOD}$ & $<\mathrm{LOD}$ & - & $<\mathrm{LOD}$ & - & $<\mathrm{LOD}$ & - & $<\mathrm{LOD}$ & - & $<\mathrm{LOD}$ & - & $<\mathrm{LOD}$ & - \\
\hline n-nonane & $6.70 \mathrm{E}-05$ & $2.86 \mathrm{E}-04$ & $1.42 \mathrm{E}-04$ & $5.74 \mathrm{E}-05$ & $1.78 \mathrm{E}-04$ & 7.82E-05 & $1.40 \mathrm{E}-04$ & $2.38 \mathrm{E}-05$ & $2.26 \mathrm{E}-04$ & $1.15 \mathrm{E}-04$ & $1.40 \mathrm{E}-04$ & $3.10 \mathrm{E}-05$ & $2.03 \mathrm{E}-04$ & 8.37E-05 \\
\hline t2-nonene & $6.70 \mathrm{E}-05$ & $<\mathrm{LOD}$ & $<\mathrm{LOD}$ & - & $<\mathrm{LOD}$ & - & $<\mathrm{LOD}$ & - & $<\mathrm{LOD}$ & - & $<\mathrm{LOD}$ & - & $<\mathrm{LOD}$ & - \\
\hline c2-nonene & $6.70 \mathrm{E}-05$ & $1.25 \mathrm{E}-04$ & $1.29 \mathrm{E}-04$ & - & $<\mathrm{LOD}$ & - & $1.89 \mathrm{E}-04$ & - & $<\mathrm{LOD}$ & - & $2.33 \mathrm{E}-04$ & 8.87E-05 & $1.22 \mathrm{E}-04$ & - \\
\hline ip-benzene & $6.70 \mathrm{E}-05$ & $<$ LOD & $<$ LOD & - & $<\mathrm{LOD}$ & - & $<$ LOD & - & $<\mathrm{LOD}$ & - & $<\mathrm{LOD}$ & - & $<\mathrm{LOD}$ & - \\
\hline 22-dm-octane & $6.70 \mathrm{E}-05$ & $<\mathrm{LOD}$ & $<\mathrm{LOD}$ & - & $<\mathrm{LOD}$ & - & $<\mathrm{LOD}$ & - & $<\mathrm{LOD}$ & - & 4.30E-04 & - & $2.88 \mathrm{E}-04$ & - \\
\hline ip-суH & $6.70 \mathrm{E}-05$ & $<\mathrm{LOD}$ & $<$ LOD & - & $<\mathrm{LOD}$ & - & $<\mathrm{LOD}$ & - & $<\mathrm{LOD}$ & - & $<\mathrm{LOD}$ & - & $<\mathrm{LOD}$ & - \\
\hline nb-cyP & $6.70 \mathrm{E}-05$ & $<\mathrm{LOD}$ & $<\mathrm{LOD}$ & - & $<\mathrm{LOD}$ & - & $<\mathrm{LOD}$ & - & $2.34 \mathrm{E}-04$ & - & $1.20 \mathrm{E}-03$ & - & $1.10 \mathrm{E}-03$ & - \\
\hline 33-dm-octane & $6.70 \mathrm{E}-05$ & $<\mathrm{LOD}$ & $1.74 \mathrm{E}-04$ & $6.41 \mathrm{E}-05$ & $3.48 \mathrm{E}-04$ & - & $2.49 \mathrm{E}-04$ & $8.63 \mathrm{E}-05$ & $2.95 \mathrm{E}-04$ & $1.50 \mathrm{E}-04$ & $1.53 \mathrm{E}-03$ & $1.87 \mathrm{E}-04$ & $6.06 \mathrm{E}-04$ & $6.05 \mathrm{E}-06$ \\
\hline n-propylbenzene & $6.70 \mathrm{E}-05$ & 9.57E-05 & $1.25 \mathrm{E}-04$ & $3.30 \mathrm{E}-05$ & $1.39 \mathrm{E}-04$ & - & $1.47 \mathrm{E}-04$ & - & $1.49 \mathrm{E}-04$ & - & $1.61 \mathrm{E}-04$ & 9.82E-05 & $1.58 \mathrm{E}-04$ & 6.19E-05 \\
\hline 3e-toluene & $6.70 \mathrm{E}-05$ & $2.20 \mathrm{E}-04$ & $2.06 \mathrm{E}-04$ & $1.37 \mathrm{E}-04$ & $2.68 \mathrm{E}-04$ & $2.26 \mathrm{E}-04$ & $2.61 \mathrm{E}-04$ & $1.30 \mathrm{E}-04$ & $2.98 \mathrm{E}-04$ & $1.82 \mathrm{E}-04$ & $2.33 \mathrm{E}-04$ & 3.78E-05 & 4.07E-04 & $1.86 \mathrm{E}-04$ \\
\hline 4e-toluene/23-dm-octane & $6.70 \mathrm{E}-05$ & $<\mathrm{LOD}$ & $1.57 \mathrm{E}-04$ & - & $2.45 \mathrm{E}-04$ & - & $1.54 \mathrm{E}-04$ & - & $1.79 \mathrm{E}-04$ & $8.41 \mathrm{E}-05$ & $1.11 \mathrm{E}-04$ & $3.26 \mathrm{E}-05$ & $1.89 \mathrm{E}-04$ & $1.13 \mathrm{E}-04$ \\
\hline 135-tm-benzene & $6.70 \mathrm{E}-05$ & $1.05 \mathrm{E}-04$ & $<$ LOD & - & $1.38 \mathrm{E}-04$ & - & $<$ LOD & - & $1.99 \mathrm{E}-04$ & - & $<\mathrm{LOD}$ & - & 2.09E-04 & - \\
\hline 2m-nonane & $6.70 \mathrm{E}-05$ & 1.17E-04 & $<\mathrm{LOD}$ & - & $<\mathrm{LOD}$ & - & $<\mathrm{LOD}$ & - & $<\mathrm{LOD}$ & - & $<\mathrm{LOD}$ & - & $1.83 \mathrm{E}-04$ & $1.79 \mathrm{E}-06$ \\
\hline 3e-octane & $6.70 \mathrm{E}-05$ & $<$ LOD & $<\mathrm{LOD}$ & - & $<\mathrm{LOD}$ & - & $<\mathrm{LOD}$ & - & $<\mathrm{LOD}$ & - & $<\mathrm{LOD}$ & - & $<\mathrm{LOD}$ & - \\
\hline
\end{tabular}

Note: $<\mathrm{LOD}=$ Below Level of Detection 


\begin{tabular}{|c|c|c|c|c|c|c|c|c|c|c|c|c|c|c|}
\hline \multirow{2}{*}{$\begin{array}{l}\text { Non-Methane Hydrocarbons } \\
\text { g/mile }\end{array}$} & \multirow{2}{*}{$\begin{array}{l}\text { Limit of } \\
\text { Detection }\end{array}$} & \multicolumn{5}{|c|}{$\begin{array}{c}\text { Phase I } \\
\text { Baseline \& OEM Catalyst }\end{array}$} & \multicolumn{4}{|c|}{$\begin{array}{c}\text { Phase II } \\
\text { New WVU-Lubrizol Aftertreatment }\end{array}$} & \multicolumn{4}{|c|}{\begin{tabular}{|c|} 
Phase III \\
Post Demo WVU-Lubrizol Aftertreatment
\end{tabular}} \\
\hline & & $\begin{array}{c}\text { QCBD } \\
\text { (Baseline) }\end{array}$ & $\begin{array}{c}\text { QCBD } \\
\text { (OEM } \\
\text { Catalyst) } \\
\end{array}$ & $\begin{array}{c}\text { Standard } \\
\text { Deviation }\end{array}$ & Background & $\begin{array}{l}\text { Standard } \\
\text { Deviation }\end{array}$ & QCBD & $\begin{array}{c}\text { Standard } \\
\text { Deviation }\end{array}$ & Background & $\begin{array}{l}\text { Standard } \\
\text { Deviation }\end{array}$ & QCBD & $\begin{array}{c}\text { Standard } \\
\text { Deviation }\end{array}$ & Background & $\begin{array}{l}\text { Standard } \\
\text { Deviation }\end{array}$ \\
\hline 3m-nonane & $6.70 \mathrm{E}-05$ & $<\mathrm{LOD}$ & $1.24 \mathrm{E}-04$ & - & $1.35 \mathrm{E}-04$ & $1.40 \mathrm{E}-05$ & $<\mathrm{LOD}$ & - & $9.57 \mathrm{E}-05$ & - & $1.33 \mathrm{E}-04$ & - & $1.44 \mathrm{E}-04$ & - \\
\hline 2e-toluene & $6.70 \mathrm{E}-05$ & $<\mathrm{LOD}$ & $1.35 \mathrm{E}-04$ & $3.30 \mathrm{E}-05$ & $1.52 \mathrm{E}-04$ & - & $<\mathrm{LOD}$ & - & $1.78 \mathrm{E}-04$ & - & $<$ LOD & - & $1.82 \mathrm{E}-04$ & - \\
\hline 124-tm-benzene/1-decene & $6.70 \mathrm{E}-05$ & $<$ LOD & $<\mathrm{LOD}$ & - & $<$ LOD & - & $<\mathrm{LOD}$ & - & $<\mathrm{LOD}$ & - & $2.36 \mathrm{E}-04$ & $3.36 \mathrm{E}-05$ & 4.95E-04 & $3.85 \mathrm{E}-04$ \\
\hline ib-cyH & $6.70 \mathrm{E}-05$ & $<\mathrm{LOD}$ & $<\mathrm{LOD}$ & - & $<\mathrm{LOD}$ & - & $1.45 \mathrm{E}-03$ & - & $1.82 \mathrm{E}-04$ & $4.66 \mathrm{E}-06$ & $4.32 \mathrm{E}-03$ & $4.55 \mathrm{E}-03$ & 4.74E-04 & $1.51 \mathrm{E}-04$ \\
\hline n-decane & $6.70 \mathrm{E}-05$ & $3.26 \mathrm{E}-04$ & $3.28 \mathrm{E}-04$ & $5.89 \mathrm{E}-05$ & $2.92 \mathrm{E}-04$ & $5.58 \mathrm{E}-05$ & $1.93 \mathrm{E}-04$ & $43.74 \mathrm{E}-05$ & $2.84 \mathrm{E}-04$ & $1.26 \mathrm{E}-04$ & $1.99 \mathrm{E}-04$ & $3.21 \mathrm{E}-05$ & $3.10 \mathrm{E}-04$ & $1.66 \mathrm{E}-04$ \\
\hline ib-benzene/t-1m-2p-CyH & $6.70 \mathrm{E}-05$ & $<\mathrm{LOD}$ & $<\mathrm{LOD}$ & - & $<\mathrm{LOD}$ & - & $<\mathrm{LOD}$ & - & $<\mathrm{LOD}$ & - & $<\mathrm{LOD}$ & - & $<\mathrm{LOD}$ & - \\
\hline sb-benzene & $6.70 \mathrm{E}-05$ & $<\mathrm{LOD}$ & $<\mathrm{LOD}$ & - & $<\mathrm{LOD}$ & - & $<\mathrm{LOD}$ & - & $<\mathrm{LOD}$ & - & $<$ LOD & - & $<\mathrm{LOD}$ & - \\
\hline 3-ip-toluene & $6.70 \mathrm{E}-05$ & $4.17 \mathrm{E}-04$ & 7.89E-04 & $6.83 \mathrm{E}-04$ & $3.77 \mathrm{E}-04$ & $6.20 \mathrm{E}-05$ & $2.16 \mathrm{E}-04$ & $41.36 \mathrm{E}-04$ & $<\mathrm{LOD}$ & - & $2.66 \mathrm{E}-04$ & $5.59 \mathrm{E}-05$ & $2.26 \mathrm{E}-04$ & $3.98 \mathrm{E}-05$ \\
\hline 4-ip-toluene & $6.70 \mathrm{E}-05$ & $2.37 \mathrm{E}-04$ & $2.51 \mathrm{E}-04$ & - & $<$ LOD & - & $<$ LOD & - & $<\mathrm{LOD}$ & - & $<$ LOD & - & $3.27 \mathrm{E}-04$ & - \\
\hline 2-ip-toluene & $6.70 \mathrm{E}-05$ & $<\mathrm{LOD}$ & $<\mathrm{LOD}$ & - & $<\mathrm{LOD}$ & - & $<\mathrm{LOD}$ & - & $<\mathrm{LOD}$ & - & $<\mathrm{LOD}$ & - & $<\mathrm{LOD}$ & - \\
\hline 3-np-toluene & $6.70 \mathrm{E}-05$ & $1.91 \mathrm{E}-04$ & $2.34 \mathrm{E}-04$ & $8.58 \mathrm{E}-05$ & $1.65 \mathrm{E}-04$ & 7.57E-05 & $<$ LOD & - & $1.47 \mathrm{E}-04$ & - & 2.77E-04 & $1.31 \mathrm{E}-05$ & $2.11 \mathrm{E}-04$ & $6.65 \mathrm{E}-05$ \\
\hline 4-np-toluene/nb-benz/13dm5e-benzene & $6.70 \mathrm{E}-05$ & $<\mathrm{LOD}$ & $2.48 \mathrm{E}-04$ & $5.40 \mathrm{E}-05$ & $<\mathrm{LOD}$ & - & $<\mathrm{LOD}$ & - & $1.54 \mathrm{E}-04$ & - & 3.32E-04 & $7.86 \mathrm{E}-05$ & $2.80 \mathrm{E}-04$ & $1.30 \mathrm{E}-04$ \\
\hline 12de-benzene & $6.70 \mathrm{E}-05$ & $<\mathrm{LOD}$ & $<\mathrm{LOD}$ & - & $<\mathrm{LOD}$ & - & $<\mathrm{LOD}$ & - & $<\mathrm{LOD}$ & - & $<\mathrm{LOD}$ & - & $<\mathrm{LOD}$ & - \\
\hline 2-np-toluene & $6.70 \mathrm{E}-05$ & $<\mathrm{LOD}$ & $1.33 \mathrm{E}-04$ & $2.10 \mathrm{E}-05$ & $1.12 \mathrm{E}-04$ & - & $<\mathrm{LOD}$ & - & $1.31 \mathrm{E}-04$ & - & $1.22 \mathrm{E}-04$ & - & $1.54 \mathrm{E}-04$ & - \\
\hline 14dm-2e-benzene & $6.70 \mathrm{E}-05$ & $<\mathrm{LOD}$ & $<\mathrm{LOD}$ & $0.00 \mathrm{E}+00$ & $<\mathrm{LOD}$ & - & $<\mathrm{LOD}$ & - & $<\mathrm{LOD}$ & - & $<\mathrm{LOD}$ & - & $<\mathrm{LOD}$ & - \\
\hline $12 \mathrm{dm}-4 \mathrm{e}-$ benzene & $6.70 \mathrm{E}-05$ & $<\mathrm{LOD}$ & $<\mathrm{LOD}$ & - & $<\mathrm{LOD}$ & - & $<\mathrm{LOD}$ & - & $<\mathrm{LOD}$ & - & $<$ LOD & - & $1.36 \mathrm{E}-04$ & - \\
\hline $13 \mathrm{dm}-2 \mathrm{e}$-benzene & $6.70 \mathrm{E}-05$ & $1.26 \mathrm{E}-04$ & $<\mathrm{LOD}$ & - & $<\mathrm{LOD}$ & - & $<\mathrm{LOD}$ & - & $<\mathrm{LOD}$ & - & $<\mathrm{LOD}$ & - & $<\mathrm{LOD}$ & - \\
\hline
\end{tabular}

Note: $<$ LOD $=$ Below Level of Detection 
Contd...

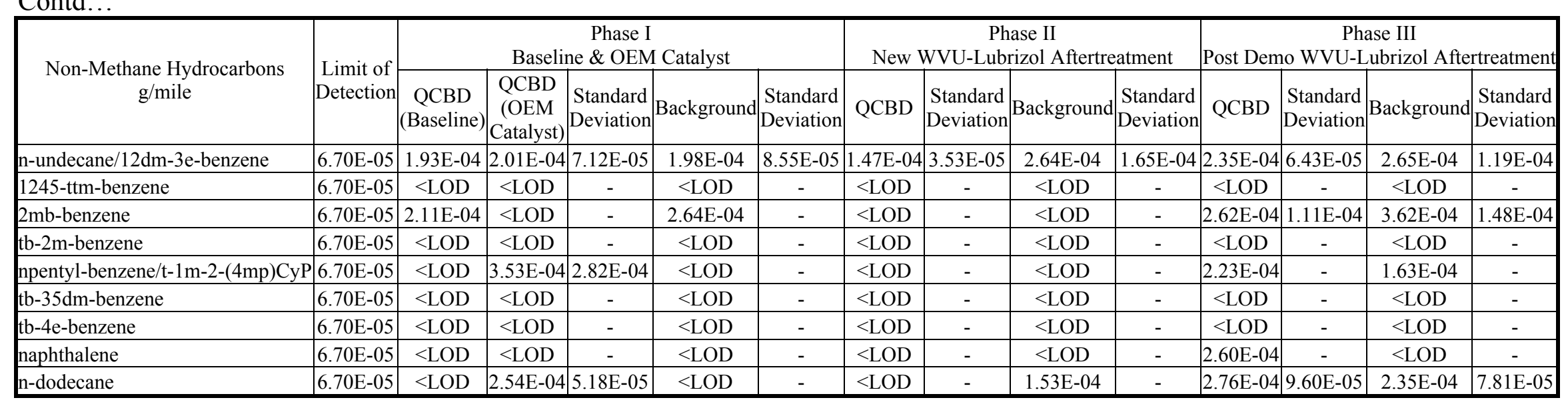


Table C. 6 Emissions of Toxic Gases Measured using Lab Grade Gas Chromatography, in Different Phases

\begin{tabular}{|c|c|c|c|c|c|c|c|c|c|c|c|c|c|c|}
\hline \multirow{2}{*}{$\begin{array}{l}\text { Toxic Gases } \\
\text { (Lab } \\
\text { Analysis) } \\
\text { g/mile }\end{array}$} & \multirow{2}{*}{$\begin{array}{c}\text { Limit of } \\
\text { Detection }\end{array}$} & \multicolumn{5}{|c|}{$\begin{array}{c}\text { Phase I } \\
\text { Baseline \& OEM Catalyst }\end{array}$} & \multicolumn{4}{|c|}{$\begin{array}{c}\text { Phase II } \\
\text { New WVU-Lubrizol Aftertreatment }\end{array}$} & \multicolumn{4}{|c|}{$\begin{array}{c}\text { Phase III } \\
\text { Post Demo WVU-Lubrizol } \\
\text { Aftertreatment }\end{array}$} \\
\hline & & $\begin{array}{c}\text { QCBD } \\
\text { (Baseline) }\end{array}$ & $\begin{array}{c}\text { QCBD } \\
\text { (OEM } \\
\text { Catalyst) } \\
\end{array}$ & $\begin{array}{c}\text { Standard } \\
\text { Deviation }\end{array}$ & Background & $\begin{array}{l}\text { Standard } \\
\text { Deviation }\end{array}$ & QCBD & $\begin{array}{c}\text { Standard } \\
\text { Deviation }\end{array}$ & Background & $\begin{array}{l}\text { Standard } \\
\text { Deviation }\end{array}$ & QCBD & $\begin{array}{c}\text { Standard } \\
\text { Deviation }\end{array}$ & Background & $\begin{array}{l}\text { Standard } \\
\text { Deviation }\end{array}$ \\
\hline 13-butadiene & $6.70 \mathrm{E}-05$ & $<\mathrm{LOD}$ & $<\mathrm{LOD}$ & - & $4.80 \mathrm{E}-05$ & - & $<\mathrm{LOD}$ & - & $9.63 \mathrm{E}-05$ & $9.67 \mathrm{E}-05$ & $3.08 \mathrm{E}-04$ & - & $<\mathrm{LOD}$ & - \\
\hline benzene & $6.70 \mathrm{E}-05$ & 7.72E-03 & $1.16 \mathrm{E}-03$ & $3.43 \mathrm{E}-04$ & $9.80 \mathrm{E}-04$ & $5.60 \mathrm{E}-04$ & $5.03 \mathrm{E}-04$ & $1.48 \mathrm{E}-04$ & $6.12 \mathrm{E}-04$ & $3.06 \mathrm{E}-04$ & 6.19E-04 & $2.03 \mathrm{E}-05$ & $7.98 \mathrm{E}-04$ & $2.60 \mathrm{E}-04$ \\
\hline toluene & $6.70 \mathrm{E}-05$ & $5.30 \mathrm{E}-03$ & $2.95 \mathrm{E}-03$ & $1.10 \mathrm{E}-03$ & $3.78 \mathrm{E}-03$ & $2.91 \mathrm{E}-03$ & $2.48 \mathrm{E}-03$ & 8.49E-04 & $3.09 \mathrm{E}-03$ & $1.52 \mathrm{E}-03$ & $2.17 \mathrm{E}-03$ & $3.00 \mathrm{E}-04$ & $3.05 \mathrm{E}-03$ & $1.45 \mathrm{E}-03$ \\
\hline e-benzene & $6.70 \mathrm{E}-05$ & $6.01 \mathrm{E}-04$ & $4.13 \mathrm{E}-04$ & $1.34 \mathrm{E}-04$ & $4.35 \mathrm{E}-04$ & $3.32 \mathrm{E}-04$ & $2.41 \mathrm{E}-03$ & - & $3.47 \mathrm{E}-04$ & - & $3.13 \mathrm{E}-04$ & $2.83 \mathrm{E}-05$ & $5.04 \mathrm{E}-04$ & 2.39E-04 \\
\hline m\&p-xylene & $6.70 \mathrm{E}-05$ & $1.15 \mathrm{E}-03$ & $8.69 \mathrm{E}-04$ & $3.98 \mathrm{E}-04$ & $1.15 \mathrm{E}-03$ & 9.49E-04 & $1.10 \mathrm{E}-03$ & $3.54 \mathrm{E}-04$ & $1.33 \mathrm{E}-03$ & $7.60 \mathrm{E}-04$ & $6.32 \mathrm{E}-04$ & $1.46 \mathrm{E}-04$ & $1.28 \mathrm{E}-03$ & $1.02 \mathrm{E}-03$ \\
\hline o-xylene & $6.70 \mathrm{E}-05$ & 4.45E-04 & $3.48 \mathrm{E}-04$ & $1.80 \mathrm{E}-04$ & $4.50 \mathrm{E}-04$ & $3.60 \mathrm{E}-04$ & $4.92 \mathrm{E}-04$ & $1.77 \mathrm{E}-04$ & $5.77 \mathrm{E}-04$ & $3.09 \mathrm{E}-04$ & $2.83 \mathrm{E}-04$ & $3.42 \mathrm{E}-05$ & $5.21 \mathrm{E}-04$ & 3.33E-04 \\
\hline
\end{tabular}

Table C. 7 Emissions of Toxic Gases Measured using Onsite Gas Chromatography, in Different Phases

\begin{tabular}{|c|c|c|c|c|c|c|c|c|c|c|c|c|c|c|}
\hline \multirow{2}{*}{$\begin{array}{l}\text { Toxic Gases } \\
\text { (Onsite } \\
\text { Analysis) } \\
\text { g/mile }\end{array}$} & \multirow{2}{*}{$\begin{array}{c}\text { Limit of } \\
\text { Detection }\end{array}$} & \multicolumn{5}{|c|}{$\begin{array}{c}\text { Phase I } \\
\text { Baseline \& OEM Catalyst }\end{array}$} & \multicolumn{4}{|c|}{$\begin{array}{c}\text { Phase II } \\
\text { New WVU-Lubrizol Aftertreatment }\end{array}$} & \multicolumn{4}{|c|}{$\begin{array}{c}\text { Phase III } \\
\text { Post Demo WVU-Lubrizol } \\
\text { Aftertreatment }\end{array}$} \\
\hline & & $\begin{array}{c}\text { QCBD } \\
\text { (Baseline) }\end{array}$ & $\begin{array}{c}\text { Standard } \\
\text { Deviation }\end{array}$ & $\begin{array}{c}\text { QCBD } \\
\text { (OEM } \\
\text { Catalyst) }\end{array}$ & $\begin{array}{l}\text { Standard } \\
\text { Deviation }\end{array}$ & Background & QCBD & $\begin{array}{c}\text { Standard } \\
\text { Deviation }\end{array}$ & Background & $\begin{array}{c}\text { Standard } \\
\text { Deviation }\end{array}$ & QCBD & $\begin{array}{c}\text { Standard } \\
\text { Deviation }\end{array}$ & Background & $\begin{array}{l}\text { Standard } \\
\text { Deviation }\end{array}$ \\
\hline 13-butadiene & $6.70 \mathrm{E}-05$ & $<\mathrm{LOD}$ & - & $1.37 \mathrm{E}-04$ & - & $3.36 \mathrm{E}-05$ & $4.17 \mathrm{E}-05$ & $2.45 \mathrm{E}-05$ & $2.71 \mathrm{E}-04$ & $2.71 \mathrm{E}-04$ & $<\mathrm{LOD}$ & - & $<\mathrm{LOD}$ & - \\
\hline benzene & $6.70 \mathrm{E}-05$ & $1.57 \mathrm{E}-03$ & $1.06 \mathrm{E}-04$ & $2.31 \mathrm{E}-04$ & $6.54 \mathrm{E}-05$ & 7.02E-04 & $1.08 \mathrm{E}-03$ & $2.70 \mathrm{E}-04$ & $1.41 \mathrm{E}-03$ & 9.32E-04 & $1.15 \mathrm{E}-03$ & $3.40 \mathrm{E}-04$ & $1.20 \mathrm{E}-03$ & 4.77E-04 \\
\hline toluene & $6.70 \mathrm{E}-05$ & $9.67 \mathrm{E}-04$ & $4.48 \mathrm{E}-05$ & $1.23 \mathrm{E}-03$ & $1.45 \mathrm{E}-04$ & $4.57 \mathrm{E}-03$ & $4.31 \mathrm{E}-03$ & $1.33 \mathrm{E}-03$ & $6.34 \mathrm{E}-03$ & $4.12 \mathrm{E}-03$ & $4.24 \mathrm{E}-03$ & $1.34 \mathrm{E}-03$ & $4.50 \mathrm{E}-03$ & $1.76 \mathrm{E}-03$ \\
\hline e-benzene & $6.70 \mathrm{E}-05$ & 7.49E-05 & $1.20 \mathrm{E}-05$ & $1.02 \mathrm{E}-04$ & $3.29 \mathrm{E}-05$ & $5.55 \mathrm{E}-04$ & $1.11 \mathrm{E}-03$ & $5.20 \mathrm{E}-04$ & $<\mathrm{LOD}$ & - & $1.21 \mathrm{E}-03$ & $4.32 \mathrm{E}-04$ & $6.99 \mathrm{E}-04$ & $1.60 \mathrm{E}-04$ \\
\hline m\&p-xylene & $6.70 \mathrm{E}-05$ & $1.77 \mathrm{E}-04$ & $4.85 \mathrm{E}-05$ & $3.00 \mathrm{E}-04$ & $4.23 \mathrm{E}-05$ & $1.42 \mathrm{E}-03$ & $3.76 \mathrm{E}-03$ & $1.30 \mathrm{E}-03$ & $5.29 \mathrm{E}-03$ & $3.88 \mathrm{E}-03$ & $1.69 \mathrm{E}-03$ & $8.45 \mathrm{E}-04$ & $1.59 \mathrm{E}-03$ & $1.03 \mathrm{E}-03$ \\
\hline o-xylene & $6.70 \mathrm{E}-05$ & 7.11E-05 & $2.89 \mathrm{E}-05$ & $1.70 \mathrm{E}-04$ & $6.11 \mathrm{E}-05$ & $6.00 \mathrm{E}-04$ & $1.64 \mathrm{E}-03$ & $4.95 \mathrm{E}-04$ & $2.04 \mathrm{E}-03$ & $1.48 \mathrm{E}-03$ & $7.46 \mathrm{E}-04$ & $3.42 \mathrm{E}-04$ & $6.84 \mathrm{E}-04$ & 3.49E-04 \\
\hline
\end{tabular}

Note: (1) denotes the Tedlar bags used in Phase II and Phase III were different from Phase I tests, $<$ LOD = Below Level of Detection 
Table C. 8 Emissions of Carbonyls Measured in Different Phases

\begin{tabular}{|c|c|c|c|c|c|c|c|c|c|c|c|c|}
\hline \multirow{2}{*}{$\begin{array}{l}\text { Carbonyls } \\
\text { g/mile }\end{array}$} & \multirow{2}{*}{$\begin{array}{l}\text { Limit of } \\
\text { Detection }\end{array}$} & \multicolumn{3}{|c|}{$\begin{array}{c}\text { Phase I } \\
\text { Baseline \& OEM Catalyst }\end{array}$} & \multicolumn{4}{|c|}{$\begin{array}{c}\text { Phase II } \\
\text { New WVU-Lubrizol Aftertreatment }\end{array}$} & \multicolumn{4}{|c|}{$\begin{array}{c}\text { Phase III } \\
\text { Post Demo WVU-Lubrizol Aftertreatment }\end{array}$} \\
\hline & & $\begin{array}{c}\text { QCBD } \\
\text { (Baseline) }\end{array}$ & \begin{tabular}{|c|} 
QCBD \\
(OEM \\
Catalyst)
\end{tabular} & Background & QCBD & $\begin{array}{c}\text { Standard } \\
\text { Deviation }\end{array}$ & Background & $\begin{array}{l}\text { Standard } \\
\text { Deviation }\end{array}$ & QCBD & $\begin{array}{c}\text { Standard } \\
\text { Deviation }\end{array}$ & Background & $\begin{array}{l}\text { Standard } \\
\text { Deviation }\end{array}$ \\
\hline formaldehyde & $4.25 \mathrm{E}-04$ & $1.28 \mathrm{E}+01$ & $1.10 \mathrm{E}+00$ & $3.61 \mathrm{E}-01$ & 3.94E-03 & $1.30 \mathrm{E}-04$ & $4.83 \mathrm{E}-03$ & $4.77 \mathrm{E}-04$ & $3.07 \mathrm{E}-03$ & $1.60 \mathrm{E}-03$ & $4.61 \mathrm{E}-03$ & 7.95E-05 \\
\hline acetaldehyde & $1.93 \mathrm{E}-04$ & $3.35 \mathrm{E}-01$ & $1.91 \mathrm{E}-01$ & $3.66 \mathrm{E}-01$ & $<\mathrm{LOD}$ & - & $<\mathrm{LOD}$ & - & $1.70 \mathrm{E}-03$ & $1.74 \mathrm{E}-03$ & $7.12 \mathrm{E}-03$ & 6.49E-05 \\
\hline acrolein & $7.73 \mathrm{E}-05$ & $<\mathrm{LOD}$ & $<\mathrm{LOD}$ & $<\mathrm{LOD}$ & $<\mathrm{LOD}$ & - & $1.74 \mathrm{E}-04$ & - & $<\mathrm{LOD}$ & - & $<\mathrm{LOD}$ & - \\
\hline acetone & $1.93 \mathrm{E}-04$ & $2.54 \mathrm{E}+00$ & $2.21 \mathrm{E}+00$ & $1.29 \mathrm{E}+00$ & 7.77E-03 & $1.75 \mathrm{E}-03$ & $9.63 \mathrm{E}-03$ & $2.03 \mathrm{E}-03$ & $2.22 \mathrm{E}-03$ & - & $1.07 \mathrm{E}-02$ & 5.66E-04 \\
\hline propionaldehyde & $1.55 \mathrm{E}-04$ & $2.18 \mathrm{E}-02$ & $1.40 \mathrm{E}-02$ & $2.38 \mathrm{E}-02$ & $<$ LOD & - & $<\mathrm{LOD}$ & - & $5.47 \mathrm{E}-04$ & - & $9.13 \mathrm{E}-04$ & $1.21 \mathrm{E}-04$ \\
\hline crotonaldehyde & $1.93 \mathrm{E}-04$ & $<\mathrm{LOD}$ & $<\mathrm{LOD}$ & $<\mathrm{LOD}$ & $<\mathrm{LOD}$ & - & $<\mathrm{LOD}$ & - & $3.12 \mathrm{E}-04$ & $1.32 \mathrm{E}-04$ & $2.47 \mathrm{E}-04$ & $1.26 \mathrm{E}-04$ \\
\hline methacrolein & $6.96 \mathrm{E}-04$ & $<\mathrm{LOD}$ & $<\mathrm{LOD}$ & $<\mathrm{LOD}$ & $<\mathrm{LOD}$ & - & $<\mathrm{LOD}$ & - & $<$ LOD & - & $6.79 \mathrm{E}-04$ & $6.07 \mathrm{E}-05$ \\
\hline 2-butanone & 4.64E-04 & $<\mathrm{LOD}$ & $<\mathrm{LOD}$ & $<\mathrm{LOD}$ & $<\mathrm{LOD}$ & - & $<\mathrm{LOD}$ & - & $4.26 \mathrm{E}-04$ & - & $1.36 \mathrm{E}-03$ & $1.54 \mathrm{E}-04$ \\
\hline iso\&butyraldehyde & $7.73 \mathrm{E}-05$ & $<\mathrm{LOD}$ & $<\mathrm{LOD}$ & $<\mathrm{LOD}$ & $<\mathrm{LOD}$ & - & $<\mathrm{LOD}$ & - & $4.33 \mathrm{E}-04$ & $3.02 \mathrm{E}-04$ & $9.49 \mathrm{E}-04$ & $5.18 \mathrm{E}-05$ \\
\hline benzaldehyde & $1.93 \mathrm{E}-04$ & $<\mathrm{LOD}$ & $<\mathrm{LOD}$ & $<\mathrm{LOD}$ & $<\mathrm{LOD}$ & - & $<\mathrm{LOD}$ & - & $4.83 \mathrm{E}-04$ & $3.40 \mathrm{E}-04$ & $6.12 \mathrm{E}-04$ & 3.31E-04 \\
\hline isovaleraldehyde & 3.09E-04 & $<\mathrm{LOD}$ & $<\mathrm{LOD}$ & $<\mathrm{LOD}$ & $<\mathrm{LOD}$ & - & $<\mathrm{LOD}$ & - & $2.87 \mathrm{E}-04$ & - & $7.96 \mathrm{E}-04$ & 3.89E-04 \\
\hline valeraldehyde & $3.87 \mathrm{E}-04$ & $<\mathrm{LOD}$ & $<\mathrm{LOD}$ & $<\mathrm{LOD}$ & $<\mathrm{LOD}$ & - & $<\mathrm{LOD}$ & - & $3.20 \mathrm{E}-03$ & - & $7.90 \mathrm{E}-04$ & 2.59E-04 \\
\hline o-tolualdehyde & 2.32E-04 & $<\mathrm{LOD}$ & $<\mathrm{LOD}$ & $<\mathrm{LOD}$ & $<\mathrm{LOD}$ & - & $<\mathrm{LOD}$ & - & $<\mathrm{LOD}$ & - & $5.94 \mathrm{E}-04$ & 6.94E-05 \\
\hline m\&p-tolualdehyde & 4.64E-04 & $<\mathrm{LOD}$ & $<\mathrm{LOD}$ & $<\mathrm{LOD}$ & $<\mathrm{LOD}$ & - & $<\mathrm{LOD}$ & - & $<\mathrm{LOD}$ & - & $4.71 \mathrm{E}-04$ & - \\
\hline hexanaldehyde & $1.55 \mathrm{E}-04$ & $<$ LOD & $<\mathrm{LOD}$ & $<\mathrm{LOD}$ & $<\mathrm{LOD}$ & - & $<\mathrm{LOD}$ & - & $2.75 \mathrm{E}-04$ & - & $4.51 \mathrm{E}-04$ & 2.03E-04 \\
\hline 2-5 dimethylbenzaldehyde & $2.32 \mathrm{E}-04$ & $<\mathrm{LOD}$ & $<\mathrm{LOD}$ & $<\mathrm{LOD}$ & $<\mathrm{LOD}$ & - & $<\mathrm{LOD}$ & - & $<\mathrm{LOD}$ & - & $<\mathrm{LOD}$ & - \\
\hline
\end{tabular}


Table C. 9 Emissions of nitro-Polycyclic Aromatic Hydrocarbons Measured in Different Phases

\begin{tabular}{|c|c|c|c|c|c|c|c|c|c|c|}
\hline \multirow{2}{*}{$\begin{array}{c}\text { nitro-Polycyclic Aromatic } \\
\text { Hydrocarbons } \\
\text { g/mile }\end{array}$} & \multirow{2}{*}{$\begin{array}{l}\text { Limit of } \\
\text { Detection }\end{array}$} & \multicolumn{3}{|c|}{$\begin{array}{c}\text { Phase I } \\
\text { Baseline \& OEM Catalyst }\end{array}$} & \multicolumn{2}{|c|}{$\begin{array}{c}\text { Phase II } \\
\text { New WVU-Lubrizol } \\
\text { Aftertreatment }\end{array}$} & \multicolumn{4}{|c|}{$\begin{array}{c}\text { Phase III } \\
\text { Post Demo WVU-Lubrizol Aftertreatment }\end{array}$} \\
\hline & & $\begin{array}{c}\text { QCBD } \\
\text { (Baseline) }\end{array}$ & $\begin{array}{c}\text { QCBD (OEM } \\
\text { Catalyst) }\end{array}$ & Background & QCBD & Background & QCBD & $\begin{array}{c}\text { Standard } \\
\text { Deviation }\end{array}$ & Background & $\begin{array}{c}\text { Standard } \\
\text { Deviation }\end{array}$ \\
\hline 2-nitrofluorene & $1.30 \mathrm{E}-10$ & $<\mathrm{LOD}$ & $<\mathrm{LOD}$ & $<\mathrm{LOD}$ & $\mathrm{n} / \mathrm{a}$ & $\mathrm{n} / \mathrm{a}$ & $1.46 \mathrm{E}-07$ & $1.8 \mathrm{E}-07$ & $5.62 \mathrm{E}-07$ & $2.1 \mathrm{E}-07$ \\
\hline 9-nitroanthracene & $5.21 \mathrm{E}-10$ & $1.45 \mathrm{E}-08$ & $1.93 \mathrm{E}-09$ & $4.4 \mathrm{E}-09$ & $\mathrm{n} / \mathrm{a}$ & $\mathrm{n} / \mathrm{a}$ & $3.65 \mathrm{E}-07$ & $3.56 \mathrm{E}-07$ & $3.42 \mathrm{E}-07$ & $1.26 \mathrm{E}-07$ \\
\hline 2-nitroanthracene & $1.30 \mathrm{E}-10$ & $<\mathrm{LOD}$ & $<\mathrm{LOD}$ & $<\mathrm{LOD}$ & $\mathrm{n} / \mathrm{a}$ & $\mathrm{n} / \mathrm{a}$ & $1.9 \mathrm{E}-08$ & - & $4.18 \mathrm{E}-09$ & - \\
\hline 9-nitrophenanthrene & $1.30 \mathrm{E}-10$ & $4.83 \mathrm{E}-09$ & $<\mathrm{LOD}$ & $<\mathrm{LOD}$ & $\mathrm{n} / \mathrm{a}$ & $\mathrm{n} / \mathrm{a}$ & $1.42 \mathrm{E}-06$ & $1.9 \mathrm{E}-06$ & $2.73 \mathrm{E}-06$ & $1.83 \mathrm{E}-06$ \\
\hline 2-nitrofluoranthene & $3.90 \mathrm{E}-10$ & $4.1 \mathrm{E}-09$ & $1.13 \mathrm{E}-09$ & $2.67 \mathrm{E}-09$ & $\mathrm{n} / \mathrm{a}$ & $\mathrm{n} / \mathrm{a}$ & $2.76 \mathrm{E}-08$ & $1.92 \mathrm{E}-08$ & $5.9 \mathrm{E}-08$ & $4.9 \mathrm{E}-08$ \\
\hline 3-nitrofluoranthene & $1.30 \mathrm{E}-10$ & $<$ LOD & $<$ LOD & $<$ LOD & $\mathrm{n} / \mathrm{a}$ & $\mathrm{n} / \mathrm{a}$ & $1.78 \mathrm{E}-08$ & - & $1.58 \mathrm{E}-08$ & - \\
\hline 4-nitropyrene & $2.60 \mathrm{E}-10$ & $<$ LOD & $<$ LOD & $<$ LOD & $\mathrm{n} / \mathrm{a}$ & $\mathrm{n} / \mathrm{a}$ & $<\mathrm{LOD}$ & - & $<\mathrm{LOD}$ & - \\
\hline 1-nitropyrene & $9.11 \mathrm{E}-10$ & $1.82 \mathrm{E}-08$ & $9.43 \mathrm{E}-10$ & $1.64 \mathrm{E}-09$ & $\mathrm{n} / \mathrm{a}$ & $\mathrm{n} / \mathrm{a}$ & $1.59 \mathrm{E}-07$ & $1.08 \mathrm{E}-07$ & $1.51 \mathrm{E}-07$ & $1.46 \mathrm{E}-07$ \\
\hline 2-nitropyrene & $1.30 \mathrm{E}-10$ & $<\mathrm{LOD}$ & $<\mathrm{LOD}$ & $<\mathrm{LOD}$ & $\mathrm{n} / \mathrm{a}$ & $\mathrm{n} / \mathrm{a}$ & $<\mathrm{LOD}$ & - & $<\mathrm{LOD}$ & - \\
\hline 7-nitrobenzo(a)anthracene & $1.30 \mathrm{E}-10$ & $<\mathrm{LOD}$ & $<\mathrm{LOD}$ & $<$ LOD & $\mathrm{n} / \mathrm{a}$ & $\mathrm{n} / \mathrm{a}$ & $3.05 \mathrm{E}-08$ & - & $1.04 \mathrm{E}-08$ & - \\
\hline 6-nitrochrysene & $1.30 \mathrm{E}-10$ & $<\mathrm{LOD}$ & $<$ LOD & $<\mathrm{LOD}$ & $\mathrm{n} / \mathrm{a}$ & $\mathrm{n} / \mathrm{a}$ & $<\mathrm{LOD}$ & - & $<\mathrm{LOD}$ & - \\
\hline 1-nitrobenzo(e)pyrene & $1.30 \mathrm{E}-10$ & $<\mathrm{LOD}$ & $<$ LOD & $<\mathrm{LOD}$ & $\mathrm{n} / \mathrm{a}$ & $\mathrm{n} / \mathrm{a}$ & $<$ LOD & - & $<\mathrm{LOD}$ & - \\
\hline 6-nitrobenzo(a)pyrene & $1.30 \mathrm{E}-10$ & $<\mathrm{LOD}$ & $<\mathrm{LOD}$ & $<\mathrm{LOD}$ & $\mathrm{n} / \mathrm{a}$ & $\mathrm{n} / \mathrm{a}$ & $<\mathrm{LOD}$ & - & $<$ LOD & - \\
\hline 4-nitrobenzo(e)pyrene & $1.30 \mathrm{E}-10$ & $<\mathrm{LOD}$ & $<$ LOD & $<\mathrm{LOD}$ & $\mathrm{n} / \mathrm{a}$ & $\mathrm{n} / \mathrm{a}$ & $<$ LOD & - & $<$ LOD & - \\
\hline 3-nitrobenzo(e)pyrene & $1.30 \mathrm{E}-10$ & $<\mathrm{LOD}$ & $<\mathrm{LOD}$ & $<\mathrm{LOD}$ & $\mathrm{n} / \mathrm{a}$ & $\mathrm{n} / \mathrm{a}$ & $<\mathrm{LOD}$ & - & $<\mathrm{LOD}$ & - \\
\hline 3-nitrobenzo(a)pyrene & $1.30 \mathrm{E}-10$ & $<\mathrm{LOD}$ & $<\mathrm{LOD}$ & $<\mathrm{LOD}$ & $\mathrm{n} / \mathrm{a}$ & $\mathrm{n} / \mathrm{a}$ & $<\mathrm{LOD}$ & - & $<\mathrm{LOD}$ & - \\
\hline 1-nitrobenzo(a)pyrene & $1.30 \mathrm{E}-10$ & $<\mathrm{LOD}$ & $<$ LOD & $<$ LOD & $\mathrm{n} / \mathrm{a}$ & $\mathrm{n} / \mathrm{a}$ & $<$ LOD & - & $<\mathrm{LOD}$ & - \\
\hline 2-nitrobenzo(a)pyrene & $1.30 \mathrm{E}-10$ & $<$ LOD & $<$ LOD & $<$ LOD & $\mathrm{n} / \mathrm{a}$ & $\mathrm{n} / \mathrm{a}$ & $<$ LOD & - & $<\mathrm{LOD}$ & - \\
\hline 9-nitrodibenz(ac)anthracene & $1.30 \mathrm{E}-10$ & $<\mathrm{LOD}$ & $<$ LOD & $<$ LOD & $\mathrm{n} / \mathrm{a}$ & $\mathrm{n} / \mathrm{a}$ & $<$ LOD & - & $<\mathrm{LOD}$ & - \\
\hline 1,3-dinitropyrene & $1.30 \mathrm{E}-10$ & $<\mathrm{LOD}$ & $<\mathrm{LOD}$ & $<$ LOD & $\mathrm{n} / \mathrm{a}$ & $\mathrm{n} / \mathrm{a}$ & $<$ LOD & - & $<\mathrm{LOD}$ & - \\
\hline 1,6-dinitropyrene & $1.30 \mathrm{E}-10$ & $<$ LOD & $<\mathrm{LOD}$ & $<\mathrm{LOD}$ & $\mathrm{n} / \mathrm{a}$ & $\mathrm{n} / \mathrm{a}$ & $<\mathrm{LOD}$ & - & $<\mathrm{LOD}$ & - \\
\hline
\end{tabular}

Note: $\angle \mathrm{LOD}=$ Below Level of Detection, the reported values are the average of three QCBD repeats excluding the outliers and not detected values 


\begin{tabular}{|c|c|c|c|c|c|c|c|c|c|c|}
\hline \multirow{2}{*}{$\begin{array}{c}\text { nitro-Polycyclic Aromatic } \\
\text { Hydrocarbons } \\
\text { g/mile }\end{array}$} & \multirow{2}{*}{$\begin{array}{l}\text { Limit of } \\
\text { Detection }\end{array}$} & \multicolumn{3}{|c|}{$\begin{array}{c}\text { Phase I } \\
\text { Baseline \& OEM Catalyst }\end{array}$} & \multicolumn{2}{|c|}{$\begin{array}{c}\text { Phase II } \\
\text { New WVU-Lubrizol } \\
\text { Aftertreatment }\end{array}$} & \multicolumn{4}{|c|}{$\begin{array}{c}\text { Phase III } \\
\text { Post Demo WVU-Lubrizol Aftertreatment }\end{array}$} \\
\hline & & $\begin{array}{c}\text { QCBD } \\
\text { (Baseline) }\end{array}$ & $\begin{array}{l}\text { QCBD (OEM } \\
\text { Catalyst) }\end{array}$ & Background & QCBD & Background & QCBD & $\begin{array}{c}\text { Standard } \\
\text { Deviation }\end{array}$ & Background & $\begin{array}{l}\text { Standard } \\
\text { Deviation }\end{array}$ \\
\hline 1,8-dinitropyrene & $1.30 \mathrm{E}-10$ & $<\mathrm{LOD}$ & $<\mathrm{LOD}$ & $<\mathrm{LOD}$ & $\mathrm{n} / \mathrm{a}$ & $\mathrm{n} / \mathrm{a}$ & $<\mathrm{LOD}$ & - & $<\mathrm{LOD}$ & - \\
\hline 7-nitro-1,2-methylbenz(a)anthracene & $1.30 \mathrm{E}-10$ & $<\mathrm{LOD}$ & $<$ LOD & $<$ LOD & $\mathrm{n} / \mathrm{a}$ & $\mathrm{n} / \mathrm{a}$ & $<\mathrm{LOD}$ & - & $<$ LOD & - \\
\hline 12-ethyl-6-nitrochrysene & $1.30 \mathrm{E}-10$ & $<\mathrm{LOD}$ & $<$ LOD & $<$ LOD & $\mathrm{n} / \mathrm{a}$ & $\mathrm{n} / \mathrm{a}$ & $<$ LOD & - & $6.31 \mathrm{E}-08$ & - \\
\hline Total Nitro-C13* & $2.50 \mathrm{E}-08$ & $5.57 \mathrm{E}-07$ & $8.62 \mathrm{E}-08$ & $8.54 \mathrm{E}-08$ & $\mathrm{n} / \mathrm{a}$ & $\mathrm{n} / \mathrm{a}$ & $1.05 \mathrm{E}-06$ & 7.9E-07 & 7.23E-07 & $3.92 \mathrm{E}-07$ \\
\hline Total Nitro-C14* & $3.16 \mathrm{E}-08$ & $1.65 \mathrm{E}-06$ & $5.21 \mathrm{E}-08$ & $1.21 \mathrm{E}-07$ & $\mathrm{n} / \mathrm{a}$ & $\mathrm{n} / \mathrm{a}$ & $2.09 \mathrm{E}-06$ & $2.33 \mathrm{E}-06$ & $3.61 \mathrm{E}-06$ & $2.38 \mathrm{E}-06$ \\
\hline Total Nitro-C16* & $9.11 \mathrm{E}-10$ & $2.22 \mathrm{E}-08$ & 2.07E-09 & 4.09E-09 & $\mathrm{n} / \mathrm{a}$ & $\mathrm{n} / \mathrm{a}$ & $2.02 \mathrm{E}-07$ & $1.31 \mathrm{E}-07$ & $2.39 \mathrm{E}-07$ & $2.45 \mathrm{E}-07$ \\
\hline Total Nitro-C18* & 7.81E-10 & $8.3 \mathrm{E}-09$ & 7.84E-10 & $3.17 \mathrm{E}-09$ & $\mathrm{n} / \mathrm{a}$ & $\mathrm{n} / \mathrm{a}$ & $3.05 \mathrm{E}-08$ & - & 1.04E-08 & - \\
\hline Total Nitro-C20* & $7.81 \mathrm{E}-10$ & $<$ LOD & $<\mathrm{LOD}$ & $<$ LOD & $\mathrm{n} / \mathrm{a}$ & $\mathrm{n} / \mathrm{a}$ & $<$ LOD & - & & - \\
\hline Total Nitro-C22* & $7.81 \mathrm{E}-10$ & $<$ LOD & $1.87 \mathrm{E}-08$ & $<\mathrm{LOD}$ & $\mathrm{n} / \mathrm{a}$ & $\mathrm{n} / \mathrm{a}$ & $<\mathrm{LOD}$ & - & & - \\
\hline
\end{tabular}

Note: $<\mathrm{LOD}=$ Below Level of Detection, $\mathrm{n} / \mathrm{a}=$ not available. 
Table C. 10 Emissions of Regulated Compounds Measured in Different Phases

\begin{tabular}{|c|c|c|c|c|c|c|c|c|c|c|}
\hline \multirow{2}{*}{$\begin{array}{l}\text { Regulated Emissions } \\
\text { and Fuel Consumption } \\
\text { Values } \\
\text { g/mile }\end{array}$} & \multicolumn{4}{|c|}{$\begin{array}{c}\text { Phase I } \\
\text { Baseline \& OEM Catalyst }\end{array}$} & \multicolumn{2}{|c|}{$\begin{array}{c}\text { Phase II } \\
\text { New WVU-Lubrizol } \\
\text { Aftertreatment }\end{array}$} & \multicolumn{4}{|c|}{$\begin{array}{c}\text { Phase III } \\
\text { Post Demo WVU-Lubrizol Aftertreatment }\end{array}$} \\
\hline & $\begin{array}{l}\text { QCBD } \\
\text { Baseline }\end{array}$ & $\begin{array}{l}\text { Standard } \\
\text { Deviation }\end{array}$ & $\begin{array}{l}\text { QCBD } \\
\text { OEM } \\
\text { Catalyst }\end{array}$ & $\begin{array}{l}\text { Standard } \\
\text { Deviation }\end{array}$ & $\begin{array}{l}\text { QCBD } \\
\text { WVU-Lubrizol }\end{array}$ & $\begin{array}{l}\text { Standard } \\
\text { Deviation }\end{array}$ & $\begin{array}{l}\text { QCBD } \\
\text { Baseline }\end{array}$ & $\begin{array}{l}\text { Standard } \\
\text { Deviation }\end{array}$ & \begin{tabular}{|c|} 
QCBD \\
WVU- \\
Lubrizol \\
aftertreatment \\
\end{tabular} & $\begin{array}{l}\text { Standard } \\
\text { Deviation }\end{array}$ \\
\hline NOx & $3.77 \mathrm{E}+01$ & $2.00 \mathrm{E}-01$ & $3.28 \mathrm{E}+01$ & $2.90 \mathrm{E}+00$ & $2.10 \mathrm{E}+01$ & $6.00 \mathrm{E}-01$ & $2.76 \mathrm{E}+01$ & $2.00 \mathrm{E}-01$ & $2.34 \mathrm{E}+01$ & $3.00 \mathrm{E}-01$ \\
\hline FIDHC (THC) & $2.19 \mathrm{E}+01$ & $4.00 \mathrm{E}-01$ & $1.58 \mathrm{E}+01$ & $8.00 \mathrm{E}-01$ & $1.18 \mathrm{E}+01$ & $3.00 \mathrm{E}-01$ & $2.87 \mathrm{E}+01$ & $4.00 \mathrm{E}-01$ & $2.40 \mathrm{E}+01$ & $3.00 \mathrm{E}-01$ \\
\hline GCHC (Methane) & $2.06 \mathrm{E}+01$ & - & $1.49 \mathrm{E}+01$ & $7.00 \mathrm{E}-01$ & $1.00 \mathrm{E}+01$ & $3.00 \mathrm{E}-01$ & $\mathrm{n} / \mathrm{a}$ & - & $2.22 \mathrm{E}+01$ & $3.00 \mathrm{E}-01$ \\
\hline GCHC (Non-Methane) & $5.40 \mathrm{E}-01$ & - & $1.30 \mathrm{E}-01$ & $5.00 \mathrm{E}-03$ & $1.14 \mathrm{E}+00$ & $3.90 \mathrm{E}-01$ & $\mathrm{n} / \mathrm{a}$ & - & $4.90 \mathrm{E}-01$ & $6.00 \mathrm{E}-02$ \\
\hline $\mathrm{CO}$ & $1.32 \mathrm{E}+01$ & $1.00 \mathrm{E}-01$ & $3.80 \mathrm{E}-01$ & $5.00 \mathrm{E}-02$ & $1.30 \mathrm{E}-01$ & - & $1.71 \mathrm{E}+01$ & $3.00 \mathrm{E}-01$ & $1.40 \mathrm{E}-01$ & $6.00 \mathrm{E}-02$ \\
\hline TPM & $3.90 \mathrm{E}-02$ & $1.70 \mathrm{E}-02$ & $1.50 \mathrm{E}-02$ & $3.00 \mathrm{E}-03$ & $7.00 \mathrm{E}-04$ & - & $6.40 \mathrm{E}-02$ & $2.00 \mathrm{E}-03$ & $6.50 \mathrm{E}-03$ & $4.00 \mathrm{E}-03$ \\
\hline $\mathrm{CO} 2$ & $2.48 \mathrm{E}+03$ & $1.20 \mathrm{E}+01$ & $2.43 \mathrm{E}+03$ & $2.80 \mathrm{E}+01$ & $2.70 \mathrm{E}+03$ & $2.80 \mathrm{E}+01$ & $3.11 \mathrm{E}+03$ & $2.40 \mathrm{E}+01$ & $2.98 \mathrm{E}+03$ & $4.40 \mathrm{E}+01$ \\
\hline Fuel Economy (mile/gal) & $2.73 \mathrm{E}+00$ & $1.00 \mathrm{E}-02$ & $2.82 \mathrm{E}+00$ & $3.00 \mathrm{E}-02$ & $2.85 \mathrm{E}+00$ & $2.00 \mathrm{E}-02$ & $2.42 \mathrm{E}+00$ & $2.00 \mathrm{E}-02$ & $2.56 \mathrm{E}+00$ & $4.00 \mathrm{E}-02$ \\
\hline
\end{tabular}

Note: $\mathrm{n} / \mathrm{a}=$ not available, ${ }^{\mathrm{-}}{ }^{\mathrm{c}}=$ missing component 